\title{
INFERÊNCIA SOBRE PARÂMETROS RELATIVOS À ESTRUTURA GENÉTICA DE POPULAÇÕES COM DADOS DE FREQUÊNCLAS GÊNICAS
}

JOEL AUGUSTO MUNZ

Inpantio Agrónomo

Ordentador. Prot. Dr. DECIO BARBIN

Tese apresentada d̀ Escola Superior de Agricultura "Luiz de Queiroz", da Universidade de São Paulo, para obtenção do título de Doutor em Agronomia, área de concentrą̧ão: Estatística e Experimentação Agronômica

PIRACICABA

Estado de São Paulo - Brasil

SETEMBRO - 1994 
Ficha catalografica preparada pela Seça de livros da Divisão de Eitilioteca e Documentaçăo - FCLQ/USF-

Munia, Jael Augusto
MSbii Inferencia sobre parametros relativas a estrutura genetica de forpulaçes com dados de frequericias génicas. Firacicaba, 1994. $224 \mathrm{p}$.

Tese - ESALG

Eibliografia.

1. Estatistica experimental 2. Experimentasaa agr1 cola \$. Genetica de fopulagazo - Analise de variancia 1. Escolal Superior de Agricultura Luiz de Queiroz, Firacicata

$$
\begin{aligned}
& C D D \quad 575.15 \\
& 519.5 \\
& 630.72
\end{aligned}
$$




\section{INFER ÂNCIA SOBRE PARAMETROS RELATIVOS A ESTRUTURA GENETICA DE POPULAÇŌES COM DADOS DE FREQUENCLAS GENICAS}

\section{JOEL AUGUSTO MUNIZ}

Aproveda em : 25. 11. 1994

Comissão julgadora

Prof. Dr. Décio Barbin

ESALQ/USP

Prof. Dra Clarice Garcia Borges Demétrio

ESALQ/USP

Prof. Dr. Roland Vencovsky

ESALQ/USP

Prof. Dr. Evaristo Bianchini Sobrinho

FMNAJ/UNESP

Prof. Dr. Sérgio do Nascimento Kronks

FMVAJ/NNESP

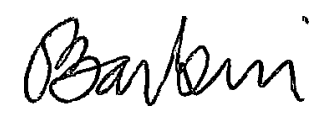

Prof. Dr. DECIO Barbin

Orientador 
Aos meus pais e sogros: Cors e João, Vera (in memoriam) e Antônio, pelo exemplo de vida.

Ao meu irmão José Aurélio (in memoriam) pela pouca

oportunidade que teve no vide.

Aos demais irmãos, cunhados e sobrinhos

\section{OFEREÇO}

À Orminds minhs espose e aos nossos filhos: Frederico e Fabiana 


\section{AGRADECDMANTOS}

Ao Profesent Dr. Décio Batin pela eficiento e dedicada orientação, pela confiange e amizade

Ao Professor Dr. Roland Vencovsiky pelos ensmameatos e estímulos, pelo desprendimento e amor à Ciência, a guem mais dovo esto trabalho.

A minhe esposs, Orminds, crmprenheira carimhose e paciente, pelo apoio, compreensăo, forçe e garre oferecidos em todos os momentos.

A Escola Superior de Africultura de Lavras e seu Departamento de Ciências Exatas, pela oportumidado de aperfeicoamento.

A Escola Superior de Africultura 'Luiz de Quevior"e seu Departamento de Matemática e Estatistica por possibilitarem a realizacåo do Curso de PósGractuação.

A Coordenadaris de Aperféfoamemto de Pessoal de Nivel superiors (CAPES/PICD) pela bolsa de estado concodida.

Aos Professcures do Departamento de Matemática e Estatística da ESALQUUSP, pelos ensinamentos.

Aos fumcionários do Departamento de Matemática e Estatistica e do Departamento de Genétic da ESALQVUSP, pela atençảo e amizade.

Alos colegas de curso: Amarri, Angusto, César, Eufrázio, Gener, Gilmar, Guideni, Joaquim, Paulo Cecon, Rosans, Rui, Samoel, Sônia e Tadou pels agradível corvivência.

Ao Professar Ruben Delly Veiga, chefe do Centro de Processamento de Dados da ESAL polo apoio na simulaçảo dos dados.

A Srta. Vera Lúcia de Oliverira pelos servicos de digitagảo.

A todos que, de alguma forma contribuiram para a realizafáo deste trabalho. 


\section{SUMÁRIO}

Página

RESUMO

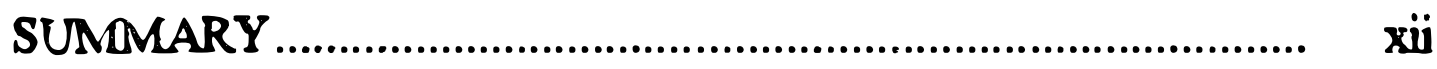

1. INTRODUÇÃO ............................................................... 1

2. REVISÃO DE LTERATURA ........................................... 4

2.1. Parâmetros de variabilidade e diversidade genética.......... 4

2.2. Estimaçåo de parâmetros de variabilidade e diversidade genética ..................................................... 18

2.3. Estimação de parâmetros definidos como o quociente entre duas variáveis aleatórias

2.4. Teste de hipótese sobre os parâmetros de variabilidade e diversidade genética estimados através da análise de variância das frequências gênicas.

3. MATERIAL E MÉTODOS.

3.1. Modelo matemático e análise de variância

3.2. Estimaçâo dos parâmetros genéticos ................................. 53

3.3. Md́dia e variância dos estimadores .................................. 54

3.4. $O$ teste $F$................................................................... 54

3.5. Métodos e formas de simulafăo ...................................... 55

3.6. Critérios de comparaf̧̉o................................................ 59 
4.1. Amostras de indivíduos de uma populafão

4.1.1. Obtencåo das esperanças dos quadrados médios na análise de variância das frequências gênicas de amostras de individuos de uma populacăo.

4.1.2. Estimafão do coeficiente de endogamia na análise de variância das frequências gênices de amostras de indivíduos de uma populaç̄o

4.1.3. Estimafão da taxa de fecundação cruzada na análise de variância das frequências gênicas de amostras de indivíduos de uma populafão...............

4.1.4. Média e variância do estimedor do coeficiente de endogamia na análise de variância das frequências gênicas de amostras de indivíduos de uma populacão.

4.1.5. Média e variância do estimador da taxa de fecundaģāo cruzads na análise de variância das frequências gênicas de amostras de indivíduos de uma populaçäo

4.1.6. Média e variância do estimador do coeficiente de endogamia na anólise de variância das frequências gênicas de amostras de indivíduos de uma populafão no caso de alelos múltiplos 
4.1.7. O teste F para o coeficiente de endogamia na análise de variância das frequências gênicas de amostras de indivíduos de uma populacāo............ 139

4.2. Amostras de indivíduos de populagões diferentes ........... 188

4.2.1. Obtençîno das esperancas dos quadrados médios na análise de variância das frequências gênicas de amostras de indivíduos de populaçōes diferentes.. 188

4.2.2. Estimação dos parâmetros genéticos análise de variância das frequências gêtuicas de amostras de individuos de populagões difereates.

4.2.3. Estimaçảo da taxa de fecundacāo cruzads análise de variância das frequências gênicas de amostras de indivíduos de populaģôes diferentes

4.2.4. Média e variância dos estimadores dos parâmetros genéticos obtidos na análise de variância das frequências gênicas de amostras de individuos de populagőes diferentes

4.2.5. Média e variância do estimador da taxa de fecundaçāo cruzada na análise de variância das frequências gênicas de amostras de individuos de populaçōes diferentes

5.1. Análise das frequências gênicas de amostras de individuos de uma populaça 
5.2. Análise das frequências gênicas de emostras de individuos de populaģ̋es diferentes ................................. 201 REFERÊNCIAS BIBLIOGRÁFICAS ...................................... 202

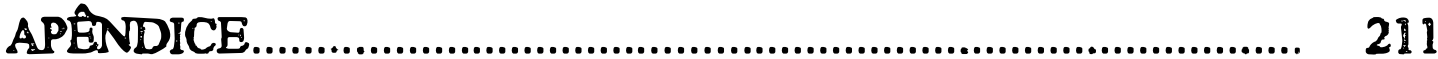




\title{
INFDRÊNCLA SOBRE PARÂMETROS RELATIVOS A ESTRUTURA GENETICA DE POPULAÇÕES COM DADOS DE FREQUENCLAS GÊNICAS
}

\author{
Autor: JOEL AUGUSTO MUNL \\ Orientador: PROF. DR DEECIO BARBN
}

\section{RESUMO}

Com o objetivo de catudar a análise de variância de frequéncias génicas visando a caracterizaço da estrutura genética de populagőes de indivíduos diplóides, estabeleceram-se as propriedades dos estimadores dos parâmetros genéticos obtidos pelo método dos momentos, bem como a distribuiq̧ão do quociente entre quadrados médios tentando propor um critério para testar a nulidade do coeficiente de endogamia Foram considerados os seguirtes casos:

a. análise de variencia das frequências gênicas de amostras de indivíduos de uma populaģa;

b. and́lise de variância das frequências geñicas de amostras de individuos de populacõos diferentes.

No estudo dos estimadores dos parámetros genéticos, por se tratar, da estimą̧ão de quocientes entre variáveis aleatórias, utilizou-se a aproximą̧̊̊ através do desenvolvimento de uma função em série de Trylor. 
No caso de amostras de individuos de uma populagảo, as expressōes dos estimadores foram avaliadas numericamente utilizando-se os resultados da extimafāo em $\mathrm{N}=100$ experimentos simulados através do SAS ("Statistical Analysis System"), considerando-se amostras com $n=10$ , 20, 30, 50, 100 e 200 individuos, extraidas em 99 populasōes de dois alelos e em 110 populagōes de três alelos, com diferentes coeficientes de endogamia e frequências gênicas. Nas populações de três alelos, comparou-se ainda a estimaça do coeficiente de endogamia obtida da média das estimativas de cada alelo e através da análise conjunta envolvendo os três alelos. No estudo da distribuição do quociente entre quadrados médios, os resultados foram avaliados numericamente utilizando-se os resultados da simulaçâo de $\mathrm{N}=1000$ experimentos através do SAS, considerando-se 17 tamanhos diferentes de amostra entre 5 e 500 individuos em 19 populaçōes não endogâmicas de dois alelos e 21 populafões não endogâmicas de três alelos, com diferentes frequências gênicas.

Os estimadores do coeficiente de endogamia e da taxa de fecundsçāo cruzada foram tendenciosos. As expressōes das tendências apresentaram-se em função de $1 / n$, tomando-se despreziveis com o aumento de $n$. As fórmulas propostas para estimagăa da variância do estimador do coeficiente de endogamia e do estimador da taxa de fecundação cruzada apresentaram resultados satisfatórios quando o coeficiente de endogamia da população foi inferior a 0,5 , a frequência gênica estava entre 0,3 e 0,7 e o tamanho da amostra superior a 30 
individuos. A estimacăo do coeficiente de endogamia em populafões com alelos múltiplos, usando a análise conjurta com todos os alelos foi menos tendenciosa que a estimeqảo através da média das extimativas nas andises de cada alelo, embora apresentassem a mesma variância . O critério para testar a nulidade do coeficiente de endogamia mostrou-se válido usando-se: 30 individuos se a frequência gênica de populagão estiver entre 0,3 e 0,7; 50 individuos se a frequência gênica estiver entre 0,25 e 0,75 e 100 individuos se a frequência gênica estiver entre 0,2 e 0,8 . No caso de três alelos o critério usando a enálise conjunta foi bastante restrito, valendo apenas se a frequência de cada alelo não for menor que 0,2, o número de individuos estiver entre 10 e 30 e o nivel de significância for 0,01 .

No caso de amostras de individuos de populacōes diferentes, os estimadores do coeficiente de endogamia de todos os indivíduos das populaçōes, do coeficiente de endogamia dos individuos dentro das populações, do coeficiente de coancestria e da taxa de fecundação cruzsda foram tendenciosos. As tendências dos estimadores dos coeficientes de endogamia foram negativas. As variâncias dos estimadores dos coeficientes de endogamia e da tax $a$ de fecundacho cruzada tiveram expressões semelhantes ds fórmulas obtidas no caso de amostras de individuos de uma populaçăo. 


\title{
DNFERENCE UPON PARAMETERS CONCERNING THE GENETICAL STRUCTURE OF POPULATIONS WTIH GENE FREQUENCY DATA
}

\author{
Author: JOEL AUGUSTO MUNIZ \\ Adviser: PROF. DR DÉCIO BARBIN
}

\section{SUMMARY}

The purpose of this study was to investigate the analysis of variance of gene freguencies aiming to charecterize the genetic structure of diploid populations. Properties of the genetic parameters estimators obtained by the method of moments and the distribution of ratios between mean squares were studied in order to propose a criterion to test the nullity of the inbreeding coefficient. The following cases were considered:

a analysis of variance of gene frequencies of samples from a single population.

b. analysis of variance of gene frequencies of samples from different populations.

In studing the estimators of genetic parameters an approximation through the development of Taylor's function series was used.

In the case of samples of individuals from a population, the expressions of the estimators were numerically evaluated from one hundred experiments simulated through SAS (Statistical Analysis System) and 
considering samples of $10,20,30,50,100$ and 200 individuals extracted from 99 populations with two alleles and from 110 populations with three alleles, and different inbreeding coefficient and gene frequencies. In populations with three alleles the inbreeding coefficient estimated as the mean coefficient from the anelysis for each allele, was compared with the inbreeding coefficient obtained from the joint analysis of variance for all three alleles. The distribution of ratios between mean squares was evaluated numerically from one thousand experiments simulated through SAS and considering 17 different sample sizes varying from 5 to 500 individuals from 19 non-inbred populations with two alleles and from 21 non-inbred populations with three alleles, and having different gene frequencies .

The estimators for the inbreeding coefficient and for the cross-fertilization rate were biased. The expressions for bieses were functions of $1 / n$ and became negligible as the sample size (n) increased.The formulae proposed for estimating the variance of estimators for the inbreeding coefficients and for the rate of cross-fertilization presented satisfactory results for populations with inbreeding coefficient lower than 0.5 , gene frequencies varying from 0.3 and 0.7 , and sample size greater than 30 individuals. The estimate of the inbreeding coefficient in populations with multiple alleles was least biased using the joint analysis of variance than the mean estimate obtained from the analysis of variance for each allele, though they presented the same variance. The criterion for testing nullity of the inbreeding coefficient proved to be valid for 
populations with sample size of 30 individuals and gene frequencies between 0.30 and 0.70 , or 50 individuals with gene frequencies between 0.25 and 0.75 or 100 individuals if gene frequencies were between 0.20 and 0.80 . In populations with three alleles the criterion using the joint analysis of variance proved to be highly restricted, being valid only if any sllele has frequency not smaller than 0.20 , the sample size is between 10 and 30 individuals and significance leved is 0.01 .

In the case of samples from different populations the estimators for the inbreeding coefficient of all individuals in the populations, for the inbreeding coefficient of individuals within the populations, for the coefficient of coancestry and of the rate of crossfertilization were bissed. The biases of the extimators for the inbreeding coefficients were negative. Expressions for the variances of the estimators of the inbreeding coefficient and of the rate of cross-fertilization were similar to those obtained from samples taken from a single population. 


\section{NTRODUÇÃO}

O conhecimento da estrutura genética de populacões fornece importantes subsídios para o entendimento da dinâmica evolutiva destas populaç̃es.

No melhoramento de plantas, é importante conhecer o máximo de fontes de variabilidade genética visando atingir o objetivo básico de reumir em um só individuo, as características de alta produfão e outros caracteres agronômicos de interesse. O melhorista conta com a variabilidade genética da espécie como o principal meio para ampliar a potencialidade de cultivo, nas diversas condiçōes de clima e solo.

Nas últimas décadas a técnica de eletroforese de enzimas tem sido utilizada para estudar a variagẽo genética existente tanto em plantas como em animais. Segundo MORAES (1993), a separaçån de isoenzimas por eletroforese é uma técnica poderosa com grande abrangência de aplicąão nas diversas áreas da biologia devido à simplificacão da infraestrutura necessária à sua ưilizaç̧ว e a tempo gasto nas análises para obtenşão dos resultados. Seu uso tem sido ferramenta auxiliar nos estudos de genética e melhoramento de plantas com aplicacões entre outras, nas áreas de genética de populações, identificação de cultivares e genética evolutiva. A eletroforese de enzimas permite a separaçấo dos produtos de alelos de um mesmo gene possibilitando a 
caracterização de um indivíduo pelo seu genótipo representado por uma amostra de genes.

A variância é uma propriedade imporante das freqūências gênicas e sua análise permite descrever eficientemente a estrutura de populaçōes quando se dispōe de dados de marcadores bioquímicos ou moleculares (VENCOVSKY, 1992). A técnica de análise com os dados obtidos de marcadores considers a variável indicadora $x$, que vale um quando um dado alelo, por exemplo $A_{1}$ de um loco, está no individuo, e vale zero quando este alelo estí ausente, e presente por exemplo $A_{2}, A_{3}$, ..., A $A_{\text {v }}$ A análise de variência é realizada de acordo com o procedimento cléssico da Estatística Experimental, associando-se um modelo de acordo com a estrutura do problema e estimando-se os parâmetros genéticos afins. No processo de inferência, a respeito dos parâmetros genéticos envolvidos no modelo, existem algumas dificuldades pois a variável indicadora não tem distribuição normal e em consequêéncia, o quociente entre dois quadrados médios na análise de variância não terá uma distribuiçåo F (WEIR, 1990).

Visando estudar a análise de variância de frequências gênicas para a caracterização da estrutura genética de populações no caso de individuos diplóides, o presente trabalho teve os seguintes objetivos:

a. estabelecer as propriedades dos estimadores do coeficiente de endogamia e da taxa aparente de fecundação cruzada, na análise de 
variência de uma amostra de indivíduos de uma populagâa com dois ou mais alelos.

b. estabelecer as propriedades dos extimadores dos coeficientes de endogamia e de coancestria e da taxs aparente de fecundação cruzada na análise de variância de uma amostra de indivíduos de populagões diferentes.

c. conhecer a distribuição do quociente entre os quadrados médios, para verificar a validade do teste $F$ para testar o coeficiente de endogamia, no caso de uma amostra de indivíduos de uma populagåo.

d. comprovar numericamente, através de simulafão de dados considerando diferentes combinações de números de indivíduos e frequência gênicas, os resultados obtidos no caso de uma amostra de indivíduos de uma população com dois ou mais alelos. 


\section{REVISĀO DE LITERATURA}

A estimafảo de parámetros genéticos com dados de frequências génicas é uma técnica relativamente recente, apresentando poucos trabalhos na literatura .

\subsection{Parametros de variabllidade e diversidade genetica}

Endogamia, variância das frequências gênicas e seus correspondentes tamanhos efetivos de população são termos comuns no estudo de genética de populagões. Os conceitos e a maior parte da teoria se devem aos trabalhos clássicos desenvolvidos por Fisher e Wright (COCKERHAM, 1969).

FALCONER(1964) e HARTL \& CLARK(1989) definem endogamia como o acasalamento entre individuos que são relacionados por ascendência tendo como primeiro efeito uma mudança nas frequências genotípicas de Hardy-Weinberg devido a um aumento na frequencia de genótipos homozigóticos à custa da frequência de genótipos heterozigóticos. O coeficiente $\mathrm{F}$, de endogamia segundo os autores, mede a probabilidade de dois genes em qualquer loco, num indivíduo, serem idênticos por ascendência, isto é, de os genes serem originados da cópia de um gene apenas numa geração anterior. 
HARTL \& CLARK (1989) afirmam que existem duas interpretafōes a serem dadas ao coeficiente de endogamia. Quando $F$ for utilizado em modelos para predizer frequêencias genotípicas, entẫo ele é um parânetro assumido como conhecido e sem erro. Por outro lado, quando F for estimado numa populacåo, ele é um extimador estatistico e assim representa uma descrição de uma observafāo. Em termos biológicos, $F$ mede a redução fracionária na heterozigosidade, em relação a uma populagão de acasalamento alestório com a mesma frequêencia alélice. No caso de um loco com dois alelos, as freqüências genotípicas de AA, Aa e as podem ser expressas em relaça ao coeficiente de endogamia pela expressāo

$$
(1-F)\left(p^{2}, 2 p q, q^{2}\right)+F(p, 0, q)
$$

SOUZA JÚNIOR (1989) apresents o seguinte quadro sintetizando a estrutura genotípica de ume populagão no caso de um loco com dois alelos:

\section{Genótipos}

Frequuêencias Genoúpicas

$$
F=F \quad F=0 \quad F=1
$$

\begin{tabular}{llll}
$\mathrm{AA}$ & $\mathrm{p}^{2}+\mathrm{pqF}$ & $\mathrm{p}^{2}$ & $\mathrm{p}$ \\
$\mathrm{Aa}$ & $2 \mathrm{pq}-2 \mathrm{pqF}$ & $2 \mathrm{pq}$ & 0 \\
$\mathrm{aa}$ & $\mathrm{q}^{2}+\mathrm{pqF}$ & $\mathrm{q}^{2}$ & $\mathrm{q}$ \\
\hline
\end{tabular}


O quadro facilita as comparagỏes com as frequências genotípicas no principio de Hardy-Weinberg. Quando $F=0$, o que representa acaselamento sleatónio ou susência de endogamia, as frequêencias genotípicas estarẽo nas proporcōes de Hardy- Weinberg. Quando $F=1$, o que representa endogamia total, a população terá somente genótipos homozigóticos AA e aa nas frequêencias p e q.

O autor mostra ainda um esquema de uma populacäo inicial nåo endogâmica, apresentando a estrutura genética desta populagāo sob autofecundafōes sucessivas para um loco com os alelos $A_{i}$ e $A_{j}$.

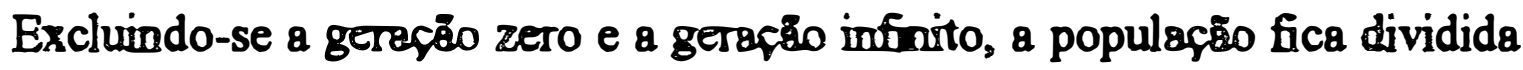
em duas classes a saber: individuos endogâmicos (homozigotos $A_{i} A_{i} e$ $\left.A_{j} A_{j}\right)$ e não endogâmicos (heterozigotos $A_{i} A_{j}$. Em cada geraçåo a probabilidade de o indivíduo ser heterozigótico é $(1 / 2)^{\mathrm{g}}$ e de ser homozigótico é $1-(1 / 2)^{g}$. Portanto, numa gereção g qualquer, o coeficiente de endogamia é dado por

$$
F_{g}=1-(1 / 2)^{g} \text {. }
$$

HALLAUER \& MIRANDA FILHO (1981) afirmam que a endogamia é uma descrĩ̧̧̃o dos zigotos e não dos gametas, sendo determinada pela porcentagem de homozigose no zigoto. 
WRIGHT (1965) discute o relacionamento entre gametas mostrando o significado do coeficiente de endogamia e de parâmetros similares relacionados a pares de gametas em geral, realçando o fato de que eles podem sempre ser interpretados tanto como coeficientes de correlação, quanto como probabilidade de identidade de genes de mesma origem. No caso de populações naturais hierarquicamente subdivididas, três parâmetros de descrição ou índices de fixação foram propostos em termos de população total (T), de subpopulações(S) e de individuos (I). Os parâmetros são os seguintes:

(i) $\mathrm{F}_{\mathrm{T}}$ - representa a correlação entre os gametas que se unem para produzir os indivíduos em relação aos gametas da população total.

(ii) $\mathrm{F}_{\mathrm{IS}}$ - representa a média das correlações, sendo cada uma delas proveniente dos gametas que se unem em cada subpopulação em relação aos gametas desta subpopulação.

(iii) $\mathrm{F}_{\mathrm{ST}}$ - representa a correlação entre os gametas ao acaso dentro das subpopulações em relação aos gametas da população total.

O parâmetro $F_{\text {IT }}$ reúne informações dos outros dois parâmetros, existindo a seguinte relação

$$
1-F_{I T}=\left(1-F_{I S}\right)\left(1-F_{S T}\right)
$$


COCKERHAM(1969) utiliza as diversas correlegōes como medidas de probabilidades de identidade por descendéncia, tomando por base a análise de variância das frequências génicas em populaçōes experimentais ou naturais. Para tanto, considera o modelo linear

$$
x_{k i j}=p+a_{k}+b_{k i}+w_{k i j}
$$

sendo:

$x_{k i j}$ o valor observado do gene $j$, do individuo $i$, pertencente ao grupo

$k$, que vale 1 se o alelo é $A$ e vale 0 se o alelo é a;

p uma constante associada a todas observacooes ;

8. o efeito do grupo $\mathrm{k}$;

$b_{h i} \quad o$ efeito do indivíduo i dentro do grupo $\mathrm{k}$;

$w_{b i j}$ o efeito do gene $\mathrm{j}$ dentro de cada indivíduo .

Os parâmetros a , $b_{\mathbf{k i}}$ e $w_{\mathrm{bjj}}$ são todos aleatórios e não correlacionados e têm variâncias $\sigma_{\mathrm{s}}^{2}, \sigma_{\mathrm{b}}^{2} e \sigma_{\mathrm{w}}^{2}$, respectivamente.

De acordo com o modelo, as esperanças matemáticas dos quadrados dos termos são os seguintes: 


$$
\begin{aligned}
E\left[x_{k i j} x_{k^{\prime} i^{\prime} j^{\prime}}\right] & =p^{2}+\sigma^{2} \text { se } k=k^{\prime}, i=i^{\prime} \text { e } j=j^{\prime} ; \\
& =p^{2}+\operatorname{Cov} \text { se } k=k^{\prime}, i=i^{\prime} \text { e } j \neq j^{\prime} ; \\
& =p^{2}+\operatorname{Cov} \text {, se } k=k^{\prime}, i \neq i^{\prime} \text { e } \\
& =p^{2}+\operatorname{Cov}_{\text {s }} \text { se } k \neq k^{\prime} .
\end{aligned}
$$

Considerando-se os gupos n\&̊م correlacionados, $\operatorname{Cov}_{8}=0$ e parametricamente em termos de correlafões tem-se:

$$
\sigma^{2}=p(1-p), \operatorname{Cov}_{a b}=\rho_{a b} p(1-p), \operatorname{Cov}_{\bullet}=\rho_{a} p(1-p)
$$

As correlaçoes $\rho_{a} e \rho_{\mathrm{b}}$ eståo associadas aos

componentes de variância da seguinte maneira:

$$
\begin{aligned}
\left(1-\rho_{\mathrm{Bb}}\right) p(1-p) & =\sigma_{\mathrm{w}}^{2}, \\
\left(\rho_{\mathrm{Bb}}-\rho_{\mathrm{a}}\right) p(1-p) & =\sigma_{\mathrm{b}}^{2}, \\
\rho_{\mathrm{a}} p(1-p) & =\sigma_{\mathrm{a}}^{2}
\end{aligned}
$$

e portanto $\quad \sigma^{2}=\sigma_{\mathrm{w}}^{2}+\sigma_{\mathrm{b}}^{2}+\sigma_{\mathrm{a}}^{2}=p(1-p)$.

Percebe-se, então, que as correlaçōes intraclasse, as covariâncias e os componentes de variância, embora de diferentes formas, representam parametrizaçoes equivalentes.

COCKERHAM (1969) afirma que se a variaça se origina inteiramenté devido à deriva e a sistema de acasalamento, entăo os resultados podem ser expressos em termos de $F$ e $\bar{\theta}$, sendo que a barra 
sobre $\theta$ quer enfatizar que se trata de uma medida global. Assim, a correlą̧⿸尸o entre freqüếncias gênicas de diferentes indivíduos no mesmo grupo é

$$
\rho_{\mathrm{a}}=\frac{\sigma_{\mathrm{a}}^{2}}{\sigma_{\mathrm{w}}^{2}+\sigma_{\mathrm{b}}^{2}+\sigma_{\mathrm{a}}^{2}}=\bar{\theta}
$$

entre genes dentro de individuos de diferentes grupos é

$$
\rho_{\mathrm{ab}}=\frac{\sigma_{\mathrm{b}}^{2}+\sigma_{\mathrm{a}}^{2}}{\sigma_{\mathrm{w}}^{2}+\sigma_{\mathrm{b}}^{2}+\sigma_{\mathrm{a}}^{2}}=F
$$

e entre genes dentro de individuos dentro de grupos é

$$
\rho_{\mathrm{b}}=\frac{\sigma_{\mathrm{b}}^{2}}{\sigma_{\mathrm{w}}^{2}+\sigma_{\mathrm{b}}^{2}}=\frac{F-\bar{\theta}}{1-\bar{\theta}} .
$$

Percebe-se a equivalência entre as correlą̧⿸尸es propostas por COCKERHAM (1969) e os indices de fixacão apresentados por WRIGHT (1965), isto é,

$$
\rho_{\mathrm{z}}=F_{S T}, \rho_{\mathrm{sb}}=F_{I T} \quad \text { e } \rho_{\mathrm{b}}=F_{I S} .
$$


COCKERHAM (1973) afimma que uma dificuldade em se relacionarem as correlaçoes com a teoria geral envolvendo componentes de variância como usualmente apresentado, é que por hipótese, não se admitem valores negativos para componentes de variância, enquanto as correlagôes podem ser negativas.

VENCOVSKY (1993) mostra para o caso de um loco com dois alelos, que F é o coeficiente de correlaça cntre os genes. Para tanto, utilizando a variável indicadora $x=1$, se o gene é $A, e x=0$, se o gene é $a$, considera o quadro que se segue :

\begin{tabular}{ccccc}
\hline Genótipos & $x_{1}$ & $x_{2}$ & Frequência $(f)$ & Produto $\left(x_{1} x_{2}\right)$ \\
\hline$A A$ & 1 & 1 & $p^{2}+F p q$ & 1 \\
$A \&$ & 1 & 0 & $p q(1-F)$ & 0 \\
$8 A$ & 0 & 1 & $p q(1-F)$ & 0 \\
$8 a$ & 0 & 0 & $q^{2}+F p q$ & 0 \\
\hline
\end{tabular}

Para estes dados, tem-se:

$$
\begin{aligned}
& \sum f=1, \quad \sum f \mathrm{x}_{1} \mathrm{x}_{2}=p^{2}+F p q, \quad \sum f \mathrm{x}_{1}=p \\
& \sum f \mathrm{x}_{2}=p, \quad \sum f \mathrm{x}_{1}^{2}=p, \quad\left(\sum f \mathrm{x}_{1}\right)^{2}=p^{2} .
\end{aligned}
$$


Assim,

$$
\begin{gathered}
\operatorname{Cov}\left(\mathrm{x}_{1}, \mathrm{x}_{2}\right)=\frac{1}{\sum f}\left[\sum f \mathrm{x}_{1} \mathrm{x}_{2}-\frac{\left(\sum f \mathrm{x}_{1}\right)\left(\sum f \mathrm{x}_{2}\right)}{\sum f}\right]=F p q, \\
\sigma_{\mathrm{x}_{1}}^{2}=\frac{1}{\sum f}\left[\sum f \mathrm{x}_{1}^{2}-\frac{\left(\sum f \mathrm{x}_{1}\right)^{2}}{\sum f}\right]=p q=\sigma_{\mathrm{x}_{2}}^{2} .
\end{gathered}
$$

Portanto,

$$
\rho\left(\mathrm{x}_{1}, \mathrm{x}_{2}\right)=\frac{\operatorname{Cov}\left(\mathrm{x}_{1}, \mathrm{x}_{2}\right)}{\sigma_{\mathrm{x}_{1}} \sigma_{\mathrm{x}_{2}}}=\frac{F p q}{\sqrt{p q \cdot p q}}=F,
$$

confirmando que o coeficiente de endogamia $\mathrm{F}$ é realmente o coeficiente de correlação entre os genes.

HARTL \& CLARK (1989) discutem a equivaléncia entre endogamia e correlą̧åo. Quando não existe endogamia, $F=0$ e $\rho=0$. Se a endogamia é total, $\mathrm{F}=1$ e $\rho=1$, pois os gametas são idênticos por descendência, sendo absolutamente correlacionados. WRIGHT (1965) enfatiza a importante diferença de interpretacảo dos parâmetros na discriminação da estrutura de populaf̧̋es. A definiçăo de endogamia como correlação na união de gametas deve ser preferida em relagão a probabilidade de autozigosidade, pois por definição a correlação pode ser 
negativa como o coeficiente de endogamia ao contrário dos valores de probabilidade que são sempre positivos entre 0 e 1 .

COCKERHAM (1973) afirma que, conforme discutido em FISHER (1970) o menor valor que a correlacão intraclasse pode assurnir num esquema de hierarquização simples é

$$
-\frac{1}{k-1}
$$

onde $\mathrm{k}$ representa o número de elementos na classe . Considerando-se $\mathrm{k}=2$ o número de genes nos individuos, percebe-se que o menor valor que a correlaģão entre genes pode assumir é -1. SANTOS \& ALBIERI (1982) mostram que o coeficiente de correlafäo intraclasse, no caso de congiomerados de tamanhos iguais se situa - se no intervalo

$$
\left(-\frac{1}{k-1}, 1\right) \text {. }
$$

WEIR \& COCKERHAM (1984) consideram, para o caso de um dos alelos de um loco, as seguintes definiçōes e notações: $F$, a correlação entre genes dentro de individuos ou endogamia; $\theta$, a correlef̧ã entre genes de diferentes indivíduos da mesma populaçึึo ou coancestria e f, a correlaçäo entre genes dentro de indivíduos dentro de populagões. Os três parâmetros correspondem às estatísticas $F$ de WRIGHT da seguinte forma

$$
F=F_{\text {IT }} \quad, \quad \theta=F_{S T} \quad \text { e } \quad f=F_{\text {IS }}
$$


estando relacionados por

$$
\mathbf{f}=\frac{\mathrm{F}-\boldsymbol{\theta}}{1-\theta}
$$

LONG (1986) estims as estatisticas F para dois grupos tribais vizinhos Gainj e Kalam na Nova Guiné , que constitúam duas populapōes linguisticamente diferentes mas culturalmente e ecologicamente bastante similares. $\mathrm{O}$ autor considera o modelo hierárquico com os genes estratificados em três níveis a saber : individuos, subdivisões e populaçåo total e afirms que o modelo com as estatisticas $F$ é pertinente a uma populacalo natural hierarquicamente subdividida em que as correlagobes podem se originar como consequêencia de ume diversidade do processo evolucionário.

COCKERHAM \& WEIR (1983) apontam os coeficientes de endogamia e de coancestria bem como outras medidas de identidade por descendéncia dos genes, como parâmetros importantes em genética quantitativa e de populações. Estes parâmetros são úteis para informar sobre homozigosidade, deriva, endogamia e variaģa quantitativa $\mathbf{O}$ cálculo dos coeficientes de endogamia e de coancestria a partir de linhagens e do conhecimento do sistema de acasalamento e do tamanho da populacão levam a valores esperados em tomo dos quais as identidades reais se diversificam através dos descendentes. É importante saber a extensåo através da qual o conceito de "real" e "esperado" se correspondem. 
REYNOLDS et al. (1983) usem o coeficiente de coancestria $\theta$ como base para uma medida da distância genética da evolufão a curto prazo, quando a divergência entre populasōes com um ancestral comum pode ser considerada como sendo exclusivamente devido à deriva As distâncias baseadas no coeficiente de coancestria såo consideradas como medidas da divergência entre as populacōes apenas pela deriva.

NEI (1973) discute um método no qual a diversidade genética de uma populasăo subdividida pode ser analisada em seus componentes, isto é, a diversidade entre e dentro de subpopulagőes. $O$ método é aplicado para qualquer populacão sem considerar o número de alelos por loco, as forças padrões de evolução tais como mutação, seleção e migração, além do sistema de reprodução e do tipo de organismo considerado. $\mathrm{O}$ método se baseia na identidade de duas amostras de genes dentro e entre populagooes. No caso de um loco, a frequêencia do alelo $k$ na população é $\mathbf{x}_{\mathbf{4}}$. Assim, a probabilidade de identidade de dois genes escolhidos aleatoriamente é dada por

$$
J=\sum_{\mathbf{k}} \mathrm{x}_{\mathbf{k}}^{2},
$$

enquanto que a probabilidade de não identidade é 


$$
\mathrm{H}=\mathrm{I}-\mathrm{J} \text {, }
$$

chamads de heterozigosidade. $\mathrm{O}$ autor, entretanto, considera este termo impróprio para o caso de uma população com acasalamento não aleatório preferindo adotar a palavra diversidade.

No caso de uma populaçäo subdividida em $\mathrm{s}$ subpopulafões pode-se estabelecer a relacâo

$$
\mathrm{J}_{\mathrm{T}}=\mathrm{J}_{\mathrm{S}}-\mathrm{D}_{\mathrm{ST}}
$$

em que $J_{T}$ e $J_{S}$ sẽo, respectivamente, as identidades genéticas médias total e dentro das subpopulagões e $D_{S T}$ é a diversidade genética média entre subpopulafões.

A diversidade genética média na população total pode ser desdobrada nas diversidades médias dentro e entre subpopulafões de acordo com a seguinte expressēo

$$
\mathrm{H}_{\mathrm{T}}=\mathrm{H}_{\mathrm{S}}+\mathrm{D}_{\mathrm{ST}} \text {, }
$$

sendo $H_{T}=1-J_{T}$ e $H_{S}=1-J_{S}$.

A diversidade entre subpopulagões relativa à populaf̧ão total é obtida por

$$
G_{S T}=\frac{D_{S T}}{H_{T}},
$$


portanto as expressões apresentadas permitem obter a releção

$$
1-J_{g}=\left(1-G_{g T}\right)\left(1-J_{T}\right)
$$

que é uma expressão análoga àquela apresentads por WRIGHT (1965) para as estatísticas F, diferindo apenas no enfoque das interpretrąoes. $\mathrm{Na}$ expressåo de WRIGHT (1965), $F_{\text {IS }}$ e $F_{\text {IT }}$ medem os desvios des frequêências genotípicas em reląão às proporções de Hardy - Weinberg. $\mathrm{Na}$ expressão de NEI (1973), J\& e $J_{T}$ são identidades genéticas. Além disso, $F_{\text {IS }}$ e $F_{I T}$ podem assumir valores negativos, enquanto que $J_{S}, J_{T}$ e $G_{S T}$ são todos não negetivos.

NEI (1977) estende a idéia de seu trabalho anterior $e$ mostra que as estatísticas F não precisam ser definidas como correlacão entre gametss, podendo ser definidas como uma função ds heterozigosidade esperada e observada. Os parâmetros definidos desta forma podem ser utilizados em qualquer situação, havendo ou não seleção, e sem qualquer questionamento sobre quantos alelos estão segregando num loco. Os índices de fixaça estabelecidos na populacåo sảo dados por

$$
F_{\mathrm{IS}}=\frac{\mathrm{H}_{\mathrm{S}}-\mathrm{H}_{\mathrm{O}}}{\mathrm{H}_{\mathrm{S}}} \quad, \mathrm{F}_{\mathrm{IT}}=\frac{\mathrm{H}_{\mathrm{T}}-\mathrm{H}_{\mathrm{O}}}{\mathrm{H}_{\mathrm{T}}}, \mathrm{F}_{\mathrm{ST}}=\frac{\mathrm{H}_{\mathrm{T}}-\mathrm{H}_{\mathrm{S}}}{\mathrm{H}_{\mathrm{T}}}
$$

sendo $\mathrm{H}_{\mathrm{S}}$ a heterozigosidade esperads, $\mathrm{H}_{\mathrm{O}}$ a heterozigosidade observada e

$$
\mathrm{H}_{\mathrm{T}}=1-\sum \bar{p}_{k}^{2}
$$


$O$ indice $F_{S T}$ é idêntico ao coeficiente de diferenciaçäo genética, $G_{S T}$ definido em NEI (1973).

VENCOVSKY (1993) discute os indices propostos por NEI (1973) ilustrando os resultados através de um exemplo numérico envolvendo três alelos.

\subsection{Estimaça de parametros de variabilidade e diversidade genética}

VENCOVSKY (1992) descreve a técnica de análise de variância com frequêências gênicas, quando os dados enț̉o organizados em progênies e discute sua utilizacăo para descrever a estrutura genética de populacōes. O autor admite dados de marcadores colhidos numa estrutura hierárquica a saber.

(i) Uma ou mais populações de uma espécie são tomadas para o estudo ;

(ii) Colhem-se sementes de plantas-mẽe, que são mantidas separadamente constituindo progênies;

(iii) Os marcadores são pesquisados planta a planta, permitindo-se um número arbitrário de locos e de alelos por loco.

De acordo com o autor, considerando-se a frequência da variável indicadora $x$ que vale um, quando um dado alelo, por exemplo $A_{1}$, de um loco está na planta e vale zero quando este alelo está ausente, e presente por exemplo $A_{2}, A_{3}, \ldots, A_{0}$. Considerando-se ainda r populações, 
m progênies por populaçảo, n plantas por progênie e dois genes de um dado loco por plants, tem-se o seguinte modelo hierárquico para cada frequiência alélica:

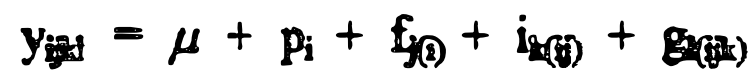

sendo:

Yis a frequéncia do gene 1 , dentro do individuo $k$, da familia $j$, pertencente à populaç⿸厃㔾 i ;

He uma constente associada a todas observações;

$p_{i}$ o efeito da populą̧ão $i, \operatorname{com} i=1,2, \ldots, r$;

f(a) o efeito da família j dentro da populą̧âo i , com j $=1,2, \ldots, m$;

$i_{\text {k(g) }}$ o efeito do indivíduo $k$ dentro da família $j$ e da populaşão $i, c o m k$ $=1,2, \ldots, \mathrm{n}$;

gafia 0 efeito do gene 1 dentro do indivíduo $k$, dentro da familia $j$ e da populeção i, com $1=1,2$.

Este modelo, segundo o autor, é \&leatório conforme COCKERHAM (1969), o que pressupõe que todas as entidades da estrutura hierárquica são obtidas por amostragem no estudo. Geneticamente este modelo admite que a diversidade entre as populacõos foi, fundamentalmente, provocada por deriva genética ocorrida nas 
gerafões passadas. O esquema da análise de veriência para o modelo é o da Tabela 1.

Tabela 1. Análise de variância das frequûencias (variável $x$ ) de um alelo de um loco.

\begin{tabular}{|c|c|c|c|c|}
\hline$\overline{F V}$ & $\overline{\mathrm{GL}}$ & SQ & $\mathrm{QM}$ & $\mathrm{E}(\mathrm{QM})$ \\
\hline Popul\&fōes (P) & $\overline{r-1}$ & $\overline{S_{P}}$ & $\overline{Q_{p}}$ & $\sigma_{\mathrm{G}}^{2}+2 \sigma_{\mathrm{I}}^{2}+2 n \sigma_{\mathrm{P}}^{2}+2 \pi m \sigma_{\mathrm{P}}^{2}$ \\
\hline Famulia (F)/P & $r(m-1)$ & $S_{F}$ & $Q_{p}$ & $\sigma_{\mathrm{G}}^{2}+2 \sigma_{\mathrm{I}}^{2}+2 n \sigma_{\mathrm{F}}^{2}$ \\
\hline Individuos $(I) / F$ & $\operatorname{Im}(n-1)$ & $\mathbf{S}_{\mathrm{I}}$ & $Q_{t}$ & $\sigma_{\sigma}^{2}+2 \sigma_{1}^{2}$ \\
\hline Genes / I & $\operatorname{mmn}$ & $S_{G}$ & $Q_{0}$ & $\sigma_{\mathrm{G}}^{2}$ \\
\hline Total & $2 m n-1$ & $\overline{\mathbf{S}_{\mathbf{T}}}$ & & \\
\hline
\end{tabular}

Havendo g locos com u alelos cads um, ou com urn número variável de alelos, procede-se a gu análises de variância da variável $\mathrm{x}$ ou a $\sum \mathbf{u}$ análises.

Em cada análise, a variância total da frequência alélica para o alelo em queståo é dada por

$$
\sigma_{T}^{2}=\sigma_{\mathrm{P}}^{2}+\sigma_{\mathrm{P}}^{2}+\sigma_{\mathrm{I}}^{2}+\sigma_{\mathrm{G}}^{2}=\mathrm{p}(1-\mathrm{p})
$$


sendo:

$\sigma_{P}^{2}$ a variência entre populações,

$\sigma_{\nexists}^{2}$ a variância entre famólias,

$\sigma_{1}^{2}$ a variância entre individuos,

$\sigma_{\sigma}^{2}$ a variância entre genes $\mathrm{e}$

$\sigma_{T}^{2}$ a variância total, que corresponde à soma de todas as variâncias.

O autor mostra ainda as seguintes relacões parametricas:

$$
\begin{aligned}
& \sigma_{P}^{2}=\mathrm{p}(1-\mathrm{p}) \theta_{2}, \\
& \sigma_{F}^{2}=\mathrm{p}(1-\mathrm{p})\left(\theta_{1}-\theta_{2}\right), \\
& \sigma_{I}^{2}=\mathrm{p}(1-\mathrm{p})\left(\mathrm{F}-\theta_{1}\right), \\
& \sigma_{O}^{2}=\mathrm{p}(1-\mathrm{p})(1-\mathrm{F}), \\
& f=\frac{F-\theta_{2}}{1-\theta_{2}},
\end{aligned}
$$

sendo:

p a freqüência de um gene em um determinado loco; 
F o coeficiente médio de endogamia de todas as plantas nas populaçoes analissdas, ao nível de espécie;

f o coeficiente médio de endogarnia dentro das populagões;

$\theta_{1}$ o coeficiente de parentesco das plantas dentro das familias;

$\theta_{2}$ a medida da distância genética entre as populagỏes estudadas, correspondendo tamberm ao parentesco entre as plantas de familias diferentes dentro das populagōes.

As taxas aparentes de autofecundaçåo, s, ou de fecundaçåo cruzada, $t$, relacionam-se com $f$ como segue:

$$
f=\frac{s}{2-s}=\frac{1-t}{1+t}
$$

o que é válido quando as populą̧aes eståo em equilibrio de WRIGHT, isto $e$ é equilíbrio com endocruzamento.

A partir da análise de variância apresentada na Tabela 1, 0 método dos momentos pode ser empregado para obter as estimativas dos componentes de variância e dos parâmetros genéticos, fornecendo as expressões seguintes: 


$$
\begin{aligned}
\hat{\sigma}_{\mathrm{P}}^{2} & =\frac{1}{2 m \mathrm{~m}}\left[\mathrm{Q}_{\mathrm{P}}-\mathrm{Q}_{\mathrm{F}}\right], \\
\hat{\sigma}_{\mathrm{F}}^{2} & =\frac{1}{2 \mathrm{n}}\left[\mathrm{Q}_{\mathrm{F}}-\mathrm{Q}_{\mathrm{I}}\right], \\
\hat{\sigma}_{\mathrm{I}}^{2} & =\frac{1}{2}\left[\mathrm{Q}_{\mathrm{I}}-\mathrm{Q}_{\mathrm{Q}}\right], \\
\hat{\sigma}_{\mathrm{G}}^{2} & =\mathrm{Q}_{\mathrm{O}}, \\
\hat{\theta}_{2} & =\frac{\hat{\sigma}_{\mathrm{E}}^{2}}{\hat{\sigma}_{\mathrm{T}}^{2}}, \\
\hat{\theta}_{1}-\hat{\theta}_{2} & =\frac{\hat{\sigma}_{\mathrm{I}}^{2}}{\hat{\sigma}_{\mathrm{T}}^{2}}, \\
\hat{\mathrm{F}}-\hat{\theta}_{1} & =\frac{\hat{\sigma}_{\mathrm{I}}^{2}}{\hat{\sigma}_{\mathrm{T}}^{2}} \mathrm{e} \\
1-\hat{\mathrm{F}} & =\frac{\hat{\sigma}_{\mathrm{G}}^{2}}{\hat{\sigma}_{\mathrm{T}}^{2}} .
\end{aligned}
$$

$\mathrm{Na}$ obtença das estimativas, envolvendo quocientes usa-se a aproximafão que considera a estimativa do quociente como sendo o quociente das estimativas. A estimativa da taxa aparente de fecundaça cruzada segundo o autor é obtida por

$$
\hat{t}=\frac{1-\hat{f}}{1+\hat{f}}
$$

MORAES (1993) discute a técnica de eletroforese e a caracterização de isoenzimas, apresentando um organograma que mostra todas as etapas de uma análise eletroforética desde a escolha e coleta das amostras, passando pela interpretação genética dos fenótipos enzimáticos 
apresentados nos zimogramas, o que permite a obtenfäo dọs dados das frequências alélicas para análise de variância e estimaçảo dos parâmetros genéticos.

WEIR (1990) aborda a técnica de análise de variância com frequiências gênicas para organismos haplóides e diplóides. No caso de diplóides são apresentados modelos hierárquicos com até quatro níveis de hierarquia

MORAES (1992), estuda a variabilidade genética em populafões naturais de aroeira (Myracrodruon unondeuva FF \& MF), comparando a divergência genética entre as populafỏes através da técnica de eletroforese e por caracteres quantitativos. São avaliadas duas populafōes, utilizando-se 25 famílias de uma populafâo e 26 de outta, e 20 indivíduos de cada família. Os dados de frequêencias gênicas såo analisados segundo um modelo de classificafảo hierárquica desbalanceado com três níveis de hierarquia. Os parâmetros de variabilidade genética são estimados mostrando expressiva endogamia e baixa taxa aparente de fertilizacão cruzada nas populações. O autor encontra ainda maior variabilidade genética dentro do que entre as populafỏes.

PAIVA (1992) avalia a variabilidade enzimática em populagōes naturais de seringueira (Hevea brasilienses Willd ex Adr de Juss) para fazer inferências sobre a estrutura genética dessas populagões procurando orientar o processo de amostragem na coleta e conserveção de germoplasma. São estudadas duas populaçōes envolvendo 53 famílias, 
utilizando 30 indivíduos de cada familia A variabilidade e diversidade genética das populações é determinada usando para cada alelo identificado uma análise de veriância de acordo com um modelo desbalanceado em classificafåzo hierárquica com três níveis de hierarquia. Os resultados mostram que as duas populaģoes apresentam distâncias genéticas bem semelhantes.

MORI (1993) estuds a variabilidade isoenzimética em uma populagåo de Eucalyptus grandis Hill ex Maiden com diferentes intensidades de seleçäo, quantificando a variabilidade genética através de uma análise de variância semelhante às apresentadas por PAIVA (1992) e MORAES (1992). Os resultados mostram pequena distância genétics entre subpopulações, havendo fixacão de alelos em locos originalmente polimórficos na subpopulą̧ảo composta por menor número de clones.

Se um loco tem apenas dois alelos, somente um deles deve ser utilizado para estimar os parâmetros através da análise de variância proposta por WEIR (1990) e VENCOVSKY (1992), pois a análise em relagão a qualquer entre dois alelos é sempre a mesma. No caso de u alelos de um loco haverá u análises de variância e em consequeência, u estimativas dos parâmetros. Para estimar o coeficiente de coancestria, $\partial$, REYNOLDS et al. (1983) sugerem, no caso de u alelos, obter um estimador médio sobre todos alelos, por dois métodos. Seja um determinado alelo $k$ para o qual o estimador de $\theta$, é dado por 


$$
\hat{\theta_{k}}=\frac{\mathbf{a}_{k}}{a_{k}+b_{k}} \text {, }
$$

o primeiro método consiste em obter uma múdia aritmética sobre todos alelos dada por

$$
\hat{\theta}_{u}=\frac{1}{u} \Sigma \dot{\theta}_{k},
$$

enquanto que o segundo método propõe uma média somando-se numerador e denominador dos estimadores individuais, isto é,

$$
\hat{\theta}_{w}=\frac{\sum a_{1}}{\sum\left(a_{1}+b_{1}\right)} .
$$

WEIR \& COCKERHAM (1984) afimam que o primeiro método não é tão satisfatório quanto o segundo, e que no caso de mais de um loco o conceito se generalizs

REYNOLDS et al. (1983) concluem que o estimador médio nos dois casos só é imparcial se for considerado que a esperança matemática de uma razåo é a razăo das esperanças matemáticas, o que não é verdade.

WEIR (1990) propõe também a ưlilizaçå dos métodos de reamostragem numérica conforme discutido em EFRON (1982) como meio para se fazerem inferéncias sobre os parâmetros associados d̀s frequêencias gênicas de populações, através das frequêencias amostrais. 
Estes métodos conhecidos por Jackknife e Bootstrap, possibilitam estimar variências e construir intervalos de confiança.

\subsection{Estimação de parâmetros definidos como o quociente}

\section{entre duas variáveis aleatórias}

De acordo com SUTHERLAND (1965), o autor que primeiro estuda a variância de uma rzzåo é Pearson em 1897, propondo uma fórmula aproximada para a variância da razåo $x_{1} / x_{2}$, quando momentos superiores 80 de segunda ordem sảo desprezados, dada por

$$
\operatorname{Var}\left(x_{1} / x_{2}\right) \approx\left(\bar{x}_{1} / \bar{x}_{2}\right)^{2}\left(c_{1}^{2}+c_{2}^{2}-2 r_{12} c_{1} c_{2}\right)
$$

sendo:

$\overline{\mathbf{x}}_{\mathbf{i}}$ a média da variável $\mathbf{x}_{\mathbf{i}}$,

$I_{12}$ o coeficiente de correlação entre $x_{1}$ e $x_{2}$ e

$c_{i}$ o coeficiente de variagâo da variável $x_{i}$.

Em seu estudo o autor aplica a sugestân de Pearson para encontrar a variância genética da razão $x_{1} / x_{2}$. Sendo $h_{i}^{2}$ a herdabilidade de $x_{i}, I_{G i j}$ a correlação genética entre $x_{i}$ e $x_{j}$ e $c_{i}$ o coeficiente de variaçåo de $x_{i}$, então a variância genética de $x_{1} / x_{2}$ pode ser escrita por: 


$$
\left(x_{1} / x_{2}\right)^{2}\left(h_{1}^{2} c_{1}^{2}+h_{2}^{2} c_{2}^{2}-2 I_{G 12} h_{1} h_{2} c_{1} c_{2}\right)
$$

e em consequência , a hendabilidade da razão, ou a razão entre a variância genética e a variância fenotípica pode ser expresse como:

$$
h_{x_{1} / x_{2}}^{2}=\frac{h_{1}^{2} c_{1}^{2}+h_{2}^{2} c_{2}^{2}-2 r_{G 12} h_{1} h_{2} c_{1} c_{2}}{c_{1}^{2}+c_{2}^{2}-2 r_{12} c_{1} c_{2}}
$$

Todos os trabalhos que desenvolvem expressōes aproximadas para a variância de um quociente entre variáveis aleatórias baseiam-se no estudo da aproximafão de ums função através da expansão em série de Taylor. Para tanto, é importante entender o comportamento de sequências de números reais $\left\{a_{n}\right\} n \geq 1$ e $\left\{b_{n}\right\} n \geq 1$, quando $n$ tende ao infinito, conhecendo-se as ordens de magnitude destas sequencias, o que exige a compreensão da notação $O($.$) e o(.) e sua aplicação$ (LEITE \& SINGER, 1990).

De acordo com os autores, se $\left\{b_{n}\right\}_{\geq 1}$ e $\left\{b_{n}\right\}_{n \geq 1}$ são seqüências de números reais, então:

(i) $a_{n}=O\left(b_{n}\right)$ se existirem um número real $k>0$ e um número inteiro positivo $n_{0}=n_{0}(k)$ tal que

$$
\left|\mathrm{a}_{\mathbf{n}} / \mathrm{b}_{\mathrm{p}}\right| \leq \mathrm{k}, \forall n \geq n_{0}
$$

(ii) $a_{n}=o\left(b_{n}\right)$ se para todo $\varepsilon>0$ existir um número inteiro positivo $\mathrm{n}_{0}=\mathrm{n}_{0}(\varepsilon)$ tal que 


$$
\left|a_{n} / b_{n}\right|<\epsilon, \forall n \geq n_{0}
$$

Em outros termos, $a_{n}=O\left(b_{n}\right)$ se a razão $\left|a_{n} / b_{n}\right|$ for limitada para todo $n$ suficientemente grande e $a_{n}=o\left(b_{n}\right)$ se

$a_{n} / b_{n} \longrightarrow 0$ quando $n \longrightarrow \infty$.

Segundo LEITE \& SNGER (1990), dentre as varias maneiras de aproximar uma função $f$ por um polinômio, a que mais interessa corresponde ao caso em que:

(i) f coincide com o polinômio em um determinado ponto $x_{0}$;

(ii) a k-ésima derivada de $\mathrm{f}$ coincide com a k-ésima derivada do polinômio no ponto $\mathrm{x}_{0}, \mathrm{k}=1,2, \ldots, \mathrm{n}$.

Assim, sendo f uma função derivável até a ordem $n$ em um ponto $x_{0}$, o polinômio de Taylor, de ordem $n$, de $f$ em tomo de $x_{0}$, é

$$
P(\mathrm{x})=\sum_{k=0}^{n} \frac{f^{k}\left(\mathrm{x}_{0}\right)}{k !}\left(\mathrm{x}-\mathrm{x}_{\mathrm{o}}\right)^{k}
$$

Então, para todo $x \in D f, P_{n}(x)=f(x)-P(x)$ é o resto ou o erro de aproximação de $f(x)$ por $P(x)$. Portanto, se $f$ for derivável até a ordem $n$ em um ponto $x_{0}$, tem-se:

$$
f(x)=\sum_{k=0}^{n} \frac{f^{(k)}\left(x_{0}\right)}{k !}\left(x-x_{0}\right)^{k}+R_{\mathbf{a}}(x)
$$


que é chamada de formula de Taylor com resto $R_{a}$, de $f$ em torno de $x_{0}$, onde $R_{0}(x)$ é tal que

$$
R_{0}(x)=o\left(\left(x-x_{0}\right)^{2}\right) \text { quando } x \rightarrow x_{0} .
$$

Em conseqüência, a função $f(x)$ pode ser escrita como:

$$
f(x)=\sum_{k=0}^{n} \frac{f^{(k)}\left(x_{0}\right)}{k !}\left(x-x_{0}\right)^{k}+o\left(\left(x-x_{0}\right)^{n}\right) .
$$

Como $R_{0}$ também é tal que $R_{0}(x)=O\left(\left(x-x_{0}\right)^{2}\right)$ a fórmula de Taylor pode tambem ser escrita como

$$
f(x)=\sum_{k=0}^{n} \frac{f^{(k)}\left(x_{0}\right)}{k !}\left(x-x_{0}\right)^{k}+o\left(\left(x-x_{0}\right)^{n}\right)
$$

Finalmente, conclui-se que, se uma funço real $f$, definida em algum intervalo aberto em torno de um ponto $x_{0}$, tem derivadas de todas as ordens nesse intervalo, a série de Taylor de $\mathrm{f}$ em torno de $x_{0}$ é:

$$
\sum_{k=0}^{\infty} \frac{f^{(k)}\left(\mathrm{x}_{0}\right)}{k !}\left(\mathrm{x}-\mathrm{x}_{0}\right)^{k}=f\left(\mathrm{x}_{0}\right)+\sum_{k=1}^{\infty} \frac{f^{k}\left(\mathrm{x}_{0}\right)}{k !}\left(\mathrm{x}-\mathrm{x}_{0}\right)^{k}
$$

De acordo com KENDALL \& STUART (1963), supondo que $x_{i}$ tenha média $\theta_{i}$ e variância de ordem $n^{-1}$ e que $g$ 
tenha média e variância finitas, então se $\mathrm{g}$ é diferenciável para $\mathrm{x}_{i}=\theta_{t}$, tem-se escrevendo $\partial \mathrm{g} / \partial \theta_{\mathrm{i}}$ por $\theta \mathrm{g} / \partial \mathrm{x}_{\mathrm{i}}$ para $\mathrm{x}_{\mathrm{i}}=\theta_{t}$,

$$
\Delta g=\sum_{i=1}^{k} \frac{\partial g}{\partial \theta_{i}} \Delta x_{i}+O(\Delta x)^{2}
$$

em que os $x_{i}$ são tomados em seus valores esperados.

Com amostras grandes, a esperança de $(\Delta x)^{2}$ é $O(1)$. Entáo tem-se, para primeira ordem, uma vez que $E\left(\Delta \mathbf{x}_{i}\right)=0$,

$$
E[\Delta g]=0 .
$$

Portanto o valor médio de $\mathrm{g}$ é $\mathrm{g}\left(\theta_{1}, \theta_{2}, \ldots, \theta_{\mathrm{k}}\right)$.

Se as derivadas não são nulas, tem-se também para a primeira ordem,

$$
\operatorname{Var}[g]=E\left[\sum \frac{\partial g}{\partial \theta_{t}} \Delta \mathbf{x}_{i}\right]^{2}=\sum_{i, N}^{k}\left[\frac{\partial g}{\partial \theta_{i}} \frac{\partial g}{\partial \theta_{j}} \operatorname{Cov}\left(\mathbf{x}_{\mathrm{i}}, \mathrm{x}_{\mathrm{j}}\right)\right]
$$

onde $i$ e $j$ podem ser iguais, caso em que $\operatorname{Cov}\left(x_{i}, x_{j}\right)=\operatorname{Var}\left(x_{i}\right)$.

Os autores consideram a expressão $\operatorname{Var}[\mathrm{g}]$ de fundamental importância, pois ela fornece a variância de uma função de variáveis aleatórias em termos de suas variâncias e covariâncias. Três particularizą̧̃os de $\operatorname{Var}[\mathrm{g}]$ são de interesse: 
(i) g é uma função de uma única variável aleatónia. Então

$$
\operatorname{Var}[g(x)]=\left(\frac{d g}{d \theta}\right)^{2} \operatorname{Var}[x] ;
$$

(ii) g é uma função linear de variáveis aleatórias. Se

$$
g\left(x_{1}, \ldots, x_{k}\right)=\sum_{i=1}^{k} a_{i} x_{t}
$$

então $\operatorname{Var}[g]=\sum_{j=1}^{t} a_{i}^{2} \operatorname{Var}\left[x_{i}\right]+\sum_{j \neq j} a_{i} a_{j} \operatorname{Cov}\left(x_{i}, x_{j}\right)$

Se as variáveis $x_{i}$ são independentes, a variância de $g$ é uma soma ponderada de suas variâncias individuais.

(iii) $g$ é o quociente entre duas variáveis aleatórias, por exemplo $x_{1} / x_{2}$ com $x_{2}>0$. Então,

$$
\begin{aligned}
\operatorname{Var}\left[\mathrm{x}_{1} / \mathrm{x}_{2}\right] & =\frac{\operatorname{Var}\left[\mathrm{x}_{1}\right]}{\theta_{2}^{2}}+\frac{\theta_{1}^{2} \operatorname{Var}\left[\mathrm{x}_{2}\right]}{\theta_{2}^{t}}-\frac{2 \theta_{1} \operatorname{Cov}\left(\mathrm{x}_{1} \mathrm{x}_{2}\right)}{\theta_{2}^{3}} \\
& =\left[\frac{E\left(\mathrm{x}_{1}\right)}{E\left(\mathrm{x}_{2}\right)}\right]^{2}\left\{\frac{\operatorname{Var}\left[\mathrm{x}_{1}\right]}{\left[E\left(\mathrm{x}_{1}\right)\right]^{2}}+\frac{\operatorname{Var}\left[\mathrm{x}_{2}\right]}{\left[E\left(\mathrm{x}_{2}\right)\right]^{2}}-\frac{2 \operatorname{Cov}\left(\mathrm{x}_{1}, \mathrm{x}_{2}\right)}{E\left(\mathrm{x}_{1}\right) E\left(\mathrm{x}_{2}\right)}\right\}
\end{aligned}
$$

A expressão final, segundo os autores, é a soma de quadrados dos coeficientes de variação das duas variáveis aleatórias menos duas vezes o quadrado do que pode ser analogamente chamado de coeficiente de covariação das duas variáveis. 
MOOD et al. (1974) afirmam que a módia e a variância de uma função das variáveis aleatórias $\mathrm{X} \in \mathrm{Y}$ podem ser aproximadas através da expansão em série de Taylor por:

$$
\begin{gathered}
E[g(X, Y)] \approx g\left(\mu_{X}, \mu_{Y}\right)+\left.\frac{1}{2} \operatorname{Var}[X] \frac{\partial^{2}}{\partial x^{2}} g(x, y)\right|_{\mu_{X}, \mu_{Y}}+ \\
+\left.\frac{1}{2} \operatorname{Var}[Y] \frac{\partial^{2}}{\partial y^{2}} g(x, y)\right|_{\mu_{X}, \mu_{Y}}+\left.\operatorname{Cov}[X, Y] \frac{\partial^{2}}{\partial x \partial y} g(x, y)\right|_{\mu_{X}, \mu_{Y}} \\
\mathrm{e}
\end{gathered}
$$

$$
\begin{aligned}
\operatorname{Var}[\mathrm{g}(\mathrm{X}, \mathrm{Y})] & \approx \operatorname{Var}[X]\left\{\left.\frac{\partial}{\partial x} g(x, y)\right|_{\mu_{2}, \mu_{3}}\right\}^{2}+\operatorname{Var}[Y]\left\{\left.\frac{\partial}{\partial y} g(x, y)\right|_{\mu_{2}, \mu_{3}}\right\}^{2}+ \\
& +2 \operatorname{Cov}[\mathrm{X}, \mathrm{Y}]\left\{\left.\left.\frac{\partial}{\partial x} g(x, y)\right|_{\mu_{2, \mu_{3}}} \cdot \frac{\partial}{\partial y} g(x, y)\right|_{\mu_{2}, \mu_{3}}\right\} .
\end{aligned}
$$

Se a função das variáveis aleatónias $\mathrm{X}$ e $\mathrm{Y}$ for definida por $\mathrm{g}(\mathrm{X}, \mathrm{Y})=\mathrm{X} / \mathrm{Y}$, então:

$$
\begin{gathered}
E[X / Y] \approx \frac{\mu_{X}}{\mu_{Y}}-\frac{1}{\mu_{Y}^{2}} \operatorname{Cov}[X, Y]+\frac{\mu_{X}}{\mu_{Y}^{3}} \operatorname{Var}[Y] \\
e \\
\operatorname{Var}[X / Y] \approx\left(\frac{\mu_{X}}{\mu_{Y}}\right)^{2}\left\{\frac{\operatorname{Var}[X]}{\mu_{X}^{2}}+\frac{\operatorname{Var}[Y]}{\mu_{Y}^{2}}-\frac{2 \operatorname{Cov}[X, Y]\}}{\mu_{X} \mu_{Y}}\right\}
\end{gathered}
$$

WEIR (1990) afirma que os estimadores de parâmetros genéticos envolvem sempre quocientes de frequências multinomiais, os quais não permitem estabelecer expressões exatas para as variâncias. Neste caso, usa-se um método aproximado, comumente chamado de 
método delta, baseado na expansão em série de Taylor de funções a partir da qual as variâncias são obtidas. Se a variância a ser encontrada é da função $T$ das variáveis $n_{l}$, o método delta fornece

$$
\operatorname{Var}[T] \approx \sum_{i}\left(\frac{\partial \mathrm{T}}{\partial \mathrm{n}_{i}}\right)^{2} \operatorname{Var}\left[\mathrm{n}_{t}\right]+\sum_{i} \sum_{j} \frac{\partial \mathrm{T}}{\partial \mathrm{n}_{i}} \frac{\partial \mathrm{T}}{\partial \mathrm{n}_{j}} \operatorname{Cov}\left(\mathrm{n}_{t}, \mathrm{n}_{j}\right)
$$

sendo cada derivada avaliada com os valores de $n_{i}$ substituidos por suas esperanças matemáticas.

COX (1990) usa o método delta para uma aproximafão da variância de um quociente entre estimativas de parâmetros, no caso de se assumir uma parametrizaça linear. A expressão obtida para a variância do quociente entre as estimativas $\hat{\alpha}$ e $\hat{\beta}$ em função de suas esperanças, variâncias e covariâncias é a seguinte:

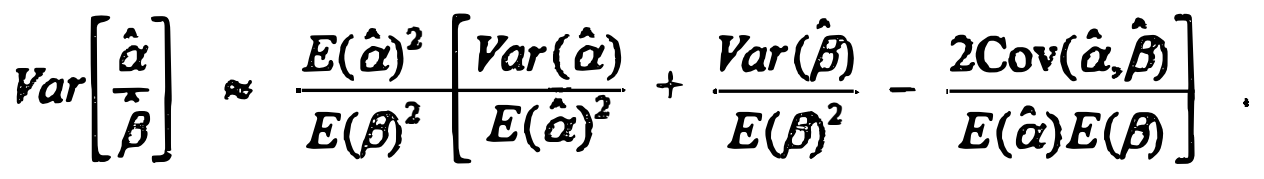

BIELER \& WILLIAMS (1993), estudando a variância do estimador $p_{i}^{\prime}=y_{i} / n_{i}^{\prime}$ da resposta quantal ajustada, utiliza a expressão aproximada pela expansão em série de Taylor

$$
\operatorname{Var}\left[p_{i}^{\prime}\right] \approx \frac{\operatorname{Var}\left[\mathrm{y}_{\mathrm{i}}\right]+\left(p_{i}^{\prime}\right)^{2} \operatorname{Var}\left[n_{i}^{\prime}\right]-2 p_{i}^{\prime} \operatorname{Cov}\left[y_{i}, n_{i}^{\prime}\right]}{\left(n_{i}^{\prime}\right)^{2}}
$$


Vários trabalhos têm utilizado a expansão de uma função pela série de Taylor como método para obtenção de uma aproximação de variância do coeficiente de herdabilidade. OSBORNE \& PATERSON (1952) detuzem as estimativas das variâncias das estimativas dos componentes de variância relacionadas a um modelo, com o objetivo de se estimar o erro padrão do coeficiente de herdabilidade. BARBIN \& PIMENIEL GOMES (1970) apresentam fórmulas para estimagăo da variância das seguintes expressర̃es do coeficiente de herdabilidade, no caso de familias de meio-irmãos:

$$
h_{1}^{2}=\frac{4 S}{E+D+S} \quad, h_{2}^{2}=\frac{4 D}{E+D+S} \quad \text { e } h_{3}^{2}=\frac{2(D+S)}{E+D+S}
$$

calculadas a partir da análise de variância seguindo o modelo de blocos incompletos, onde:

E é a estimativa da variância do ambiente,

D é a estimativa da variância devida a vacas e

S é a estimativa da variância devida a touros .

GORDON et al. (1972) estudam as herdabilidades no sentido amplo e restrito, estimando as variâncias das estimativas de ambas as formas em dois modelos aleatórios. A estimação das variâncias dos componentes de variância, baseia-se na expressão seguinte: 


$$
\operatorname{Var}\left[\hat{\sigma}_{\mathrm{t}}^{2}\right]=\frac{1}{\mathrm{n}_{\mathrm{t}}^{2}} \sum_{\mathrm{u}} \frac{2\left[E\left(Q M_{\mathrm{u}}\right)\right]^{2}}{f_{\mathrm{u}}}
$$

sendo:

$n_{t} \quad$ o divisor apropriado no estimador de $\sigma_{t}^{2}$,

$\mathrm{QM}_{0}$ o u-ésimo quadrado médio no estimador de $\sigma_{z}^{2}$ e

f. o número de graus de liberdade do u-ésimo quadrado médio.

VELLO \& VENCOVSKY (1974) deduzem expressz̋es para a estimação das variâncias associadas às estimativas de algumas variâncias genéticas e coeficientes de herdabilidade, em populaf̧es alógamas e autógamas. IWAISAKI \& WILTON (1993) estudam a regressão do valor genotípico sobre o valor fenotípico de um caráter razão, usando aproximação através da expansão de uma função em série de Taylor.

BURNHAM \& REXSTAD (1993), estudando a variância da distribuição de probabilidade de sobrevivência

$$
\sigma_{g}^{2}=S_{1}\left(S_{2}-S_{1}\right)=S_{1}\left(1-S_{1}\right) \frac{a}{a+1}
$$

propãem um estimador dado por

$$
\hat{\sigma}_{\mathbf{g}}=\hat{S}_{1}\left(1-\hat{S}_{1}\right) \frac{\hat{a}}{\hat{a}+1},
$$


cuja variância é aproximada por uma expansão em série de Taylor, fornecendo

$\operatorname{Var}\left[\hat{\sigma}_{s}\right] \approx\left[\frac{s_{1}\left(1-s_{1}\right)}{(a+1)^{2}}\right]^{2} \operatorname{Var}[\hat{a}]+\left[\frac{\hat{a}\left(1-2 s_{1}\right)}{a+1}\right]^{2} \operatorname{Var}\left[\hat{s}_{1}\right]+\frac{2 \Delta s_{1}\left(1-s_{1}\right)\left(1-2 s_{1}\right)}{(a+1)^{3}} \operatorname{Cov}\left[\hat{a}_{0}, s_{1}\right]$

$\mathrm{Na}$ obtenção de estimativa não tendenciosa da variância de um componente de variância, OSBORNE \& PATERSON (1952) sugerem que se some 2 ao número de graus de liberdade, de acordo com sugestão de DANIELS (1939), o que segundo os autores, não tem consenso na literatura.

CRUMP (1946) sugere a correçåo do viés das estimativas somando-se 2 ao número de graus de liberdade $v$, o que não é feito por SATTERTHWATTE (1946). Entretanto BARBIN \& PIMENTEL GOMES (1970), GORDON et al. (1972) e VELLO \& VENCOVSKY (1974) fazem a corroça do viés das estimativas das variâncias de um componente de variância utilizando $v+2$ como denominador de suas fórmulas.

JOHNSON \& KOTZ (1970) discutem a distribuição do coeficiente de correlação

$$
R=\frac{\sum_{t=1}^{\infty}\left(X_{t}-\bar{X}\right)\left(Y_{t}-\bar{Y}\right)}{\left[\sum_{t=1}^{n}\left(X_{t}-\bar{X}\right)^{2} \sum_{t=1}^{n}\left(Y_{t}-\bar{Y}\right)^{2}\right]^{1 / 2}}
$$


e, através do desenvolvimento aproximado de uma função em série de Taylor, mostram que o viés de R como estimador de $\rho$ é

$$
-\frac{1}{2} \frac{\rho\left(1-\rho^{2}\right)}{n}
$$

e que a variância do estimador de $\rho$ é dada por

$$
\operatorname{Var}[R] \approx \frac{\left(-\rho^{2}\right)^{2}}{n}
$$

FISHER (1970) afima que, trabalhando-se com amostras grandes, correlą̧es moderadas ou baixas, o coeficiente de correlação de uma amostra de $n$ pares de valores tem distribuição normal em torno do verdadeiro valor de $\rho$, com variância

$$
\frac{\left(1-\rho^{2}\right)^{2}}{n-1}
$$

Assim, segundo o autor, é comum utilizar para um valor observado $r$ um erro padrão $\left(1-r^{2}\right) / \sqrt{n-1}$ ou $\left(1-r^{2}\right) / \sqrt{n}$. Para o caso de $\mathbf{k}$ classes, a variância do coeficiente de correlação intraclasse é dada por

$$
\frac{\{(1-\rho)[1+(k-1) \rho]\}^{2}}{1 / 2 k(k-1) n}
$$


SWIGER et al. (1964) propãen uma fómula aproximada para a variância do coeficiente de correlação intraclasse quando ocorre número diferente de observacōes por grupo, utilizando a fómula da variância de um quociente obtida por série de Taylor. Assim, a variância do estimador da correlação intraclasse

$$
t=\frac{\hat{\sigma}_{g}^{2}}{\hat{\sigma}_{c}^{2}+\hat{\sigma}_{g}^{2}}
$$

é dada por

$$
\operatorname{Var}(t) \approx \frac{2(\mathrm{n}-1)(1-t)^{2}[1+(\mathrm{k}-1) t]^{2}}{\mathbf{k}^{2}(N-s)(s-1)}
$$

sendo:

N o número total de observações,

s o número de grupos,

$\mathrm{k}=\frac{1}{8-1}\left(N-\frac{\sum n_{i}^{2}}{N}\right) \mathrm{e}$

$n_{i}$ é o número de observações por grupo.

Um estudo é feito para avaliação da fómula proposta, através de simulação utilizando-se grupos com tamanhos $25,50,100$ e 200. Os números de observações por gnupo são de $2,3,6,10,15,20$ e 50 e as correlações intraclasse avaliadas são de 0,05 e 0,10 . Os 
resultados mostram que a fómmula apresentada para a variância do coeficiente de correlação intraclasse é satisfatória.

NEI \& CHAKRAVARTI (1977) estudam a média e a variância da diversidade genética entre subpopulações

$$
\mathrm{G}_{\mathrm{ST}}=\frac{D_{S T}}{H_{T}}=\frac{\mathrm{H}_{\mathrm{T}}-H_{S}}{H_{T}}
$$

obtendo fómulas aproximadas usando a expansão de Taylor. A média de $G_{S T}$ é dada por

$$
\mathrm{E}\left[\mathrm{G}_{\mathrm{ST}}\right]=1-\frac{E\left(H_{S}\right)}{E\left(H_{T}\right)}+\frac{\operatorname{Cov}\left(\mathrm{H}_{\mathrm{S}}, H_{T}\right)}{\left[E\left(H_{T}\right)\right]^{2}}-\frac{\mathrm{E}\left(\mathrm{H}_{S}\right) \operatorname{Var}\left(H_{T}\right)}{\left[E\left(H_{T}\right)\right]^{3}} \text {, }
$$

e a variância por

$$
\operatorname{Var}\left[\mathrm{G}_{\mathrm{ST}}\right]=\frac{\left[E\left(H_{S}\right)\right]^{2}}{\left[E\left(H_{T}\right)\right]^{2}}\left\{\frac{\operatorname{Var}\left(\mathrm{H}_{\mathrm{S}}\right)}{\left[\mathrm{E}\left(\mathrm{H}_{\mathrm{T}}\right)\right]^{2}}+\frac{\operatorname{Var}\left(\mathrm{H}_{\mathrm{T}}\right)}{\left[\mathrm{E}\left(\mathrm{H}_{\mathrm{S}}\right)\right]^{2}}-\frac{2 \mathrm{Cov}\left(\mathrm{H}_{\mathrm{S}}, H_{T}\right)}{E\left(H_{S}\right) E\left(H_{T}\right)}\right\}
$$

Segundo os autores, a exatidão das fớmulas depende da magnitude dos termos restantes da série. A avaliaçåo analítica dos termos restantes é bastante dificil pois envolve termos de momentos de ordem superior de $\mathrm{H}_{S}$ e $\mathrm{H}_{\mathrm{T}}$ os quais são funções complexas das frequências alélicas iniciais, do tamanho da população, do número de subpopulaçóes e do tempo de geraç̋o. As formulas são avaliadas através de um estudo de simulação a partir de dois conjuntos de 
frequências gênicas iniciais: $p_{1}=0,1 ; p_{2}=0,9$ e $p_{1}=0,05 ; \quad p_{2}$ $=0,95$, utilizando $s=10$ subpopulações com tamanho efetivo $\mathbf{N}=10$. A acurácia das fórmulas piora se as frequências iniciais dos alelos são muito diferentes.

LONG (1986) afirma que os extimadores das estatísticas $\mathrm{F}$, à semelhança dos coeficientes de correlą̧a intraclasse, são tendenciosos, por serem funções de razỏes de estimadores não tendenciosos. Segundo o autor, a variância da estimativa de uma estatística F pode ser estimada pela expansão en série de Taylor ou através de método de reamostragem numérica. A aproximafåo pela série de Tayior é recomendada, pois fornece expressão analítica acessivel possibilitando a construção de intervalos de confiança aproximados para as estimativas das estatísticas F .

\section{ROBERTSON \& HILL (1984) estudam algumas} propriedades amostrais dos desvios das proporções de Hardy-Weinberg e das estimativas obtidas destes desvios. Os autores consideram uma amostra de $\mathbf{N}$ indivíduos, com $\mathbf{N}_{\mathrm{ij}}(\mathrm{i} \leq \mathrm{j} ; \mathrm{i}, \mathrm{j}=1,2, \ldots, \mathrm{k}$ alelos) $\mathrm{o}$ número de indivíduos do genótipo $\mathrm{A}_{\mathbf{j}} \mathrm{A}_{\mathbf{j}}$ e $\mathrm{N}_{\mathrm{i}}$ o número de indivíduos do alelo $A_{1}$. A frequência do alelo $A_{i}$ na amostra é $N_{i} / 2 N$ e na populaçâo é $p_{\mathfrak{l}}$. $O$ afastamento $D_{\mathfrak{l}}$ ou $D_{\mathfrak{l y}}$ dos números de indivíduos dos valores esperados de Hardy-Weinberg é

$$
D_{i j}=\mathrm{N}_{\mathrm{i}}-\frac{\mathrm{N}_{\mathrm{i}}^{2}}{4 \mathrm{~N}} \text { e } D_{\mathrm{ij}}=\mathrm{N}_{\mathrm{ij}}-\frac{\mathrm{N}_{\mathrm{i}} N_{\mathrm{j}}}{2 \mathrm{~N}}
$$


Considerando dois alelos e usando aproximaçöes apropriadas tais que termos de $O\left(1 / \mathrm{N}^{2}\right)$ podem ser ignorados em relação àqueles de $O(L / N)$, a expansão de $D$ em série de Taylor nos termos $\mathrm{N}_{11}, \mathrm{~N}_{12}$ e $\mathrm{N}_{22}$ fornece:

$$
\begin{aligned}
\operatorname{Var}[D] & =\left(\frac{\partial \mathrm{D}}{\partial \mathrm{N}_{11}}\right)^{2} \operatorname{Var}\left(\mathrm{N}_{11}\right)+2\left(\frac{\partial \mathrm{D}}{\partial \mathrm{N}_{11}}\right)\left(\frac{\partial \mathrm{D}}{\partial \mathrm{N}_{12}}\right) \operatorname{Cov}\left(\mathrm{N}_{11}, \mathrm{~N}_{12}\right)+\ldots \\
& =\operatorname{Var}\left[\mathrm{N}_{11}(1-p)^{2}-\mathrm{N}_{12} p(1-p)+\mathrm{N}_{22} p^{2}\right] \\
& =\mathrm{Np}^{2}(1-p)^{2}[1+(\mathrm{n}-1) r]
\end{aligned}
$$

Os autores estudam ainda a estimaçao do coeficiente de endogamia $f$ numa populaçăo subdividida, com acasalamento aleatónio dentro das subpopulaç̃es, ou seja, $F_{\text {ST }} \neq 0$ e $F_{\text {IS }}=0$. Neste caso o valor populacional esperado de $\hat{\mathrm{f}}$ modido através do excesso de homozigotos, $p_{i j}-p_{i}^{2}$, é diferente para diferentes genes. No caso de uma populafåo consistindo de $\mathbf{n}$ subpopulaçßes escolhidas aleatoriamente, $e$ um gene com frequência $P_{m}$ na m-ésima subpopulação, o excesso de homozigotos é dado por

$$
P_{i i}-P_{i}^{2}=\sum_{m} \frac{P_{i m}^{2}}{n}-\frac{\left(\sum_{m} P_{i m}\right)^{2}}{n^{2}}=\frac{n-1}{n} \frac{\left[\sum_{m} P_{i m}^{2}-\left(\sum_{m} P_{i m}\right)^{2} / n\right]}{n-1} .
$$


O termo multiplicado por $(n-1) / n$ na última expressão é uma estimativa da variância, $V$, da frequência gênica entre subpopulaç̋̋es com n-1 graus de liberdade. Assim,

$$
E\left[\hat{f}_{i j}\right]=\frac{n-1}{n}\left[\frac{V}{P_{i o}\left(1-P_{i 0}\right)}\right]=\frac{n-1}{n} F_{S T}
$$

sendo $P_{t o}$ a frequência na população original. Admitindo que a endogamia das subpopulaç̋̈es, $F_{\text {ST }}$, seja suficientemente pequena de modo que $P_{t m}$ tenha distribuição normal, então a variância de $\mathrm{V}$ nos locos é $2 V^{2} /(n-1)$. Assim, a variância de $\hat{f}$ nos genes de uma mesma população é

$$
\frac{2[E(\hat{\mathbf{f}})]^{2}}{\mathrm{n}-1}
$$

sendo $\hat{f}$ uma estimativa do coeficiente de endogamia devido ao excesso de homozigotos.

2.4.Teste de hipótese sobre os parâmetros de variabilidade e diversidade genética estimados através da análise de variância das frequências gênicas

COCKERHAM (1969) considera, para o caso de um grupo de $n$ indivíduos, a análise de variância apresentada na Tabela 2. 
Tabela 2. Análise de Variância das frequências gênicas de um simples grupo.

\begin{tabular}{cccc}
\hline Causa de Variafão & GL & QM & E[QM] \\
\hline Entre individuos & $\mathrm{n}-1$ & $\mathrm{~S}_{\mathrm{b}}$ & $\sigma_{\mathrm{w}}^{2}+2 \sigma_{b}^{2}$ \\
Dentro de individuos & $\mathrm{n}$ & $\mathrm{S}_{\mathrm{w}}$ & $\sigma_{w}^{2}$ \\
\hline
\end{tabular}

No caso de m grupos, cada um deles com um número constante $\mathrm{n}$ de indivíduos, de acordo com o autor, a análise de variância é a apresentada na Tabela 3.

Tabela 3. Análise de variância combinada das frequências gênicas.

Causa de Variação
GL
QM
$\mathrm{E}[\mathrm{QM}]$

Entre grupos (G)

$\mathrm{m}-1$

$S_{\mathbf{a}}$

$\sigma_{w}^{2}+2 \sigma_{b}^{2}+2 n \sigma_{a}^{2}$

Entre individuos/G

$m(n-1)$

$S_{b}$

$\sigma_{w}^{2}+2 \sigma_{b}^{2}$

Dentro de individuos

$\mathrm{mn}$

$S_{w} \quad \sigma_{w}^{2}$

Na Tabela 2, para testar a hipótese de que para os dados de um grupo os genes se reuniram ao acaso ou $F_{\mathbf{T T}}=0$, segundo 
o autor, dois testes aproximados são sugeridos. O primeiro consiste em assumir que

$$
T_{b w}=\frac{S_{b}}{S_{w}}
$$

apresenta distribuição de F, podendo-se aplicar o teste F de Snedecor. $O$ outro teste consiste em calcular as frequências observadas (AA, $\triangle \bar{A}$ e $\bar{A} \bar{A}$ ) no modelo incluindo $\mathrm{F}_{\mathrm{rI}}$ e no modelo considerando $\mathrm{F}_{\mathrm{r}}=0$ aplicando-se um teste de $\chi^{2}$ com as frequências obtidas.

No caso da Tabela 3, o autor afirma que três hipóteses podem ser testadas:

$\mathrm{H}_{01}$ : genes uniram-se aleatoriamente dentro de grupos,

$$
\mathbf{F}_{\text {IT }}-\mathbf{F}_{\text {ST }}=0 \text { ou } \sigma_{b}^{2}=0
$$

$\mathrm{H}_{02}$ : genes săo distribuídos aletoriamente entre grupos, $\mathrm{F}_{\mathrm{ST}}=0$ ou $\sigma_{a}^{2}=0$

$\mathrm{H}_{03}$ : genes são distribuídos aleatoriamente entre e dentro de

$$
\text { grupos, } \quad \mathbf{F}_{\mathrm{rT}}=\mathbf{F}_{\mathrm{ST}}=0 \text { ou } \sigma_{a}^{2}=\sigma_{b}^{2}=0
$$

Os testes estatísticos envolvendo as funçð̌es de quadrados médios são:

$\mathrm{H}_{01}$ : idêntico ao teste da Tabela 2; 


$$
\begin{aligned}
& \mathrm{H}_{02}: \mathrm{T}_{\omega b}=\frac{\mathrm{S}_{a}}{\mathrm{~S}_{b}} ; \\
& \mathrm{H}_{03}: \mathrm{T}_{(b) w}=\frac{(n-2) S_{b}+2 S_{a}}{m n \mathrm{~S}_{n}}
\end{aligned}
$$

Os dois primeiros testes podem ser aproximados pela distribuição de $\mathrm{F}$ e o último por uma distribuição aproximada adequada para razbees de quadrados médios combinados. As três hipóteses podem também ser testadas pelo teste de $x^{2}$ com as frequências obtidas de forma análoga ao caso da Tabela 2.

WEIR (1990) aponta as limitações de se aplicar o teste $F$ na análise de variância envolvendo a variável indicadora de ocorrência de um gene, por se tratar de uma variável que não tem distribuiç̃o normal, e em consequência, o quociente entre dois quadrados médios da análise de variância não terá distribuição de $F$.

Alguns trabalhos na área de modelos lineares generalizados desenvolvem testes assintóticos para dados que não apresentam distribuição normal. J $\$$ RGENSEN (1983) discute o modelo da forma

$$
f(y ; \theta, k)=c(y, k) \exp \{a(k) t(y, \theta)\}
$$

considerado classe estendida de modelos lineares generalizados, o qual tem propriedades semelhantes às propriedades dos modelo lineares generalizados. Neste modelo, $y, \theta$ e $k$ podem ser vetores, $a(k)>0$ e a parte sistemática do modelo é especificada por $\theta=\theta(\beta)$, onde $\beta$ é um vetor de parâmetros. São incluidas as possibilidades de erros 
correlacionados e hipóteses não lineares sem levar em consideragão as suposições da familia exponencial. O modelo satisfaz às suposições da teoria de verossimilhança para amostras grande e apresenta analogias com a distribuição normal uma vez que $\theta$ faz o papel da média, a $(k)^{-1}$ o da variância e $t(y, \theta)$ o da soma de quadrados dos desvios. Para amostras grandes, de maneira análoga às estatísticas familiares, as distribuições t, F e $\chi^{2}$ aparocem, e as estimativas de máxima verossimilhança podem ser calculadas através de um algoritmo iterativo de mínimos quadrados ponderados.

O autor generaliza a análise de "deviance" introduzida por NELDER \& WEDDERBURN (1972) para a classe de modelos lineares generalizados estendidos, propondo um teste $\mathrm{F}$ assintótico. São consideradas $\mathrm{H}_{\mathrm{i}}: \theta \in \Omega_{\mathbf{q}}(\mathrm{i}=0,1,2)$ três hipóteses hierárquicas $\Omega_{0} \supseteq \Omega_{1} \supseteq \Omega_{2}$ de dimensões $p_{0}, p_{1}$ e $p_{2}$ respectivamente, todas com valores arbitrários $\mathbf{k}$. Uma vez que a estimativa $\hat{\theta}_{i}$ de máxima verossimilhança de $\theta$ sob $H_{j}$ é a mesma para todos os valores de $k$, a diferença em logaritmo de máxima verossimilhança entre $\mathrm{H}_{0}$ e $\mathrm{H}_{\mathbf{b}}$ para $\mathrm{k}$ conhecido é,

$$
\mathbf{L}\left(\hat{\theta}_{0}, k\right)-\mathbf{L}\left(\hat{\theta}_{\mathrm{i}}, \mathrm{k}\right)=\mathrm{a}(\mathrm{k})\left\{\mathrm{t}\left(\mathrm{y}, \hat{\theta}_{0}\right)-\mathrm{t}\left(\mathrm{y}, \hat{\theta}_{\mathrm{i}}\right)=1 / 2 \mathrm{a}(\mathrm{k}) \mathrm{D}_{\mathrm{i}}\right.
$$

sendo $D_{i}$ a "deviance" de $H_{i}$ em relação a $H_{0}$. Através de um argumento adequado de amostra grande, prova-se que sob $\mathrm{H}_{2}$, 
assintoticamente $a(k) D_{1}$ e $a(k)\left(D_{2}-D_{1}\right)$ têm distribuiç̋̃es de $\chi^{2}$ independentes com graus de liberdade $p_{0}-p_{1}$ e $p_{1}-p_{2}$, respectivamente. Em consequência, um teste assintótico de $\mathrm{H}_{2}$ sob $\mathrm{H}_{1}$, com $k$ desconhecido é dado por

$$
F=\frac{\left(D_{2}-D_{1}\right) /\left(p_{1}-p_{2}\right)}{D_{1} /\left(p_{0}-p_{1}\right)}
$$

JфRGENSEN (1987a) estuda o modelo de dispersão exponencial estabelecendo regra importante para o parâmetro de dispersão $\sigma^{2}=1 / \lambda$. Através da teoria assintótica, é generalizada a análise de "deviance" para modelos lineares generalizados, originando a versão assintótica dos testes $t, F$ e $\chi^{2}$ da teoria dos modelos lineares. Expandindo o domínio de aplicąão da teoria de amostra grande, é utilizada uma estrutura assintótica, chamada de pequena dispersão assintótica que se aplica para $\lambda$ grande, deservolvida por J $\$$ RGENSEN (1987b). Esta estrutura inclui resultados assintóticos nos quais as aproximações requerem que um certo parâmetro ou conjunto de parâmetros tendam para infinito quando o tamanho da amostra é fixo. Assim, JфRGENSEN (1987a) mostra que um teste de $\mathrm{H}_{2}$ pode ser baseado na convergência em distribuição, sob $\mathrm{H}_{2}$, de

$$
\tilde{F}=\frac{\{\mathrm{D}(\mathrm{y} ; \hat{\gamma})-\mathrm{D}(\mathrm{y} ; \hat{\bar{\beta}})\} /\left(\mathrm{p}_{1}-\mathrm{p}_{2}\right)}{\tilde{\sigma}^{2}} \rightarrow \mathrm{F}\left(\mathrm{p}_{1}-\mathrm{p}_{2}, \mathrm{k}-\mathrm{p}_{1}\right)
$$


à medida que $\lambda \rightarrow \infty$, em que $F\left(d_{1}, d_{2}\right)$ é a distribuição de $F$ com $\left(d_{1}, d_{2}\right)$ graus de liberdade e $\tilde{\sigma}^{2}$ é uma estimativa de $\sigma^{2}$ sob $H_{1}$.

\section{BARNDORFF - NIELSEN \& J $\$$ RGENSEN (1991)}

estudando o modelo proprio de dispersåo propżem um teste utilizando dois tipos de teoria assintótica, a teoria padrão de amostra grande $(n \rightarrow \infty)$ e a pequena dispersåo assintótica da expressão

$$
W_{\min }=\min \left\{W_{1}, \ldots, W_{n}\right\} \rightarrow \infty
$$

em que $W_{1}, \ldots, W_{n}$ são ponderą̧̋̃es conhecidas. Os autores indicam um teste geral para $\mathrm{H}_{2}$ sob $\mathrm{H}_{1}$ dado por

$$
F=\frac{\left(D_{2}-D_{1}\right) /\left(k_{1}-k_{2}\right)}{D_{1} /\left(n k-k_{1}\right)},
$$

se $W_{\min } \rightarrow \infty$, em que $k_{1}, k_{2}, D_{1}$ e $D_{2}$ representam respectivamente as dimensões e as "deviances" estimadas considerando $\mathrm{H}_{1}$ e sob $\mathrm{H}_{2}$ e k representa a dimensão dos $\mathrm{n}$ vetores $\mathrm{y}$ independentes.

DEMÉTRIO (1993) apresenta uma análise através do GLIM de um experimento em blocos casualizados com os tratamentos num fatorial $2 \times 3 \times 3$, em que a variável resposta é binária, $e$ a distribuição de $\mathrm{F}$ é utilizada para verificar a significância das razões calculadas. A autora chama a atenção para o fato de que a "deviance" não tem distribuição conhecida, mas que a diferença de "deviance" tem distribuição de $\chi^{2}$, assintótica. 


\section{MATERIAL E MÉTODOS}

São consideradas as enálises de variância de frequências gênicas para a caracterizacáo da estrutura genética de dados diplóides, no caso de amostras de indivíduos de uma população e no caso de amostras de indivíduos de populagōes diferentes.

\subsection{Modelo matemático e análise de variância}

Para o caso da análise de variância para amostras de individuos de uma populafão, o modelo para cada alelo, é representado por:

$$
y_{i j}=m+a_{i}+g_{i(i)}
$$

sendo:

$y_{i j}$ a frequência do gene $j$ dentro do individuo $i$, comespondente aos valores de uma variável binária que assume o valor um, se o gene $\mathrm{j}$ dentro do indivíduo $\mathrm{i}$ é o alelo $\mathrm{A}$ e assume o valor zero, caso contrário;

m uma frequência constante;

$a_{i}$ o efeito do indivíduo $\mathrm{i}, \operatorname{com} \mathrm{i}=1,2, \ldots, \mathrm{n}$;

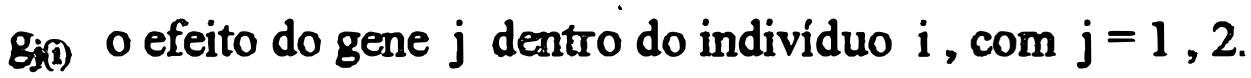


Pars este modelo considerado aleatório, tem-se:

$$
\begin{array}{ll}
E(m)=m=p, & E\left(m^{2}\right)=m^{2}=p^{2}, \\
E\left(a_{i}\right)=0, & E\left(g_{i}^{2}\right)=\sigma_{1}^{2}=p(1-p) F, \\
E\left[g_{j(i)}\right]=0, & E\left[g_{j(g)}^{2}\right]=\sigma_{G}^{2}=p(1-p)(1-F), \\
E\left[y_{i j}\right]=p, & \operatorname{Var}\left[y_{i j}\right]=p(1-p),
\end{array}
$$

sendo $p$ a frequência gênica da população e $F$ o coeficiente médio de endogamia de todos os individuos. As fontes de variagão e as esperanças dos quadrados médios da análise de variância relativa 80 modelo de acordo com WEIR (1990), eståo na Tabela 4.

Tabela 4. Análise de variância com as frequências gênicas de ưn alelo, em uma amostras de $\mathbf{n}$ indivíduos.

\begin{tabular}{lcll}
\hline Causa de variagåo & $\mathrm{GL}$ & $\mathrm{QM}$ & $\mathrm{E}[\mathrm{QM}]$ \\
\hline Individuos & $\mathrm{n}-1$ & $\mathrm{QM}$ & $\mathrm{p}(1-\mathrm{p})[(1-\mathrm{F})+2 \mathrm{~F}]$ \\
Genes d. Ind. & $\mathrm{n}$ & $\mathrm{QMG}$ & $\mathrm{p}(1-\mathrm{p})(1-\mathrm{F})$
\end{tabular}

Para o caso da análise de variância com amostras de individuos de populaģoes diferentes, o modelo para cada alelo, é representado por:

$$
y_{i j}-m+s_{i}+a_{j(i)}+g_{k}(j)
$$

sendo: 
Y a frequência do gene $k$ dentro do indivíduo $j$ da populą̧ão $i$, correspondente aos valores de uma variável binéria que assume o valor um, se o gene $k$ no indivíduo $j$ da populaçąo i é alelo A, e assume o valor zero, caso contrário;

m una frequência constante;

$s_{i}$ o efeito da populafão $i, c o m i=1,2, \ldots, r$;

$\theta_{j(1)}$ o efeito do indivíduo $j$ dentro da populagão $i, c o m$ $\mathrm{j}=1,2, \ldots, \mathrm{n}$;

(3k) o efeito do gene $k$ dentro do indivíduo $j$ da populagão $i$, com $\mathrm{k}=1,2$.

Para este modelo considerado aleatório, tem-se:

$$
\begin{aligned}
& E(m)=m=p, E\left(m^{2}\right)=m^{2}=p^{2}, \\
& \mathrm{E}\left(\mathrm{s}_{\mathrm{i}}\right)=0 \quad, \mathrm{E}\left(\mathrm{s}_{\mathrm{i}}^{2}\right)=\sigma_{\mathrm{p}}^{2}=\mathrm{p}(1-\mathrm{p}) \theta \text {, } \\
& \mathrm{E}\left[\mathrm{q}_{\mathrm{i} \theta}\right]=0 \quad, \mathrm{E}\left[\mathrm{a}_{\mathrm{j} \theta}{ }^{2}\right]=\sigma_{1}^{2}=\mathrm{p}(1-\mathrm{p})(\mathrm{F}-\theta), \\
& \mathrm{E}\left[\mathrm{g}_{\mathrm{k}(\mathrm{p})}\right]=0 \quad, \mathrm{E}\left[\mathrm{g}_{\mathrm{k}}\left(\mathrm{f}^{2}\right]=\sigma_{\mathrm{G}}^{2}=\mathrm{p}(1-\mathrm{p})(1-\mathrm{F})\right. \text {, } \\
& E\left[y_{i j}\right]=p \quad, \operatorname{Var}\left[y_{i j}\right]=p(1-p),
\end{aligned}
$$

sendo $\mathrm{p}$ a frequência gênica geral de todas populaģöes, F o coeficiente médio de endogamia dos indivíduos dentro das populagões e $\theta$ o coeficiente médio de coancestria entre os individuos de diferentes populaçōes que é uma medida de parentesco (WEIR \& COCKERHAM, 1984). As fontes de variafão e as esperanças dos quadrados médios da análise de variância relativa ao modelo, de acordo com WEIR(1990), estão na Tabela 5 . 
Tabela 5. Análise de variância com as frequências gênicas de um alelo, em amostras de $\mathrm{n}$ indivíduos de $\mathrm{I}$ populasōes.

\begin{tabular}{lccl}
\hline Causa de variagão & GL & QM & \multicolumn{1}{c}{$E[Q M]$} \\
\hline Populaş̉es & $\mathrm{r}-1$ & $\mathrm{QMP}$ & $\mathrm{p}(1-\mathrm{p})[(1-\mathrm{F})+2(\mathrm{~F}-\theta)+2 \mathrm{n} \theta]$ \\
Individuos d. Pop. & $\mathrm{r}(\mathrm{n}-1)$ & $\mathrm{QMI}$ & $\mathrm{p}(1-\mathrm{p})[(1-\mathrm{F})+2(\mathrm{~F}-\theta)]$ \\
Genes d. Indiv. & $\mathrm{m}$ & $\mathrm{QMG}$ & $\mathrm{p}(1-\mathrm{p})[1-\mathrm{F}]$ \\
\hline
\end{tabular}

No caso de se terem $u$ alelos, com $u>2$, săo realizadas $u$ análises de variância da mesma maneira como as apresentadas nas Tabelas 4 e 5 .

\subsection{Estimação dos parâmetros genéticos}

Os parâmetros genéticos envolvidos nos dois modelos foram estimados pelo método dos momentos ou da análise de variância. De acordo com BARBIN (1993) e VALÉRIO FILHO (1991), o método dos momentos é o mais utilizado para estimar componentes de variância principalmente quando os dados såo balanceados. As estimativas foram feitas utilizando-se a aproximagão que considera a estimativa de um quociente como sendo o quociente das estimativas, conforme WEIR (1990) e VENCOVSKY (1992).

No caso de mais de 2 alelos, foram comparados os dois métodos de estimação sugeridos por REYNOLDS et al. (1983). 


\subsection{Média e variêncie dos estimadores}

Pare estudar as propriedades dos estimadores dos parâmetros genéticos associados aos dois modelos, foi utilizada, para os estimsdores envolvendo o quociente entre variáveis alestórias, a aproximaşåo de uma funçảo através da expansão em série de Taylor, conforme KENDAL \& STUART (1963), MOOD et al. (1974), NEI \& CHAKRAVARTI (1977) e LEIIE \& SINGER (1990).

Foram desenvolvidas expressões da média e da variência dos estimadores dos parâmetros no caso de dois alelos e de mais de dois alelos, permitindo comparar os métodos sugeridos por REYNOLDS et al. (1983) para estimagảo no caso de alelos múltiplos.

\subsection{O teste $\mathbf{F}$}

Para o caso da análise de variância das frequências gênicas de amostras de individuos de uma população, cuja estrưura de análise está apresentada na Tabela 4, foram desenvolvidas as expressōes das distribuições dos quadrados médios com o objetivo de definir a distribuição relativa ao quociente entre dois quadrados médios, tentando propor um critério para testar se o coeficiente médio de endogamia de todos os individuos $\mathrm{F}_{\mathrm{IT}}$ é nulo, conforme COCKERHAM (1969).

O critério proposto foi avaliado comparando-se a sua distribuição com a distribuição do teste F de Snedecor, com diferentes 
combinações de tamanhos de amostras e frequências gênicas, nos casos de dois e de três alelos.

\subsection{Métodos e formess de stmulnção}

$\mathrm{Na}$ simulaçåo dos dados para a and́lise de variância de frequências gênicas, no caso de amostras de indivíduos de uma população, foram considerados os casos de dois e de três alelos. As frequências genotipicas foram constrúdas, considerando-se que a população estava em equilibrio com endogamia Estas frequências, de acordo com CROW (1978) são dadas por:

genótipo homozigótico $A_{i} A_{i} \quad p_{i}{ }^{2}(1-F)+p_{i} F$

genótipo heterozigótico $A_{i} A_{j} \quad 2$ pip $\{(1-F)$.

No caso de dois alelos $A_{1}$ e $A_{2}$ com frequências gênicas p e $q=1-p$, respectivamente, com $p+q=1$, os genótipos ocorrem com as seguintes frequências:

$$
\begin{array}{ll}
A_{1} A_{1} & p^{2}(1-F)+p F \\
A_{1} A_{2} & 2 p(1-p)(1-F) \\
A_{2} A_{2} & (1-p)^{2}(1-F)+(1-p) F
\end{array}
$$

No caso de três alelos $A_{1}, A_{2}$ e $A_{3}$ com frequências gênicas $p_{1}, p_{2}$ e $p_{3}$, respectivamente, sendo $p_{1}+p_{2}+p_{3}=1$, os genótipos podem ser representados de acordo com as seguintes frequências: 


$\begin{array}{ll}A_{1} A_{1} & p_{1}{ }^{2}(1-F)+p_{1} F \\ A_{1} A_{2} & 2 p_{1} p_{2}(1-F) \\ A_{1} A_{3} & 2 p_{1} p_{3}(1-F) \\ A_{2} A_{2} & p_{2}{ }^{2}(1-F)+p_{2} F \\ A_{2} A_{3} & 2 p_{2} p_{3}(1-F) \\ A_{3} A_{3} & p_{3}{ }^{2}(1-F)+p_{3} F\end{array}$

onde se .admite F constante para todos os genótipos.

Para avaliação das expressões desenvolvidas para a média e a variância dos estimadores dos parâmetros, no caso de dois alelos, foram constrúdas noventa e nove (99) populacōes, definidas pelas combinaçōes entre os seguintes valores de frequência gênica (p) e coeficiente de endogamia (F):

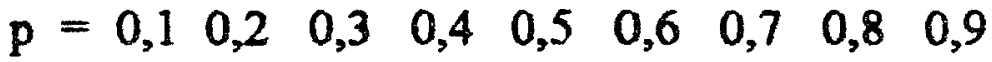

$$
\begin{aligned}
& F=0,0 \quad 0,1 \quad 0,2 \quad 0,3 \quad 0,4 \quad 0,5 \quad 0,6 \quad 0,7 \quad 0,8 \quad 0,9 \quad 1,0 .
\end{aligned}
$$

Foram simulados cem (100) experimentos considerando-se os seguintes números de individuos amostrados com reposição:

$$
\mathbf{n}=\begin{array}{llllll}
10 & 20 & 30 & 50 & 100 \quad 200
\end{array}
$$


totalizando seiscentos (600) experimentos em cads populacåo e cinquenta e nove mil e quatrocentos (59.400) experimentos em todas as populagöes.

Para avaliafão do teste $F$ proposto por COCKERHAM (1969), foram construidas dezenove (19) populaģoes nåo endogâmicas, admitindo-se a hipótese $\mathrm{H}_{0}: F=0$, com as seguintes frequências gênicas:

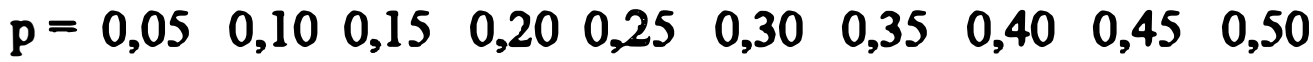

$$
\begin{aligned}
& \begin{array}{lllllllll}
0,55 & 0,60 & 0,65 & 0,70 & 0,75 & 0,80 & 0,85 & 0,90 & 0,95
\end{array}
\end{aligned}
$$

e simulados mil (1000) experimentos em cada populąão considerando-se os seguintes números de individuos amostrados com reposiçå

$$
\mathrm{n}=\begin{array}{rrrrrrrrr}
5 & 10 & 15 & 20 & 25 & 30 & 35 & 40 & 45 \\
50 & 75 & 100 & 150 & 200 & 300 & 400 & 500 &
\end{array}
$$

totalizando dezessete mil (17.000) experimentos em cada população e trezentos e vinte e três mil (323.000) experimentos em todas as populaçōes.

No estudo completo das populasōes com dois alelos foram simulados trezentos e oiterta e dois mil e quatrocentos (382.400) experimentos.

Para avalią̧åo das expressōes desenvolvidas para a média e a variância dos extimadores dos parâmetros e dos métodos de estimafão de REYNOLDS et al. (1983), no caso de três alelos, foram construídas cento e dez (110) populafões, definidas pelas combinafões entre as seguintes frequências gênicas e valores do coeficiente de endogamia: 


$$
\begin{aligned}
\left(p_{1} ; p_{2} ; p_{3}\right)= & (0,50 ; 0,30 ; 0,20)(0,50 ; 0,25 ; 0,25)(0,50 ; 0,40 ; 0,10) \\
& (0,50 ; 0,45 ; 0,05)(0,50 ; 0,49 ; 0,01)(0,60 ; 0,20 ; 0,20) \\
& (0,60 ; 0,30 ; 0,10)(0,60 ; 0,39 ; 0,01)(0,40 ; 0,30 ; 0,30) \\
& (0,33 ; 0,33 ; 0,34)
\end{aligned}
$$

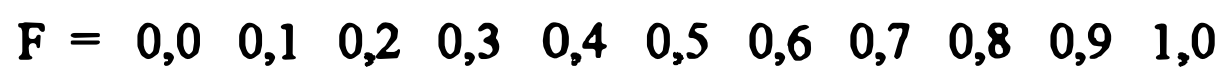

e simulados cem (100) experimentos utilizando-se os seguintes números de individuos amostrados com reposição

$$
n=\begin{array}{llllll}
10 & 20 & 30 & 50 & 100 & 200,
\end{array}
$$

totalizando seiscentos (600) experimentos em cada populaçåo e sessenta e seis mil (66.000) experimentos em todas as populsgỏes.

Para avaliação do teste $F$ proposto por COCKERHAM (1969), no caso de três alelos, foram constrúdas vinte e uma (21) populaçōes não endogâmicas, admitindo-se a hipótese $H_{0}: F=0$ com as seguintes frequências gênicas:

$$
\begin{aligned}
& \left(p_{1} ; p_{2} ; p_{3}\right)=(0,50 ; 0,25 ; 0,25)(0,50 ; 0,30 ; 0,20) \quad(0,50 ; 0,35 ; 0,15) \\
& (0,50 ; 0,40 ; 0,10)(0,50 ; 0,45 ; 0,05)(0,50 ; 0,49 ; 0,01) \\
& (0,40 ; 0,30 ; 0,30)(0,40 ; 0,35 ; 0,25) \quad(0,40 ; 0,40 ; 0,20) \\
& (0,40 ; 0,45 ; 0,15)(0,40 ; 0,59 ; 0,01)(0,60 ; 0,20 ; 0,20) \\
& (0,60 ; 0,25 ; 0,15)(0,60 ; 0,30 ; 0,10)(0,60 ; 0,35 ; 0,05) \\
& (0,60 ; 0,39 ; 0,01)(0,70 ; 0,15 ; 0,15)(0,70 ; 0,20 ; 0,10) \\
& (0,70 ; 0,25 ; 0,05) \quad(0,70 ; 0,29 ; 0,01)(0,80 ; 0,10 ; 0,10)
\end{aligned}
$$

e simulados mil (1.000) experimentos em cada populaçâo considerando-se os seguintes números de individuos amostrados com reposição: 


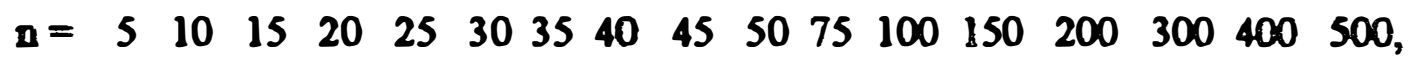

totalizando dezessete mil (17.000) experimentos em cada populagåo e trezentos e cinquento e sete mil (357.000) experimentos em todas as populações.

No estudo completo das populações com trés alelos foram simulados quatrocentos e vinte e trés mil (423.000) experimentos. No total foram simulados oitocentos e cinco mil e quatrocentos (805.400) experimentos.

A simulacảo de cada experimento foi feita através de um programa no SAS (Statistical Analysis System), utilizando-se a fungão RANUNI (SAS, 1985), na geraça dos efeitos aleatórios. Esta função produz valores de uma variável aleatória uniformente distribuída no intervalo entre zero e um.

\subsection{Critértos de comparação}

As expressōes desenvolvidas para a média e variância dos estimadores dos parâmetros foram avaliadas, comparando-se os valores esperados e variâncias dos estimadores nas populağões, considerando os diversos tamanhos de amostra com aqueles obtidos através do PROC. UNIVARIATE (Procedimento Univariado) do SAS, em cada conjunto de cem (100) experimentos simulados. 
$O$ teste $F$ foi avaliado, calculando-se as estatísticas descritivas: médie, variência, percentil 0,95 e percentil 0,99 da variável "nivel significância" dada por:

$$
\text { Nivel de significência = 1-PROBF( } x \text {, ndf, ddf }) \text {, }
$$

sendo:

$$
\operatorname{PROBF}(\mathrm{x}, \mathrm{ndf}, \mathrm{ddf})=\int_{0}^{x} \mathrm{f}(\mathrm{F}) \mathrm{dF} \text {. }
$$

A função PROBF do SAS calcula a probabilidade de que uma variável aleatória tendo distribuiçă $F$, com n graus de liberdade no numerador e d graus de liberdade no denominador, assuma valores menores que o valor de $\mathrm{x}$.

Para cada experimento realizado, o valor de $\mathrm{x}$ foi obtido pelo quociente

$$
\frac{\mathrm{QM} \text { Individuos }}{\mathrm{QM} \text { Genes }}
$$

Os valores obtidos pelas estatísticas descritivas nos $\mathrm{N}=1.000$ experimentos foram comparados com os valores teóricos da distribuição do teste F de Snedecor. 


\section{RESULTADOS E DISCUSSÃO}

\subsection{Amostras de indivíduos de uma população}

4.1.1. Obtenção das esperanças dos quadrados médios na andilise de variância das frequências gênicas de amostras de indivíduos de una população

A análise de veriência apresentada na Tabela 4 corresponde à análise de um experimento inteiramente casualizado, com n tratamentos e duas repetições. Para esta análise, de acordo com os procedimentos clássicos da Estatística Experimental, as somas de quadrados são definidas por:

SQ Indivíduos $\quad=\frac{1}{2} \sum_{i} y_{i=}^{2}-\frac{1}{2 n}\left(\sum_{i j} y_{i j}\right)^{2}$ e

SQ Genes d. Ind. $=\sum_{i j} y_{i j}^{2}-\frac{1}{2} \sum_{i} y_{i \infty}^{2}$. 
WEIR (1990) apresenta as seguintes expressōes para as somas de quadrados:

$\mathrm{SQ}$ Individuos $=n\left[\hat{\mathrm{p}}_{\mathrm{A}}+\hat{\mathrm{p}}_{\mathrm{A}}-2 \hat{\mathrm{p}}_{\mathrm{A}}^{2}\right]$ e

SQ Genes d. Ind. $=\frac{n}{2} \hat{H}_{A}=\mathbf{n}\left[\hat{p}_{A}-\hat{p}_{A A}\right]$,

sendo:

$\hat{\mathrm{H}}_{\mathrm{A}}$ a frequência de individuos heterozigóticos na amostra;

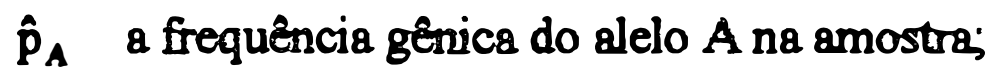

$\hat{p}_{\text {AA }}$ a frequência de individuos homozigóticos em relação ao alelo A na amostra

A frequência amostral do alelo A é dada por:

$$
\hat{\mathrm{p}}_{\mathrm{A}}=\frac{1}{2 \mathrm{n}} \sum_{\mathrm{i}} \mathrm{y}_{\mathrm{i}} \text {. }
$$

Assim, utilizendo-se os conceitos de esperanga matemática, 


$$
\begin{aligned}
E\left[\hat{p}_{A}\right] & =E\left[\frac{1}{2 n} \sum_{i j} y_{i j}\right]=\frac{1}{2 n} \sum_{i j} E\left[y_{i j}\right]=p_{A} \\
E\left[\hat{p}_{A}^{2}\right] & =E\left[\left(\frac{1}{2 n} \sum_{i j} y_{i j}\right)^{2}\right]=\frac{1}{4 n^{2}} E\left[\sum_{i j} y_{i j}\right]^{2} \\
& =\frac{1}{4 n^{2}}\left[E\left(\sum_{i j} y_{i j}^{2}\right)+E\left(\sum_{i} \sum_{j} \sum_{j \neq j} y_{i j} y_{i j}\right)+E\left(\sum_{i} \sum_{i \neq i} \sum_{j} \sum_{j \neq j} y_{i j} y_{i j}\right)\right] \\
& =\frac{1}{4 n^{2}}\left[2 n p_{A}+2 n p_{A A}+4 n(n-1) p_{A}^{2}\right] \\
& =p_{A}^{2}+\frac{1}{2 n}\left(p_{A}+p_{A A}-2 p_{A}^{2}\right)
\end{aligned}
$$

podendo-se obter a variância de $\hat{p}_{A}$ dada por:

$$
\operatorname{Var}\left[\hat{p}_{A}\right]=\frac{1}{2 n}\left(p_{A}+p_{A A}-2 p_{A}^{2}\right)
$$

A frequência de homozigotos do alelo $\mathrm{A}$, admitindo que a população esteja em equilíbrio de Wright com endogamia é dada por:

$$
p_{A A}=p_{A}^{2}+p_{A}\left(1-p_{A}\right) F \text {. }
$$

e consequentemente, a variância de $\hat{p}_{A}$ tem a seguinte expressåo:

$$
\operatorname{Var}\left[\hat{p}_{A}\right]=\frac{1}{2 n} p_{A}\left(1-p_{A}\right)(1+F) \text {. }
$$


A frequência amostral de homozigotos em relação ao alelo A é dada por:

$$
\hat{\mathbf{p}}_{\mathrm{AA}}=\frac{1}{\mathrm{n}} \sum_{\mathbf{i}} \mathrm{y}_{i j} \mathrm{y}_{i \mathbf{i}} \cdot\left(j \neq j^{\prime}\right)
$$

logo,

$$
E\left[\hat{p}_{A A}\right]=\frac{1}{n} \sum_{i} E\left[y_{i j} y_{\mathbf{j}^{\prime}}\right]\left(j \neq j^{\prime}\right) .
$$

Mas pela definição da variável indicadora, o produto $y_{i} y_{i j}$ (jғj) é diferente de zero apenas quando ambos os genes $j$ e j' no individuo i forem do alelo A e portanto,

$$
E\left[y_{i j} y_{i i^{\prime}}\right]=\Sigma y_{i j} y_{i i^{\prime}} P\left[y_{i j} y_{i i^{\prime}}\right]=1 p_{A A}+0\left(1-p_{A A}\right)=p_{A A},
$$

e em consequência,

$$
E\left[\hat{p}_{A \mathcal{A}}\right]=p_{\text {AA }} \text {. }
$$

Trabalhando-se com as expressões apresentadas por WEIR (1990) para as somas de quadrados, tem-se:

$\mathrm{E}[\mathrm{SQ}$ Individuos $]=\mathrm{E}\left[\mathrm{n}\left(\hat{\mathrm{p}}_{\mathrm{A}}+\hat{\mathrm{p}}_{\mathrm{AA}}-2 \hat{\mathrm{p}}_{\mathrm{A}}^{2}\right)\right]=\mathrm{n}\left[\mathrm{E}\left(\hat{\mathrm{p}}_{\mathrm{A}}\right)+\mathrm{E}\left(\hat{\mathrm{p}}_{\mathrm{AA}}\right)-2 \mathrm{E}\left(\hat{\mathrm{p}}_{\mathrm{A}}^{2}\right)\right]$

$$
=n p_{A}+n p_{A A}-2 n p_{A}^{2}-p_{A}-p_{A A}+2 p_{A}^{2}
$$


$E[$ SQIndividuos $]=n p_{A}+n p_{A}^{2}+n p_{A}\left(1-p_{A}\right) F-2 n p_{A}^{2}-p_{A}$

$$
\begin{aligned}
& -p_{A}^{2}-p_{A}\left(1-p_{A}\right) F+2 p_{A}^{2} \\
& =(n-1) p_{A}-(n-1) p_{A}^{2}+(n-1) p_{A}\left(1-p_{A}\right) F \\
& =(n-1) p_{A}\left(1-p_{A}\right)+(n-1) p_{A}\left(1-p_{A}\right) F \\
& =(n-1) p_{A}\left(1-p_{A}\right)[1+F] ;
\end{aligned}
$$

$\mathrm{E}[$ SQGenesd.Ind. $]=\mathrm{E}\left[\mathrm{n}\left(\hat{\mathrm{p}}_{\mathrm{A}}-\hat{\mathrm{p}}_{\mathrm{A} A}\right)\right]=\mathrm{nE}\left(\hat{\mathrm{p}}_{\mathrm{A}}\right)-\mathrm{nE}\left(\hat{\mathrm{p}}_{\mathrm{A}}\right)$

$$
\begin{aligned}
& =n p_{A}-n p_{A}^{2}-n p_{A}\left(1-p_{A}\right) F \\
& =n p_{A}\left(1-p_{A}\right)-n p_{A}\left(1-p_{A}\right) F \\
& =n p_{A}\left(1-p_{A}\right)[1-F] .
\end{aligned}
$$

Portanto, desconsiderando o índice $A$, as esperanças matemáticas dos quadrados médios na análise de variância das frequências gênicas são dadas por:

$$
\begin{aligned}
\mathrm{E}[\mathrm{Q} \text { MIndividuos }] & =\frac{1}{\mathrm{n}-1} \mathrm{E}[\mathrm{SQIndividuos}] \\
& =\mathrm{p}(1-\mathrm{p})[(1-\mathrm{F})+2 \mathrm{~F}],
\end{aligned}
$$

$E[Q M G e n e s$ d. Ind. $]=\frac{1}{n} E[S Q G e n e s ~ d$. Ind. $]$

$$
=\mathrm{p}(1-\mathrm{p})[1-\mathrm{F}] \text {. }
$$


4.1.2. Entimação do coeficiente de endogemia na análise de variância das frequências gênicas de amostras de indivíduos de uma popalação

$\mathrm{Na}$ análise de variância apresentada na Tabela 4 pode ser identificado o componente de variância devido a genes

$$
\sigma_{\mathrm{G}}^{2}=\mathrm{p}(1-\mathrm{p})[1-\mathrm{F}],
$$

que é extimado pelo método dos momentos por

$$
\hat{\sigma}_{\mathrm{G}}^{2}=\mathrm{QMGenes} \mathrm{d} \text {. Ind. }
$$

O componente de variância devido a individuos é

$$
\sigma_{1}^{2}=p(1-p) F,
$$

que é estimado através do método dos momentos por

$$
\hat{\sigma}_{\mathrm{I}}^{2}=\frac{\mathrm{QMI}-\mathrm{QMG}}{2} .
$$

A soma dos componentes de variância devido a genes e a individuos fornece a variância total dada por

$$
\sigma^{2}=\sigma_{\mathrm{o}}^{2}+\sigma_{\mathrm{I}}^{2}=\mathrm{p}(1-\mathrm{p})[1-\mathrm{F}]+\mathrm{p}(1-\mathrm{p}) \mathrm{F}=\mathrm{p}(1-\mathrm{p}),
$$

que é estimada por

$$
\hat{\sigma}^{2}=\mathrm{QMG}+\frac{\mathrm{QMI}-\mathrm{QMG}}{2}=\frac{\mathrm{QMG}+\mathrm{QMI}}{2} .
$$

O quociente entre o componente de variância devido a indivíduos e a variância total fornece o valor paramétrico de $F$, isto é,

$$
\frac{\sigma_{\mathrm{I}}^{2}}{\sigma^{2}}=\frac{p(1-p) F}{p(1-p)}=F
$$


Assim, utilizando-se a aproximsçåo que considera a estimativa de um quociente como sendo o quociente das estimativas, obtém-se a estimativa do coeficiente de endogamia F dada pela expressão seguinte:

$$
\hat{\mathrm{F}}=\frac{\hat{\sigma}_{\mathrm{I}}^{2}}{\hat{\sigma}^{2}}=\frac{\mathrm{QMI}-\mathrm{QMG}}{\mathrm{QMI}+\mathrm{QMG}} .
$$

4.1.3 Estumação da taxa de fecundação crurada na anflise de vartîncla das frequências gênicas de amostras de individuos de uma populoção

Para o modelo em questån, admitindo-se equilíbrio de Wright, isto é, equilíbrio com endogamia, a taxa de fecundaça cruzada, $t$, se relaciona com $F$ através da seguinte expressä:

$$
F=\frac{1-t}{1+t},
$$

a qual pode ser resolvida isolando-se $t$ fomecendo

$$
t=\frac{1-F}{1+F} \text {. }
$$

Assim, obtida a estimativa de F ela pode ser utilizada para fomecer uma estimativa de $t$ dada pela expressão:

$$
\hat{\mathbf{t}}=\frac{1-\hat{\mathrm{F}}}{1+\hat{\mathrm{F}}} \text {. }
$$


4.1.4. Média e varî̂ncia do estimador do coeficiente de endogamia na análise de variância das frequências gênicas de amostras de indivíduos de uma populaçæ̃o

A esperança matemática do estimador de $\mathrm{F}$ pode ser obtida através do desenvolvimento em série de Taylor, no ponto $X=\mu_{\mathrm{x}} \mathrm{e}$ $Y=\mu_{Y}$, da função $X Y$ conforme MOOD et al. (1974) que define:

$$
\mathrm{E}[\mathrm{X} / \mathrm{Y}] \approx \mu_{\mathrm{X}} / \mu_{\mathrm{Y}}-1 / \mu_{\mathrm{Y}}^{2} \operatorname{Cov}[\mathrm{X}, \mathrm{Y}]+\mu_{\mathrm{X}} / \mu_{\mathrm{Y}}^{3} \operatorname{Var}[\mathrm{Y}]
$$

Assim,

$$
\mathrm{E}[\hat{\mathrm{F}}]=\mathrm{E}\left[\frac{\mathrm{QMI}-\mathrm{QMG}}{\overline{\mathrm{QMI}+\mathrm{QMG}}}\right]=\mathrm{E}\left[\frac{\mathrm{X}}{\mathrm{Y}}\right]
$$

sendo:

$$
\mathrm{X}=\mathrm{QMI}-\mathrm{QMG} \text { e } \mathrm{Y}=\mathrm{QMI}+\mathrm{QMG} \text {. }
$$

Como QMI e QMG são independentes, podem-se obter os seguintes resultados:

(8) $\quad \mathrm{E}[\mathrm{X}]=\mathrm{E}[\mathrm{QMI}-\mathrm{QMG}]$

$=\mathrm{E}[\mathrm{QMI}]-\mathrm{E}[\mathrm{QMG}]$

$=\mathrm{p}(1-\mathrm{p})(1+\mathrm{F})-\mathrm{p}(1-\mathrm{p})(1-\mathrm{F})$

$=2 \mathrm{p}(1-\mathrm{p}) \mathrm{F}$,

$\operatorname{Var}[\mathrm{X}]=\operatorname{Var}[\mathrm{QMI}-\mathrm{QMG}]$

$$
\begin{aligned}
& =\operatorname{Var}(\mathrm{QMI})+\operatorname{Var}(\mathrm{QMG})-2 \operatorname{Cov}[\mathrm{QM}, \mathrm{QMG}] \\
& =\operatorname{Var}(\mathrm{QMI})+\operatorname{Var}(\mathrm{QMG}) ;
\end{aligned}
$$


(b)

$$
\begin{aligned}
E[Y] & =E[Q M I+Q M G] \\
& =E[Q M]+E[Q M G] \\
& =p(1-p)(1+F)+p(1-p)(1-F) \\
& =2 p(1-p), \\
\operatorname{Var}[Y] & =\operatorname{Var}[Q M I+Q M G]=\operatorname{Var}(Q M I)+\operatorname{Var}(Q M G) ;
\end{aligned}
$$

(c) $\operatorname{Cov}[\mathrm{X}, \mathrm{Y}]=\operatorname{Cov}[(\mathrm{QMI}-\mathrm{QMG}),(\mathrm{QM}+\mathrm{QMG})]$

$$
\begin{aligned}
& =E[(Q M I-Q M O)-E(Q M I-Q M O)][(Q M I+Q M O)-E(Q M I+Q M O)]\} \\
& =E\{(Q M I-E(Q M I))-(Q M O-E(Q M O))][(Q M I-E(Q M I))+Q M O-E(Q M O))]\} \\
& =\left\{\begin{array}{l}
Q M I-E(Q M I)]^{2}+[Q M I-E(Q M I)][Q M O-E(Q M G)] \\
-[Q M I-E(Q M)][Q M O-E(Q M G)]-[Q M G-E(Q M G)\}
\end{array}\right\} \\
& =\operatorname{Var}(Q M I)-\operatorname{Var}(Q M G) .
\end{aligned}
$$

Substituindo-se os resultados (a), (b) e (c ) na expresså de $E[\hat{F}]$, obtém-se:

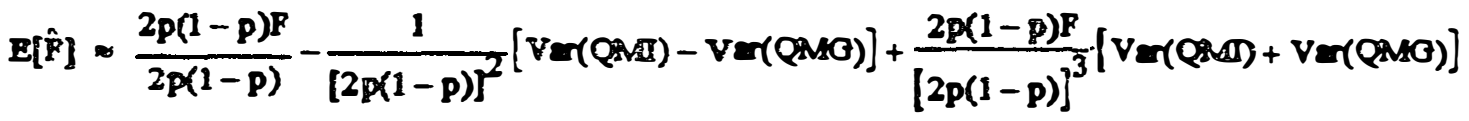

$$
\begin{aligned}
& \sim F+\frac{(P-1) \operatorname{VE}(Q M A I)+(F+1) \operatorname{Var}(Q M O)}{[2 P(1-P)]^{2}}
\end{aligned}
$$

De acordo com KSHIRSAGAR (1983), para todos os parâmetros independentes e com distribuição normal de um modelo balanceado, a distribuição de qualquer SQ DR analise de variancin $\mathrm{B}[\mathrm{QM}$ ansogendente ] 
é uma variável $\chi^{2}$ com os graus de liberdade, $v$, da SQ correspondente.

Assim,

$$
\frac{\mathrm{SQ}}{\mathrm{E}(\mathrm{QM})}=\frac{\mathbf{Q M}}{\mathrm{E}(\mathrm{QM})} \sim \chi_{v}^{2} .
$$

Esta reląảo permite obter a variância de um $Q M$, conforme mostrado em SEARLE (1958,1971) e BARBIN (1993), e dada pela expressão

$$
\operatorname{Var}[\mathrm{QM}]=\frac{2[\mathrm{E}(\mathrm{QM})]^{2}}{\mathrm{v}} .
$$

Considerando-se que na análise de variância das frequências génicas, o número de individuos e a frequência génica sejam suficientes para que

$$
\frac{\mathrm{v} \cdot \mathrm{QM}}{\mathrm{E}(\mathrm{QM})} \approx x_{\mathrm{v}}^{2}
$$

e consequentemente

$$
\operatorname{Var}(\mathrm{QM}) \approx \frac{2[\mathrm{E}(\mathrm{QM})]^{2}}{\mathbf{v}},
$$

entåo pode-se escrever que:

$$
\begin{aligned}
& \operatorname{Var}(Q M I) \approx \frac{2[E(Q M I)]^{2}}{v}=\frac{2[p(1-p)(1+F)]^{2}}{n-1} e \\
& \operatorname{Var}(Q M G) \approx \frac{2[E(Q M G)]^{2}}{v}=\frac{2[p(1-p)(1-F)]^{2}}{n} .
\end{aligned}
$$


Substituindo-se estes resultados na expressåo de E[ $[\hat{F}]$, obtém-se:

$$
\begin{aligned}
E[\hat{F}] \approx F+\frac{2[p(1-p)]^{2}}{[2 p(1-p)]^{2}}\left[\frac{(F+1)^{2}(F-1)+(F+1)(1-F)^{2}}{n-1}\right] & n \\
& \approx F+\frac{1}{2}\left[\frac{F^{3}+F^{2}-F-1}{n-1}+\frac{F^{3}-F^{2}-F+1}{n}\right] .
\end{aligned}
$$

Considerando-se que o número de indivíduos seja tal que

$n-1 \approx n$, entå:

$$
\begin{aligned}
E[\hat{F}] & \approx F+\frac{1}{2}\left[\frac{2 F^{3}-2 F}{n}\right] \approx F+\frac{F^{3}-F}{n} \\
& \approx F-\frac{F\left(1-F^{2}\right)}{n} .
\end{aligned}
$$

O resultado obtido mostrou que o estimador encontrado pelo método dos momentos é tendencioso, considerando-se a aproximação de primeira ordem pela série de Taylor. $O$ viés do estimador foi negativo, isto é, as estimativas de $\mathrm{F}$ obtidas pelo método do momentos tendem a ser em média inferiores ao verdadeiro valor de $F$. $O$ viés do estimador é funçåo de $1 / n$ portanto à medida que o tamanho da amostra aumenta ele reduz. 
A expressåo encontrada para o viés do estimador de F

$$
-\frac{F\left(1-F^{2}\right)}{n}
$$

foi semelhante dquela apresentada por JOHNSON \& KOTZ (1970), para viés do estimador do coeficiente de correlafão, diferindo apenas por não ter o valor 2 no denominador.

A variância do estimador de $F$ pode ser obtida também pelo desevolvimento em série de Taylor da funçåo $X / Y$ no ponto $X=\mu_{X}$ e $Y=\mu_{Y}$ conforme MOOD et al. (1974) que define

$$
\operatorname{Var}\left[\frac{X}{Y}\right] \approx \frac{\mu_{Y}^{2} \operatorname{Var}[X]+\mu_{X}^{2} \operatorname{Var}[Y]-2 \mu_{X} \mu_{Y} \operatorname{Cov}[X, Y]}{\mu_{Y}^{4}}
$$

Substituindo-se os resultados (a), (b) e (c ) obtidos anteriormente na expressão de $\operatorname{Var}[\hat{\mathrm{F}}]$, obtém-se:

$\operatorname{Var}[\hat{\mathrm{p}}] \approx \frac{[2 \mathrm{p}(1-\mathrm{p})]^{2} \operatorname{Var}[\mathrm{QM}-\mathrm{QMG}]+[2 \mathrm{p}(1-\mathrm{p}) \mathrm{F}]^{2} \operatorname{Var}[\mathrm{QM}+\mathrm{QMG}]-2[2 \mathrm{p}(1-\mathrm{p}) \operatorname{Var}(\mathrm{Q} \mathrm{Q})-\operatorname{Var}(\mathrm{Q} M G)]}{[2 \mathrm{p}(1-\mathrm{p})]^{4}}$

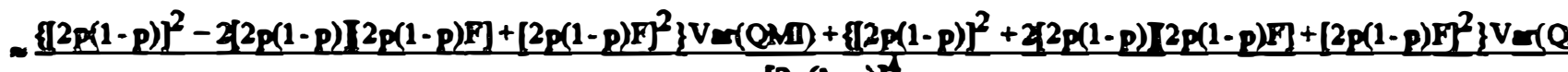
$[2 p(1-p)]^{4}$

$\approx \frac{[2 p(1-p)-2 p(1-p) F]^{2} \operatorname{Var}(Q M I)+[2 p(1-p)+2 p(1-p) F]^{2} \operatorname{Var}(Q M G)}{[2 p(1-p)]^{4}}$ 
$\operatorname{Var}[\hat{F}] \approx \frac{[2 p(1-p)(1-F)]^{2} \operatorname{Var}(Q M I)+[2 p(1-p)(1+F)]^{2} \operatorname{Var}(Q M Q)}{[2 p(1-p)]^{3}}$

$$
\begin{aligned}
& \approx \frac{(1-F)^{2} \operatorname{Var}(Q M I)+(1+F)^{2} \operatorname{Var}(Q M G)}{[2 p(1-p)]^{2}} \\
& \approx \frac{1}{[2 p(1-P)]^{2}}\left\{(1-F)^{2} \frac{2[p(1-P)(1+F)\}^{2}}{n-1}+(1+F)^{2} 2\left[p(1-P)(1-F)^{2}\right\}\right. \\
& \approx \frac{1}{2}\left\{\frac{(1-F)^{2}(1+F)^{2}}{n-1}+\frac{(1+F)^{2}(1-F)^{2}}{n}\right\} \\
& \approx \frac{(1-F)^{2}(1+F)^{2}}{n} \\
& \approx \frac{\left(1-F^{2}\right)^{2}}{n} .
\end{aligned}
$$

A expressão encontrada para a variência do estimador de $F$ assemelhou-se às expressões apresentadas por JOHNSON \& KOTZ (1970) e FISHER (1970).

Na prática, quando se toma uma amostra de $n$ individuos, não se conhece F. Assim, é importante ter-se uma maneira de obter uma estimativa $\hat{F}$ e de sua variância. Na estimação da variância de $\hat{\mathrm{F}}$ precisou-se estimar a variância de um quadrado médio. 
Utilizando-se como estimador de um quadrado médio a expressåo sugerida por vários autores tais como SEARLE (1971),

$$
\operatorname{Vâr}(Q M)=\frac{2(Q M)^{2}}{v+2} \text {, }
$$

pode-se obter um estimador de $\operatorname{Var}[\hat{\mathrm{F}}]$.

Substituindo-se os parâmetros por suas extimativas na expressåo:

$$
\begin{aligned}
\operatorname{Var}[\hat{\mathrm{F}}] & \approx \frac{(1-\mathrm{F})^{2} \operatorname{Var}(\mathrm{QMI})+(1+\mathrm{F})^{2} \operatorname{Var}(\mathrm{QMG})}{[2 \mathrm{p}(1-\mathrm{P})]^{2}} \\
\approx & \frac{(1-F)^{2} \operatorname{Var}(\mathrm{QMI})+(1+F)^{2} \operatorname{Var}(\mathrm{QMG})}{\left(2 \sigma^{2}\right)^{2}}
\end{aligned}
$$

obteve-se um estimador de $\operatorname{Var}[\mathrm{F}]$ dado por:

$$
\begin{aligned}
& \operatorname{Vâ}_{1}(\hat{F}) \approx \frac{1}{\left(2 \hat{\sigma}^{2}\right)^{2}}\left\{(1-\hat{F})^{2} \frac{2\left[\hat{\sigma}^{2}(1+\hat{F})\right]^{2}}{n+1}+(1+\hat{F})^{2} 2\left[\hat{\sigma}^{2}(1-\hat{F})\right]^{2}\right\} \\
& \approx \frac{1}{2}\left[\frac{(1-\hat{F})^{2}(1+\hat{F})}{n+1}+\frac{(1+\hat{F})^{2}(1-\hat{F})^{2}}{n+2}\right] \\
& \approx \frac{2 n+3}{2(n+1)(n+2)}\left(1-\hat{F}^{2}\right)^{2} \text {. }
\end{aligned}
$$

Uma outra fórmula para estimar $\operatorname{Var}[\hat{\mathrm{F}}]$ foi obtida utilizando-se como estimador da variância de um quadrado médio a expressão

$$
\operatorname{Vâr}(Q M)=\frac{2(Q M)^{2}}{v} \text {, }
$$

que não soma 2 aos graus de liberdade v. Para este caso, o estimador da variância de $\hat{F}$ foi dado por 


$$
\operatorname{Vâr}_{2}(\hat{F}) \approx \frac{2 n-1}{2 n(n-1)}\left(1-\hat{F}^{2}\right)^{2} .
$$

Pode-se também utilizar como estimador da variância de $\hat{F}$ a fórmula obtida para esta variância, substituindo os parámetros por suas estimativas, correspondente à expressåo sugerida por FISHER (1970) para estimativa da variância do coeficiente de correlaçảo, dada por

$$
\operatorname{Vâr}_{3}(\hat{F}) \approx \frac{\left(1-\hat{F}^{2}\right)^{2}}{n} .
$$

A Tabela 6 apresenta a média $(\overline{\hat{F}})$, a variância $\operatorname{Var}(\hat{\mathrm{F}})$ e as médias dos três extimadores da variância de $\hat{\mathrm{F}}$ obtidas em $\mathrm{N}=100$ experimentos com diferentes números de indivíduos em populacões de dois alelos com diversas combineģões de frequências gênicas e coeficientes de endogamia.

A Tabela 7 apresenta o valor esperado e a variância das estimativas do coeficiente de endogamia para populações de dois alelos, com diferentes valores de coeficiente de endogamia, calculado através das expressö́es obtidas pelo desenvolvimento em série de Taylor com diferentes números de indivíduos.

As médias $(\overline{\hat{F}})$ obtidas em todas populaçōes, considerando as diversas combinaçōes de número de indivíduos comprovaram que o estimador

$$
\hat{\mathrm{F}}=\frac{\mathrm{QMI}-\mathrm{QMG}}{\mathrm{QMI}+\mathrm{QMG}}
$$

obtido pelo método dos momentos foi realmente um estimador tendencioso, apresentando um viés negativo, o que pode ser visto na Tabela 6 onde a maioria 
dos valores de $\overline{\hat{F}}$ esté abaixo do valor $\mathrm{F}$ da populasåa. Com o aumento do tamanho da amostra os valores de $\overline{\hat{F}}$ se aproximaram de $F$. Comparando-se os valores de $\overline{\hat{F}}$ da Tabela 6 com os valores esperados de $\hat{F}$, apresentados na Tabela 7, observase que houve uma concordância entre os resultados observados e os teóricos.

Os valores das variâncias de $\hat{F}$, apresentados na Tabela 6 indicaram que, quando a frequência gênica da populaçåo esteve entre 0,3 e $0,7,0$ coeficiente de endogamia foi inferior a 0,5 e se trabalhou com pelo menos 30 individuos, houve uma concordância entre os resultados observados e aqueles teoricamente esperados na Tabela 7. Com a frequência gênica entre 0,3 e 0,7 e o coeficiente de endogamia inferior a 0,3 , a concordância se verificou quando se usaram 20 ou mais individuos. Estes resultados comprovaram que a fórmula proposta para a variância de $\hat{F}$ foi válida quando a populą̧ão teve baixo coeficiente de endogamia, a frequência gênica e o número de indivíduos foram suficientes para se admitir ums razoável aproximsçāo normal, concordando com as condições apresentadas por FISHER (1970), para a distribuição do coeficiente de correlação.

Com relação aos três estimadores da variância de $\hat{\mathrm{F}}$, eles formeceram valores que se aproximaram bem dos valores de $\operatorname{Var}[\hat{\mathrm{F}}]$ na Tabela 6 nas mesmas faixas de frequência gênica, coeficiente de endogamia e número de indivíduos. Os resultados obtidos para os três estimadores de $\operatorname{Var}(\hat{F})$ foram semelhantes aos teóricos da Tabela 7, quando o coeficiente de endogamia foi inferior a 0,8 independentemente da frequência gênica e do número de individuos. Os três estimadores praticamente fomeceram os mesmos resultados quando se 
usaram pelo menos 20 individuos, em qualquer situação, indicando que se pode utilizar o último deles cuje expressão

$$
\operatorname{Vâr}(\hat{\mathrm{F}}) \approx \frac{\left(1-\hat{\mathrm{F}}^{2}\right)^{2}}{n}
$$

é bastante simples e semelhante com aquela apresentada por FISHER (1970). 
TABELA 6 - Média e variância do estimador de F e médias dos estimadores de $\operatorname{Var}(\hat{\mathrm{F}})$ em $\mathrm{N}=100$ experimentos com amostras de tamanhos diferentes, extraidas em populaçôes de dois alelos com diverses combinacỏes de frequências gênicas e coeficientes de endogamia.

\begin{tabular}{|c|c|c|c|c|c|c|c|}
\hline D & $P$ & F & $\hat{\mathbf{F}}$ & $\operatorname{Var}(\hat{\mathrm{F}})$ & Vấ, & 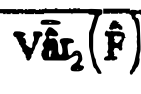 & $\mathrm{V} \overline{\hat{A}}_{3}(\hat{\mathrm{F}})$ \\
\hline $\begin{array}{c}10 \\
20 \\
30 \\
50 \\
100 \\
200 \\
\end{array}$ & 0,1 & 0,0 & $\begin{array}{l}0,0197 \\
-0,0090 \\
0,0144 \\
0,0009 \\
0,0207 \\
0,0096\end{array}$ & $\begin{array}{l}0,0273 \\
0,0267 \\
0,0354 \\
0,0170 \\
0,0112 \\
0,0053 \\
\end{array}$ & $\begin{array}{l}0,0953 \\
0,0488 \\
0,0318 \\
0,0195 \\
0,0098 \\
0,0050\end{array}$ & $\begin{array}{l}0,0786 \\
0,0443 \\
0,0298 \\
0,0188 \\
0,0096 \\
0,0049\end{array}$ & $\begin{array}{l}0,0903 \\
0,0476 \\
0,0313 \\
0,0193 \\
0,0098 \\
0,0050\end{array}$ \\
\hline $\begin{array}{c}10 \\
20 \\
30 \\
50 \\
100 \\
200 \\
\end{array}$ & 0,1 & 0.1 & $\begin{array}{l}0,0440 \\
0,0794 \\
0,0888 \\
0,0866 \\
0,1096 \\
0,0862 \\
\end{array}$ & $\begin{array}{l}0,0610 \\
0,0637 \\
0,0520 \\
0,0271 \\
0,0157 \\
0,0086 \\
\end{array}$ & $\begin{array}{l}0,0879 \\
0,0459 \\
0,0304 \\
0,0190 \\
0,0095 \\
0,0049 \\
\end{array}$ & $\begin{array}{l}0,0725 \\
0,0416 \\
0,0285 \\
0,0182 \\
0,0093 \\
0,0048\end{array}$ & $\begin{array}{l}0,0832 \\
0,0447 \\
0,0299 \\
0,0187 \\
0,0095 \\
0,0048 \\
\end{array}$ \\
\hline $\begin{array}{c}10 \\
20 \\
30 \\
50 \\
100 \\
200 \\
\end{array}$ & 0,1 & 0,2 & $\begin{array}{l}0,1220 \\
0,1356 \\
0,1713 \\
0,1436 \\
0,1893 \\
0,1847 \\
\end{array}$ & $\begin{array}{l}0,0842 \\
0,0704 \\
0,0568 \\
0,0338 \\
0,0211 \\
0,0120 \\
\end{array}$ & $\begin{array}{l}0,0699 \\
0,0424 \\
0,0290 \\
0,0182 \\
0,0090 \\
0,0046 \\
\end{array}$ & $\begin{array}{l}0,0577 \\
0,0385 \\
0,0271 \\
0,0175 \\
0,0088 \\
0,0045 \\
\end{array}$ & $\begin{array}{l}0,0662 \\
0,0413 \\
0,0285 \\
0,0180 \\
0,0089 \\
0,0046 \\
\end{array}$ \\
\hline $\begin{array}{c}10 \\
20 \\
30 \\
50 \\
100 \\
200\end{array}$ & 0,1 & 0,3 & $\begin{array}{l}0,1890 \\
0,2072 \\
0,2471 \\
0,2766 \\
0,2753 \\
0,2958\end{array}$ & $\begin{array}{l}0,1341 \\
0,1004 \\
0,0842 \\
0,0461 \\
0,0216 \\
0,0083\end{array}$ & $\begin{array}{l}0,0596 \\
0,0397 \\
0,0260 \\
0,0160 \\
0,0082 \\
0,0041\end{array}$ & $\begin{array}{l}0,0492 \\
0,0360 \\
0,0243 \\
0,0153 \\
0,0081 \\
0,0040\end{array}$ & $\begin{array}{l}0,0565 \\
0,0387 \\
0,0255 \\
0,0158 \\
0,0082 \\
0,0041\end{array}$ \\
\hline
\end{tabular}

$\hat{\mathrm{F}} \quad:$ media de $\hat{\mathrm{F}}$ nos N=100 experimentos;

$\operatorname{Var}(\hat{\mathrm{F}})$ : verimeis de $\hat{\mathrm{F}}$ noo $\mathrm{N}=100$ experimation;

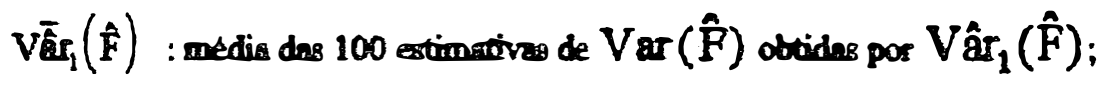

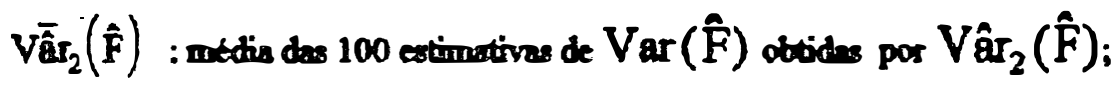

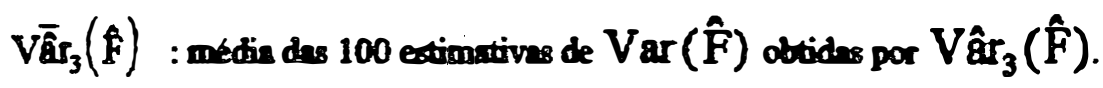


TABELA 6 - Média e variência do extimador de $\mathrm{F}$ e médias dos extimadores de $\operatorname{Var}(\hat{\mathrm{F}})$ em $\mathrm{N}=100$ experimentos com amostras de tamanhos diferentes, extraidas em populagoos de dois alelos com diverses combinaços de frequências génicas e coeficientes de endogamia

\begin{tabular}{|c|c|c|c|c|c|c|c|}
\hline n & P & $\mathbf{F}$ & $\overline{\hat{F}}$ & $\operatorname{Var}(\hat{\mathrm{F}})$ & $V \bar{A}_{1}(\hat{F})$ & $\mathrm{VAT}_{2}(\hat{\mathrm{F}})$ & $v \bar{A}_{r_{3}}(\hat{F})$ \\
\hline $\begin{array}{c}10 \\
20 \\
30 \\
50 \\
100 \\
200 \\
\end{array}$ & 0,1 & 0,4 & $\begin{array}{l}0,2771 \\
0,3518 \\
0,3455 \\
0,3801 \\
0,3844 \\
0,4030 \\
\end{array}$ & $\begin{array}{l}0,1595 \\
0,1314 \\
0,0949 \\
0,0465 \\
0,0246 \\
0,0137 \\
\end{array}$ & $\begin{array}{l}0,0579 \\
0,0328 \\
0,0222 \\
0,0138 \\
0,0070 \\
0,0034 \\
\end{array}$ & $\begin{array}{l}0,0478 \\
0,0297 \\
0,0208 \\
0,0133 \\
0,0069 \\
0,0034 \\
\end{array}$ & $\begin{array}{l}0,0549 \\
0,0320 \\
0,219 \\
0,0137 \\
0,0070 \\
0,0034 \\
\end{array}$ \\
\hline $\begin{array}{c}10 \\
20 \\
30 \\
50 \\
100 \\
200 \\
\end{array}$ & 0,1 & 0,5 & $\begin{array}{l}0,2362 \\
0,4069 \\
0,4472 \\
0,4753 \\
0,5009 \\
0,4892 \\
\end{array}$ & $\begin{array}{l}0,1491 \\
0,1332 \\
0,0846 \\
0,0558 \\
0,0168 \\
0,0104 \\
\end{array}$ & $\begin{array}{l}0,0536 \\
0,0267 \\
0,0192 \\
0,0112 \\
0,0053 \\
0,0029\end{array}$ & $\begin{array}{l}0,0442 \\
0,0242 \\
0,0180 \\
0,0108 \\
0,0054 \\
0,0028\end{array}$ & $\begin{array}{l}0,0508 \\
0,0260 \\
0,0189 \\
0,0111 \\
0,0055 \\
0,0029\end{array}$ \\
\hline $\begin{array}{l}10 \\
20 \\
30 \\
30 \\
100 \\
200 \\
\end{array}$ & 0,1 & 0,6 & $\begin{array}{l}0,3879 \\
0,4709 \\
0,5284 \\
0,5587 \\
0,5800 \\
0,5855 \\
\end{array}$ & $\begin{array}{l}0,1974 \\
0,1580 \\
0,0825 \\
0,0482 \\
0,0192 \\
0,0119 \\
\end{array}$ & $\begin{array}{l}0,0393 \\
0,0218 \\
0,0161 \\
0,0093 \\
0,0044 \\
0,0022 \\
\end{array}$ & $\begin{array}{l}0,0324 \\
0,0197 \\
0,0151 \\
0,0089 \\
0,0043 \\
0,0021 \\
\end{array}$ & $\begin{array}{l}0,0372 \\
0,0212 \\
0,0159 \\
0,0092 \\
0,0044 \\
0,0022 \\
\end{array}$ \\
\hline $\begin{array}{l}10 \\
20 \\
30 \\
50 \\
100 \\
200 \\
\end{array}$ & 0,1 & 0,7 & $\begin{array}{l}0,4605 \\
0,5646 \\
0,6585 \\
0,6876 \\
0,6961 \\
0,6986 \\
\end{array}$ & $\begin{array}{l}0,1956 \\
0,1681 \\
0,0731 \\
0,0422 \\
0,0197 \\
0,0070 \\
\end{array}$ & $\begin{array}{l}0,0217 \\
0,0187 \\
0,0106 \\
0,0061 \\
0,0029 \\
0,0013 \\
\end{array}$ & $\begin{array}{l}0,0180 \\
0,0170 \\
0,0099 \\
0,0058 \\
0,0029 \\
0,0013 \\
\end{array}$ & $\begin{array}{l}0,0206 \\
0,0182 \\
0,0104 \\
0,0060 \\
0,0029 \\
0,0013 \\
\end{array}$ \\
\hline $\begin{array}{l}10 \\
20 \\
30 \\
50 \\
100 \\
200 \\
\end{array}$ & 0,1 & 0,8 & $\begin{array}{l}0,5665 \\
0,6826 \\
0,7624 \\
0,8083 \\
0,7998 \\
0,7963 \\
\end{array}$ & $\begin{array}{l}0,2150 \\
0,1244 \\
0,0622 \\
0,0164 \\
0,0128 \\
0,0054 \\
\end{array}$ & $\begin{array}{l}0,0180 \\
0,0108 \\
0,0067 \\
0,0030 \\
0,0015 \\
0,0007 \\
\end{array}$ & $\begin{array}{l}0,0149 \\
0,0098 \\
0,0063 \\
0,0029 \\
0,0013 \\
0,0007 \\
\end{array}$ & $\begin{array}{l}0,0171 \\
0,0105 \\
0,0066 \\
0,0030 \\
0,0015 \\
0,0007 \\
\end{array}$ \\
\hline $\begin{array}{l}10 \\
20 \\
30 \\
50 \\
100 \\
200 \\
\end{array}$ & 0,1 & 0,9 & $\begin{array}{l}0,4922 \\
0,8552 \\
0,8568 \\
0,8886 \\
0,8956 \\
0,9014 \\
\end{array}$ & $\begin{array}{l}0,2284 \\
0,0714 \\
0,0533 \\
0,0135 \\
0,0077 \\
0,0028 \\
\end{array}$ & $\begin{array}{l}0,0133 \\
0,0036 \\
0,0039 \\
0,0015 \\
0,0006 \\
0,0002 \\
\end{array}$ & $\begin{array}{l}0,0126 \\
0,0033 \\
0,0037 \\
0,0014 \\
0,0006 \\
0,0002 \\
\end{array}$ & $\begin{array}{l}0,0145 \\
0,0036 \\
0,0039 \\
0,0015 \\
0,0006 \\
0,0002 \\
\end{array}$ \\
\hline $\begin{array}{l}10 \\
20 \\
30 \\
50 \\
100 \\
200\end{array}$ & 0,1 & 1,0 & $\begin{array}{l}0,3880 \\
0,8488 \\
0,9478 \\
0,9920 \\
0,9966 \\
0,9950\end{array}$ & $\begin{array}{l}0,2431 \\
0,1286 \\
0,0480 \\
0,0014 \\
0,0002 \\
0,0001 \\
\end{array}$ & $\begin{array}{l}0,0001 \\
0,0000 \\
0,0004 \\
0,0001 \\
0,0000 \\
0,0000\end{array}$ & $\begin{array}{l}0,0001 \\
0,0000 \\
0,0003 \\
0,0001 \\
0,0000 \\
0,0000\end{array}$ & $\begin{array}{l}0,0001 \\
0,0000 \\
0,0004 \\
0,0001 \\
0,0000 \\
0,0000\end{array}$ \\
\hline
\end{tabular}


TABELA 6 - Média e variância do estimador de F e médias dos estimadores de $\operatorname{Var}(\hat{\mathrm{F}})$ em $\mathrm{N}=100$ experimentos com emostras de tamanhos diferentes, extraidas em populaçōes de dois alelos com diversas combinaç̄es de frequências génicas e coeficientes de endogamia

\begin{tabular}{|c|c|c|c|c|c|c|c|}
\hline$D$ & $\bar{P}$ & $\overline{\mathbf{F}}$ & $\hat{\mathrm{F}}$ & $\operatorname{Var}(\hat{F})$ & $v_{\bar{R}_{1}}(\hat{F})$ & $V \overline{\hat{C}_{2}}(\hat{\mathrm{F}})$ & $\mathrm{V}^{\bar{a}_{3}}(\hat{\mathbf{F}})$ \\
\hline $\begin{array}{l}10 \\
20 \\
30 \\
30 \\
100 \\
200 \\
\end{array}$ & 0,2 & 0,0 & $\begin{array}{l}0,0015 \\
-0,0362 \\
0,0235 \\
0,0090 \\
0,0098 \\
0,000\end{array}$ & $\begin{array}{l}0,0726 \\
0,0359 \\
0,0297 \\
0,0185 \\
0,0088 \\
0,0037\end{array}$ & $\begin{array}{l}0,0917 \\
0,0477 \\
0,0319 \\
0,0195 \\
0,0099 \\
0,0050 \\
\end{array}$ & $\begin{array}{l}0,0737 \\
0,0432 \\
0,0299 \\
0,0187 \\
0,0097 \\
0,0049 \\
\end{array}$ & $\begin{array}{l}0,0869 \\
0,0463 \\
0,0314 \\
0,0193 \\
0,0098 \\
0,0050 \\
\end{array}$ \\
\hline $\begin{array}{l}10 \\
20 \\
30 \\
50 \\
100 \\
200 \\
\end{array}$ & 0,2 & 0,1 & $\begin{array}{l}0,1026 \\
0,0829 \\
0,0995 \\
0,1060 \\
0,0863 \\
0,0958 \\
\end{array}$ & $\begin{array}{l}0,0885 \\
0,0515 \\
0,0371 \\
0,0286 \\
0,0132 \\
0,0060 \\
\end{array}$ & $\begin{array}{l}0,0874 \\
0,0460 \\
0,0309 \\
0,0187 \\
0,0096 \\
0,0049 \\
\end{array}$ & $\begin{array}{l}0,0722 \\
0,0417 \\
0,0290 \\
0,0180 \\
0,0095 \\
0,0048\end{array}$ & $\begin{array}{l}0,0828 \\
0,0448 \\
0,0304 \\
0,0185 \\
0,0098 \\
0,0048 \\
\end{array}$ \\
\hline $\begin{array}{l}10 \\
20 \\
30 \\
30 \\
100 \\
200 \\
\end{array}$ & 0,2 & 0,2 & $\begin{array}{l}0,2088 \\
0,1954 \\
0,1716 \\
0,1820 \\
0,1986 \\
0,1898\end{array}$ & $\begin{array}{l}0,1312 \\
0,0629 \\
0,0375 \\
0,0298 \\
0,0122 \\
0,0052 \\
\end{array}$ & $\begin{array}{l}0,0 \mathrm{~m} 7 \\
0,0424 \\
0,0298 \\
0,0179 \\
0,0091 \\
0,0046 \\
\end{array}$ & $\begin{array}{l}0,0641 \\
0,0385 \\
0,0279 \\
0,0172 \\
0,0089 \\
0,0046 \\
\end{array}$ & $\begin{array}{l}0,0736 \\
0,0414 \\
0,0293 \\
0,0177 \\
0,0090 \\
0,0046 \\
\end{array}$ \\
\hline $\begin{array}{l}10 \\
20 \\
30 \\
50 \\
100 \\
200 \\
\end{array}$ & 0,2 & 0,3 & $\begin{array}{l}0,3114 \\
0,2742 \\
0,2687 \\
0,2746 \\
0,2948 \\
0,3096 \\
\end{array}$ & $\begin{array}{l}0,1472 \\
0,0730 \\
0,0433 \\
0,0268 \\
0,0118 \\
0,0052 \\
\end{array}$ & $\begin{array}{l}0,0695 \\
0,0386 \\
0,0270 \\
0,0163 \\
0,0082 \\
0,0040 \\
\end{array}$ & $\begin{array}{l}0,0573 \\
0,0350 \\
0,0253 \\
0,0158 \\
0,0080 \\
0,0040 \\
\end{array}$ & $\begin{array}{l}0,0658 \\
0,0376 \\
0,0266 \\
0,0163 \\
0,0082 \\
0,0040\end{array}$ \\
\hline $\begin{array}{l}10 \\
20 \\
30 \\
50 \\
100 \\
200 \\
\end{array}$ & 0,2 & 0,4 & $\begin{array}{l}0,4032 \\
0,3793 \\
0,4192 \\
0,3637 \\
0,3935 \\
0,3893 \\
\end{array}$ & $\begin{array}{l}0,1430 \\
0,0708 \\
0,0655 \\
0,0289 \\
0,0119 \\
0,0065 \\
\end{array}$ & $\begin{array}{l}0,0611 \\
0,0334 \\
0,0216 \\
0,0145 \\
0,0071 \\
0,0036 \\
\end{array}$ & $\begin{array}{l}0,0504 \\
0,0303 \\
0,0203 \\
0,0139 \\
0,0069 \\
0,0035\end{array}$ & $\begin{array}{l}0,0579 \\
0,0326 \\
0,0213 \\
0,0143 \\
0,0070 \\
0,0036 \\
\end{array}$ \\
\hline $\begin{array}{l}10 \\
20 \\
30 \\
50 \\
100 \\
200 \\
\end{array}$ & 0,2 & 0,5 & $\begin{array}{l}0,4097 \\
0,4873 \\
0,5003 \\
0,4872 \\
0,4811 \\
0,4856 \\
\end{array}$ & $\begin{array}{l}0,1410 \\
0,0756 \\
0,0497 \\
0,0233 \\
0,0106 \\
0,0054\end{array}$ & $\begin{array}{l}0,0564 \\
0,0273 \\
0,0182 \\
0,0115 \\
0,0059 \\
0,0029 \\
\end{array}$ & $\begin{array}{l}0,0466 \\
0,0248 \\
0,0170 \\
0,0110 \\
0,0058 \\
0,0029 \\
\end{array}$ & $\begin{array}{l}0,0534 \\
0,0266 \\
0,0179 \\
0,0114 \\
0,0058 \\
0,0029 \\
\end{array}$ \\
\hline $\begin{array}{l}10 \\
20 \\
30 \\
50 \\
100 \\
200 \\
\end{array}$ & 0,2 & 0,6 & $\begin{array}{l}0,3089 \\
0,5735 \\
0,5976 \\
0,6331 \\
0,6012 \\
0,5908 \\
\end{array}$ & $\begin{array}{l}0,1419 \\
0,0548 \\
0,0300 \\
0,0175 \\
0,0082 \\
0,0068 \\
\end{array}$ & $\begin{array}{l}0,0470 \\
0,0229 \\
0,0143 \\
0,0073 \\
0,0041 \\
0,0021 \\
\end{array}$ & $\begin{array}{l}0,0388 \\
0,0208 \\
0,0134 \\
0,0071 \\
0,0040 \\
0,0021 \\
\end{array}$ & $\begin{array}{l}0,0445 \\
0,0223 \\
0,0140 \\
0,0073 \\
0,0041 \\
0,0021\end{array}$ \\
\hline
\end{tabular}


TABELA 6 - Média e variância do estimador de F e médias dos estimadores de $\operatorname{Var}(\hat{F})$ em $N=100$ experimentos com amostras de tamanhos diferentes, extraidas em populacōes de dois alelos com diverses combinaçóes de frequências gênicas e coeficientes de endogamia

\begin{tabular}{|c|c|c|c|c|c|c|c|}
\hline D & P & $\mathbb{P}$ & $\hat{\mathbf{F}}$ & $\operatorname{Var}(\hat{F})$ & $V_{\bar{a}_{1}}(\hat{F})$ & $V \bar{A}_{y}(\hat{F})$ & $\mathbf{V}^{\bar{R}} \mathbf{r}_{3}(\hat{\mathbf{F}})$ \\
\hline $\begin{array}{l}10 \\
20 \\
30 \\
50 \\
100 \\
200 \\
\end{array}$ & 0,2 & 0,7 & $\begin{array}{l}0,6192 \\
0,6621 \\
0,6942 \\
0,6836 \\
0,7071 \\
0,6893 \\
\end{array}$ & $\begin{array}{l}0,1149 \\
0,0536 \\
0,0227 \\
0,0242 \\
0,0083 \\
0,0047 \\
\end{array}$ & $\begin{array}{l}0,0369 \\
0,0165 \\
0,0097 \\
0,0060 \\
0,0026 \\
0,0014 \\
\end{array}$ & $\begin{array}{l}0,0304 \\
0,0150 \\
0,0091 \\
0,0058 \\
0,0025 \\
0,0014 \\
\end{array}$ & $\begin{array}{l}0,0349 \\
0,0161 \\
0,0095 \\
0,0060 \\
0,0026 \\
0,0014\end{array}$ \\
\hline $\begin{array}{l}10 \\
20 \\
30 \\
50 \\
100 \\
200\end{array}$ & 0,2 & 0,8 & $\begin{array}{l}0,6712 \\
0,7902 \\
0,7737 \\
0,7792 \\
0,7879 \\
0,8026\end{array}$ & $\begin{array}{l}0,1558 \\
0,0375 \\
0,0236 \\
0,0106 \\
0,0045 \\
0,0036\end{array}$ & $\begin{array}{l}0,0253 \\
0,0088 \\
0,0065 \\
0,0034 \\
0,0015 \\
0,0007\end{array}$ & $\begin{array}{l}0,0209 \\
0,0079 \\
0,0061 \\
0,0033 \\
0,0015 \\
0,0007\end{array}$ & $\begin{array}{l}0,0240 \\
0,0083 \\
0,0064 \\
0,0034 \\
0,0015 \\
0,0007\end{array}$ \\
\hline $\begin{array}{l}10 \\
20 \\
30 \\
50 \\
100 \\
200 \\
\end{array}$ & 0,2 & 0,9 & $\begin{array}{l}0,8138 \\
0,8831 \\
0,8740 \\
0,8974 \\
0,8981 \\
0,8952 \\
\end{array}$ & $\begin{array}{l}0,0947 \\
0,0349 \\
0,0229 \\
0,0110 \\
0,0030 \\
0,0017 \\
\end{array}$ & $\begin{array}{l}0,0122 \\
0,0047 \\
0,0027 \\
0,0013 \\
0,0005 \\
0,0002 \\
\end{array}$ & $\begin{array}{l}0,0100 \\
0,0043 \\
0,0025 \\
0,0012 \\
0,0004 \\
0,0002 \\
\end{array}$ & $\begin{array}{l}0,0115 \\
0,0046 \\
0,0027 \\
0,0012 \\
0,0003 \\
0,0002 \\
\end{array}$ \\
\hline $\begin{array}{l}10 \\
20 \\
30 \\
50 \\
100 \\
200 \\
\end{array}$ & 0,2 & 1,0 & $\begin{array}{l}0,8879 \\
0,9854 \\
1,0000 \\
0,9949 \\
0,9969 \\
0,0000 \\
\end{array}$ & $\begin{array}{l}0,0989 \\
0,0104 \\
0,0000 \\
0,0004 \\
0,0001 \\
0,0000\end{array}$ & $\begin{array}{l}0,0012 \\
0,0001 \\
0,0000 \\
0,0000 \\
0,0000 \\
0,0000 \\
\end{array}$ & $\begin{array}{l}0,0010 \\
0,0001 \\
0,0000 \\
0,0000 \\
0,0000 \\
0,0000 \\
\end{array}$ & $\begin{array}{l}0,0012 \\
0,0001 \\
0,0000 \\
0,0000 \\
0,0000 \\
0,0000 \\
\end{array}$ \\
\hline $\begin{array}{l}10 \\
20 \\
30 \\
30 \\
100 \\
200 \\
\end{array}$ & 0,3 & 0,0 & $\begin{array}{l}-0,0104 \\
-0,0295 \\
0,0084 \\
-0,0070 \\
-0,0016 \\
-0,0045\end{array}$ & $\begin{array}{l}0,0922 \\
0,0455 \\
0,0282 \\
0,0274 \\
0,0086 \\
0,0051\end{array}$ & $\begin{array}{l}0,0884 \\
0,0468 \\
0,0301 \\
0,0192 \\
0,0099 \\
0,0050 \\
\end{array}$ & $\begin{array}{l}0,0730 \\
0,0425 \\
0,0301 \\
0,0184 \\
0,0097 \\
0,0049 \\
\end{array}$ & $\begin{array}{l}0,0838 \\
0,0456 \\
0,0315 \\
0,0190 \\
0,0098 \\
0,0050 \\
\end{array}$ \\
\hline $\begin{array}{l}10 \\
20 \\
30 \\
50 \\
100 \\
200 \\
\end{array}$ & 0,3 & 0,1 & $\begin{array}{l}0,1069 \\
0,0909 \\
0,0935 \\
0,1083 \\
0,1037 \\
0,0851 \\
\end{array}$ & $\begin{array}{l}0,1019 \\
0,0511 \\
0,0337 \\
0,0189 \\
0,0139 \\
0,0046 \\
\end{array}$ & $\begin{array}{l}0,0849 \\
0,0439 \\
0,0312 \\
0,0190 \\
0,0096 \\
0,0049 \\
\end{array}$ & $\begin{array}{l}0,0700 \\
0,0416 \\
0,0292 \\
0,0183 \\
0,0094 \\
0,0048 \\
\end{array}$ & $\begin{array}{l}0,0804 \\
0,0447 \\
0,0307 \\
0,0188 \\
0,0095 \\
0,0049 \\
\end{array}$ \\
\hline $\begin{array}{l}10 \\
20 \\
30 \\
50 \\
100 \\
200 \\
\end{array}$ & 0,3 & 0,2 & $\begin{array}{l}0,1980 \\
0,1941 \\
0,2146 \\
0,2006 \\
0,2000 \\
0,1964 \\
\end{array}$ & $\begin{array}{l}0,0983 \\
0,0630 \\
0,0467 \\
0,0208 \\
0,0099 \\
0,0059 \\
\end{array}$ & $\begin{array}{l}0,0182 \\
0,0422 \\
0,0284 \\
0,0179 \\
0,0091 \\
0,0046 \\
\end{array}$ & $\begin{array}{l}0,0670 \\
0,0383 \\
0,0266 \\
0,0172 \\
0,0089 \\
0,0045 \\
\end{array}$ & $\begin{array}{l}0,0769 \\
0,0412 \\
0,0279 \\
0,0177 \\
0,0090 \\
0,0046 \\
\end{array}$ \\
\hline
\end{tabular}


TABELA 6 - Média e variância do esümador de F e médias dos estimadores de $\operatorname{Var}(\hat{\mathrm{F}})$ em $\mathrm{N}=100$ experimentos com amostras de tamanhos diferentes, extraidas em populações de dois alelos com diversas combinaçốes de frequências gênicas e coeficientes de endogamia

\begin{tabular}{|c|c|c|c|c|c|c|c|}
\hline n & $\mathbf{p}$ & $\mathbf{P}$ & $\overline{\hat{F}}$ & $\operatorname{Var}(\hat{\mathrm{F}})$ & $\mathrm{Vâ}_{\mathbf{r}_{1}}(\hat{\mathrm{k}})$ & $V \bar{a}_{2}(\hat{F})$ & $\mathrm{VAAs}_{3}(\bar{F}$ \\
\hline $\begin{array}{l}10 \\
20 \\
30 \\
30 \\
100 \\
200 \\
\end{array}$ & 0,3 & 0,3 & $\begin{array}{l}0,2728 \\
0,3278 \\
0,2927 \\
0,2932 \\
0,2893 \\
0,2988 \\
\end{array}$ & $\begin{array}{l}0,1135 \\
0,0440 \\
0,0281 \\
0,0245 \\
0,0098 \\
0,0049\end{array}$ & $\begin{array}{l}0,0751 \\
0,0378 \\
0,0270 \\
0,0162 \\
0,0083 \\
0,0041 \\
\end{array}$ & $\begin{array}{l}0,0619 \\
0,0343 \\
0,0253 \\
0,0156 \\
0,0081 \\
0,0041\end{array}$ & $\begin{array}{l}0,0711 \\
0,0369 \\
0,0265 \\
0,0160 \\
0,0083 \\
0,0041\end{array}$ \\
\hline $\begin{array}{l}10 \\
20 \\
30 \\
50 \\
100 \\
200 \\
\end{array}$ & 0,3 & 0,4 & $\begin{array}{l}0,3646 \\
0,3518 \\
0,3837 \\
0,3967 \\
0,4053 \\
0,3885 \\
\end{array}$ & $\begin{array}{l}0,1325 \\
0,0552 \\
0,0364 \\
0,0199 \\
0,0084 \\
0,0052\end{array}$ & $\begin{array}{l}0,0645 \\
0,0361 \\
0,0233 \\
0,0139 \\
0,0069 \\
0,0036 \\
\end{array}$ & $\begin{array}{l}0,0532 \\
0,0327 \\
0,0218 \\
0,0134 \\
0,0068 \\
0,0036 \\
\end{array}$ & $\begin{array}{l}0,0611 \\
0,0352 \\
0,0229 \\
0,0138 \\
0,0069 \\
0,0036 \\
\end{array}$ \\
\hline $\begin{array}{l}10 \\
20 \\
30 \\
50 \\
100 \\
200 \\
\end{array}$ & 0,3 & 0,5 & $\begin{array}{l}0,4935 \\
0,4728 \\
0,4757 \\
0,4841 \\
0,4950 \\
0,4781 \\
\end{array}$ & $\begin{array}{l}0,1007 \\
0,0450 \\
0,0391 \\
0,0183 \\
0,0089 \\
0,0043\end{array}$ & $\begin{array}{l}0,0532 \\
0,0291 \\
0,0195 \\
0,0117 \\
0,0057 \\
0,0030 \\
\end{array}$ & $\begin{array}{l}0,0439 \\
0,0264 \\
0,0183 \\
0,0112 \\
0,0056 \\
0,0029\end{array}$ & $\begin{array}{l}0,0504 \\
0,0284 \\
0,0192 \\
0,0115 \\
0,0056 \\
0,0030\end{array}$ \\
\hline $\begin{array}{l}10 \\
20 \\
30 \\
50 \\
100 \\
200 \\
\end{array}$ & $\mathbf{0 , 3}$ & 0,6 & $\begin{array}{l}0,5002 \\
0,5755 \\
0,5932 \\
0,6168 \\
0,6008 \\
0,5928 \\
\end{array}$ & $\begin{array}{l}0,1010 \\
0,0373 \\
0,0321 \\
0,0147 \\
0,0075 \\
0,0046 \\
\end{array}$ & $\begin{array}{l}0,0519 \\
0,0228 \\
0,0143 \\
0,0078 \\
0,0041 \\
0,0021 \\
\end{array}$ & $\begin{array}{l}0,0428 \\
0,0207 \\
0,0133 \\
0,0075 \\
0,0040 \\
0,0021 \\
\end{array}$ & $\begin{array}{l}0,0492 \\
0,0222 \\
0,0140 \\
0,0078 \\
0,0041 \\
0,0021\end{array}$ \\
\hline $\begin{array}{l}10 \\
20 \\
30 \\
50 \\
100 \\
200 \\
\end{array}$ & 0,3 & 0,7 & $\begin{array}{l}0,7022 \\
0,6681 \\
0,7033 \\
0,6841 \\
0,7014 \\
0,6956\end{array}$ & $\begin{array}{l}0,0679 \\
0,0405 \\
0,0197 \\
0,0117 \\
0,0032 \\
0,0032\end{array}$ & $\begin{array}{l}0,0285 \\
0,0168 \\
0,0092 \\
0,0059 \\
0,0026 \\
0,0013\end{array}$ & $\begin{array}{l}0,0235 \\
0,0152 \\
0,0086 \\
0,0056 \\
0,0026 \\
0,0013\end{array}$ & $\begin{array}{l}0,0270 \\
0,0163 \\
0,0090 \\
0,0058 \\
0,0026 \\
0,0013\end{array}$ \\
\hline $\begin{array}{l}10 \\
20 \\
30 \\
50 \\
100 \\
200 \\
\end{array}$ & 0,3 & 0,8 & $\begin{array}{l}0,7446 \\
0,7606 \\
0,7888 \\
0,7974 \\
0,7943 \\
0,7953 \\
\end{array}$ & $\begin{array}{l}0,0741 \\
0,0356 \\
0,0157 \\
0,0095 \\
0,0039 \\
0,0022 \\
\end{array}$ & $\begin{array}{l}0,0246 \\
0,0104 \\
0,0057 \\
0,0030 \\
0,0014 \\
0,0007\end{array}$ & $\begin{array}{l}0,0203 \\
0,0094 \\
0,0034 \\
0,0029 \\
0,0014 \\
0,0007\end{array}$ & $\begin{array}{l}0,0233 \\
0,0101 \\
0,0056 \\
0,0030 \\
0,0014 \\
0,0007 \\
\end{array}$ \\
\hline $\begin{array}{l}10 \\
20 \\
30 \\
50 \\
100 \\
200 \\
\end{array}$ & 0,3 & 0,9 & $\begin{array}{l}0,8498 \\
0,9114 \\
0,8821 \\
0,8994 \\
0,8907 \\
0,9011 \\
\end{array}$ & $\begin{array}{l}0,0649 \\
0,0109 \\
0,0098 \\
0,0049 \\
0,0021 \\
0,0010 \\
\end{array}$ & $\begin{array}{l}0,0127 \\
0,0029 \\
0,0024 \\
0,0010 \\
0,0005 \\
0,0002 \\
\end{array}$ & $\begin{array}{l}0,0104 \\
0,0026 \\
0,0023 \\
0,0010 \\
0,0005 \\
0,0002 \\
\end{array}$ & $\begin{array}{l}0,0120 \\
0,0028 \\
0,0024 \\
0,0010 \\
0,0005 \\
0,0002 \\
\end{array}$ \\
\hline
\end{tabular}


TABELA 6 - Média e variência do estimador de F e médias dos estimadores de $\operatorname{Var}(\hat{\mathrm{F}})$ em $\mathrm{N}=100$ experimentos com amostras de tamanhos diferentes, extraídas em populagooes de dois alelos com diversas combinacões de frequências gênicas e coeficientes de endogamia

\begin{tabular}{|c|c|c|c|c|c|c|c|}
\hline $\bar{D}$ & $\mathbf{p}$ & $\overline{\mathbf{F}}$ & $\overline{\hat{F}}$ & $\operatorname{Var}(\hat{\mathrm{R}})$ & $V \bar{A}_{1}(\hat{F})$ & $V \bar{A}_{2}(E)$ & $\mathrm{VAs}_{3}(\mathrm{~F}$ \\
\hline $\begin{array}{l}10 \\
20 \\
30 \\
50 \\
100 \\
200 \\
\end{array}$ & 0,3 & 1,0 & $\begin{array}{l}1,0000 \\
0,9968 \\
0,9986 \\
0,9983 \\
0,9972 \\
0,9986\end{array}$ & $\begin{array}{l}0,0000 \\
0,0006 \\
0,0001 \\
0,0001 \\
0,0001 \\
0,0000 \\
\end{array}$ & $\begin{array}{l}0,0000 \\
0,0001 \\
0,0000 \\
0,0000 \\
0,0000 \\
0,0000\end{array}$ & $\begin{array}{l}0,0000 \\
0,0001 \\
0,0000 \\
0,0000 \\
0,0000 \\
0,0000\end{array}$ & $\begin{array}{l}0,0000 \\
0,0001 \\
0,0000 \\
0,0000 \\
0,0000 \\
0,0000 \\
\end{array}$ \\
\hline $\begin{array}{l}10 \\
20 \\
30 \\
50 \\
100 \\
200 \\
\end{array}$ & 0,4 & 0,0 & $\begin{array}{l}-0,0684 \\
-0,0101 \\
0,0183 \\
0,0262 \\
0,0112 \\
-0,0050\end{array}$ & $\begin{array}{l}0,1133 \\
0,0548 \\
0,0353 \\
0,0172 \\
0,0095 \\
0,0058 \\
\end{array}$ & $\begin{array}{l}0,0846 \\
0,0461 \\
0,0316 \\
0,0195 \\
0,0099 \\
0,0050\end{array}$ & $\begin{array}{l}0,0698 \\
0,0418 \\
0,0296 \\
0,0187 \\
0,0097 \\
0,0049 \\
\end{array}$ & $\begin{array}{l}0,0801 \\
0,0449 \\
0,0311 \\
0,0193 \\
0,0098 \\
0,0049 \\
\end{array}$ \\
\hline $\begin{array}{l}10 \\
20 \\
30 \\
50 \\
100 \\
200 \\
\end{array}$ & 0,4 & 0,1 & $\begin{array}{l}0,0887 \\
0,0850 \\
0,1344 \\
0,1168 \\
0,1103 \\
0,1046\end{array}$ & $\begin{array}{l}0,1046 \\
0,0446 \\
0,0274 \\
0,0194 \\
0,0100 \\
0,0058\end{array}$ & $\begin{array}{l}0,0859 \\
0,0464 \\
0,0310 \\
0,0189 \\
0,0096 \\
0,0049\end{array}$ & $\begin{array}{l}0,0709 \\
0,0420 \\
0,0291 \\
0,0182 \\
0,0094 \\
0,0048 \\
\end{array}$ & $\begin{array}{l}0,0813 \\
0,0452 \\
0,0305 \\
0,0187 \\
0,0096 \\
0,0048 \\
\end{array}$ \\
\hline $\begin{array}{l}10 \\
20 \\
30 \\
50 \\
100 \\
200 \\
\end{array}$ & 0,4 & 0,2 & $\begin{array}{l}0,1844 \\
0,1951 \\
0,2156 \\
0,2139 \\
0,2027 \\
0,1935\end{array}$ & $\begin{array}{l}0,1110 \\
0,0470 \\
0,0329 \\
0,0212 \\
0,0070 \\
0,0056\end{array}$ & $\begin{array}{l}0,0807 \\
0,0436 \\
0,0290 \\
0,0177 \\
0,0091 \\
0,0046\end{array}$ & $\begin{array}{l}0,0666 \\
0,0395 \\
0,0271 \\
0,0170 \\
0,0089 \\
0,0045 \\
\end{array}$ & $\begin{array}{l}0,0764 \\
0,0425 \\
0,0285 \\
0,0173 \\
0,0091 \\
0,0046 \\
\end{array}$ \\
\hline $\begin{array}{l}10 \\
20 \\
30 \\
50 \\
100 \\
200 \\
\end{array}$ & 0,4 & 0,3 & $\begin{array}{l}0,2644 \\
0,3133 \\
0,2701 \\
0,2960 \\
0,2870 \\
0,2945\end{array}$ & $\begin{array}{l}0,0946 \\
0,0587 \\
0,0305 \\
0,0185 \\
0,0111 \\
0,0048\end{array}$ & $\begin{array}{l}0,0771 \\
0,0377 \\
0,0276 \\
0,0163 \\
0,0083 \\
0,0041\end{array}$ & $\begin{array}{l}0,0636 \\
0,0342 \\
0,0259 \\
0,0157 \\
0,0081 \\
0,0041\end{array}$ & $\begin{array}{l}0,0730 \\
0,0367 \\
0,0272 \\
0,0161 \\
0,0082 \\
0,0041 \\
\end{array}$ \\
\hline $\begin{array}{l}10 \\
20 \\
30 \\
50 \\
100 \\
200 \\
\end{array}$ & 0,4 & 0,4 & $\begin{array}{l}0,3732 \\
0,3759 \\
0,3788 \\
0,4018 \\
0,3907 \\
0,3888 \\
\end{array}$ & $\begin{array}{l}0,0947 \\
0,0406 \\
0,0282 \\
0,0163 \\
0,0091 \\
0,0045\end{array}$ & $\begin{array}{l}0,0673 \\
0,0357 \\
0,0239 \\
0,0139 \\
0,0071 \\
0,0036 \\
\end{array}$ & $\begin{array}{l}0,0555 \\
0,0324 \\
0,0224 \\
0,0133 \\
0,0070 \\
0,0036\end{array}$ & $\begin{array}{l}0,0637 \\
0,0348 \\
0,0239 \\
0,0137 \\
0,0071 \\
0,0036 \\
\end{array}$ \\
\hline $\begin{array}{l}10 \\
20 \\
30 \\
50 \\
100 \\
200 \\
\end{array}$ & 0,4 & 0,5 & $\begin{array}{l}0,4780 \\
0,5006 \\
0,4727 \\
0,5041 \\
0,4794 \\
0,4918 \\
\end{array}$ & $\begin{array}{l}0,0945 \\
0,0436 \\
0,0330 \\
0,0130 \\
0,0080 \\
0,0045 \\
\end{array}$ & $\begin{array}{l}0,0568 \\
0,0277 \\
0,0197 \\
0,0111 \\
0,0059 \\
0,0029 \\
\end{array}$ & $\begin{array}{l}0,0469 \\
0,0251 \\
0,0185 \\
0,0107 \\
0,0058 \\
0,0028 \\
\end{array}$ & $\begin{array}{l}0,0538 \\
0,0270 \\
0,0194 \\
0,0110 \\
0,0059 \\
0,0029 \\
\end{array}$ \\
\hline
\end{tabular}


TABELA 6 - Média e variância do estimsdor de F e médias dos estimadores de $\operatorname{Var}(\hat{F})$ em $N=100$ experimentos com amostras de tamanhos diferentes, extraidas em populaçōes de dois alelos com diversas combinacões de freauências aênicas e coeficientes de endogamia.

\begin{tabular}{|c|c|c|c|c|c|c|c|}
\hline $\mathbf{n}$ & P & $\bar{F}$ & $\overline{\hat{F}}$ & $\operatorname{Var}(\hat{\mathrm{F}})$ & $\mathbf{V} \overline{a ̆}_{1}(\hat{F})$ & $v \bar{t}_{r_{2}}(\hat{F})$ & $V \overline{A x}_{3}(\hat{E})$ \\
\hline $\begin{array}{l}10 \\
20 \\
30 \\
50 \\
100 \\
200 \\
\end{array}$ & 0,4 & 0,6 & $\begin{array}{l}0,5804 \\
0,5920 \\
0,6034 \\
0,5866 \\
0,5856 \\
0,5919 \\
\end{array}$ & $\begin{array}{l}0,0726 \\
0,0343 \\
0,0200 \\
0,0137 \\
0,0060 \\
0,0043\end{array}$ & $\begin{array}{l}0,0455 \\
0,0218 \\
0,0139 \\
0,0087 \\
0,0043 \\
0,0021\end{array}$ & $\begin{array}{l}0,0376 \\
0,0198 \\
0,0130 \\
0,0083 \\
0,0043 \\
0,0021 \\
\end{array}$ & $\begin{array}{l}0,0431 \\
0,0213 \\
0,0136 \\
0,0086 \\
0,0043 \\
0,0021\end{array}$ \\
\hline $\begin{array}{l}10 \\
20 \\
30 \\
50 \\
100 \\
200 \\
\end{array}$ & 0,4 & 0,7 & $\begin{array}{l}0,6901 \\
0,6716 \\
0,7282 \\
0,6888 \\
0,6920 \\
0,6978 \\
\end{array}$ & $\begin{array}{l}0,0524 \\
0,0251 \\
0,0149 \\
0,0090 \\
0,0060 \\
0,0026 \\
\end{array}$ & $\begin{array}{l}0,0314 \\
0,0160 \\
0,0080 \\
0,0037 \\
0,0028 \\
0,0013 \\
\end{array}$ & $\begin{array}{l}0,0259 \\
0,0145 \\
0,0075 \\
0,0055 \\
0,0027 \\
0,0013\end{array}$ & $\begin{array}{l}0,0298 \\
0,0156 \\
0,0079 \\
0,0057 \\
0,0028 \\
0,0013\end{array}$ \\
\hline $\begin{array}{l}10 \\
20 \\
30 \\
30 \\
100 \\
200 \\
\end{array}$ & 0,4 & 0,8 & $\begin{array}{l}0,8077 \\
0,8107 \\
0,80034 \\
0,8013 \\
0,8086 \\
0,7972 \\
\end{array}$ & $\begin{array}{l}0,0536 \\
0,0187 \\
0,0112 \\
0,0069 \\
0,0037 \\
0,0018 \\
\end{array}$ & $\begin{array}{l}0,0182 \\
0,0078 \\
0,0049 \\
0,0028 \\
0,0013 \\
0,0007\end{array}$ & $\begin{array}{l}0,0150 \\
0,0070 \\
0,0046 \\
0,0027 \\
0,0012 \\
0,0007\end{array}$ & $\begin{array}{l}0,0172 \\
0,0076 \\
0,0048 \\
0,0028 \\
0,0013 \\
0,0007 \\
\end{array}$ \\
\hline $\begin{array}{l}10 \\
20 \\
30 \\
50 \\
100 \\
200 \\
\end{array}$ & 0,4 & 0,9 & $\begin{array}{l}0,9052 \\
0,9036 \\
0,9098 \\
0,8925 \\
0,8964 \\
0,8979\end{array}$ & $\begin{array}{l}0,0187 \\
0,0091 \\
0,0053 \\
0,0049 \\
0,0016 \\
0,0012 \\
\end{array}$ & $\begin{array}{l}0,0081 \\
0,0030 \\
0,0015 \\
0,0011 \\
0,0004 \\
0,0002 \\
\end{array}$ & $\begin{array}{l}0,0067 \\
0,0027 \\
0,0014 \\
0,0010 \\
0,0004 \\
0,0002\end{array}$ & $\begin{array}{l}0,0077 \\
0,0029 \\
0,0015 \\
0,0010 \\
0,0004 \\
0,0002\end{array}$ \\
\hline $\begin{array}{l}10 \\
20 \\
30 \\
50 \\
100 \\
200 \\
\end{array}$ & 0,4 & 1,0 & $\begin{array}{l}0,9900 \\
1,0000 \\
0,9953 \\
0,9987 \\
0,9983 \\
0,9977\end{array}$ & $\begin{array}{l}0,0100 \\
0,0000 \\
0,0004 \\
0,0001 \\
0,0000 \\
0,0000\end{array}$ & $\begin{array}{l}0,0000 \\
0,0000 \\
0,0001 \\
0,0000 \\
0,0000 \\
0,0000\end{array}$ & $\begin{array}{l}0,0000 \\
0,0000 \\
0,0000 \\
0,0000 \\
0,0000 \\
0,0000\end{array}$ & $\begin{array}{l}0,0000 \\
0,0000 \\
0,0001 \\
0,0000 \\
0,0000 \\
0,0000\end{array}$ \\
\hline $\begin{array}{l}10 \\
20 \\
30 \\
50 \\
100 \\
200 \\
\end{array}$ & 0.5 & 0,0 & $\begin{array}{l}-0,0409 \\
-0,0070 \\
-0,0017 \\
0,0060 \\
-0,0168 \\
-0,0162\end{array}$ & $\begin{array}{l}0,0811 \\
0,0434 \\
0,0488 \\
0,0158 \\
0,0099 \\
0,0046\end{array}$ & $\begin{array}{l}0,0903 \\
0,0471 \\
0,0308 \\
0,0196 \\
0,0098 \\
0,0050 \\
\end{array}$ & $\begin{array}{l}0,0749 \\
0,0428 \\
0,0289 \\
0,0188 \\
0,0097 \\
0,0049 \\
\end{array}$ & $\begin{array}{l}0,0853 \\
0,0459 \\
0,0303 \\
0,0194 \\
0,0098 \\
0,0050\end{array}$ \\
\hline $\begin{array}{l}10 \\
20 \\
30 \\
50 \\
100 \\
200 \\
\end{array}$ & 0,5 & 0,1 & $\begin{array}{l}0,0375 \\
0,1045 \\
0,0949 \\
0,0918 \\
0,1055 \\
0,1008 \\
\end{array}$ & $\begin{array}{l}0,1203 \\
0,0413 \\
0,0293 \\
0,0234 \\
0,0086 \\
0,0037 \\
\end{array}$ & $\begin{array}{l}0,0840 \\
0,0463 \\
0,0314 \\
0,0190 \\
0,0097 \\
0,0049 \\
\end{array}$ & $\begin{array}{l}0,0693 \\
0,0420 \\
0,0294 \\
0,0182 \\
0,0095 \\
0,0048 \\
\end{array}$ & $\begin{array}{l}0,0796 \\
0,0451 \\
0,0309 \\
0,0188 \\
0,0096 \\
0,0049\end{array}$ \\
\hline
\end{tabular}


TABELA 6 - Média e variância do estimador de F e médias dos estimadores de $\operatorname{Var}(\hat{F})$ em $N=100$ experimentos com amostras de tamanhos diferentes, extraidas em populacōes de dois alelos com diversas combinacótes de frequéncias génicas e coeficientes de endogamia

\begin{tabular}{|c|c|c|c|c|c|c|c|}
\hline D & $P$ & $\mathbf{F}$ & $\overline{\hat{\mathbf{F}}}$ & $\operatorname{Var}(\hat{R})$ & $V \overline{\bar{x}_{1}}(\mathrm{f})$ & $\mathrm{VA}_{\bar{s}_{2}}(\hat{f})$ & $v \bar{a}_{3}(\hat{F})$ \\
\hline $\begin{array}{l}10 \\
20 \\
30 \\
50 \\
100 \\
200 \\
\end{array}$ & 0,5 & 0,2 & $\begin{array}{l}0,2164 \\
0,2134 \\
0,2045 \\
0,2095 \\
0,1956 \\
0,2092\end{array}$ & $\begin{array}{l}0,1021 \\
0,0608 \\
0,0257 \\
0,0192 \\
0,0087 \\
0,0046\end{array}$ & $\begin{array}{l}0,0796 \\
0,0418 \\
0,0296 \\
0,0178 \\
0,0091 \\
0,0045\end{array}$ & $\begin{array}{l}0,0637 \\
0,0379 \\
0,0278 \\
0,0171 \\
0,0090 \\
0,0045 \\
\end{array}$ & $\begin{array}{l}0,0734 \\
0,0407 \\
0,0292 \\
0,0176 \\
0,0091 \\
0,0045\end{array}$ \\
\hline $\begin{array}{l}10 \\
20 \\
30 \\
50 \\
100 \\
200 \\
\end{array}$ & 0,5 & 0,3 & $\begin{array}{l}0,2314 \\
0,2570 \\
0,3198 \\
0,3045 \\
0,2870 \\
0,3148\end{array}$ & $\begin{array}{l}0,0995 \\
0,0604 \\
0,0291 \\
0,0180 \\
0,0067 \\
0,0033 \\
\end{array}$ & $\begin{array}{l}0,0795 \\
0,0403 \\
0,0260 \\
0,0162 \\
0,0084 \\
0,0040\end{array}$ & $\begin{array}{l}0,0636 \\
0,0365 \\
0,0243 \\
0,0155 \\
0,0082 \\
0,0040\end{array}$ & $\begin{array}{l}0,0753 \\
0,0392 \\
0,0256 \\
0,0160 \\
0,0083 \\
0,0040\end{array}$ \\
\hline $\begin{array}{l}10 \\
20 \\
30 \\
50 \\
100 \\
200 \\
\end{array}$ & 0,5 & 0,4 & $\begin{array}{l}0,4114 \\
0,3943 \\
0,4130 \\
0,3749 \\
0,3860 \\
0,3949\end{array}$ & $\begin{array}{l}0,0337 \\
0,0331 \\
0,0276 \\
0,0159 \\
0,0117 \\
0,0042 \\
\end{array}$ & $\begin{array}{l}0,0648 \\
0,0348 \\
0,0225 \\
0,0145 \\
0,0071 \\
0,0035 \\
\end{array}$ & $\begin{array}{l}0,0534 \\
0,0316 \\
0,0210 \\
0,0140 \\
0,0070 \\
0,0035\end{array}$ & $\begin{array}{l}0,0614 \\
0,0339 \\
0,0221 \\
0,0144 \\
0,0071 \\
0,0035\end{array}$ \\
\hline $\begin{array}{l}10 \\
20 \\
30 \\
50 \\
100 \\
200 \\
\end{array}$ & 0,5 & 0,5 & $\begin{array}{l}0,4935 \\
0,4851 \\
0,5142 \\
0,5182 \\
0,4962 \\
0,4900\end{array}$ & $\begin{array}{l}0,0758 \\
0,0439 \\
0,0226 \\
0,0151 \\
0,0073 \\
0,0036 \\
\end{array}$ & $\begin{array}{l}0,0366 \\
0,0286 \\
0,0180 \\
0,0107 \\
0,0037 \\
0,0029 \\
\end{array}$ & $\begin{array}{l}0,0467 \\
0,0260 \\
0,0169 \\
0,0103 \\
0,0055 \\
0,0029\end{array}$ & $\begin{array}{l}0,0536 \\
0,0279 \\
0,0177 \\
0,0106 \\
0,0056 \\
0,0029\end{array}$ \\
\hline $\begin{array}{l}10 \\
20 \\
30 \\
50 \\
100 \\
200 \\
\end{array}$ & 0,5 & 0,6 & $\begin{array}{l}0,5783 \\
0,5874 \\
0,5950 \\
0,5685 \\
0,5929 \\
0,5996 \\
\end{array}$ & $\begin{array}{l}0,0813 \\
0,0346 \\
0,0196 \\
0,0120 \\
0,0061 \\
0,0027\end{array}$ & $\begin{array}{l}0,0436 \\
0,0222 \\
0,0142 \\
0,0092 \\
0,0042 \\
0,0021\end{array}$ & $\begin{array}{l}0,0376 \\
0,0201 \\
0,0133 \\
0,0089 \\
0,0041 \\
0,0020 \\
\end{array}$ & $\begin{array}{l}0,0432 \\
0,0216 \\
0,0140 \\
0,0091 \\
0,0042 \\
0,0020\end{array}$ \\
\hline $\begin{array}{l}10 \\
20 \\
30 \\
50 \\
100 \\
200 \\
\end{array}$ & 0,5 & 0,7 & $\begin{array}{l}0,6527 \\
0,7101 \\
0,6830 \\
0,7053 \\
0,6996 \\
0,6858\end{array}$ & $\begin{array}{l}0,0722 \\
0,0278 \\
0,0211 \\
0,0093 \\
0,0055 \\
0,0028\end{array}$ & $\begin{array}{l}0,0374 \\
0,0140 \\
0,0101 \\
0,0053 \\
0,0027 \\
0,0014 \\
\end{array}$ & $\begin{array}{l}0,0309 \\
0,0127 \\
0,0095 \\
0,0051 \\
0,0026 \\
0,0014 \\
\end{array}$ & $\begin{array}{l}0,0355 \\
0,0137 \\
0,0099 \\
0,0052 \\
0,0026 \\
0,0014\end{array}$ \\
\hline $\begin{array}{l}10 \\
20 \\
30 \\
50 \\
100 \\
200 \\
\end{array}$ & 0,5 & 0,8 & $\begin{array}{l}0,8194 \\
0,8011 \\
0,7894 \\
0,7922 \\
0,7997 \\
0,7914\end{array}$ & $\begin{array}{l}0,0342 \\
0,0180 \\
0,0118 \\
0,0088 \\
0,0036 \\
0,0016\end{array}$ & $\begin{array}{l}0,0173 \\
0,0081 \\
0,0054 \\
0,0031 \\
0,0014 \\
0,0007\end{array}$ & $\begin{array}{l}0,0144 \\
0,0073 \\
0,0051 \\
0,0030 \\
0,0013 \\
0,0007\end{array}$ & $\begin{array}{l}0,0166 \\
0,0079 \\
0,0053 \\
0,0030 \\
0,0014 \\
0,0007 \\
\end{array}$ \\
\hline
\end{tabular}


TABELA 6 - Média e variância do estimador de F e médias dos estimadores de $\operatorname{Var}(\hat{\mathrm{F}})$ em $\mathrm{N}=100$ experimentos com amostras de tamanhos diferentes, extraídas em populaçoes de dois alelos com diversas combinacões de freouências qênicas e coeficientes de endogamia.

\begin{tabular}{|c|c|c|c|c|c|c|c|}
\hline n & P & $\mathbf{F}$ & $\overline{\hat{F}}$ & $\operatorname{Var}(\hat{\mathrm{P}})$ & $v_{a_{1}}(\hat{F})$ & $v_{\bar{t}} r_{2}(\hat{F})$ & $\mathrm{VÂ}_{\mathbf{r}_{3}}(\hat{\mathrm{F}})$ \\
\hline $\begin{array}{l}10 \\
20 \\
30 \\
30 \\
100 \\
200 \\
\end{array}$ & 0,5 & 0,9 & $\begin{array}{l}0,8881 \\
0,9013 \\
0,8744 \\
0,8955 \\
0,8961 \\
0,9013 \\
\end{array}$ & $\begin{array}{l}0,0300 \\
0,0112 \\
0,0084 \\
0,0038 \\
0,0022 \\
0,0009\end{array}$ & $\begin{array}{l}0.0098 \\
0,0033 \\
0,0025 \\
0,0010 \\
0,0004 \\
0,0002\end{array}$ & $\begin{array}{l}0,0081 \\
0,0030 \\
0,0023 \\
0,0010 \\
0,0004 \\
0,0002\end{array}$ & $\begin{array}{l}0,0093 \\
0,0032 \\
0,0025 \\
0,0010 \\
0,0004 \\
0,0002 \\
\end{array}$ \\
\hline $\begin{array}{l}10 \\
20 \\
30 \\
50 \\
100 \\
200 \\
\end{array}$ & 0,5 & 1,0 & $\begin{array}{l}0,9923 \\
0,9971 \\
0,9971 \\
0,9984 \\
0,9972 \\
0,9978 \\
\end{array}$ & $\begin{array}{l}0,0014 \\
0,0003 \\
0,0002 \\
0,0001 \\
0,0001 \\
0,0000 \\
\end{array}$ & $\begin{array}{l}0,0005 \\
0,0001 \\
0,0000 \\
0,0000 \\
0,0000 \\
0,0000 \\
\end{array}$ & $\begin{array}{l}0,0004 \\
0,0001 \\
0,0000 \\
0,0000 \\
0,0000 \\
0,0000\end{array}$ & $\begin{array}{l}0,0003 \\
0,0001 \\
0,0000 \\
0,0000 \\
0,0000 \\
0,0000\end{array}$ \\
\hline $\begin{array}{l}10 \\
20 \\
30 \\
50 \\
100 \\
200 \\
\end{array}$ & 0,6 & 0,0 & $\begin{array}{l}0,0326 \\
-0,0016 \\
0,0056 \\
0,0052 \\
0,0174 \\
-0,0090\end{array}$ & $\begin{array}{l}0,0954 \\
0,0479 \\
0,0274 \\
0,0280 \\
0,0086 \\
0,0053\end{array}$ & $\begin{array}{l}0,0877 \\
0,0468 \\
0,0321 \\
0,0193 \\
0,0099 \\
0,0050 \\
\end{array}$ & $\begin{array}{l}0,0724 \\
0,0424 \\
0,0301 \\
0,0186 \\
0,0097 \\
0,0049\end{array}$ & $\begin{array}{l}0,0831 \\
0,0456 \\
0,0316 \\
0,0191 \\
0,0098 \\
0,0049\end{array}$ \\
\hline $\begin{array}{l}10 \\
20 \\
30 \\
50 \\
100 \\
200 \\
\end{array}$ & 0,6 & 0,1 & $\begin{array}{l}0,1230 \\
0,1272 \\
0,1112 \\
0,0947 \\
0,0940 \\
0,0893 \\
\end{array}$ & $\begin{array}{l}0,0984 \\
0,0537 \\
0,0342 \\
0,0209 \\
0,0114 \\
0,0044\end{array}$ & $\begin{array}{l}0,0860 \\
0,0450 \\
0,0310 \\
0,0190 \\
0,0097 \\
0,0049\end{array}$ & $\begin{array}{l}0,0710 \\
0,0408 \\
0,0290 \\
0,0183 \\
0,0095 \\
0,0048 \\
\end{array}$ & $\begin{array}{l}0,0815 \\
0,0438 \\
0,0304 \\
0,0188 \\
0,0096 \\
0,0049\end{array}$ \\
\hline $\begin{array}{l}10 \\
20 \\
30 \\
50 \\
100 \\
200 \\
\end{array}$ & 0,6 & 0,2 & $\begin{array}{l}0,1943 \\
0,1703 \\
0,2025 \\
0,2337 \\
0,2008 \\
0,1899 \\
\end{array}$ & $\begin{array}{l}0,1003 \\
0,0551 \\
0,0241 \\
0,0140 \\
0,0087 \\
0,0049\end{array}$ & $\begin{array}{l}0,0815 \\
0,0437 \\
0,0299 \\
0,0176 \\
0,0091 \\
0,0046\end{array}$ & $\begin{array}{l}0,0673 \\
0,0396 \\
0,0280 \\
0,0169 \\
0,0089 \\
0,0046 \\
\end{array}$ & $\begin{array}{l}0,0772 \\
0,0426 \\
0,0294 \\
0,0174 \\
0,0091 \\
0,0046\end{array}$ \\
\hline $\begin{array}{l}10 \\
20 \\
30 \\
50 \\
100 \\
200 \\
\end{array}$ & 0,6 & 0,3 & $\begin{array}{l}0,2860 \\
0,2918 \\
0,2964 \\
0,2896 \\
0,2909 \\
0,2854 \\
\end{array}$ & $\begin{array}{l}0,0966 \\
0,0421 \\
0,0301 \\
0,0211 \\
0,0096 \\
0,0047\end{array}$ & $\begin{array}{l}0,0741 \\
0,0399 \\
0,0268 \\
0,0163 \\
0,0083 \\
0,0042\end{array}$ & $\begin{array}{l}0,0612 \\
0,0362 \\
0,0251 \\
0,0157 \\
0,0081 \\
0,0042 \\
\end{array}$ & $\begin{array}{l}0,0702 \\
0,0389 \\
0,0263 \\
0,0161 \\
0,0082 \\
0,0042 \\
\end{array}$ \\
\hline $\begin{array}{l}10 \\
20 \\
30 \\
50 \\
100 \\
200 \\
\end{array}$ & 0,6 & 0,4 & $\begin{array}{l}0,4081 \\
0,3987 \\
0,3698 \\
0,4123 \\
0,3783 \\
0,3803\end{array}$ & $\begin{array}{l}0,1088 \\
0,0446 \\
0,0295 \\
0,0185 \\
0,0087 \\
0,0043 \\
\end{array}$ & $\begin{array}{l}0,0622 \\
0,0343 \\
0,0241 \\
0,0136 \\
0,0073 \\
0,0036 \\
\end{array}$ & $\begin{array}{l}0,0313 \\
0,0311 \\
0,0226 \\
0,0131 \\
0,0071 \\
0,0036 \\
\end{array}$ & $\begin{array}{l}0,0389 \\
0,0334 \\
0,0237 \\
0,0134 \\
0,0072 \\
0,0036 \\
\end{array}$ \\
\hline
\end{tabular}


TABELA 6 - Média e variância do estimador de F e médias dos estimadores de $\operatorname{Var}(\hat{\mathrm{F}})$ em $\mathrm{N}=100$ experimentos com amostras de tamanhos diferentes, extraídas em populaçes de dois alelos com diversas combinaçóes de frequências gênicas e coeficientes de endogamia.

\begin{tabular}{|c|c|c|c|c|c|c|c|}
\hline$\overline{8}$ & $\bar{P}$ & $\mathbf{P}$ & $\overline{\hat{F}}$ & $\operatorname{Var}(\hat{\mathrm{P}})$ & $V \bar{A}_{1}(\hat{F})$ & $V \bar{A}_{2}(\hat{F})$ & $\mathrm{VAs}_{3}(\overline{\mathrm{F}}$ \\
\hline $\begin{array}{l}10 \\
20 \\
30 \\
50 \\
100 \\
200 \\
\end{array}$ & 0,6 & 0,5 & $\begin{array}{l}0,5143 \\
0,5055 \\
0,4960 \\
0,5136 \\
0,4987 \\
0,4971 \\
\end{array}$ & $\begin{array}{l}0,0640 \\
0,0327 \\
0,0321 \\
0,0172 \\
0,0078 \\
0,0031 \\
\end{array}$ & $\begin{array}{l}0,0543 \\
0,0277 \\
0,0186 \\
0,0108 \\
0,0056 \\
0,0028 \\
\end{array}$ & $\begin{array}{l}0,0448 \\
0,0251 \\
0,0174 \\
0,0104 \\
0,0053 \\
0,0028\end{array}$ & $\begin{array}{l}0,0515 \\
0,0270 \\
0,0183 \\
0,0107 \\
0,0056 \\
0,0028\end{array}$ \\
\hline $\begin{array}{l}10 \\
20 \\
30 \\
50 \\
100 \\
200 \\
\end{array}$ & $0, \overline{6}$ & 0,6 & $\begin{array}{l}0,3630 \\
0,5681 \\
0,6121 \\
0,5997 \\
0,6047 \\
0,6028 \\
\end{array}$ & $\begin{array}{l}0,0913 \\
0,0426 \\
0,0268 \\
0,0119 \\
0,0059 \\
0,0031 \\
\end{array}$ & $\begin{array}{l}0,0470 \\
0,0234 \\
0,0133 \\
0,0083 \\
0,0040 \\
0,0020 \\
\end{array}$ & $\begin{array}{l}0,0388 \\
0,0212 \\
0,0124 \\
0,0080 \\
0,0041 \\
0,0020\end{array}$ & $\begin{array}{l}0,0445 \\
0,0228 \\
0,0131 \\
0,0082 \\
0,0040 \\
0,0020\end{array}$ \\
\hline $\begin{array}{l}10 \\
20 \\
30 \\
50 \\
100 \\
200 \\
\end{array}$ & 0,6 & 0,7 & $\begin{array}{l}0,7258 \\
0,7150 \\
0,7093 \\
0,7053 \\
0,7021 \\
0,6990 \\
\end{array}$ & $\begin{array}{l}0,0558 \\
0,0341 \\
0,0175 \\
0,0119 \\
0,0044 \\
0,0025 \\
\end{array}$ & $\begin{array}{l}0,0288 \\
0,0137 \\
0,0089 \\
0,0053 \\
0,0026 \\
0,0013 \\
\end{array}$ & $\begin{array}{l}0,0238 \\
0,0124 \\
0,0084 \\
0,0051 \\
0,0027 \\
0,0013\end{array}$ & $\begin{array}{l}0,0273 \\
0,0134 \\
0,0088 \\
0,0053 \\
0,0026 \\
0,0013\end{array}$ \\
\hline $\begin{array}{l}10 \\
20 \\
30 \\
50 \\
100 \\
200 \\
\end{array}$ & 0,6 & 0,8 & $\begin{array}{l}0,8067 \\
0,7938 \\
0,7840 \\
0,7979 \\
0,7968 \\
0,7971 \\
\end{array}$ & $\begin{array}{l}0,0484 \\
0,0191 \\
0,0166 \\
0,0100 \\
0,0041 \\
0,0021\end{array}$ & $\begin{array}{l}0,0191 \\
0,0084 \\
0,0059 \\
0,0030 \\
0,0014 \\
0,0007 \\
\end{array}$ & $\begin{array}{l}0,0158 \\
0,0076 \\
0,0055 \\
0,0029 \\
0,0014 \\
0,0007\end{array}$ & $\begin{array}{l}0,0181 \\
0,0082 \\
0,0058 \\
0,0029 \\
0,0026 \\
0,0007 \\
\end{array}$ \\
\hline $\begin{array}{l}10 \\
20 \\
30 \\
50 \\
100 \\
200 \\
\end{array}$ & 0,6 & 0,9 & $\begin{array}{l}0,9103 \\
0,8887 \\
08930 \\
0,9036 \\
0,8900 \\
0,9012\end{array}$ & $\begin{array}{l}0,0168 \\
0,0112 \\
0,0061 \\
0,0036 \\
0,0024 \\
0,0011 \\
\end{array}$ & $\begin{array}{l}0,0074 \\
0,0036 \\
0,0019 \\
0,0020 \\
0,0005 \\
0,0002 \\
\end{array}$ & $\begin{array}{l}0,0061 \\
0,0033 \\
0,0018 \\
0,0008 \\
0,0005 \\
0,0002 \\
\end{array}$ & $\begin{array}{l}0,0070 \\
0,0035 \\
0,0019 \\
0,0009 \\
0,0005 \\
0,0002\end{array}$ \\
\hline $\begin{array}{l}10 \\
20 \\
30 \\
50 \\
100 \\
200 \\
\end{array}$ & 0,6 & 1,0 & $\begin{array}{l}1,0000 \\
0,9988 \\
0,9993 \\
0,9983 \\
0,9977 \\
0,9979 \\
\end{array}$ & $\begin{array}{l}0,0000 \\
0,0001 \\
0,0001 \\
0,0001 \\
0,0000 \\
0,0000\end{array}$ & $\begin{array}{l}0,0000 \\
0,0000 \\
0,0000 \\
0,0000 \\
0,0000 \\
0,0000\end{array}$ & $\begin{array}{l}0,0000 \\
0,0000 \\
0,0000 \\
0,0000 \\
0,0000 \\
0,0000\end{array}$ & $\begin{array}{l}0,0000 \\
0,0000 \\
0,0000 \\
0,0000 \\
0,0000 \\
0,0000\end{array}$ \\
\hline $\begin{array}{l}10 \\
20 \\
30 \\
50 \\
100 \\
-200 \\
\end{array}$ & 0,7 & 0,0 & $\begin{array}{l}-0,0048 \\
0,0415 \\
-0,0145 \\
-0,0030 \\
-0,0049 \\
-0,0205\end{array}$ & $\begin{array}{l}0,1083 \\
0,0461 \\
0,0244 \\
0,0237 \\
0,0076 \\
0,0034 \\
\end{array}$ & $\begin{array}{l}0,0833 \\
0,0468 \\
0,0323 \\
0,0193 \\
0,0099 \\
0,0050\end{array}$ & $\begin{array}{l}0,0705 \\
0,0424 \\
0,0323 \\
0,0185 \\
0,0097 \\
0,0049 \\
\end{array}$ & $\begin{array}{l}0,0810 \\
0,0456 \\
0,0318 \\
0,0191 \\
0,0098 \\
0,0050 \\
\end{array}$ \\
\hline
\end{tabular}


TABELA 6 - Média e variância do estimador de F e médias dos estimadores de $\operatorname{Var}(\hat{\mathrm{F}})$ en $\mathbf{N}=100$ experimentos com amostras de tamanhos diferentes, extraidas em populaçōes de dois alelos com diversas combinacões de frequências gênicas e coeficientes de endogamia.

\begin{tabular}{|c|c|c|c|c|c|c|c|}
\hline $\mathbf{n}$ & P & $F$ & $\hat{\mathrm{F}}$ & $\operatorname{Var}(\hat{\mathrm{F}}$ & $\overline{v a t}_{r_{1}}(\hat{F})$ & $v \overline{\hat{A}}_{2}(\hat{\mathrm{F}})$ & VĒ \\
\hline $\begin{array}{l}10 \\
20 \\
30 \\
50 \\
100 \\
200 \\
\end{array}$ & 0.7 & 0,1 & $\begin{array}{l}0,0836 \\
0,0777 \\
0,0887 \\
0,0882 \\
0,0983 \\
0,1144\end{array}$ & $\begin{array}{l}0,1084 \\
0,0679 \\
0,0452 \\
0,0177 \\
0,0100 \\
0,0058\end{array}$ & $\begin{array}{l}0,0848 \\
0,0447 \\
0,0307 \\
0,0192 \\
0,0097 \\
0,0048\end{array}$ & $\begin{array}{l}0,0700 \\
0,0405 \\
0,0287 \\
0,0185 \\
0,0093 \\
0,0048\end{array}$ & $\begin{array}{l}0,0803 \\
0,0435 \\
0,0301 \\
0,0190 \\
0,0096 \\
0,0048 \\
\end{array}$ \\
\hline $\begin{array}{l}10 \\
20 \\
30 \\
50 \\
100 \\
200 \\
\end{array}$ & 0,7 & 0,2 & $\begin{array}{l}0,1904 \\
0,1855 \\
0,2060 \\
0,1917 \\
0,1952 \\
0,1891\end{array}$ & $\begin{array}{l}0,1142 \\
0,0624 \\
0,0312 \\
0,0218 \\
0,0123 \\
0,0053 \\
\end{array}$ & $\begin{array}{l}0,0800 \\
0,0430 \\
0,0293 \\
0,0180 \\
0,0091 \\
0,0046 \\
\end{array}$ & $\begin{array}{l}0,0660 \\
0,0390 \\
0,0274 \\
0,0173 \\
0,0089 \\
0,0046 \\
\end{array}$ & $\begin{array}{l}0,0758 \\
0,0419 \\
0,0288 \\
0,0178 \\
0,0090 \\
0,0046 \\
\end{array}$ \\
\hline $\begin{array}{l}10 \\
20 \\
30 \\
50 \\
100 \\
200 \\
\end{array}$ & 0,7 & 0,3 & $\begin{array}{l}0,2364 \\
0,2674 \\
0,2809 \\
0,2841 \\
0,2828 \\
0,2962 \\
\end{array}$ & $\begin{array}{l}0,1220 \\
0,0632 \\
0,0396 \\
0,0238 \\
0,0092 \\
0,0048 \\
\end{array}$ & $\begin{array}{l}0,0739 \\
0,0396 \\
0,0270 \\
0,0164 \\
0,0084 \\
0,0041 \\
\end{array}$ & $\begin{array}{l}0,0627 \\
0,0359 \\
0,0252 \\
0,0157 \\
0,0082 \\
0,0041\end{array}$ & $\begin{array}{l}0,0719 \\
0,0386 \\
0,0265 \\
0,0162 \\
0,0083 \\
0,0041\end{array}$ \\
\hline $\begin{array}{l}10 \\
20 \\
30 \\
30 \\
100 \\
200 \\
\end{array}$ & 0,7 & 0,4 & $\begin{array}{l}0,3287 \\
0,4033 \\
0,4052 \\
0,3904 \\
0,4078 \\
0,3975 \\
\end{array}$ & $\begin{array}{l}0,1081 \\
0,0483 \\
0,0353 \\
0,0230 \\
0,0096 \\
0,0041\end{array}$ & $\begin{array}{l}0,0691 \\
0,0334 \\
0,0224 \\
0,0140 \\
0,0069 \\
0,0035 \\
\end{array}$ & $\begin{array}{l}0,0570 \\
0,0303 \\
0,0210 \\
0,0135 \\
0,0068 \\
0,0035 \\
\end{array}$ & $\begin{array}{l}0,0654 \\
0,0326 \\
0,0221 \\
0,0139 \\
0,0068 \\
0,0035 \\
\end{array}$ \\
\hline $\begin{array}{l}10 \\
20 \\
30 \\
50 \\
100 \\
200 \\
\end{array}$ & 0,7 & 0,5 & $\begin{array}{l}0,4798 \\
0,4921 \\
0,4868 \\
0,4912 \\
0,4771 \\
0,4956 \\
\end{array}$ & $\begin{array}{l}0,0959 \\
0,0456 \\
0,0252 \\
0,0157 \\
0,0091 \\
0,0035\end{array}$ & $\begin{array}{l}0,0558 \\
0,0281 \\
0,0192 \\
0,0115 \\
0,0039 \\
0,0028 \\
\end{array}$ & $\begin{array}{l}0,0461 \\
0,0255 \\
0,0180 \\
0,0110 \\
0,0058 \\
0,0028\end{array}$ & $\begin{array}{l}0,0529 \\
0,0273 \\
0,0189 \\
0,0114 \\
0,0059 \\
0,0028\end{array}$ \\
\hline $\begin{array}{l}10 \\
20 \\
30 \\
50 \\
100 \\
200 \\
\end{array}$ & 0,7 & 0,6 & $\begin{array}{l}0,5633 \\
0,5421 \\
0,5900 \\
0,6085 \\
0,5828 \\
0,5984 \\
\end{array}$ & $\begin{array}{l}0,0925 \\
0,0364 \\
0,0289 \\
0,0158 \\
0,0076 \\
0,0041\end{array}$ & $\begin{array}{l}0,0450 \\
0,0252 \\
0,0144 \\
0,0081 \\
0,0044 \\
0,0021 \\
\end{array}$ & $\begin{array}{l}0,0371 \\
0,0228 \\
0,0133 \\
0,0077 \\
0,0043 \\
0,0020 \\
\end{array}$ & $\begin{array}{l}0,0426 \\
0,0245 \\
0,0142 \\
0,0080 \\
0,0044 \\
0,0021\end{array}$ \\
\hline $\begin{array}{l}10 \\
20 \\
30 \\
50 \\
100 \\
200\end{array}$ & 0,7 &, 07 & $\begin{array}{l}0,6930 \\
0,7009 \\
0,6751 \\
0,6895 \\
0,6769 \\
0,6975\end{array}$ & $\begin{array}{l}0,0739 \\
0,0293 \\
0,0206 \\
0,0123 \\
0,0066 \\
0,0042\end{array}$ & $\begin{array}{l}0,0286 \\
0,0144 \\
0,0104 \\
0,0058 \\
0,0030 \\
0,0013\end{array}$ & $\begin{array}{l}0,0236 \\
0,0131 \\
0,0097 \\
0,0059 \\
0,0029 \\
0,0013\end{array}$ & $\begin{array}{l}0,0271 \\
0,0140 \\
0,0102 \\
0,0057 \\
0,0030 \\
0,0013\end{array}$ \\
\hline
\end{tabular}


TABELA 6 - Média e variância do estimador de $F$ e médias dos estimadores de $\operatorname{Var}(\hat{\mathrm{F}})$ em $\mathrm{N}=100$ experimentos com amostras de tamanhos diferentes, extraidas em populą̧ōes de dois alelos com diversas combinacöes de frequências genicas e coeficientes de endogamia.

\begin{tabular}{|c|c|c|c|c|c|c|c|}
\hline $\mathbf{n}$ & P & $\bar{F}$ & $\hat{\mathbf{F}}$ & $\operatorname{Var}(\hat{\mathrm{F}}$ & $\bar{v}_{r_{j}}(\hat{\mathbf{F}}$ & $\bar{v}_{\bar{z}}(\hat{F}$ & $\bar{v} \overline{r_{3}}$ \\
\hline $\begin{array}{l}10 \\
20 \\
30 \\
50 \\
100 \\
200 \\
\end{array}$ & 0,7 & 0,8 & $\begin{array}{l}0,7536 \\
0,8111 \\
0,7856 \\
0,7785 \\
0,7987 \\
0,7913 \\
\end{array}$ & $\begin{array}{l}0,0770 \\
0,0332 \\
0,0200 \\
0,0107 \\
0,0043 \\
0,0024\end{array}$ & $\begin{array}{l}0,0227 \\
0,0078 \\
0,0060 \\
0,0034 \\
0,0014 \\
0,0007\end{array}$ & $\begin{array}{l}0,0187 \\
0,0070 \\
0,0056 \\
0,0033 \\
0,0014 \\
0,0007\end{array}$ & $\begin{array}{l}0,0215 \\
0,0076 \\
0,0059 \\
0,0034 \\
0,0014 \\
0,0007\end{array}$ \\
\hline $\begin{array}{l}10 \\
20 \\
30 \\
50 \\
100 \\
200 \\
\end{array}$ & 0,7 & 0,9 & $\begin{array}{l}0,8922 \\
0,8964 \\
0,8880 \\
0,8934 \\
0,9028 \\
0,9026 \\
\end{array}$ & $\begin{array}{l}0,0322 \\
0,0148 \\
0,0083 \\
0,0056 \\
0,0021 \\
0,0011\end{array}$ & $\begin{array}{l}0,0103 \\
0,0037 \\
0,0022 \\
0,0011 \\
0,0004 \\
0,0002 \\
\end{array}$ & $\begin{array}{l}0,0085 \\
0,0034 \\
0,0021 \\
0,0011 \\
0,0040 \\
0,0002 \\
\end{array}$ & $\begin{array}{l}0,0097 \\
0,0036 \\
0,0022 \\
0,0011 \\
0,0004 \\
0,0002\end{array}$ \\
\hline $\begin{array}{l}10 \\
20 \\
30 \\
50 \\
100 \\
200 \\
\end{array}$ & 0,7 & 1,0 & $\begin{array}{l}0,9682 \\
0,9978 \\
0,9978 \\
0,9950 \\
0,9983 \\
0,9972 \\
\end{array}$ & $\begin{array}{l}0,0296 \\
0,0002 \\
0,0003 \\
0,0002 \\
0,0000 \\
0,0000\end{array}$ & $\begin{array}{l}0,0001 \\
0,0000 \\
0,0000 \\
0,0000 \\
0,0000 \\
0,0000 \\
\end{array}$ & $\begin{array}{l}0,0001 \\
0,0000 \\
0,0000 \\
0,0000 \\
0,0000 \\
0,0000 \\
\end{array}$ & $\begin{array}{l}0,0001 \\
0,0000 \\
0,0000 \\
0,0000 \\
0,0000 \\
0,0000\end{array}$ \\
\hline $\begin{array}{l}10 \\
20 \\
30 \\
50 \\
100 \\
200 \\
\end{array}$ & 0,8 & 0,0 & $\begin{array}{l}-0,0066 \\
0,0160 \\
0,0205 \\
-0,0203 \\
-0,0268 \\
-0,0064\end{array}$ & $\begin{array}{l}0,0657 \\
0,0515 \\
0,0454 \\
0,0166 \\
0,0111 \\
0,0052\end{array}$ & $\begin{array}{l}0,0939 \\
0,0464 \\
0,0310 \\
0,0195 \\
0,0098 \\
0,0050 \\
\end{array}$ & $\begin{array}{l}0,0775 \\
0,0421 \\
0,0290 \\
0,0188 \\
0,0096 \\
0,0049 \\
\end{array}$ & $\begin{array}{l}0,0890 \\
0,0452 \\
0,0305 \\
0,0193 \\
0,0098 \\
0,0050\end{array}$ \\
\hline $\begin{array}{l}10 \\
20 \\
30 \\
50 \\
100 \\
200 \\
\end{array}$ & 0,8 & 0,1 & $\begin{array}{l}0,0635 \\
0,0712 \\
0,1020 \\
0,0968 \\
0,0879 \\
0,1010\end{array}$ & $\begin{array}{l}0,0956 \\
0,0491 \\
0,0405 \\
0,0248 \\
0,0117 \\
0,0046\end{array}$ & $\begin{array}{l}0,0874 \\
0,0462 \\
0,0308 \\
0,0189 \\
0,0097 \\
0,0049 \\
\end{array}$ & $\begin{array}{l}0,0721 \\
0,0419 \\
0,0288 \\
0,0182 \\
0,0099 \\
0,0048\end{array}$ & $\begin{array}{l}0,0828 \\
0,0451 \\
0,0303 \\
0,0187 \\
0,0096 \\
0,0049\end{array}$ \\
\hline $\begin{array}{l}10 \\
20 \\
30 \\
50 \\
100 \\
200 \\
\end{array}$ & 0,8 & 0,2 & $\begin{array}{l}0,1212 \\
0,2110 \\
0,1811 \\
0,1785 \\
0,1715 \\
0,1954 \\
\end{array}$ & $\begin{array}{l}0,1236 \\
0,0732 \\
0,0467 \\
0,0259 \\
0,0139 \\
0,0060 \\
\end{array}$ & $\begin{array}{l}0,0818 \\
0,0414 \\
0,0291 \\
0,0180 \\
0,0092 \\
0,0046 \\
\end{array}$ & $\begin{array}{l}0,0675 \\
0,0376 \\
0,0273 \\
0,0173 \\
0,0090 \\
0,0045\end{array}$ & $\begin{array}{l}0,0775 \\
0,0404 \\
0,0286 \\
0,0178 \\
0,0092 \\
0,0046 \\
\end{array}$ \\
\hline $\begin{array}{l}10 \\
20 \\
30 \\
50 \\
100 \\
200 \\
\end{array}$ & 0,8 & 0,3 & $\begin{array}{l}0,1786 \\
0,2406 \\
0,2603 \\
0,3175 \\
0,2951 \\
0,3064 \\
\end{array}$ & $\begin{array}{l}0,1177 \\
0,0761 \\
0,0389 \\
0,0287 \\
0,0145 \\
0,0071 \\
\end{array}$ & $\begin{array}{l}0,0802 \\
0,0396 \\
0,0276 \\
0,0156 \\
0,0082 \\
0,0041 \\
\end{array}$ & $\begin{array}{l}0,0662 \\
0,0359 \\
0,0258 \\
0,0150 \\
0,0080 \\
0,0040\end{array}$ & $\begin{array}{l}0,0760 \\
0,0386 \\
0,0271 \\
0,0154 \\
0,0081 \\
0,0041\end{array}$ \\
\hline
\end{tabular}


TABELA 6 - Média e variância do estimador de F e médias dos estimadores de $\operatorname{Var}(\hat{\mathrm{F}})$ em $\mathrm{N}=100$ experimentos com amostras de tamanhos diferentes, extraidas em populegōes de dois alelos com diversas combinacốes de freauências aênicas e coeficientes de endogamia

\begin{tabular}{|c|c|c|c|c|c|c|c|}
\hline n & $\mathbf{p}$ & $\mathbf{F}$ & $\overline{\hat{F}}$ & $\operatorname{Var}(\hat{\mathrm{F}}$ & $\operatorname{Vá}_{1}(\hat{F})$ & $V^{\bar{a}} \tilde{s}_{2}(\hat{F})$ & $\mathrm{va}_{\mathrm{A}_{3}} \hat{\mathrm{F}}$ \\
\hline $\begin{array}{l}10 \\
20 \\
30 \\
30 \\
100 \\
200 \\
\end{array}$ & 0,8 & 0,4 & $\begin{array}{l}0,2512 \\
0,3992 \\
0,3826 \\
0,4117 \\
0,4004 \\
0,3933 \\
\end{array}$ & $\begin{array}{l}0,1198 \\
0,0638 \\
0,0551 \\
0,0274 \\
0,0139 \\
0,0065\end{array}$ & $\begin{array}{l}0,0720 \\
0,0328 \\
0,0228 \\
0,0133 \\
0,0069 \\
0,0035\end{array}$ & $\begin{array}{l}0,0594 \\
0,0298 \\
0,0213 \\
0,0128 \\
0,0069 \\
0,0035\end{array}$ & $\begin{array}{l}0,0682 \\
0,0320 \\
0,0224 \\
0,0132 \\
0,0069 \\
0,0035\end{array}$ \\
\hline $\begin{array}{l}10 \\
20 \\
30 \\
50 \\
100 \\
200 \\
\end{array}$ & 0,8 & 0,5 & $\begin{array}{l}0,3886 \\
0,4203 \\
0,4644 \\
0,4828 \\
0,5174 \\
0,4861\end{array}$ & $\begin{array}{l}0,1264 \\
0,0648 \\
0,0512 \\
0,0230 \\
0,0117 \\
0,0064 \\
\end{array}$ & $\begin{array}{l}0,0599 \\
0,0316 \\
0,0196 \\
0,0116 \\
0,0053 \\
0,0029 \\
\end{array}$ & $\begin{array}{l}0,0495 \\
0,0287 \\
0,0183 \\
0,0112 \\
0,0052 \\
0,0029 \\
\end{array}$ & $\begin{array}{l}0,0568 \\
0,0308 \\
0,0193 \\
0,0115 \\
0,0053 \\
0,0029 \\
\end{array}$ \\
\hline $\begin{array}{l}10 \\
20 \\
30 \\
50 \\
100 \\
200 \\
\end{array}$ & 08 & 0,6 & $\begin{array}{l}0,4746 \\
0,5311 \\
0,5834 \\
0,6214 \\
0,5921 \\
0,6104\end{array}$ & $\begin{array}{l}0,1430 \\
0,0731 \\
0,0430 \\
0,0222 \\
0,0117 \\
0,0055 \\
\end{array}$ & $\begin{array}{l}0,0499 \\
0,0250 \\
0,0147 \\
0,0077 \\
0,0043 \\
0,0020\end{array}$ & $\begin{array}{l}0,0412 \\
0,0227 \\
0,0138 \\
0,0074 \\
0,0042 \\
0,0020 \\
\end{array}$ & $\begin{array}{l}0,0473 \\
0,0243 \\
0,0144 \\
0,0077 \\
0,0042 \\
0,0020\end{array}$ \\
\hline $\begin{array}{l}10 \\
20 \\
30 \\
50 \\
100 \\
200 \\
\end{array}$ & 0,8 & 0,7 & $\begin{array}{l}0,0,5505 \\
0,6745 \\
0,6590 \\
0,7169 \\
0,6872 \\
0,6966 \\
\end{array}$ & $\begin{array}{l}0,1310 \\
0,0605 \\
0,0402 \\
0,0141 \\
0,0116 \\
0,0043 \\
\end{array}$ & $\begin{array}{l}0,0304 \\
0,0164 \\
0,0112 \\
0,0051 \\
0,0029 \\
0,0013\end{array}$ & $\begin{array}{l}0,0231 \\
0,0149 \\
0,0105 \\
0,0049 \\
0,0028 \\
0,0013 \\
\end{array}$ & $\begin{array}{l}0,0288 \\
0,0160 \\
0,0110 \\
0,0050 \\
0,0028 \\
0,0013 \\
\end{array}$ \\
\hline $\begin{array}{l}10 \\
20 \\
30 \\
50 \\
100 \\
200 \\
\end{array}$ & 0,8 & 0,8 & $\begin{array}{l}0,6898 \\
0,7831 \\
0,7512 \\
0,7931 \\
0,7787 \\
0,7857\end{array}$ & $\begin{array}{l}0,1289 \\
0,0454 \\
0,0349 \\
0,0121 \\
0,0063 \\
0,0031 \\
\end{array}$ & $\begin{array}{l}0,0273 \\
0,0101 \\
0,0076 \\
0,0032 \\
0,0017 \\
0,0008\end{array}$ & $\begin{array}{l}0,0225 \\
0,0002 \\
0,0071 \\
0,0031 \\
0,0016 \\
0,0008 \\
\end{array}$ & $\begin{array}{l}0,00259 \\
0,0090 \\
0,0074 \\
0,0032 \\
0,0016 \\
0,0008 \\
\end{array}$ \\
\hline $\begin{array}{l}10 \\
20 \\
30 \\
50 \\
100 \\
200 \\
\end{array}$ & 0,8 & 0,9 & $\begin{array}{l}0,8791 \\
0,8956 \\
0,9023 \\
0,8834 \\
0,8977 \\
0,8956 \\
\end{array}$ & $\begin{array}{l}0,0436 \\
0,0355 \\
0,0084 \\
0,0060 \\
0,0034 \\
0,0017\end{array}$ & $\begin{array}{l}0,0093 \\
0,0044 \\
0,0019 \\
0,0013 \\
0,0005 \\
0,0002 \\
\end{array}$ & $\begin{array}{l}0,0077 \\
0,0040 \\
0,0018 \\
0,0012 \\
0,0005 \\
0,0002\end{array}$ & $\begin{array}{l}0,0088 \\
0,0043 \\
0,0019 \\
0,0013 \\
0,0005 \\
0,0002 \\
\end{array}$ \\
\hline $\begin{array}{l}10 \\
20 \\
30 \\
50 \\
100 \\
200 \\
\end{array}$ & 0,8 & 1,0 & $\begin{array}{l}0,8856 \\
0,9886 \\
0,9978 \\
0,9941 \\
0,9964 \\
0,9969 \\
\end{array}$ & $\begin{array}{l}0,0989 \\
0,0102 \\
0,0002 \\
0,0004 \\
0,0001 \\
0,0000 \\
\end{array}$ & $\begin{array}{l}0,0014 \\
0,0001 \\
0,0000 \\
0,0000 \\
0,0000 \\
0,0000 \\
\end{array}$ & $\begin{array}{l}0,0011 \\
0,0000 \\
0,0000 \\
0,0000 \\
0,0000 \\
0,0000 \\
\end{array}$ & $\begin{array}{l}0,0013 \\
0,0000 \\
0,0000 \\
0,0000 \\
0,0000 \\
0,0000\end{array}$ \\
\hline
\end{tabular}


TABELA 6 - Média e variância do extimador de $F$ e médias dos estimadores de $\operatorname{Var}(\hat{\mathrm{F}})$ em $\mathrm{N}=100$ experimentos com amostras de tamanhos diferentes, extraídas em populacões de dois alelos com diversas combinaç̃os de frequências gênicas e coeficientes de endogamia.

\begin{tabular}{|c|c|c|c|c|c|c|c|}
\hline$\overline{8}$ & $\mathbf{p}$ & $\bar{F}$ & $\overline{\hat{\mathrm{F}}}$ & $\operatorname{Var}(\hat{F}$ & $\bar{v} \bar{a}_{r_{1}}(\hat{F}$ & $\bar{V} \bar{x}_{2}(f)$ & $\bar{V}_{\hat{S}_{3}}(\hat{F}$ \\
\hline $\begin{array}{l}10 \\
20 \\
30 \\
50 \\
100 \\
200 \\
\end{array}$ & 0,9 & 0,0 & $\begin{array}{l}-0,0264 \\
-0,0235 \\
-0,0177 \\
-0,0033 \\
-0,0017 \\
-0,0148\end{array}$ & $\begin{array}{l}0,0201 \\
0,0243 \\
0,0239 \\
0,0195 \\
0,0117 \\
0,0045 \\
\end{array}$ & $\begin{array}{l}0,0880 \\
0,0480 \\
0,0324 \\
0,0195 \\
0,0098 \\
0,0050\end{array}$ & $\begin{array}{l}0,0726 \\
0,0435 \\
0,0303 \\
0,0187 \\
0,0096 \\
0,0049 \\
\end{array}$ & $\begin{array}{l}0,0834 \\
0,0468 \\
0,0318 \\
0,0193 \\
0,0098 \\
0,0050 \\
\end{array}$ \\
\hline $\begin{array}{l}10 \\
20 \\
30 \\
50 \\
100 \\
200 \\
\end{array}$ & 0,9 & 0,1 & $\begin{array}{l}0,0578 \\
0,0366 \\
0,0966 \\
0,0889 \\
0,0744 \\
0,0785\end{array}$ & $\begin{array}{l}0,0756 \\
0,0361 \\
0,0669 \\
0,0310 \\
0,0167 \\
0,0062\end{array}$ & $\begin{array}{l}0,0829 \\
0,0468 \\
0,0299 \\
0,0187 \\
0,0096 \\
0,0049 \\
\end{array}$ & $\begin{array}{l}0,0684 \\
0,0425 \\
0,0280 \\
0,0180 \\
0,0094 \\
0,0048\end{array}$ & $\begin{array}{l}0,0785 \\
0,0456 \\
0,0294 \\
0,0186 \\
0,0096 \\
0,0049\end{array}$ \\
\hline $\begin{array}{l}10 \\
20 \\
30 \\
50 \\
100 \\
200 \\
\end{array}$ & 0,9 & 0,2 & $\begin{array}{l}0,1009 \\
0,1402 \\
0,1688 \\
0,1563 \\
0,1540 \\
0,1983\end{array}$ & $\begin{array}{l}0,0940 \\
0,0790 \\
0,0614 \\
0,0408 \\
0,0180 \\
0,0087 \\
\end{array}$ & $\begin{array}{l}0,0743 \\
0,0430 \\
0,0282 \\
0,0178 \\
0,0093 \\
0,0046 \\
\end{array}$ & $\begin{array}{l}0,0613 \\
0,0390 \\
0,0264 \\
0,0171 \\
0,0091 \\
0,0045 \\
\end{array}$ & $\begin{array}{l}0,0704 \\
0,0419 \\
0,0277 \\
0,0177 \\
0,0092 \\
0,0045\end{array}$ \\
\hline $\begin{array}{l}10 \\
20 \\
30 \\
50 \\
100 \\
200 \\
\end{array}$ & 0,9 & 0,3 & $\begin{array}{l}0,1298 \\
0,1876 \\
0,2989 \\
0,2647 \\
0,2603 \\
0,3035 \\
\end{array}$ & $\begin{array}{l}0,1004 \\
0,1062 \\
0,0758 \\
0,0437 \\
0,0225 \\
0,0135 \\
\end{array}$ & $\begin{array}{l}0,0721 \\
0,0399 \\
0,0246 \\
0,0162 \\
0,0084 \\
0,0040\end{array}$ & $\begin{array}{l}0,0595 \\
0,0361 \\
0,0230 \\
0,0156 \\
0,0082 \\
0,0040 \\
\end{array}$ & $\begin{array}{l}0,0683 \\
0,0389 \\
0,0241 \\
0,0161 \\
0,0083 \\
0,0040\end{array}$ \\
\hline $\begin{array}{l}10 \\
20 \\
30 \\
50 \\
100 \\
200 \\
\end{array}$ & 0,9 & 0,4 & $\begin{array}{l}0,2055 \\
0,3540 \\
0,3337 \\
0,3729 \\
0,3720 \\
0,4026\end{array}$ & $\begin{array}{l}0,1385 \\
0,1376 \\
0,0900 \\
0,0437 \\
0,0285 \\
0,0136\end{array}$ & $\begin{array}{l}0,0652 \\
0,0297 \\
0,0227 \\
0,0140 \\
0,0071 \\
0,0034 \\
\end{array}$ & $\begin{array}{l}0,0538 \\
0,0269 \\
0,0212 \\
0,0134 \\
0,0070 \\
0,0034\end{array}$ & $\begin{array}{l}0,0617 \\
0,0289 \\
0,0233 \\
0,0138 \\
0,0071 \\
0,0034 \\
\end{array}$ \\
\hline $\begin{array}{l}10 \\
20 \\
30 \\
50 \\
100 \\
200 \\
\end{array}$ & 0,9 & 0,3 & $\begin{array}{l}0,2475 \\
0,4280 \\
0,4444 \\
0,4775 \\
0,4753 \\
0,5069\end{array}$ & $\begin{array}{l}0,1626 \\
0,1377 \\
0,0844 \\
0,0475 \\
0,0244 \\
0,0092 \\
\end{array}$ & $\begin{array}{l}0,0517 \\
0,0279 \\
0,0197 \\
0,0114 \\
0,0058 \\
0,0027 \\
\end{array}$ & $\begin{array}{l}0,0426 \\
0,0253 \\
0,0183 \\
0,0109 \\
0,0057 \\
0,0027 \\
\end{array}$ & $\begin{array}{l}0,0489 \\
0,0272 \\
0,0194 \\
0,0113 \\
0,0058 \\
0,0027 \\
\end{array}$ \\
\hline $\begin{array}{l}10 \\
20 \\
30 \\
50 \\
100 \\
200 \\
\end{array}$ & 0,9 & 0,6 & $\begin{array}{l}0,4037 \\
0,4684 \\
0,5600 \\
0,5849 \\
0,5977 \\
0,5914\end{array}$ & $\begin{array}{l}0,2012 \\
0,1389 \\
0,1018 \\
0,0421 \\
0,0243 \\
0,0114 \\
\end{array}$ & $\begin{array}{l}0,0412 \\
0,0255 \\
0,0143 \\
0,0088 \\
0,0042 \\
0,0021 \\
\end{array}$ & $\begin{array}{l}0,0340 \\
0,0231 \\
0,0134 \\
0,0084 \\
0,0041 \\
0,0021\end{array}$ & $\begin{array}{l}0,0391 \\
0,0248 \\
0,0140 \\
0,0087 \\
0,0042 \\
0,0021\end{array}$ \\
\hline
\end{tabular}


TABELA 6 - Média e variância do estimedor de F e médias dos estimadores de $\operatorname{Var}(\hat{\mathrm{F}})$ em $\mathrm{N}=100$ experimentos com amostras de tamanhos diferentes, extraidas em populacỏes de dois alelos com diversas combinações de frequências gênicas e coeficientes de endogamia.

\begin{tabular}{|c|c|c|c|c|c|c|c|}
\hline n & $\mathbf{P}$ & $\mathbf{F}$ & $\overline{\hat{F}}$ & $\operatorname{Var}$ & $V \bar{Q}_{i}(\hat{F})$ & V能 $(\hat{F}$ & $V \bar{A}_{3}$ \\
\hline $\begin{array}{l}10 \\
20 \\
30 \\
50 \\
100 \\
200 \\
\end{array}$ & 0,9 & 0,7 & $\begin{array}{l}0,5024 \\
0,5918 \\
0,6334 \\
0,6829 \\
0,6833 \\
0,7016\end{array}$ & $\begin{array}{l}0,2170 \\
0,1280 \\
0,0833 \\
0,0486 \\
0,0214 \\
0,0081\end{array}$ & $\begin{array}{l}0,0275 \\
0,0190 \\
0,0117 \\
0,0061 \\
0,0030 \\
0,0013\end{array}$ & $\begin{array}{l}0,0227 \\
0,0172 \\
0,0109 \\
0,0059 \\
0,0029 \\
0,0013\end{array}$ & $\begin{array}{l}0,0261 \\
0,0185 \\
0,0115 \\
0,0060 \\
0,0030 \\
0,0013 \\
\end{array}$ \\
\hline $\begin{array}{l}10 \\
20 \\
30 \\
50 \\
100 \\
200 \\
\end{array}$ & 0,9 & 0,8 & $\begin{array}{l}0,5109 \\
0,6895 \\
0,7263 \\
0,8208 \\
0,7895 \\
0,7908 \\
\end{array}$ & $\begin{array}{l}0,2127 \\
0,1330 \\
0,0711 \\
0,0310 \\
0,0118 \\
0,0042\end{array}$ & $\begin{array}{l}0,0199 \\
0,0118 \\
0,0079 \\
0,0028 \\
0,0016 \\
0,0007\end{array}$ & $\begin{array}{l}0,0164 \\
0,0107 \\
0,0074 \\
0,0027 \\
0,0016 \\
0,0007\end{array}$ & $\begin{array}{l}0,0189 \\
0,0115 \\
0,0078 \\
0,0028 \\
0,0016 \\
0,0007\end{array}$ \\
\hline $\begin{array}{l}10 \\
20 \\
30 \\
50 \\
100 \\
200 \\
\end{array}$ & 0,9 & 0,9 & $\begin{array}{l}0,6133 \\
0,8186 \\
0,8290 \\
0,9170 \\
0,8805 \\
0,8884 \\
\end{array}$ & $\begin{array}{l}0,2171 \\
0,0968 \\
0,0709 \\
0,0089 \\
0,0065 \\
0,0026\end{array}$ & $\begin{array}{l}0,0098 \\
0,0063 \\
0,0040 \\
0,0010 \\
0,0007 \\
0,0003\end{array}$ & $\begin{array}{l}0,0081 \\
0,0057 \\
0,0038 \\
0,0010 \\
0,0006 \\
0,0002\end{array}$ & $\begin{array}{l}0,0093 \\
0,0061 \\
0,0040 \\
0,0010 \\
0,0007 \\
0,0002\end{array}$ \\
\hline $\begin{array}{l}10 \\
20 \\
30 \\
50 \\
100 \\
200\end{array}$ & 0,9 & 1,0 & $\begin{array}{l}0,6876 \\
0,8586 \\
0,9769 \\
0,9982 \\
0,9972 \\
0,9938\end{array}$ & $\begin{array}{l}0,2151 \\
0,1214 \\
0,0202 \\
0,0002 \\
0,0002 \\
0,0002\end{array}$ & $\begin{array}{l}0,0002 \\
0,0001 \\
0,0000 \\
0,0000 \\
0,0000 \\
0,0000\end{array}$ & $\begin{array}{l}0,0002 \\
0,0000 \\
0,0000 \\
0,0000 \\
0,0000 \\
0,0000\end{array}$ & $\begin{array}{l}0,0002 \\
0,0000 \\
0,0000 \\
0,0000 \\
0,03000 \\
0,0000\end{array}$ \\
\hline
\end{tabular}


TABELA 7 - Valor esperado e variéncia das estimativas do coeficiente de endogamia (F) e ds taxa de fecundagao cruzads ( $t$ ) em populagóes de dois alelos com diversos valores de coeficiente de endogamia, considerando amostras com diferentes tamanhos, obtidos através das expressóes encorturadas pelo o desenvolvimento em série de Taylor.

\begin{tabular}{|c|c|c|c|c|c|c|}
\hline a & $\bar{F}$ & 2 & $E(\hat{F})$ & $\operatorname{Var}_{p}(\hat{F})$ & $E(\hat{t})$ & $\operatorname{Ver}_{p}(\hat{t})$ \\
\hline $\begin{array}{c}10 \\
20 \\
30 \\
50 \\
100 \\
200 \\
\end{array}$ & 0,0 & 1,0 & $\begin{array}{l}0,0 \\
0,0 \\
0,0 \\
0,0 \\
0,0 \\
0,0\end{array}$ & $\begin{array}{l}0,1000 \\
0,0500 \\
0,0333 \\
0,0200 \\
0,0100 \\
0,0050 \\
\end{array}$ & $\begin{array}{l}1,0 \\
1,0 \\
1,0 \\
1,0 \\
1,0 \\
1,0\end{array}$ & $\begin{array}{l}0,4000 \\
0,2000 \\
0,1333 \\
0,0000 \\
0,0400 \\
0,0200\end{array}$ \\
\hline $\begin{array}{c}10 \\
20 \\
30 \\
50 \\
100 \\
200 \\
\end{array}$ & 0,1 & 0,8182 & $\begin{array}{l}0,0901 \\
0,0951 \\
0,0967 \\
0,0980 \\
0,0990 \\
0,0995 \\
\end{array}$ & $\begin{array}{l}0,0980 \\
0,0490 \\
0,0327 \\
0,0196 \\
0,0098 \\
0,0049 \\
\end{array}$ & $\begin{array}{l}0,9860 \\
0,5009 \\
0,8732 \\
0,8511 \\
0,8420 \\
0,8264\end{array}$ & $\begin{array}{l}0,2678 \\
0,1339 \\
0,0893 \\
0,0536 \\
0,0268 \\
0,0134\end{array}$ \\
\hline $\begin{array}{c}10 \\
20 \\
30 \\
50 \\
100 \\
200 \\
\end{array}$ & 0,2 & 0,6667 & $\begin{array}{l}0,1808 \\
0,1904 \\
0,1936 \\
0,1962 \\
0,1981 \\
0,1990 \\
\end{array}$ & $\begin{array}{l}0,09222 \\
0,0461 \\
0,0307 \\
0,0184 \\
0,0092 \\
0,0046 \\
\end{array}$ & $\begin{array}{l}0,8058 \\
0,7348 \\
0,7117 \\
0,6935 \\
0,6800 \\
0,6734 \\
\end{array}$ & $\begin{array}{l}0,1778 \\
0,0889 \\
0,0593 \\
0,0356 \\
0,0178 \\
0,0089 \\
\end{array}$ \\
\hline $\begin{array}{c}10 \\
20 \\
30 \\
50 \\
100 \\
200 \\
\end{array}$ & 0,3 & 0,5383 & $\begin{array}{l}0,2727 \\
0,2864 \\
0,2909 \\
0,2945 \\
0,2973 \\
0,2986 \\
\end{array}$ & $\begin{array}{l}0,0828 \\
0,0414 \\
0,0276 \\
0,0166 \\
0,0083 \\
0,0041 \\
\end{array}$ & $\begin{array}{l}0,6518 \\
0,5936 \\
0,5750 \\
0,5603 \\
0,5493 \\
0,5739 \\
\end{array}$ & $\begin{array}{l}0,1160 \\
0,0580 \\
0,0387 \\
0,0232 \\
0,0116 \\
0,0058\end{array}$ \\
\hline $\begin{array}{c}10 \\
20 \\
30 \\
50 \\
100 \\
200 \\
\end{array}$ & 0,4 & 0,4286 & $\begin{array}{l}0,3664 \\
0,3832 \\
0,3888 \\
0,3933 \\
0,3966 \\
0,3983 \\
\end{array}$ & $\begin{array}{l}0,0706 \\
0,0353 \\
0,0235 \\
0,0141 \\
0,0071 \\
0,0035 \\
\end{array}$ & $\begin{array}{l}0,5190 \\
0,4726 \\
0,4576 \\
0,4459 \\
0,4373 \\
0,4329 \\
\end{array}$ & $\begin{array}{l}0,0735 \\
0,0367 \\
0,0245 \\
0,0147 \\
0,0073 \\
0,0037\end{array}$ \\
\hline
\end{tabular}

$\operatorname{Var}_{\mathrm{p}}(\hat{F})$ : Verimais de $\hat{F}$ valizando se o valor permitrico de $P$;

$\operatorname{Var}_{p}(\hat{t})$ : Verioncis de $\hat{t}$ utilizando-se o valor perrinterico de $t$ 
TABELA 7 - Valor esperado e variância das estimstivas do coeficiente de endogamia (F) e da taxa de fecundaçåo cruzada ( $t$ ) em populaços de dois alelos com diversos valores de coeficiente de endogarmia, considerando amostras com diferentes tamanhos, obtidos através das expressőes encontradas pelo o desenvolvimento em série de Taylor.

\begin{tabular}{|c|c|c|c|c|c|c|}
\hline n & $\overline{\mathbf{F}}$ & $t$ & $E(\hat{F})$ & $\mathrm{Ver}_{\mathrm{p}}(\hat{\mathrm{F}})$ & $\mathbf{E}(\hat{\mathbf{t}})$ & $\operatorname{Ver}_{p}(\hat{t})$ \\
\hline $\begin{array}{c}10 \\
20 \\
30 \\
50 \\
100 \\
200 \\
\end{array}$ & 0,5 & 0.3333 & $\begin{array}{l}0,4625 \\
0,4813 \\
0,4875 \\
0,4925 \\
0,4963 \\
0,4981 \\
\end{array}$ & $\begin{array}{l}0,0563 \\
0,0281 \\
0,0188 \\
0,0113 \\
0,0056 \\
0,0028\end{array}$ & $\begin{array}{l}0,4035 \\
0,3675 \\
0,3560 \\
0,3468 \\
0,3400 \\
0,3367\end{array}$ & $\begin{array}{l}0,0444 \\
0,0222 \\
0,0148 \\
0,0089 \\
0,0044 \\
0,0022\end{array}$ \\
\hline $\begin{array}{c}10 \\
20 \\
30 \\
50 \\
100 \\
200 \\
\end{array}$ & 0,6 & 0,2500 & $\begin{array}{l}0,5616 \\
0,5808 \\
0,5872 \\
0,5923 \\
0,5962 \\
0,5981\end{array}$ & $\begin{array}{l}0,0410 \\
0,0205 \\
0,0137 \\
0,0082 \\
0,0041 \\
0,0020 \\
\end{array}$ & $\begin{array}{l}0,3023 \\
0,2756 \\
0,2669 \\
0,2601 \\
0,2550 \\
0,2525 \\
\end{array}$ & $\begin{array}{l}0,0250 \\
0,0125 \\
0,0083 \\
0,0050 \\
0,0025 \\
0,0013\end{array}$ \\
\hline $\begin{array}{c}10 \\
20 \\
30 \\
50 \\
100 \\
200 \\
\end{array}$ & 0,7 & 0,1765 & $\begin{array}{l}0,6643 \\
0,6822 \\
0,6881 \\
0,6929 \\
0,6964 \\
0,6982 \\
\end{array}$ & $\begin{array}{l}0,0260 \\
0,0130 \\
0,0087 \\
0,0052 \\
0,0026 \\
0,0013 \\
\end{array}$ & $\begin{array}{l}0,2130 \\
0,1944 \\
0,1884 \\
0,1835 \\
0,1800 \\
0,1782\end{array}$ & $\begin{array}{l}0,0125 \\
0,0062 \\
0,0042 \\
0,0025 \\
0,0012 \\
0,0006\end{array}$ \\
\hline $\begin{array}{c}10 \\
20 \\
30 \\
50 \\
100 \\
200 \\
\end{array}$ & 0,8 & 0,1111 & $\begin{array}{l}0,7712 \\
0,7856 \\
0,7904 \\
0,7942 \\
0,7971 \\
0,7986 \\
\end{array}$ & $\begin{array}{l}0,0130 \\
0,0065 \\
0,0043 \\
0,0026 \\
0,0013 \\
0,0006\end{array}$ & $\begin{array}{l}0,1339 \\
0,1224 \\
0,1186 \\
0,1156 \\
0,1134 \\
0,1122 \\
\end{array}$ & $\begin{array}{l}0,0049 \\
0,0025 \\
0,0016 \\
0,0010 \\
0,0005 \\
0,0002\end{array}$ \\
\hline $\begin{array}{c}10 \\
20 \\
30 \\
50 \\
100 \\
200 \\
\end{array}$ & 0,9 & 0,0526 & $\begin{array}{l}0,8829 \\
0,8915 \\
0,8943 \\
0,8966 \\
0,8983 \\
0,8991\end{array}$ & $\begin{array}{l}0,0036 \\
0,0018 \\
0,0012 \\
0,0007 \\
0,0004 \\
0,0002\end{array}$ & $\begin{array}{l}0,0633 \\
0,0579 \\
0,0562 \\
0,0547 \\
0,0537 \\
0,0532 \\
\end{array}$ & $\begin{array}{l}0,0011 \\
0,0006 \\
0,0004 \\
0,0002 \\
0,0001 \\
0,0001\end{array}$ \\
\hline $\begin{array}{c}10 \\
20 \\
30 \\
50 \\
100 \\
200 \\
\end{array}$ & 1,0 & 0,0 & $\begin{array}{l}1,0 \\
1,0 \\
1,0 \\
1,0 \\
1,0 \\
1,0 \\
\end{array}$ & $\begin{array}{l}0,0 \\
0,0 \\
0,0 \\
0,0 \\
0,0 \\
0,0\end{array}$ & $\begin{array}{l}0,0 \\
0,0 \\
0,0 \\
0,0 \\
0,0 \\
0,0\end{array}$ & $\begin{array}{l}0,0 \\
0,0 \\
0,0 \\
0,0 \\
0,0 \\
0,0\end{array}$ \\
\hline
\end{tabular}


4.15. MEtin e varifincil do exthnador da tara de fecundagho

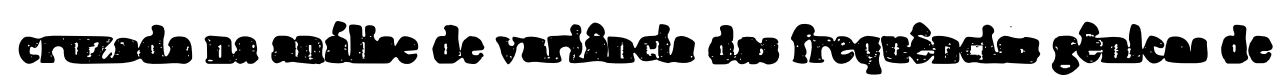

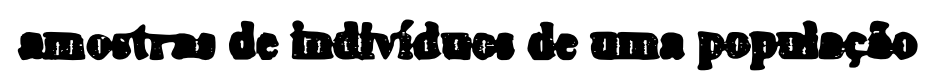

A esperenga matemótica do estimador

$$
\hat{\mathbf{t}}=\frac{1-\hat{\mathrm{F}}}{1+\hat{\mathrm{F}}}
$$

pode ser obtida através do desenvolvimento em série de Trylor da fungăo $X Y$ no ponto $X=\mu_{2} \in Y=\mu_{3}$.

Assim,

$$
E[\hat{t}]=E\left[\frac{1-\hat{F}}{1+\hat{F}}\right]=E\left[\frac{X}{Y}\right] \text {. }
$$

sendo:

$$
\begin{gathered}
E[X]=1-E[\hat{F}], \\
E[Y]=1+E[\hat{F}], \\
\operatorname{Var}[X]=\operatorname{Var}[Y]=\operatorname{Var}[\hat{F}], \\
\operatorname{Cov}[X, Y]=-\operatorname{Var}[\hat{F}] .
\end{gathered}
$$

Substituindo-se estes resultados ne expressån apresentada por MOOD et al. (1974) 


$$
E[X / Y] \sim \mu_{X} / \mu_{Y}-1 / \mu_{Y}^{2} \operatorname{Cov}[X, Y]+\mu_{X} / \mu_{Y}^{3} \operatorname{Var}[Y],
$$

obteve-se:

$$
\begin{aligned}
E[\hat{\mathrm{t}}] & \approx \frac{1-E(\hat{\mathrm{F}})}{1+E(\hat{F})}-\frac{1}{[1+E(\hat{F})]^{2}}[-\operatorname{Var}(\hat{\mathrm{F}})]+\frac{1-E(\hat{\mathrm{F}})}{[1+E(\hat{\mathrm{F}})]^{3}}[\operatorname{Var}(\hat{\mathrm{F}})] \\
& \approx \frac{1-E(\hat{F})}{1+E(\hat{F})}+\frac{2 \operatorname{Var}(\hat{\mathrm{F}})}{[1+E(\hat{F})]^{3}} \\
& \approx \frac{1-F+F / n\left(1-F^{2}\right)}{1+F-F / n\left(1-F^{2}\right)}+\frac{2}{n} \frac{\left(1-F^{2}\right)^{2}}{\left[1+F-F / n\left(1-F^{2}\right)\right]^{3}} .
\end{aligned}
$$

A expressão encoutrada mostrou que o estimador de $t$ obtido pelo métodos dos momentos foi tendencioso, ou seje, $E[\hat{t}]=t$ somente quando $n \rightarrow \infty$.

Os valores de $E(\hat{t})$ da tabela 7 e de ${ }^{\bar{t}}$ da tabela 8 comprovaram que 0 estimador de $t$ teve um viés positivo, pois os resultados se mostraram sempre acima do valor paramétrico. Com o aumento do tamanho da amostra, o viés toma-se desprezivel.

A variância do estimador de $t$ foi desenvolvida, utilizando-se a expressão apresentada por MOOD et al. (1974)

$$
\operatorname{Var}[\mathrm{X} / \mathrm{Y}] \approx \frac{\mu_{\mathrm{Y}}^{2} \operatorname{Var}[\mathrm{X}]+\mu_{\mathrm{X}}^{2} \operatorname{Var}[\mathrm{Y}]-2 \mu_{\mathrm{X}} \mu_{\mathrm{Y}} \operatorname{Cov}[\mathrm{X}, \mathrm{Y}]}{\mu_{\mathrm{Y}}^{4}},
$$

apresentando os seguintes resultados: 


$$
\begin{aligned}
\operatorname{Var}\{\hat{t}] & \approx \frac{[1+E(\hat{F})]^{2} \operatorname{Var}(\hat{F})+[1-B(\hat{F})]^{2} \operatorname{Var}(\hat{F})-2[1-E(\hat{F})[1+E(\hat{F})]-\operatorname{Var}(\hat{F})]}{[1+E(\hat{F})]^{4}} \\
& \approx \frac{\operatorname{Var}[\hat{F}]\{1+E(\hat{F})]+[1-E(\hat{F})]\}^{2}}{[1+E(\hat{F})]^{4}} \\
& \approx \frac{4}{[1+E(\hat{F})]^{4}} \operatorname{Var}(\hat{F}) .
\end{aligned}
$$

Mas a expressåo $1+E(\hat{F})$ pode ser escrita como

$$
1+E(\hat{F}) \approx(1+F)-\frac{F\left(1-F^{2}\right)}{n}
$$

e, consequentemente,

$$
\begin{aligned}
{[1+\mathrm{E}(\hat{\mathrm{P}})]^{4} \approx } & (1+\mathrm{F})^{4}-4(1+\mathrm{F})^{3} \frac{\mathrm{F}\left(1-\mathrm{F}^{2}\right)}{\mathrm{n}}+6(1+\mathrm{F})^{2}\left[\frac{\mathrm{F}\left(1-\mathrm{F}^{2}\right)}{\mathrm{n}}\right]^{2} \\
& -4(1+\mathrm{F})\left[\frac{\mathrm{F}\left(1-\mathrm{F}^{2}\right)}{\mathrm{n}}\right]^{3}+\left[\frac{\mathrm{F}\left(1-\mathrm{F}^{2}\right)}{\mathrm{n}}\right]
\end{aligned}
$$

Mas por definição $F \in(0,1)$ e a expressåo aproximada de $[1+E(\hat{F})]^{4}$, a partir do segundo termo, tem dois termos negativos e dois positivos e todos eles em funçöes de $1 / \mathbf{n}$. Portanto, a medida que $n$ cresce,

$$
[1+E(\hat{F})]^{4} *(1+F)^{4}
$$


Substinnindo-se este resultado em $\operatorname{Var}(\hat{\mathfrak{t}})$, obteve-se:

$$
\operatorname{Var}(\hat{t}) \approx \frac{4}{(1+F)^{4}} \operatorname{Var}(\hat{F})
$$

Esta expressåo essemelha-se à apresentada em WEIR (1990) para o caso geral de u alelos e discutida com mais detalhes por PAIVA et al. (1993) e VENCOVSKY (1994).

Substituindo-se o resultado obtido para $\operatorname{Var}(\hat{F})$ na expressåo de $\operatorname{Var}(\hat{\mathfrak{t}})$ encontrou-se:

$$
\begin{aligned}
\operatorname{Var}(\hat{t}) & \approx \frac{4}{(1+F)^{4}} \frac{\left(1-F^{2}\right)^{2}}{n} \\
& \approx \frac{(2 t)^{2}}{n} .
\end{aligned}
$$

Para se estimar a variância de $\hat{\mathfrak{t}}$ numa amostra de $n$ indivíduos, pode-se utilizar sem muito rigor, a estimativa $\hat{t}$, levando à expressåo:

$$
\operatorname{Vâr}(\hat{\mathfrak{t}}) \approx \frac{(2 \hat{\mathrm{t}})^{2}}{n} .
$$

A Tabela 8 apresenta a média e a variância da proporçảo genica e da taxa de fecundaçåo cruzada estimadas em N=100 experimentos 
com diferentes númetos de individuos em populapōes de dois alelos com diversas combinagôes de frequéncia génica e coeficiente de endogamia

Os valores da média e da variência da frequéncia gérica amostral estiveram de acordo com os valores téricos esperados conforme expressőes apresentadas no item 4.1.1.

Os valores das variâncias de $\hat{\mathrm{t}}$ da Tabela 8 comparados com os valores médios do estimador Vâr $(\hat{t})$ e com os valores teóricos apresentados na Tabela 7, mostraram concordância dos resultados quando a frequência genica da populagåo esteve entre 0,3 e 0,7 o coeficiente de endogamia foi inferior a 0,4 e trabahou-se com pelo menos 30 individuos. 
TABELA 8 - Média e variência de frequência génica e de texa de fecundacio crusada estimadas en $N=100$ eppeimeritas com

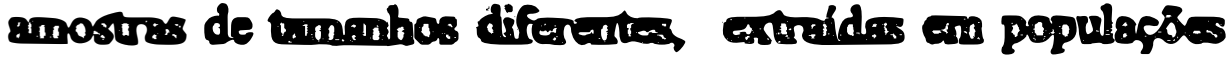
de dois alelos com diverses combinapos de frequencies génices e coeficientes de adognmis.

\begin{tabular}{|c|c|c|c|c|c|c|c|c|}
\hline $\mathbf{n}$ & $\mathbf{p}$ & $F$ & $t$ & $\$$ & $\operatorname{Ver}(\hat{0})$ & t & Ver (t) & $\sqrt{\operatorname{ta}(t)}$ \\
\hline $\begin{array}{l}10 \\
20 \\
30 \\
50 \\
100 \\
200 \\
\end{array}$ & 0.1 & 0,0 & 1,0 & $\begin{array}{l}0,1055 \\
0,0222 \\
0,0077 \\
0,2001 \\
0,0000 \\
0,1006\end{array}$ & $\begin{array}{l}0,0035 \\
0,0018 \\
0,0024 \\
0,0006 \\
0,0004 \\
0,0003\end{array}$ & $\begin{array}{l}1.0522 \\
10001 \\
1.0055 \\
10006 \\
0.0150 \\
10099\end{array}$ & $\begin{array}{l}0,06.3 \\
0,0106 \\
00203 \\
0,0565 \\
0,0370 \\
0.0210\end{array}$ & $\begin{array}{l}0,4956 \\
0,2300 \\
0,1520 \\
0,0001 \\
0,0398 \\
0,0216\end{array}$ \\
\hline $\begin{array}{l}10 \\
20 \\
30 \\
50 \\
100 \\
200 \\
\end{array}$ & 0,1 & 0,1 & 0,8188 & $\begin{array}{l}0,1045 \\
0,0905 \\
0,0045 \\
0,0997 \\
0,0956 \\
0,1003\end{array}$ & $\begin{array}{l}0,0039 \\
0,0021 \\
0,0015 \\
0,0006 \\
0,0005 \\
0,0003\end{array}$ & $\begin{array}{l}, 5240 \\
0,5301 \\
0,5051 \\
0,8815 \\
0,8250 \\
0.8546\end{array}$ & $\begin{array}{l}0,1163 \\
0,1165 \\
0,1153 \\
0,0755 \\
0,0413 \\
0,0243\end{array}$ & $\begin{array}{l}0,4414 \\
0,2961 \\
0,1247 \\
0,0681 \\
0,0289 \\
0,0151\end{array}$ \\
\hline $\begin{array}{c}10 \\
20 \\
30 \\
50 \\
100 \\
200 \\
\end{array}$ & 0.1 & 0,2 & 0,6667 & $\begin{array}{l}0,0955 \\
0,1002 \\
0,1035 \\
0,0979 \\
0,0988 \\
0,0991\end{array}$ & $\begin{array}{l}0,0003 \\
0,0028 \\
0,0018 \\
0,0011 \\
0,0005 \\
0,0002\end{array}$ & $\begin{array}{l}0,7736 \\
0,8461 \\
0,7746 \\
0,7940 \\
0,7070 \\
0,7025 \\
\end{array}$ & $\begin{array}{l}0,1320 \\
0,1410 \\
0,1150 \\
0,0520 \\
0,0450 \\
0,0247\end{array}$ & $\begin{array}{l}0,3575 \\
0,1711 \\
0,0952 \\
0,0569 \\
0,0218 \\
0,0104\end{array}$ \\
\hline $\begin{array}{l}10 \\
20 \\
30 \\
50 \\
100 \\
200 \\
\end{array}$ & 0.1 & 0,3 & 0,5385 & $\begin{array}{l}0,0980 \\
0,1055 \\
0,1022 \\
0,0927 \\
0,1004 \\
0,0999 \\
\end{array}$ & $\begin{array}{l}0,0065 \\
0,0031 \\
0,0025 \\
0,0009 \\
0,0006 \\
0,0002\end{array}$ & $\begin{array}{l}0,8109 \\
0,2629 \\
0,6885 \\
0,6130 \\
0,5904 \\
0,5513 \\
\end{array}$ & $\begin{array}{l}0.1840 \\
0.1734 \\
0.1421 \\
0.0800 \\
0.0387 \\
0.0127\end{array}$ & $\begin{array}{l}0,3359 \\
0,1507 \\
0,0020 \\
0,0364 \\
0,0155 \\
0,0063\end{array}$ \\
\hline $\begin{array}{c}10 \\
20 \\
30 \\
50 \\
100 \\
200 \\
\end{array}$ & 0,1 & 0,4 & 0,4286 & $\begin{array}{l}0,1000 \\
0,1066 \\
0,1042 \\
0,0971 \\
0,1053 \\
0,0988\end{array}$ & $\begin{array}{l}0,0054 \\
0,0037 \\
0,0026 \\
0,0012 \\
0,0007 \\
0,0003\end{array}$ & $\begin{array}{l}0,7042 \\
0,5873 \\
0,5699 \\
0,4878 \\
0,4668 \\
0,4359 \\
\end{array}$ & $\begin{array}{l}0,2056 \\
0,1724 \\
0,1417 \\
0,0652 \\
0,002 \\
0,0145\end{array}$ & $\begin{array}{l}0,2798 \\
0,1031 \\
0,0620 \\
0,0242 \\
0,0103 \\
0,0041\end{array}$ \\
\hline
\end{tabular}

$\overline{\hat{p}} \quad:$ mbdie de $\hat{\mathrm{p}} \operatorname{mon} \mathrm{N}=100$ experimentive;

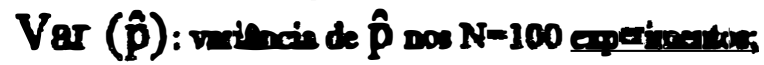

$\bar{t} \quad$ : mbalis de $\hat{t} \cos N=100$ expaimatos;

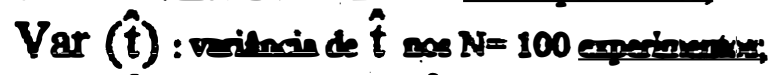

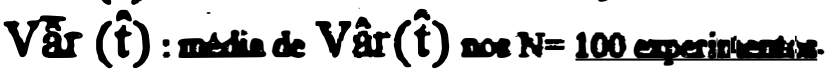


TABELA 8 - Média e veriência de frequéncia gérica e de texa de fecundacto cruzads estimadas em $\mathrm{N}=100$ experimertos com amostres de tamanhos diferentes, extraidas em populagöes de dois alelos com diversas combinagóes de frequencias génicas e coeficientes de endogamia

\begin{tabular}{|c|c|c|c|c|c|c|c|c|}
\hline $\begin{array}{c}n \\
10 \\
20 \\
30 \\
50 \\
100 \\
200 \\
\end{array}$ & $\frac{p}{0,1}$ & $\frac{F}{a, 5}$ & $\frac{t}{0,3333}$ & $\begin{array}{c}\bar{p} \\
0,0,035 \\
0,1048 \\
0,1038 \\
0,09010 \\
0,10018 \\
0,1016\end{array}$ & $\begin{array}{l}a r(\hat{p}) \\
0,0066 \\
0,0043 \\
0,0023 \\
0,0013 \\
0,0001 \\
0,0004\end{array}$ & $\begin{array}{c}\frac{7}{t} \\
0,7479 \\
0,5255 \\
0,401 \\
0,3971 \\
0,3420 \\
0,3405\end{array}$ & $\begin{array}{l}\text { Ver (t) } \\
0,1817 \\
0,16088 \\
0,1179 \\
0,0718 \\
0,0150 \\
00005 \\
\end{array}$ & $\begin{array}{l}\sqrt{8}(t) \\
0,0037 \\
0,0800 \\
0,0021 \\
0,0163 \\
0,0053 \\
0,010\end{array}$ \\
\hline $\begin{array}{c}10 \\
20 \\
30 \\
50 \\
100 \\
200 \\
\end{array}$ & 0,1 & 0,6 & 0,2500 & $\begin{array}{l}0,1115 \\
0,0910 \\
0,0937 \\
0,1052 \\
0,0902 \\
0,0974 \\
\end{array}$ & $\begin{array}{l}0,0087 \\
0,0010 \\
0,0020 \\
0,0016 \\
0,0008 \\
0,0004\end{array}$ & $\begin{array}{l}0,5946 \\
0,4730 \\
0,3646 \\
0,3130 \\
0,2763 \\
0,2675 \\
\end{array}$ & $\begin{array}{l}0,251 \\
0,1815 \\
0,0050 \\
0,0901 \\
0,0150 \\
0,0080\end{array}$ & $\begin{array}{l}0,251 \\
0,0313 \\
0,0303 \\
0,0117 \\
0,0035 \\
0,0016\end{array}$ \\
\hline $\begin{array}{c}10 \\
20 \\
30 \\
50 \\
100 \\
200 \\
\end{array}$ & 0,1 & 0,7 & 0,1763 & $\begin{array}{l}0,0693 \\
0,0948 \\
0,1028 \\
0,0983 \\
0,0962 \\
0,0988\end{array}$ & $\begin{array}{l}0,0070 \\
0,0037 \\
0,0020 \\
0,0016 \\
0,0000 \\
0,0004\end{array}$ & $\begin{array}{l}0,3062 \\
0,3,563 \\
0,2478 \\
0,2059 \\
0,1950 \\
0,1803 \\
\end{array}$ & $\begin{array}{l}0,2117 \\
0,1717 \\
0,0713 \\
0,0314 \\
0,0115 \\
0,0035\end{array}$ & $\begin{array}{l}0,1804 \\
0,0652 \\
0,0176 \\
0,0059 \\
0,0020 \\
0,0002\end{array}$ \\
\hline $\begin{array}{c}10 \\
20 \\
30 \\
50 \\
100 \\
200 \\
\end{array}$ & 0,1 & 0,8 & Q,1111 & $\begin{array}{l}0,0970 \\
0,0965 \\
0,1062 \\
0,1042 \\
0,0984 \\
0,1045\end{array}$ & $\begin{array}{l}0,0068 \\
0,0044 \\
0,0027 \\
0,0020 \\
0,0007 \\
0,0003\end{array}$ & $\begin{array}{l}0,4138 \\
0,2602 \\
0,1658 \\
0,1118 \\
0,1160 \\
0,1153\end{array}$ & $\begin{array}{l}0,2212 \\
0,1233 \\
0,0518 \\
0,0068 \\
0,0061 \\
0,0023\end{array}$ & $\begin{array}{l}0,1361 \\
0,0380 \\
0,0105 \\
0,0015 \\
0,0008 \\
0,0003\end{array}$ \\
\hline $\begin{array}{c}10 \\
20 \\
30 \\
50 \\
100 \\
200 \\
\end{array}$ & 0,1 & 0,9 & 0,0326 & $\begin{array}{l}0,0635 \\
0,1052 \\
0,1045 \\
0,1085 \\
0,0990 \\
0,1029\end{array}$ & $\begin{array}{l}0,0538 \\
0,0033 \\
0,0034 \\
0,0014 \\
0,0008 \\
0,0005\end{array}$ & $\begin{array}{l}0,038 \\
0,1139 \\
0,1022 \\
0,0635 \\
0,0575 \\
0,0527\end{array}$ & $\begin{array}{l}0,2359 \\
0,0655 \\
0,0438 \\
0,0053 \\
0,0028 \\
0,0009 \\
\end{array}$ & $\begin{array}{l}0,1910 \\
0,0156 \\
0,0072 \\
0,0008 \\
0,0002 \\
0,0001\end{array}$ \\
\hline $\begin{array}{l}10 \\
20 \\
30 \\
50 \\
100 \\
200 \\
\end{array}$ & 0,1 & 1,0 & 0,0 & $\begin{array}{l}0,0565 \\
0,1032 \\
0,1048 \\
0,0996 \\
0,0974 \\
0,1010\end{array}$ & $\begin{array}{l}0,0105 \\
0,0055 \\
0,0039 \\
0,0018 \\
0,0008 \\
0,0003 \\
\end{array}$ & $\begin{array}{l}0,4111 \\
0,1506 \\
0,0512 \\
0,0044 \\
0,0018 \\
0,0025\end{array}$ & $\begin{array}{l}0,2,36 \\
0,1286 \\
0,0479 \\
0,0005 \\
0,0001 \\
0,0001\end{array}$ & $\begin{array}{l}0,1640 \\
0,0300 \\
0,0007 \\
0,0000 \\
0,0000 \\
0,0000\end{array}$ \\
\hline $\begin{array}{c}10 \\
20 \\
30 \\
50 \\
100 \\
200 \\
\end{array}$ & 0,2 & 0,0 & 1,0 & $\begin{array}{l}0,1965 \\
0,2052 \\
0,2093 \\
0,1928 \\
0,2011 \\
0,1998 \\
\end{array}$ & $\begin{array}{l}0,0102 \\
0,0035 \\
0,0030 \\
0,0015 \\
0,0007 \\
0,0004 \\
\end{array}$ & $\begin{array}{l}1,1220 \\
1,1371 \\
1,1129 \\
1,0556 \\
1,0379 \\
1,0069 \\
\end{array}$ & $\begin{array}{l}0,2413 \\
0,1925 \\
0,1415 \\
0,0774 \\
0,0381 \\
0,0151 \\
\end{array}$ & $\begin{array}{l}0,0003 \\
0,3059 \\
0,1838 \\
0,0953 \\
0,0446 \\
0,0206\end{array}$ \\
\hline
\end{tabular}


TABELA 8 - Média e varîncia da frequéncia gênica e de texs de fecundagio cruzads cotimades em $\mathrm{N}=100$ experimentins com amostras de tamenhos diferentes extraidas em populacóes de dois alelos com diversas combinagóes de frequencias genicas e coeficientes de endogamia.

\begin{tabular}{|c|c|c|c|c|c|c|c|c|}
\hline $\begin{array}{l}\mathbf{n} \\
10 \\
20 \\
30 \\
50 \\
100 \\
200\end{array}$ & $\frac{p}{0,2}$ & $\frac{P}{0,1}$ & $\frac{t}{a, 18}$ & $\begin{array}{c}\frac{\bar{p}}{0.5105} \\
0,1915 \\
0,2013 \\
0,1978 \\
0,1982 \\
0,2010\end{array}$ & $\begin{array}{l}\operatorname{Ver}(\hat{p}) \\
0,0018 \\
0,0032 \\
0,0025 \\
0,0021 \\
0,0007 \\
0,0004\end{array}$ & 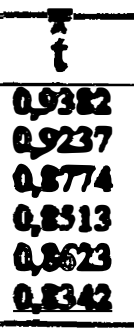 & $\begin{array}{l}\text { Ver (t) } \\
0,2331 \\
0,1412 \\
0,1185 \\
0,0038 \\
0,0417 \\
0,0172\end{array}$ & $\begin{array}{l}\sqrt{6}(t) \\
0,044 \\
0,092 \\
0,1183 \\
0,0646 \\
0,0314 \\
0,0143\end{array}$ \\
\hline $\begin{array}{c}10 \\
20 \\
30 \\
50 \\
100 \\
200\end{array}$ & 0,2 & 0,2 & 0,6667 & $\begin{array}{l}0,2105 \\
0,2030 \\
0,1950 \\
0,2061 \\
0,2092 \\
0,2005\end{array}$ & $\begin{array}{l}0,0001 \\
0,0045 \\
0,0030 \\
0,0020 \\
0,0009 \\
0,0004\end{array}$ & $\begin{array}{l}4,8103 \\
0,7512 \\
0,7546 \\
0,7302 \\
0,6828 \\
0.6872 \\
\end{array}$ & $\begin{array}{l}0,0012 \\
0,1505 \\
0,0874 \\
0,0120 \\
0,0214 \\
0.0108\end{array}$ & $\begin{array}{l}\text { 1,5805 } \\
0,1427 \\
0,0074 \\
0,0904 \\
0,0196 \\
0,0097 \\
\end{array}$ \\
\hline $\begin{array}{l}10 \\
20 \\
30 \\
50 \\
100 \\
200\end{array}$ & 0,2 & 0,3 & 0,5385 & $\begin{array}{l}0,2960 \\
0,1983 \\
0,2040 \\
0,2011 \\
0,2026 \\
0,2012\end{array}$ & $\begin{array}{l}0,0085 \\
0,0058 \\
0,0040 \\
0,0019 \\
0,0010 \\
0,0004\end{array}$ & $\begin{array}{l}0.500 \\
0,5132 \\
0,0203 \\
0,5052 \\
0,5557 \\
0,5324\end{array}$ & $\begin{array}{l}0,2538 \\
0,1306 \\
0,0834 \\
0,0167 \\
0,0180 \\
0,00: 0\end{array}$ & $\begin{array}{l}0,0707 \\
0,1006 \\
0,0626 \\
0,0321 \\
0,0131 \\
0,0058\end{array}$ \\
\hline $\begin{array}{l}10 \\
20 \\
30 \\
50 \\
100 \\
200\end{array}$ & 0,2 & 0,4 & 0,4286 & $\begin{array}{l}0,1995 \\
0,2045 \\
0,1938 \\
0,2019 \\
0,1987 \\
0,1996\end{array}$ & $\begin{array}{l}0,0165 \\
0,0068 \\
0,0033 \\
0,0023 \\
0,0010 \\
0,0006\end{array}$ & 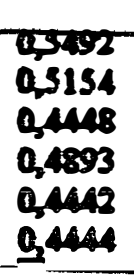 & $\begin{array}{l}0,2000 \\
0,1234 \\
0,0010 \\
0,0422 \\
0,0136 \\
0,0071\end{array}$ & $\begin{array}{l}0,7127 \\
0,0776 \\
0,0313 \\
0,0225 \\
0,0084 \\
0,0041\end{array}$ \\
\hline $\begin{array}{c}10 \\
20 \\
30 \\
50 \\
100 \\
200\end{array}$ & 0,2 & 0,5 & 0,3333 & $\begin{array}{l}0,1880 \\
0,1970 \\
0,1997 \\
0,1975 \\
0,1963 \\
0,2034\end{array}$ & $\begin{array}{l}0,0125 \\
0,0060 \\
0,0045 \\
0,0022 \\
0,0009 \\
0,0006 \\
\end{array}$ & $\begin{array}{l}0,5326 \\
0,4007 \\
0,3662 \\
0,3595 \\
0,3569 \\
0,34 \% \\
\end{array}$ & $\begin{array}{l}0,095 \\
0,0956 \\
0,0533 \\
0,0213 \\
0,0092 \\
0,0045 \\
\end{array}$ & $\begin{array}{l}0,010 \\
0,0518 \\
0,0249 \\
0,0120 \\
0,0053 \\
0,0025\end{array}$ \\
\hline $\begin{array}{l}10 \\
20 \\
30 \\
50 \\
100 \\
200\end{array}$ & 0,2 & 0,6 & 0,2500 & $\begin{array}{l}0,1935 \\
0,1982 \\
0,2075 \\
0,2045 \\
0,2008 \\
0,1948\end{array}$ & $\begin{array}{l}0,0108 \\
0,0050 \\
0,0016 \\
0,0023 \\
0,0013 \\
0,0027\end{array}$ & $\begin{array}{l}0,4273 \\
0,3038 \\
0,2667 \\
0,2333 \\
0,2531 \\
0,2506\end{array}$ & $\begin{array}{l}0,1789 \\
0,0530 \\
0,0193 \\
0,0118 \\
0,0053 \\
0,0044 \\
\end{array}$ & $\begin{array}{l}0,1438 \\
0,0290 \\
0,0120 \\
0,0053 \\
0,0028 \\
0,0014\end{array}$ \\
\hline $\begin{array}{c}10 \\
20 \\
30 \\
50 \\
100 \\
200\end{array}$ & 0,2 & 0,7 & 0,1763 & $\begin{array}{l}0,2065 \\
0,2000 \\
0,2030 \\
0,1994 \\
0,2034 \\
0,2019\end{array}$ & $\begin{array}{l}0,0136 \\
0,0073 \\
0,0049 \\
0,0025 \\
0,0013 \\
0,0008 \\
\end{array}$ & $\begin{array}{l}0,3052 \\
0,2321 \\
0,1903 \\
0,1991 \\
0,1751 \\
0,1858\end{array}$ & $\begin{array}{l}0,1198 \\
0,0469 \\
0,0126 \\
0,0155 \\
0,0043 \\
0,0024\end{array}$ & $\begin{array}{l}0,0847 \\
0,0201 \\
0,0065 \\
0,0044 \\
0,0014 \\
0,0007\end{array}$ \\
\hline
\end{tabular}


TABELA 8 - Média e veriência da frequencia génica e de taxa de fecundagaso cruzade extimadas em $\mathrm{N}=100$ experimentos com amostras de tamanhos diferentes, extrides em populagobes de dois alelos com diversas combinagäes de frequencias genicas e coeficieates de cadogaria.

\begin{tabular}{|c|c|c|c|c|c|c|c|c|}
\hline $\begin{array}{l}n \\
10 \\
20 \\
30 \\
50 \\
100 \\
200 \\
\end{array}$ & $\frac{p}{0.2}$ & $\frac{\mathbf{F}}{0,8}$ & $\frac{t}{0,1111}$ & $\begin{array}{c}\bar{p} \\
0,1785 \\
0,1972 \\
0,1970 \\
0,1900 \\
0,2008 \\
0,2016\end{array}$ & $\begin{array}{l}\text { Vor (j) } \\
0,0150 \\
0,0071 \\
0,0043 \\
0,0032 \\
0,0014 \\
0,00008\end{array}$ & $\begin{array}{c}t \\
0,504 \\
0,1340 \\
0,1368 \\
0,1200 \\
0,1201 \\
0,1108\end{array}$ & $\begin{array}{l}\text { er (t) } \\
0,1612 \\
0,0263 \\
0,0118 \\
0,0018 \\
0,0017 \\
0,015\end{array}$ & $\begin{array}{l}\sqrt{8} \times(t) \\
0,0074 \\
0,0003 \\
0,0041 \\
0,0017 \\
0,0006 \\
0,0003\end{array}$ \\
\hline $\begin{array}{l}10 \\
20 \\
30 \\
50 \\
100 \\
200 \\
\end{array}$ & 0,2 & 0,9 & 0,0326 & $\begin{array}{l}0,2100 \\
0,2120 \\
0,2107 \\
0,2026 \\
0,1994 \\
0,1995\end{array}$ & $\begin{array}{l}0,0160 \\
0,0007 \\
0,0059 \\
0,0010 \\
0,0013 \\
0,0006\end{array}$ & $\begin{array}{l}0,1522 \\
0,0176 \\
0,0767 \\
0,0577 \\
0,0546 \\
0,0558 \\
\end{array}$ & $\begin{array}{l}0,0003 \\
0,0272 \\
0,0150 \\
0,0015 \\
0,0000 \\
0,0005\end{array}$ & $\begin{array}{l}0,0050 \\
0,0065 \\
0,0028 \\
0,0006 \\
0,0002 \\
0,0001\end{array}$ \\
\hline $\begin{array}{c}10 \\
20 \\
30 \\
50 \\
100 \\
200 \\
\end{array}$ & 0,2 & 1,0 & 0,0 & $\begin{array}{l}0,2050 \\
0,2103 \\
0,2037 \\
0,1941 \\
0,2060 \\
0,1983\end{array}$ & $\begin{array}{l}0,0160 \\
0,0084 \\
0,0035 \\
0,0030 \\
0,0019 \\
0,0008\end{array}$ & $\begin{array}{l}0,1111 \\
0,0124 \\
0,0000 \\
0,0027 \\
0,0016 \\
0,0016\end{array}$ & $\begin{array}{l}0,0,083 \\
0,0101 \\
0,0000 \\
0,0001 \\
0,0000 \\
0,0000\end{array}$ & $\begin{array}{l}0,0411 \\
0,0020 \\
0,0000 \\
0,0000 \\
0,0000 \\
0,0000\end{array}$ \\
\hline $\begin{array}{c}10 \\
20 \\
30 \\
50 \\
100 \\
200 \\
\end{array}$ & 0,3 & 0,0 & 1,0 & $\begin{array}{l}0,2800 \\
0,3060 \\
0,3030 \\
0,2980 \\
0,2084 \\
0,3029 \\
\end{array}$ & $\begin{array}{l}0,0114 \\
0,0047 \\
0,0038 \\
0,0019 \\
0,0008 \\
0,0006\end{array}$ & $\begin{array}{l}, 2737 \\
1,1718 \\
1,0128 \\
1,0705 \\
1,0203 \\
1,0194\end{array}$ & $\begin{array}{l}1,1004 \\
0,2785 \\
0,1384 \\
0,1244 \\
0,0353 \\
0,0216\end{array}$ & $\begin{array}{l}1,0347 \\
0,03298 \\
0,1633 \\
0,1015 \\
0,0430 \\
0,0212 \\
\end{array}$ \\
\hline $\begin{array}{c}10 \\
20 \\
30 \\
50 \\
100 \\
200 \\
\end{array}$ & 0,3 & 0,1 & 0,8182 & $\begin{array}{l}0,3050 \\
0,3092 \\
0,3027 \\
0,3072 \\
0,3011 \\
0,3029\end{array}$ & $\begin{array}{l}0,0050 \\
0,0052 \\
0,0030 \\
0,0025 \\
0,0010 \\
0,0006\end{array}$ & $\begin{array}{l}1,0026 \\
0,9162 \\
0,8831 \\
0,8337 \\
0,8329 \\
0,8503 \\
\end{array}$ & $\begin{array}{l}0,5781 \\
0,1770 \\
0,1121 \\
0,0372 \\
0,0394 \\
0,0136\end{array}$ & $\begin{array}{l}0,6310 \\
0,2020 \\
0,1188 \\
0,0501 \\
0,0293 \\
0,0147\end{array}$ \\
\hline $\begin{array}{l}10 \\
20 \\
30 \\
50 \\
100 \\
200 \\
\end{array}$ & 0,3 & 0,2 & 0,6667 & $\begin{array}{l}0,2080 \\
0,2095 \\
0,3055 \\
0,2994 \\
0,2090 \\
0,3002\end{array}$ & $\begin{array}{l}0,0131 \\
0,0057 \\
0,0044 \\
0,0027 \\
0,0013 \\
0,0006\end{array}$ & $\begin{array}{l}0,8003 \\
0,7600 \\
0,7038 \\
0,6908 \\
0,6781 \\
0,6786\end{array}$ & $\begin{array}{l}0,2741 \\
0,1792 \\
0,1127 \\
0,0453 \\
0,0199 \\
0,0119 \\
\end{array}$ & $\begin{array}{l}0,3649 \\
0,1510 \\
0,0809 \\
0,0418 \\
0,0192 \\
0,0094 \\
\end{array}$ \\
\hline $\begin{array}{c}10 \\
20 \\
30 \\
50 \\
100 \\
200\end{array}$ & 0,3 & 0,3 & 0,5385 & $\begin{array}{l}0,2985 \\
0,3127 \\
0,3113 \\
0,2951 \\
0,3012 \\
0,2969\end{array}$ & $\begin{array}{l}0,0155 \\
0,0069 \\
0,0054 \\
0,0027 \\
0,0013 \\
0,0006\end{array}$ & $\begin{array}{l}0,7029 \\
0,5502 \\
0,5745 \\
0,5699 \\
0,5604 \\
0,5444\end{array}$ & $\begin{array}{l}0,2821 \\
0,0835 \\
0,0468 \\
0,0391 \\
0,0147 \\
0,0072 \\
\end{array}$ & $\begin{array}{l}0,3094 \\
0,0771 \\
0,0502 \\
0,0291 \\
0,0131 \\
0,0061\end{array}$ \\
\hline
\end{tabular}


TABELA 8 - Média e verif́ncia da frequencis génice e da taxa de fecundagio cruseds extinsdis em N=100 experimertas com amostres de temenhos difererter, extraidas em populacöes de dois alelos com diverses combinegöes de frequencias génicas e coeficientes de endogarmia

\begin{tabular}{|c|c|c|c|c|c|c|c|c|}
\hline $\mathbf{n}$ & $p$ & $F$ & $t$ & $\overline{\bar{p}}$ & $\operatorname{Var}(\hat{p})$ & $t$ & $\operatorname{Ver}(t)$ & VEr (t) \\
\hline $\begin{array}{c}10 \\
20 \\
30 \\
50 \\
100 \\
200 \\
\end{array}$ & 0,3 & 0,4 & 0,4886 & $\begin{array}{l}0,5350 \\
0,2870 \\
0,3023 \\
0,2018 \\
0,3012 \\
0,2090 \\
\end{array}$ & $\begin{array}{l}0,0157 \\
0,0085 \\
0,0054 \\
0,0032 \\
0,0016 \\
0,0002 \\
\end{array}$ & $\begin{array}{l}0, \operatorname{sis} 2 \\
0,5290 \\
0,4762 \\
0,4400 \\
0,4295 \\
0,4413\end{array}$ & $\begin{array}{l}0,5752 \\
0,0572 \\
0,0537 \\
0,0228 \\
0,0005 \\
0,0056\end{array}$ & $\begin{array}{l}0,2541 \\
0,0732 \\
0,0373 \\
0,017 \\
0,0078 \\
0,0041\end{array}$ \\
\hline $\begin{array}{c}10 \\
20 \\
30 \\
50 \\
100 \\
200 \\
\end{array}$ & 0,3 & $\overline{0,5}$ & 0,3333 & $\begin{array}{l}0,3015 \\
0,3005 \\
0,2000 \\
0,3028 \\
0,3033 \\
0,2066\end{array}$ & $\begin{array}{l}0,0121 \\
0,0035 \\
0,0014 \\
0,0005 \\
0,0016 \\
0,0008\end{array}$ & $\begin{array}{l}0,4121 \\
0,3922 \\
0,3816 \\
0,3587 \\
0,3132 \\
0,3557 \\
\end{array}$ & $\begin{array}{l}0,1368 \\
0,0618 \\
0,0412 \\
0,0153 \\
0,0075 \\
0,0036\end{array}$ & $\begin{array}{l}0,1221 \\
0,0130 \\
0,0248 \\
0,0115 \\
0,0050 \\
0,0026\end{array}$ \\
\hline $\begin{array}{c}10 \\
20 \\
30 \\
50 \\
100 \\
200 \\
\end{array}$ & 0,3 & 0,6 & 0,2500 & $\begin{array}{l}0,5000 \\
0,3060 \\
0,3063 \\
0,3027 \\
0,3048 \\
0,2951\end{array}$ & $\begin{array}{l}0,0169 \\
0,0001 \\
0,0050 \\
0,0020 \\
0,0020 \\
0,0008\end{array}$ & $\begin{array}{l}0,060 \\
0,2907 \\
0,2726 \\
0,2441 \\
0,2530 \\
0,2580\end{array}$ & $\begin{array}{l}0,1383 \\
0,0283 \\
0,0248 \\
0,0092 \\
0,0048 \\
0,0031 \\
\end{array}$ & $\begin{array}{l}0,1217 \\
0,0224 \\
0,0132 \\
0,0055 \\
0,0028 \\
0,0014 \\
\end{array}$ \\
\hline $\begin{array}{c}10 \\
20 \\
30 \\
50 \\
100 \\
200 \\
\end{array}$ & 0,3 & 0,7 & 0,1763 & $\begin{array}{l}0,5920 \\
0,3002 \\
0,3042 \\
0,3089 \\
0,2096 \\
0,30,13\end{array}$ & $\begin{array}{l}0,0145 \\
0,0085 \\
0,0013 \\
0,0034 \\
0,0014 \\
0,0009\end{array}$ & $\begin{array}{l}0,2,8 \\
0,2182 \\
0,1827 \\
0,1926 \\
0,1777 \\
0,1808\end{array}$ & $\begin{array}{l}0,0556 \\
0,0208 \\
0,0111 \\
0,0064 \\
0,0026 \\
0,0016\end{array}$ & $\begin{array}{l}0,0596 \\
0,0148 \\
0,0059 \\
0,0035 \\
0,0014 \\
0,0007\end{array}$ \\
\hline $\begin{array}{c}10 \\
20 \\
30 \\
30 \\
100 \\
200 \\
\end{array}$ & 0,3 & 0,8 & 0,1111 & $\begin{array}{l}0,3030 \\
0,3052 \\
0,2893 \\
0,3046 \\
0,3036 \\
0,3036\end{array}$ & $\begin{array}{l}0,0212 \\
0,0118 \\
0,0056 \\
0,0046 \\
0,0022 \\
0,0009\end{array}$ & $\begin{array}{l}0,1846 \\
0,1539 \\
0,1236 \\
0,1161 \\
0,1160 \\
0,1147 \\
\end{array}$ & $\begin{array}{l}0,0690 \\
0,0310 \\
0,0064 \\
0,0040 \\
0,0016 \\
0,0009 \\
\end{array}$ & $\begin{array}{l}0,0393 \\
0,0109 \\
0,0020 \\
0,0014 \\
0,0006 \\
0,0003 \\
\end{array}$ \\
\hline $\begin{array}{c}10 \\
20 \\
30 \\
50 \\
100 \\
200 \\
\end{array}$ & 0,3 & 0,9 & 0,0326 & $\begin{array}{l}0,2853 \\
0,3030 \\
0,2960 \\
0,2919 \\
0,2915 \\
0,2980\end{array}$ & $\begin{array}{l}0,0199 \\
0,0082 \\
0,0076 \\
0,0041 \\
0,0023 \\
0,0009\end{array}$ & $\begin{array}{l}0,1124 \\
0,0496 \\
0,0658 \\
0,0544 \\
0,0584 \\
0,0523\end{array}$ & $\begin{array}{l}0,0552 \\
0,0038 \\
0,0036 \\
0,0016 \\
0,0006 \\
0,0003 \\
\end{array}$ & $\begin{array}{l}0,0270 \\
0,0012 \\
0,0011 \\
0,0004 \\
0,0002 \\
0,0001\end{array}$ \\
\hline $\begin{array}{l}10 \\
20 \\
30 \\
50 \\
100 \\
200\end{array}$ & 0,3 & 1,0 & 0,0 & $\begin{array}{l}0,3240 \\
0,2910 \\
0,2950 \\
0,3066 \\
0,2958 \\
0,2944\end{array}$ & $\begin{array}{l}0,0190 \\
0,0096 \\
0,0063 \\
0,0032 \\
0,0021 \\
0,0010 \\
\end{array}$ & $\begin{array}{l}0,0000 \\
0,0018 \\
0,0007 \\
0,0009 \\
0,0014 \\
0,0007 \\
\end{array}$ & $\begin{array}{l}0,0000 \\
0,0002 \\
0,0000 \\
0,0000 \\
0,0000 \\
0,0000\end{array}$ & $\begin{array}{l}0,0000 \\
0,0000 \\
0,0000 \\
0,0000 \\
0,0000 \\
0,0000 \\
\end{array}$ \\
\hline
\end{tabular}


TABELA 8 - Média e variêncis de frequéncia génica e de tara de fecundagero cruasda estimedas em N=100 experimertos com amostras de temenhos diferentes, extridas em populepbes de dois slelos com diverses combinapöes de frequencias génices e coeficientes de endogamia.

\begin{tabular}{|c|c|c|c|c|c|c|c|c|}
\hline $\begin{array}{l}\mathbf{n} \\
10 \\
20 \\
30 \\
50 \\
100 \\
200\end{array}$ & $\frac{p}{a, d}$ & $\frac{\mathrm{g}}{0,0}$ & $\frac{t}{1,0}$ & $\begin{array}{c}\bar{z} \\
0,3500 \\
0,3988 \\
0,1015 \\
0,4038 \\
0,3959 \\
0,3962\end{array}$ & $\begin{array}{l}\mathrm{Var}(\mathbf{p}) \\
0,0114 \\
0,0068 \\
0,0040 \\
0,0030 \\
0,0012 \\
0,0008\end{array}$ & $\begin{array}{c}t \\
1,6453 \\
1,1447 \\
1,0360 \\
1,0919 \\
0,9653 \\
1,02020 \\
\end{array}$ & $\begin{array}{l}\text { Var (t) } \\
3,0057 \\
0,3032 \\
0,1612 \\
0,0846 \\
0,00390 \\
0,0951 \\
\end{array}$ & $\begin{array}{l}E_{r}(t) \\
2,860 \\
0,3221 \\
0,1644 \\
0,1021 \\
0,0413 \\
0,0214 \\
\end{array}$ \\
\hline $\begin{array}{l}10 \\
20 \\
30 \\
30 \\
100 \\
200 \\
\end{array}$ & 0,4 & 0,1 & 0,818 & $\begin{array}{l}0,510 \\
0,3952 \\
0,3953 \\
0,4016 \\
0,4058 \\
0,4022\end{array}$ & $\begin{array}{l}0,0105 \\
0,0044 \\
0,0039 \\
0,0025 \\
0,0013 \\
0,0007\end{array}$ & $\begin{array}{l}0,0808 \\
0,9201 \\
0.025 \\
0.8197 \\
0.8170 \\
0.8192\end{array}$ & $\begin{array}{l}0,5332 \\
0,1674 \\
0,0150 \\
0,0560 \\
0,0323 \\
0,0159\end{array}$ & $\begin{array}{l}0,0362 \\
0,025 \\
0,0003 \\
0,0592 \\
0,0280 \\
0,0137\end{array}$ \\
\hline $\begin{array}{c}10 \\
20 \\
30 \\
50 \\
100 \\
200 \\
\end{array}$ & 0,4 & 0,2 & 0,6667 & $\begin{array}{l}0,3700 \\
0,3808 \\
0,3953 \\
0,4064 \\
0,4021 \\
0,3953\end{array}$ & $\begin{array}{l}0,0137 \\
0,0065 \\
0,0043 \\
0,0026 \\
0,0016 \\
0,0007\end{array}$ & $\begin{array}{l}0,103 \\
0,7316 \\
0,6859 \\
0,6710 \\
0,6708 \\
0,6823\end{array}$ & $\begin{array}{l}0,5575 \\
0,1121 \\
0,0125 \\
0,0521 \\
0,0134 \\
0,0114\end{array}$ & $\begin{array}{l}0,5452 \\
0,1202 \\
0,0131 \\
0,0105 \\
0,0185 \\
0,0095\end{array}$ \\
\hline $\begin{array}{c}10 \\
20 \\
30 \\
50 \\
100 \\
200 \\
\end{array}$ & 0,4 & 0,3 & 0,5385 & $\begin{array}{l}0,4085 \\
0,4112 \\
0,3818 \\
0,3966 \\
0,3,066 \\
0,4002\end{array}$ & $\begin{array}{l}0,0155 \\
0,0086 \\
0,0051 \\
0,0024 \\
0,0015 \\
0,0006\end{array}$ & $\begin{array}{l}0,7114 \\
0,5820 \\
0,6010 \\
0,5602 \\
0,5650 \\
0,5404\end{array}$ & $\begin{array}{l}0,3551 \\
0,1159 \\
0,0509 \\
0,0270 \\
0,0185 \\
0,0072 \\
\end{array}$ & $\begin{array}{l}0,3,30 \\
0,0009 \\
0,0555 \\
0,0272 \\
0,0135 \\
0,0062 \\
\end{array}$ \\
\hline $\begin{array}{c}10 \\
20 \\
30 \\
50 \\
100 \\
200 \\
\end{array}$ & 0,4 & 0,4 & 0,4286 & $\begin{array}{l}0,4015 \\
0,4042 \\
0,4155 \\
0,4007 \\
0,4052 \\
0,4020 \\
\end{array}$ & $\begin{array}{l}0,0154 \\
0,0064 \\
0,0047 \\
0,0040 \\
0,0016 \\
0,0009\end{array}$ & $\begin{array}{l}0,5334 \\
0,4857 \\
0,4723 \\
0,4392 \\
0,448 \\
0,134\end{array}$ & $\begin{array}{l}0,2132 \\
0,0502 \\
0,0336 \\
0,0192 \\
0,0100 \\
0,0048\end{array}$ & $\begin{array}{l}0,0,077 \\
0,0571 \\
0,0342 \\
0,0170 \\
0,0083 \\
0,0040\end{array}$ \\
\hline $\begin{array}{c}10 \\
20 \\
30 \\
50 \\
100 \\
200 \\
\end{array}$ & 0,4 & 0,5 & 0,3333 & $\begin{array}{l}0,3940 \\
0,3970 \\
0,3997 \\
0,3929 \\
0,3972 \\
0,4026 \\
\end{array}$ & $\begin{array}{l}0,0176 \\
0,0088 \\
0,0055 \\
0,0040 \\
0,0015 \\
0,0008\end{array}$ & $\begin{array}{l}0,4291 \\
0,3607 \\
0,3804 \\
0,3374 \\
0,3569 \\
0,3433 \\
\end{array}$ & $\begin{array}{l}0,1627 \\
0,0224 \\
0,0351 \\
0,0106 \\
0,0071 \\
0,0036 \\
\end{array}$ & $\begin{array}{l}0,1381 \\
0,0344 \\
0,0239 \\
0,0100 \\
0,0054 \\
0,0024 \\
\end{array}$ \\
\hline $\begin{array}{c}10 \\
20 \\
30 \\
50 \\
100 \\
200\end{array}$ & 0,4 & 0,6 & 0,2500 & $\begin{array}{l}0,4035 \\
0,3950 \\
0,4232 \\
0,3853 \\
0,3982 \\
0,3992\end{array}$ & $\begin{array}{l}0,0171 \\
0,0076 \\
0,0069 \\
0,0031 \\
0,0019 \\
0,0010\end{array}$ & $\begin{array}{l}0,3102 \\
0,2742 \\
0,2572 \\
0,2678 \\
0,2645 \\
0,2585\end{array}$ & $\begin{array}{l}0,0752 \\
0,0249 \\
0,0129 \\
0,0098 \\
0,0039 \\
0,0028\end{array}$ & $\begin{array}{l}0,0683 \\
0,0200 \\
0,0105 \\
0,0065 \\
0,0030 \\
0,0014\end{array}$ \\
\hline
\end{tabular}


TABERA 8 - Médiz e variâncis da frequencia gêrica e da taxs de fecundagio cruzads estimsdas eon N=100 experimentos com amostres de tamenhos diferentes extrádas em populaçoes de dois alelos com diverses combinegöes de frequencias génices e coeficientes de endogamia.

\begin{tabular}{|c|c|c|c|c|c|c|c|c|}
\hline $\mathbf{n}$ & $\mathbf{p}$ & P & $t$ & $\bar{p}$ & $\sqrt{\operatorname{ar}(\hat{p})}$ & ta & $\operatorname{Var}(t)$ & $\sqrt{8 r(t)}$ \\
\hline $\begin{array}{l}10 \\
20 \\
30 \\
50 \\
100 \\
200 \\
\end{array}$ & $\overline{a, n}$ & 0,7 & 0,1765 & $\begin{array}{l}0,5000 \\
0,3938 \\
0,4013 \\
0,4095 \\
0,4004 \\
0,4051\end{array}$ & $\begin{array}{l}0,0225 \\
0,0087 \\
0,000 \\
0,0039 \\
0,0018 \\
0,0011\end{array}$ & $\begin{array}{l}0,2000 \\
0,3005 \\
0,1632 \\
0,1681 \\
0,1845 \\
0,1790\end{array}$ & $\begin{array}{l}0,0352 \\
0,0168 \\
0,0073 \\
0,0047 \\
0,0030 \\
0,0012\end{array}$ & $\begin{array}{l}0,0312 \\
0,0120 \\
0,0045 \\
0,0032 \\
0,0015 \\
0,0007\end{array}$ \\
\hline $\begin{array}{c}10 \\
20 \\
30 \\
50 \\
100 \\
200 \\
\end{array}$ & $\overline{0,4}$ & 0,8 & 0,1111 & $\begin{array}{r}0,3830 \\
0,4102 \\
0,3300 \\
0,3958 \\
0,3986 \\
0,3967\end{array}$ & $\begin{array}{l}0,0218 \\
0,0109 \\
0,0012 \\
0,0030 \\
0,0021 \\
0,0008\end{array}$ & $\begin{array}{l}0,1327 \\
0,1110 \\
0,1120 \\
0,1127 \\
0,1071 \\
0,1134 \\
\end{array}$ & $\begin{array}{l}0,0074 \\
0,0076 \\
0,0046 \\
0,0027 \\
0,0014 \\
0,0007\end{array}$ & $\begin{array}{l}0,0258 \\
0,0010 \\
0,0023 \\
0,0012 \\
0,0005 \\
0,0003\end{array}$ \\
\hline $\begin{array}{c}10 \\
20 \\
30 \\
50 \\
100 \\
200 \\
\end{array}$ & 0,4 & 0.9 & 0,0526 & $\begin{array}{l}0,3950 \\
0,3905 \\
0,3807 \\
0,4011 \\
0,3958 \\
0,3964\end{array}$ & $\begin{array}{l}0,0228 \\
0,0127 \\
0,0077 \\
0,0054 \\
0,0023 \\
0,0013\end{array}$ & $\begin{array}{l}0,0557 \\
0,0534 \\
0,0488 \\
0,0583 \\
0,0551 \\
0,0542\end{array}$ & $\begin{array}{l}0,0010 \\
0,0031 \\
0,0017 \\
0,0016 \\
0,0005 \\
0,0004\end{array}$ & $\begin{array}{l}0,0000 \\
0,0012 \\
0,0005 \\
0,0004 \\
0,0002 \\
0,0001\end{array}$ \\
\hline $\begin{array}{c}10 \\
20 \\
30 \\
50 \\
100 \\
200 \\
\end{array}$ & 0,4 & 1,0 & 0,0 & $\begin{array}{l}0,4050 \\
0,3865 \\
0,3993 \\
0,4019 \\
0,3867 \\
0,4045\end{array}$ & $\begin{array}{l}0,0253 \\
0,0106 \\
0,007 \\
0,0041 \\
0,0023 \\
0,0013\end{array}$ & $\begin{array}{l}0,0100 \\
0,0000 \\
0,0025 \\
0,0007 \\
0,0008 \\
0,0012 \\
\end{array}$ & $\begin{array}{l}0,0100 \\
0,0000 \\
0,0001 \\
0,0000 \\
0,0000 \\
0,0000\end{array}$ & $\begin{array}{l}0,0000 \\
0,0000 \\
0,0000 \\
0,0000 \\
0,0000 \\
0,0000\end{array}$ \\
\hline $\begin{array}{c}10 \\
20 \\
30 \\
50 \\
100 \\
200 \\
\end{array}$ & 0,5 & 0,0 & 1,0 & $\begin{array}{l}0,5055 \\
0,5302 \\
0,50088 \\
0,5108 \\
0,0772 \\
0,5008 \\
\end{array}$ & $\begin{array}{l}0,0083 \\
0,0064 \\
0,0010 \\
0,0027 \\
0,0011 \\
0,0007\end{array}$ & $\begin{array}{l}1,3634 \\
1,1120 \\
1,1121 \\
1,0201 \\
1,0537 \\
1,0198 \\
\end{array}$ & $\begin{array}{l}1,2209 \\
0,2428 \\
0,2725 \\
0,0693 \\
0,0474 \\
0,0211\end{array}$ & $\begin{array}{l}1,2543 \\
0,2054 \\
0,2009 \\
0,0387 \\
0,0464 \\
0,0222\end{array}$ \\
\hline $\begin{array}{l}10 \\
20 \\
30 \\
50 \\
100 \\
200 \\
\end{array}$ & 0,5 & 0,1 & 0,8182 & $\begin{array}{l}0,4875 \\
0,5060 \\
0,5010 \\
0,5042 \\
0,4934 \\
0,5016\end{array}$ & $\begin{array}{l}0,0158 \\
0,0070 \\
0,0051 \\
0,0024 \\
0,0012 \\
0,0008\end{array}$ & $\begin{array}{l}1,2567 \\
0,8006 \\
0,8738 \\
0,8710 \\
0,8221 \\
0,8226 \\
\end{array}$ & $\begin{array}{l}, 1692 \\
0,1568 \\
0,0962 \\
0,0841 \\
0,0244 \\
0,0107 \\
\end{array}$ & $\begin{array}{l}, 2124 \\
0,1861 \\
0,1145 \\
0,0674 \\
0,0280 \\
0,0137 \\
\end{array}$ \\
\hline $\begin{array}{c}10 \\
20 \\
30 \\
50 \\
100 \\
200 \\
\end{array}$ & $\overline{0,5}$ & 0,2 & 0,6667 & $\begin{array}{l}0,5070 \\
0,4945 \\
0,4978 \\
0,4941 \\
0,4971 \\
0,4976\end{array}$ & $\begin{array}{l}0,0153 \\
0,0070 \\
0,0041 \\
0,0030 \\
0,0011 \\
0,0007\end{array}$ & $\begin{array}{l}0,8047 \\
0,7269 \\
0,6936 \\
0,6761 \\
0,6833 \\
0,6393\end{array}$ & $\begin{array}{l}0,4549 \\
0,1657 \\
0,0668 \\
0,0403 \\
0,0188 \\
0,0091\end{array}$ & $\begin{array}{l}0,4392 \\
0,1385 \\
0,030 \\
0,0398 \\
0,0194 \\
0,0089\end{array}$ \\
\hline
\end{tabular}


TABELA 8 - Médis e variâncis de frequência génica e da taxs de feumdaceso crumds extimadas em N=100 experimentos com amostras de trmanhos diferentes, extraides em populagoes de dois alelos com diverses combinagós de frequencies gênicas e coeficientes de endogamia.

\begin{tabular}{|c|c|c|c|c|c|c|c|c|}
\hline $\mathbf{n}$ & $\bar{p}$ & $\bar{F}$ & $t$ & $\overline{\mathbf{p}}$ & $\operatorname{Var}(\hat{\mathrm{p}})$ & t & $\operatorname{Var}(\hat{t})$ & $\sqrt{E_{r}(t)}$ \\
\hline $\begin{array}{l}10 \\
20 \\
30 \\
50 \\
100 \\
200\end{array}$ & 0,5 & 0,3 & 0,5335 & $\begin{array}{l}0,5105 \\
0,5000 \\
0,5098 \\
0,5054 \\
0,5024 \\
0,5004\end{array}$ & $\begin{array}{l}0,0167 \\
0,0006 \\
0,0062 \\
0,0029 \\
0,0015 \\
0,0008\end{array}$ & $\begin{array}{l}0,7768 \\
0,5573 \\
0,5422 \\
0,5400 \\
0,5002 \\
0,5241\end{array}$ & $\begin{array}{l}0,1000 \\
0,1243 \\
0,0452 \\
0,1244 \\
0,0100 \\
0,0045\end{array}$ & $\begin{array}{l}0,0257 \\
0,1110 \\
0,0452 \\
0,0260 \\
0,0129 \\
0,0056\end{array}$ \\
\hline $\begin{array}{l}10 \\
20 \\
30 \\
50 \\
100 \\
200 \\
\end{array}$ & 0,5 & 0,4 & 0,4286 & $\begin{array}{l}0,4005 \\
\text { as022 } \\
0,4922 \\
0,4975 \\
0,4068 \\
0,058\end{array}$ & $\begin{array}{l}0,0154 \\
0,0006 \\
0,0049 \\
0,0036 \\
0,0020 \\
0,0008\end{array}$ & $\begin{array}{l}0,046 \\
0,4611 \\
0,1357 \\
0,4676 \\
0,4521 \\
0,068\end{array}$ & $\begin{array}{l}0,1674 \\
0,014 \\
0,0310 \\
0,02013 \\
0,0141 \\
0,0044\end{array}$ & $\begin{array}{l}0,1642 \\
0,0313 \\
0,0204 \\
0,0191 \\
0,0087 \\
0,0039\end{array}$ \\
\hline $\begin{array}{l}10 \\
20 \\
30 \\
50 \\
100 \\
200 \\
\end{array}$ & 0,5 & 0,5 & 0,3333 & $\begin{array}{l}0,5185 \\
0,4945 \\
0,5008 \\
0,5124 \\
0,5012 \\
0,5018 \\
\end{array}$ & $\begin{array}{l}0,0218 \\
0,0072 \\
0,0056 \\
0,0034 \\
0,0021 \\
0,0006\end{array}$ & $\begin{array}{l}0,3925 \\
0,3768 \\
0,3344 \\
0,3262 \\
0,3414 \\
0,3445\end{array}$ & $\begin{array}{l}0,0,31 \\
0,0487 \\
0,0192 \\
0,0122 \\
0,0009 \\
0,0030\end{array}$ & $\begin{array}{l}0,0035 \\
0,0380 \\
0,0174 \\
0,0095 \\
0,0049 \\
0,0004\end{array}$ \\
\hline $\begin{array}{c}10 \\
20 \\
30 \\
50 \\
100 \\
200 \\
\end{array}$ & 0,5 & 0,6 & 0,2500 & $\begin{array}{l}0,5093 \\
0,5110 \\
0,5063 \\
0,5034 \\
0,4052 \\
0,4987\end{array}$ & $\begin{array}{l}0,0204 \\
0,0067 \\
0,0091 \\
0,0037 \\
0,0020 \\
0,0009\end{array}$ & $\begin{array}{l}0,3193 \\
0,2718 \\
0,2639 \\
0,2814 \\
0,2586 \\
0,2516\end{array}$ & $\begin{array}{l}0,0938 \\
0,0243 \\
0,0135 \\
0,0083 \\
0,0040 \\
0,0017\end{array}$ & $\begin{array}{l}0,0779 \\
0,0202 \\
0,0111 \\
0,0070 \\
0,0028 \\
0,0013\end{array}$ \\
\hline $\begin{array}{l}10 \\
20 \\
30 \\
50 \\
100 \\
200 \\
\end{array}$ & 0,5 & 0,7 & 0,1763 & $\begin{array}{l}0,4850 \\
0,4838 \\
0,5087 \\
0,4502 \\
0,5007 \\
0,5024\end{array}$ & $\begin{array}{l}0,0020 \\
0,0104 \\
0,0051 \\
0,0039 \\
0,0025 \\
0,0008\end{array}$ & $\begin{array}{l}0,2180 \\
0,1809 \\
0,1977 \\
0,1766 \\
0,1790 \\
0,1875\end{array}$ & $\begin{array}{l}0,0581 \\
0,0142 \\
0,0122 \\
0,0045 \\
0,0027 \\
0,0014\end{array}$ & $\begin{array}{l}0,0477 \\
0,0094 \\
0,0068 \\
0,0028 \\
0,0014 \\
0,0007\end{array}$ \\
\hline $\begin{array}{l}10 \\
20 \\
30 \\
50 \\
100 \\
200 \\
\end{array}$ & 0,5 & 0,8 & 0,1111 & $\begin{array}{l}0,5070 \\
0,4922 \\
0,5015 \\
0,5096 \\
0,4858 \\
0,4968\end{array}$ & $\begin{array}{l}0,0197 \\
0,0112 \\
0,0099 \\
0,0055 \\
0,0021 \\
0,0012 \\
\end{array}$ & $\begin{array}{l}0,1117 \\
0,1169 \\
0,1220 \\
0,1191 \\
0,1125 \\
0,1170\end{array}$ & $\begin{array}{l}0,0153 \\
0,0078 \\
0,0051 \\
0,0038 \\
0,0014 \\
0,0006\end{array}$ & $\begin{array}{l}0,0110 \\
0,0043 \\
0,0026 \\
0,0014 \\
0,0006 \\
0,0003\end{array}$ \\
\hline $\begin{array}{l}10 \\
20 \\
30 \\
50 \\
100 \\
200 \\
\end{array}$ & 0,5 & 0,9 & 0,0526 & $\begin{array}{l}0,5085 \\
0,4955 \\
0,5027 \\
0,5062 \\
0,4940 \\
0,5019\end{array}$ & $\begin{array}{l}0,0210 \\
0,0106 \\
0,0094 \\
0,0042 \\
0,0023 \\
0,0012\end{array}$ & $\begin{array}{l}0,0713 \\
0,0554 \\
0,0679 \\
0,0562 \\
0,0554 \\
0,0522\end{array}$ & $\begin{array}{l}0,0187 \\
0,0039 \\
0,0028 \\
0,0013 \\
0,0007 \\
0,0003\end{array}$ & $\begin{array}{l}0,0094 \\
0,0014 \\
0,0010 \\
0,0004 \\
0,0002 \\
0,0001\end{array}$ \\
\hline
\end{tabular}


TABELA 8 - Médis e variâncis da frequêncis génica e da taxa de fecundsgäo cruzads extimadas em N=100 experimenters com amostras de tomenhos diferentes, extraidas em populagöes de dois alelos com diverses combinagoles de freguencias génicas e coeficientes de endogrmia

\begin{tabular}{|c|c|c|c|c|c|c|c|c|}
\hline $\bar{n}$ & $\mathbf{p}$ & $\bar{F}$ & $t$ & $\overline{\mathbf{p}}$ & $\operatorname{Var}(\mathrm{p})$ & $\bar{t}$ & $\operatorname{Var}(\mathbf{t})$ & $\sqrt{\operatorname{car}(t)}$ \\
\hline $\begin{array}{c}10 \\
20 \\
30 \\
50 \\
100 \\
200\end{array}$ & 0,5 & 1,0 & 0,0 & $\begin{array}{l}0,5050 \\
0,4568 \\
0,4910 \\
0,4930 \\
0,4970 \\
0,018\end{array}$ & $\begin{array}{l}0,0105 \\
0,0105 \\
0,0038 \\
0,0045 \\
0,0023 \\
0,0013\end{array}$ & $\begin{array}{l}0,0011 \\
0,0015 \\
0,0015 \\
0,0001 \\
0,0014 \\
0,0011\end{array}$ & $\begin{array}{l}0,0001 \\
0,0001 \\
0,0001 \\
0,0000 \\
0,0000 \\
0,0000\end{array}$ & $\begin{array}{l}0,0002 \\
0,0000 \\
0,0000 \\
0,0000 \\
0,0000 \\
0,0000\end{array}$ \\
\hline $\begin{array}{l}10 \\
20 \\
30 \\
50 \\
100 \\
200\end{array}$ & 0,6 & 0,0 & 1,0 & $\begin{array}{l}0,6130 \\
0,6008 \\
0,5933 \\
0,6059 \\
0,0070 \\
0,6033\end{array}$ & $\begin{array}{l}0,0111 \\
0,0057 \\
0,0039 \\
0,0021 \\
0,0009 \\
0,0005\end{array}$ & $\begin{array}{l}1,3662 \\
1,1240 \\
1,0410 \\
1,0384 \\
0,9622 \\
1,0288\end{array}$ & $\begin{array}{l}1,0596 \\
0,3633 \\
0,1189 \\
0,1156 \\
0,0331 \\
0,0218\end{array}$ & $\begin{array}{l}1,1662 \\
0,3246 \\
0,1610 \\
0,0954 \\
0,0399 \\
0,0216\end{array}$ \\
\hline $\begin{array}{c}10 \\
20 \\
30 \\
50 \\
100 \\
200 \\
\end{array}$ & 0,6 & 0,1 & 0,8182 & $\begin{array}{l}0,6125 \\
0,5852 \\
0,6092 \\
0,5969 \\
0,5907 \\
0,6054 \\
\end{array}$ & $\begin{array}{l}0,0132 \\
0,0063 \\
0,0045 \\
0,0025 \\
0,0014 \\
0,0006\end{array}$ & $\begin{array}{l}0,9512 \\
0,8546 \\
0,8569 \\
0,8612 \\
0,8460 \\
0,8426\end{array}$ & $\begin{array}{l}0,1731 \\
0,1600 \\
0,1207 \\
0,0708 \\
0,0344 \\
0,0132\end{array}$ & $\begin{array}{l}0,5300 \\
0,1795 \\
0,1150 \\
0,0649 \\
0,0300 \\
0,0145\end{array}$ \\
\hline $\begin{array}{c}10 \\
20 \\
30 \\
50 \\
100 \\
200 \\
\end{array}$ & 0,6 & 0,2 & 0,6667 & $\begin{array}{l}0,6035 \\
0,6052 \\
0,6007 \\
0,5975 \\
0,5005 \\
0,6049 \\
\end{array}$ & $\begin{array}{l}0,0143 \\
0,0051 \\
0,0049 \\
0,0028 \\
0,0014 \\
0,0007\end{array}$ & $\begin{array}{l}0,8836 \\
0,7852 \\
0,6912 \\
0,0361 \\
0,6758 \\
0,6863 \\
\end{array}$ & $\begin{array}{l}1,0740 \\
0,1626 \\
0,0496 \\
0,0253 \\
0,0184 \\
0,0098\end{array}$ & $\begin{array}{l}0,7376 \\
0,1555 \\
0,0702 \\
0,0344 \\
0,0190 \\
0,0096\end{array}$ \\
\hline $\begin{array}{c}10 \\
20 \\
30 \\
50 \\
100 \\
200 \\
\end{array}$ & 0,6 & 0,3 & 0,5385 & $\begin{array}{l}0,5850 \\
0,6058 \\
0,5983 \\
0,6038 \\
0,6013 \\
0,5992 \\
\end{array}$ & $\begin{array}{l}0,0152 \\
0,0097 \\
0,0050 \\
0,0020 \\
0,0014 \\
0,0008\end{array}$ & $\begin{array}{l}0,6799 \\
0,5910 \\
0,5721 \\
0,5718 \\
0,5585 \\
0,5604 \\
\end{array}$ & $\begin{array}{l}0,0,058 \\
0,0744 \\
0,0510 \\
0,0362 \\
0,0152 \\
0,0070 \\
\end{array}$ & $\begin{array}{l}0,3020 \\
0,0852 \\
0,0504 \\
0,0290 \\
0,0131 \\
0,0064 \\
\end{array}$ \\
\hline $\begin{array}{c}10 \\
20 \\
30 \\
50 \\
100 \\
200\end{array}$ & 0,6 & 0,4 & 0,4286 & $\begin{array}{l}0,6093 \\
0,5935 \\
0,6083 \\
0,6073 \\
0,6028 \\
0,5986 \\
\end{array}$ & $\begin{array}{l}0,0183 \\
0,0092 \\
0,0055 \\
0,0030 \\
0,0017 \\
0,0009\end{array}$ & $\begin{array}{l}0,5168 \\
0,4651 \\
0,4843 \\
0,4292 \\
0,4577 \\
04522 \\
\end{array}$ & $\begin{array}{l}0,1835 \\
0,0614 \\
0,0394 \\
0,0180 \\
0,0100 \\
0,0049\end{array}$ & $\begin{array}{l}0,1795 \\
0,0554 \\
0,0365 \\
0,0162 \\
0,0088 \\
0,0042\end{array}$ \\
\hline $\begin{array}{l}10 \\
20 \\
30 \\
50 \\
100 \\
200\end{array}$ & 0,6 & 0,5 & 0,3333 & $\begin{array}{l}0,5905 \\
0,5985 \\
0,6040 \\
0,6056 \\
0,5939 \\
0,5993\end{array}$ & $\begin{array}{l}0,0142 \\
0,0111 \\
0,0053 \\
0,0033 \\
0,0018 \\
0,0010\end{array}$ & $\begin{array}{l}0,3627 \\
0,3485 \\
0,3579 \\
0,3315 \\
0,3391 \\
0,3377\end{array}$ & $\begin{array}{l}0,0680 \\
0,0200 \\
0,0322 \\
0,0110 \\
0,0061 \\
0,0025\end{array}$ & $\begin{array}{l}0,0796 \\
0,0300 \\
0,0213 \\
0,0099 \\
0,0048 \\
0,0023\end{array}$ \\
\hline
\end{tabular}


TABELA 8 - Médis e variŝncis de frequência gériç e da tere de fecundapolo cruzada estimadas em N=100 experimentos com amostres de tamenhos diferentes extreides em populegóes de dois alelos com diverses combinagoes de frequencias génicas e coeficientes de endogramia.

\begin{tabular}{|c|c|c|c|c|c|c|c|c|}
\hline $\mathbf{n}$ & $p$ & $\mathbf{P}$ & $t$ & $\bar{p}$ & $\overline{\operatorname{Var}(\hat{\mathrm{p}})}$ & 7 & $\operatorname{Var}(t)$ & $\sqrt{8}(t)$ \\
\hline $\begin{array}{l}10 \\
20 \\
30 \\
50 \\
100 \\
200\end{array}$ & 0,6 & 0,6 & 0,2500 & $\begin{array}{l}0,5930 \\
0,5980 \\
0,6085 \\
0,6038 \\
0,5957 \\
0,6009\end{array}$ & $\begin{array}{l}0,0250 \\
0,0091 \\
0,0058 \\
0,0039 \\
0,0015 \\
0,0010\end{array}$ & $\begin{array}{l}0,3512 \\
0,2050 \\
0,2552 \\
0,2560 \\
0,2003 \\
0,2008 \\
\end{array}$ & $\begin{array}{l}0,1338 \\
0,0339 \\
0,0220 \\
0,0075 \\
0,0037 \\
0,0018\end{array}$ & $\begin{array}{l}0,1091 \\
0,0246 \\
0,0116 \\
0,0038 \\
0,0026 \\
0,0013\end{array}$ \\
\hline $\begin{array}{l}10 \\
20 \\
30 \\
50 \\
100 \\
200\end{array}$ & 0,6 & 0,7 & 0,1765 & $\begin{array}{l}0,5805 \\
0,6022 \\
0,5815 \\
0,5918 \\
0,6036 \\
0,6016\end{array}$ & $\begin{array}{l}0,0215 \\
0,0107 \\
0,0058 \\
0,0010 \\
0,0022 \\
0,0013 \\
\end{array}$ & $\begin{array}{l}0,1812 \\
0,1811 \\
0,1773 \\
0,1777 \\
0,1769 \\
0,1781\end{array}$ & $\begin{array}{l}0,0371 \\
0,0200 \\
0,0091 \\
0,0000 \\
0,0022 \\
0,0012 \\
\end{array}$ & $\begin{array}{l}9,0285 \\
0,0103 \\
0,0054 \\
9,0030 \\
0,0013 \\
0,0007\end{array}$ \\
\hline $\begin{array}{c}10 \\
20 \\
30 \\
50 \\
100 \\
200\end{array}$ & 0,6 & 0,8 & Q,1111 & $\begin{array}{l}0,5845 \\
0,5930 \\
0,6028 \\
0,5936 \\
0,5953 \\
0,5999\end{array}$ & $\begin{array}{l}0,0215 \\
0,0059 \\
0,0082 \\
0,0036 \\
0,0020 \\
0,0012 \\
\end{array}$ & $\begin{array}{l}0,1272 \\
0,1222 \\
0,1272 \\
0,1160 \\
0,1145 \\
0,1136 \\
\end{array}$ & $\begin{array}{l}0,0200 \\
0,0093 \\
0,0074 \\
0,0044 \\
0,0016 \\
0,0008\end{array}$ & $\begin{array}{l}0,0162 \\
0,0048 \\
0,0031 \\
0,0014 \\
0,0006 \\
0,0003\end{array}$ \\
\hline $\begin{array}{l}10 \\
20 \\
30 \\
30 \\
100 \\
200\end{array}$ & 0,6 & 0,9 & 0,0526 & $\begin{array}{l}0,5885 \\
0,6058 \\
0,6038 \\
0,5808 \\
0,6031 \\
0,6007\end{array}$ & $\begin{array}{l}0,0234 \\
0,0123 \\
0,0083 \\
0,0037 \\
0,0020 \\
0,0015\end{array}$ & $\begin{array}{l}0,0522 \\
0,0625 \\
0,0584 \\
0,0517 \\
0,0589 \\
0,0523\end{array}$ & $\begin{array}{l}0,0063 \\
0,0042 \\
0,0022 \\
0,0012 \\
0,0008 \\
0,0003\end{array}$ & $\begin{array}{l}0,0036 \\
0,0016 \\
0,0007 \\
0,0003 \\
0,0002 \\
0,0001\end{array}$ \\
\hline $\begin{array}{c}10 \\
20 \\
30 \\
50 \\
100 \\
200\end{array}$ & 0,6 & 1,0 & 0,0 & $\begin{array}{l}0,5920 \\
0,6152 \\
0,6188 \\
0,6092 \\
0,6046 \\
05979\end{array}$ & $\begin{array}{l}0,0199 \\
0,0108 \\
0,0081 \\
0,0041 \\
0,0022 \\
0,0014\end{array}$ & $\begin{array}{l}0,0000 \\
0,0006 \\
0,0004 \\
0,0008 \\
0,0012 \\
0,0010 \\
\end{array}$ & $\begin{array}{l}0,0000 \\
0,0000 \\
0,0000 \\
0,0000 \\
0,0000 \\
0,0000\end{array}$ & $\begin{array}{l}0,0000 \\
0,0000 \\
0,0000 \\
0,0000 \\
0,0000 \\
0,0000 \\
\end{array}$ \\
\hline $\begin{array}{c}10 \\
20 \\
30 \\
50 \\
100 \\
200 \\
\end{array}$ & 0,7 & 0,0 & 1,0 & $\begin{array}{l}0,6910 \\
0,6990 \\
0,6963 \\
0,6992 \\
0,7016 \\
0,7018 \\
\end{array}$ & $\begin{array}{l}0,0104 \\
0,0055 \\
0,0035 \\
0,0025 \\
0,0009 \\
0,0005\end{array}$ & $\begin{array}{l}1,2671 \\
1,0098 \\
1,0868 \\
1,0547 \\
1,0254 \\
1,0492 \\
\end{array}$ & $\begin{array}{l}0,7202 \\
0,2078 \\
0,1399 \\
0,1048 \\
0,0324 \\
0,0150\end{array}$ & $\begin{array}{l}0,9274 \\
0,2451 \\
0,1760 \\
00972 \\
0,0433 \\
0,0223\end{array}$ \\
\hline $\begin{array}{c}10 \\
20 \\
30 \\
50 \\
100 \\
200 \\
\end{array}$ & 0,7 & 0,1 & 0,8182 & $\begin{array}{l}0,6810 \\
0,7008 \\
0,7032 \\
0,6983 \\
0,7032 \\
0,7029 \\
\end{array}$ & $\begin{array}{l}0,0139 \\
0,0060 \\
0,0033 \\
0,0027 \\
0,0009 \\
0,0006 \\
\end{array}$ & $\begin{array}{l}1,0438 \\
0,9740 \\
0,9100 \\
0,8661 \\
0,8359 \\
0,80034\end{array}$ & $\begin{array}{l}0,5082 \\
0,2743 \\
0,1535 \\
0,0553 \\
0,0279 \\
0,0164\end{array}$ & $\begin{array}{l}0,6370 \\
0,2440 \\
0,1307 \\
0,0644 \\
0,0290 \\
0,0132\end{array}$ \\
\hline
\end{tabular}


TABELA 8 - Médir e varifincis de frequêncis genica e de taxa de fecundacho crurads extimadas em $\mathrm{N}=100$ experimentus com emostras de tamanhos diferentus extridas em populagóes de dois alelos com diversas combinacbes de frequércies génices e coeficientes de endogrmia.

\begin{tabular}{|c|c|c|c|c|c|c|c|c|}
\hline $\mathbf{n}$ & $\mathbf{p}$ & $\bar{F}$ & $t$ & $\overline{9}$ & $\operatorname{Var}(\hat{p})$ & t & $\sqrt{8 \pi}(t)$ & $\sqrt{8 / 5}(t)$ \\
\hline $\begin{array}{c}10 \\
20 \\
30 \\
50 \\
100 \\
200 \\
\end{array}$ & 0,7 & 0,2 & 0,6667 & $\begin{array}{l}0,6895 \\
0,6950 \\
0,6958 \\
0,7007 \\
0,7014 \\
0,6951\end{array}$ & $\begin{array}{l}0,0144 \\
0,0086 \\
0,0012 \\
0,0019 \\
0,0010 \\
0,0005 \\
\end{array}$ & $\begin{array}{l}0,8490 \\
0,7674 \\
0.9067 \\
0,7057 \\
0,6979 \\
0.5 \% 1\end{array}$ & $\begin{array}{l}0,4504 \\
0,1640 \\
0,0126 \\
0,0519 \\
0,0254 \\
0,0112\end{array}$ & $\begin{array}{l}0,0673 \\
0,1502 \\
0,0743 \\
0,0410 \\
0,0199 \\
0,0097\end{array}$ \\
\hline $\begin{array}{l}10 \\
20 \\
30 \\
50 \\
100 \\
200\end{array}$ & $\overline{0,7}$ & 0,3 & 0,5385 & $\begin{array}{l}0,975 \\
0,7002 \\
0,7107 \\
0,7041 \\
0,6984 \\
0,6982\end{array}$ & $\begin{array}{l}0,0165 \\
0,0074 \\
0,0043 \\
0,0032 \\
0,0017 \\
0,0004\end{array}$ & $\begin{array}{l}0,3666 \\
0,6473 \\
0,5993 \\
0,5807 \\
0,5679 \\
0,5474 \\
\end{array}$ & $\begin{array}{l}0,3058 \\
0,1320 \\
0,0628 \\
0,0390 \\
0,0142 \\
0,0070 \\
\end{array}$ & $\begin{array}{l}0,3565 \\
0,0095 \\
0,0562 \\
0,0301 \\
0,0135 \\
0,0151 \\
\end{array}$ \\
\hline $\begin{array}{l}10 \\
20 \\
30 \\
50 \\
100 \\
200\end{array}$ & 0,7 & 0,4 & 0,4286 & $\begin{array}{l}0,7100 \\
0,7000 \\
0,7078 \\
0,6972 \\
0,7010 \\
0,7026 \\
\end{array}$ & $\begin{array}{l}0,0130 \\
0,0085 \\
0,0044 \\
0,0037 \\
0,0015 \\
0,0008 \\
\end{array}$ & $\begin{array}{l}0,170 \\
0,4648 \\
0,4516 \\
0,4564 \\
0,4278 \\
0,4340\end{array}$ & $\begin{array}{l}0,2515 \\
0,0500 \\
0,0476 \\
0,00281 \\
0,0109 \\
0,0043\end{array}$ & $\begin{array}{l}0,2545 \\
0,0569 \\
0,0335 \\
0,0189 \\
0,0078 \\
0,0039\end{array}$ \\
\hline $\begin{array}{l}10 \\
20 \\
30 \\
50 \\
100 \\
200\end{array}$ & 0,7 & $\overline{0,5}$ & 0,3333 & $\begin{array}{l}0,7193 \\
0,6965 \\
0,6930 \\
0,7051 \\
0,6932 \\
0,7005\end{array}$ & $\begin{array}{l}0,0110 \\
0,0000 \\
0,0059 \\
0,0032 \\
0,0016 \\
0,0008\end{array}$ & $\begin{array}{l}0,1236 \\
0,3738 \\
0,3618 \\
0,3508 \\
0,3598 \\
0,3394 \\
\end{array}$ & $\begin{array}{l}0,1311 \\
0,0620 \\
0,0258 \\
0,0133 \\
0,0084 \\
0,0028\end{array}$ & $\begin{array}{l}0,1237 \\
0,0402 \\
0,0209 \\
0,0109 \\
0,0055 \\
0,0024\end{array}$ \\
\hline $\begin{array}{c}10 \\
20 \\
30 \\
50 \\
100 \\
200\end{array}$ & 0,7 & 0,6 & 0,2500 & $\begin{array}{l}0,6690 \\
0,7030 \\
0,7047 \\
0,6968 \\
0,7137 \\
0,6932 \\
\end{array}$ & $\begin{array}{l}0,0184 \\
0,0077 \\
0,0062 \\
0,0133 \\
0,0014 \\
0,0010\end{array}$ & $\begin{array}{l}0,3467 \\
0,3179 \\
0,2732 \\
0,2512 \\
0,2674 \\
0,2533 \\
\end{array}$ & $\begin{array}{l}0,1380 \\
0,0301 \\
0,0215 \\
0,0102 \\
0,0050 \\
0,0027 \\
\end{array}$ & $\begin{array}{l}0,1027 \\
0,0262 \\
0,0128 \\
0,0059 \\
0,0031 \\
0,0013\end{array}$ \\
\hline $\begin{array}{l}10 \\
20 \\
30 \\
50 \\
100 \\
200\end{array}$ & 0,7 & 0,7 & 0,1765 & $\begin{array}{l}0,7020 \\
0,6965 \\
0,7115 \\
0,6986 \\
0,7070 \\
0,7006\end{array}$ & $\begin{array}{l}0,0180 \\
0,0069 \\
0,0061 \\
0,0034 \\
0,0014 \\
0,0009\end{array}$ & $\begin{array}{l}0,2210 \\
0,1888 \\
0,2037 \\
0,1890 \\
0,1953 \\
0,1799 \\
\end{array}$ & $\begin{array}{l}0,0717 \\
0,0174 \\
0,0137 \\
0,0065 \\
0,0034 \\
0,0020\end{array}$ & $\begin{array}{l}0,0180 \\
0,0106 \\
0,0073 \\
0,0034 \\
0,0017 \\
0,0007 \\
\end{array}$ \\
\hline $\begin{array}{c}10 \\
20 \\
30 \\
50 \\
100 \\
200 \\
\end{array}$ & 0,7 & 0,8 & 0,1111 & $\begin{array}{l}0,6965 \\
0,6918 \\
0,7120 \\
0,7072 \\
0,7052 \\
0,7002 \\
\end{array}$ & $\begin{array}{l}0,0203 \\
0,0104 \\
0,0068 \\
0,0046 \\
0,0022 \\
0,0009\end{array}$ & $\begin{array}{l}0,1797 \\
0,1196 \\
0,1273 \\
0,1287 \\
0,1134 \\
0,1174\end{array}$ & $\begin{array}{l}0,065 \\
0,0253 \\
0,0092 \\
0,0053 \\
0,0017 \\
0,0010\end{array}$ & $\begin{array}{l}0,0389 \\
0,0079 \\
0,0034 \\
0,0017 \\
0,0006 \\
0,0003\end{array}$ \\
\hline
\end{tabular}


TABELA 8 - Média e variância da frequência génica e de tara de fecundaca o cruzada estimadas em $\mathrm{N}=100$ experimentos com amostras de tamanhos diferentes extraidas em populagôes de dois slelos com diverses combinagbes de frequencias gênicas e coeficientes de endogamia.

\begin{tabular}{|c|c|c|c|c|c|c|c|c|}
\hline $\mathbf{n}$ & $p$ & $\mathbf{F}$ & $t$ & $\overline{8}$ & $\sqrt{\operatorname{ar}(0)}$ & $t$ & $\operatorname{Ver}(t)$ & $\sqrt{\mathbb{R}}(t)$ \\
\hline $\begin{array}{c}10 \\
20 \\
30 \\
50 \\
100 \\
200\end{array}$ & 0,7 & 0,9 & 0,0336 & $\begin{array}{l}0,0855 \\
0,7140 \\
0,6828 \\
0,7016 \\
0,7002 \\
0.6906\end{array}$ & $\begin{array}{l}0,0188 \\
0,0084 \\
0,0081 \\
0,0037 \\
0,0025 \\
0,0011\end{array}$ & $\begin{array}{l}0,0304 \\
0,0594 \\
0,0518 \\
0,0580 \\
0,0517 \\
0,0513 \\
\end{array}$ & $\begin{array}{l}0,0115 \\
0,0057 \\
0,0028 \\
0,0018 \\
0,0007 \\
0,0003\end{array}$ & $\begin{array}{l}0,0093 \\
0,0018 \\
0,0009 \\
0,0004 \\
0,0001 \\
0,0001\end{array}$ \\
\hline $\begin{array}{l}10 \\
20 \\
30 \\
50 \\
100 \\
200\end{array}$ & 0.7 & 1,0 & 0,0 & $\begin{array}{l}0,7065 \\
0,6010 \\
0,7052 \\
0,6952 \\
0,6984 \\
0,7067\end{array}$ & $\begin{array}{l}0,0247 \\
0,0104 \\
0,0081 \\
0,0037 \\
0,0020 \\
0,0014 \\
\end{array}$ & $\begin{array}{l}0,0310 \\
0,0012 \\
0,0012 \\
0,0026 \\
0,0008 \\
0.0014\end{array}$ & $\begin{array}{l}0,0204 \\
0,0001 \\
0,0001 \\
0,0001 \\
0,0000 \\
0,0000\end{array}$ & $\begin{array}{l}0,0120 \\
0,0000 \\
0,0000 \\
0,0000 \\
0,0000 \\
0,0000\end{array}$ \\
\hline $\begin{array}{c}10 \\
20 \\
30 \\
50 \\
100 \\
200\end{array}$ & 0,8 & 00 & 1,0 & $\begin{array}{l}0,7955 \\
0,4008 \\
0,8073 \\
0,7967 \\
0,8014 \\
0,7987 \\
\end{array}$ & $\begin{array}{l}0,0055 \\
0,0010 \\
0,0050 \\
0,0014 \\
0,0008 \\
0,0004\end{array}$ & $\begin{array}{l}1,1572 \\
1,0646 \\
1,1334 \\
1,0768 \\
1,0792 \\
1,0235 \\
\end{array}$ & $\begin{array}{l}0,0355 \\
0,1990 \\
0,1906 \\
0,0758 \\
0,0515 \\
0,0221\end{array}$ & $\begin{array}{l}\text { 13,0169 } \\
0,2661 \\
0,1964 \\
0,0988 \\
0,0486 \\
0,0214\end{array}$ \\
\hline $\begin{array}{l}10 \\
20 \\
30 \\
50 \\
100 \\
200\end{array}$ & 0,8 & 0,1 & 0,8182 & $\begin{array}{l}0,8173 \\
0,8002 \\
0,8013 \\
0,8019 \\
0,8059 \\
0,7998\end{array}$ & $\begin{array}{l}0,0074 \\
0,0047 \\
0,028 \\
0,0015 \\
0,0009 \\
0,0004 \\
\end{array}$ & $\begin{array}{l}1,0190 \\
0,9468 \\
0,8757 \\
0,8515 \\
0,8571 \\
0,8235 \\
\end{array}$ & $\begin{array}{l}0,2534 \\
0,1687 \\
0,1192 \\
0,0734 \\
0,0370 \\
0,0129\end{array}$ & $\begin{array}{l}0,5156 \\
0,2134 \\
0,1180 \\
0,0652 \\
0,0309 \\
0,0138\end{array}$ \\
\hline $\begin{array}{l}10 \\
20 \\
30 \\
50 \\
100 \\
200\end{array}$ & 0,8 & 0,2 & 0,6667 & $\begin{array}{l}0,8120 \\
0,7922 \\
0,8132 \\
0,0057 \\
0,7977 \\
0,8012 \\
\end{array}$ & $\begin{array}{l}0,0075 \\
0,0056 \\
0,0026 \\
0,0017 \\
0,0009 \\
0,0006\end{array}$ & $\begin{array}{l}0,921 \\
0,9421 \\
0,7513 \\
0,7304 \\
0,7249 \\
0,6801 \\
\end{array}$ & $\begin{array}{l}0,2798 \\
0,2798 \\
0,1073 \\
0,0620 \\
0,0324 \\
0,0120 \\
\end{array}$ & $\begin{array}{l}0,4658 \\
0,4658 \\
0,0304 \\
0,0477 \\
0,0223 \\
0,0095\end{array}$ \\
\hline $\begin{array}{c}10 \\
20 \\
30 \\
50 \\
100 \\
200\end{array}$ & 0,8 & 0,3 & 0,3383 & $\begin{array}{l}0,7965 \\
0,7928 \\
0,7918 \\
0,8013 \\
0,7990 \\
0,7964 \\
\end{array}$ & $\begin{array}{l}0,0050 \\
0,0051 \\
0,0042 \\
0,0019 \\
0,0009 \\
0,0004\end{array}$ & $\begin{array}{l}0,8572 \\
0,7005 \\
0,6259 \\
0,5442 \\
0,5576 \\
0,5372 \\
\end{array}$ & $\begin{array}{l}0,2506 \\
0,1693 \\
0,0660 \\
0,0434 \\
0,0213 \\
0,0008\end{array}$ & $\begin{array}{l}0,3796 \\
0,1317 \\
0,0610 \\
0,0271 \\
0,0133 \\
0,0060\end{array}$ \\
\hline $\begin{array}{l}10 \\
20 \\
30 \\
50 \\
100 \\
200\end{array}$ & 0,8 & 0,4 & 0,4286 & $\begin{array}{l}0,8280 \\
0,7892 \\
0,8042 \\
0,8016 \\
0,8016 \\
0,7997 \\
\end{array}$ & $\begin{array}{l}0,0114 \\
0,0058 \\
0,0036 \\
0,0020 \\
0,0012 \\
0,0005\end{array}$ & $\begin{array}{l}0,7154 \\
0,4880 \\
0,4932 \\
0,4389 \\
0,4383 \\
0,4404\end{array}$ & $\begin{array}{l}0,1920 \\
0,1182 \\
0,0811 \\
0,0380 \\
0,0151 \\
0,0073\end{array}$ & $\begin{array}{l}0,28088 \\
0,0710 \\
0,0431 \\
0,0184 \\
0,0083 \\
0,0040\end{array}$ \\
\hline
\end{tabular}


TABELA 8 - Média e variância de frequência génice e da taxa de foundacto crusada estimadas em N=100 experimentos com amostres de tamanhos diferentes, extridas em populaçós de dois alelos com diversas combinapōes de frequencias gêricas e coeficientes de endogamia.

\begin{tabular}{|c|c|c|c|c|c|c|c|c|}
\hline $\mathbf{n}$ & $p$ & $\mathbf{F}$ & $t$ & 8 & $\operatorname{Var}(\hat{\mathrm{p}})$ & t & $\operatorname{Ver}(t)$ & $\sqrt{8 r}(t)$ \\
\hline $\begin{array}{l}10 \\
20 \\
30 \\
50 \\
100 \\
200 \\
\end{array}$ & 0,8 & 0,5 & 0,3333 & $\begin{array}{l}0,8105 \\
0,7935 \\
0,7978 \\
0,0050 \\
0,7996 \\
0,7998 \\
\end{array}$ & $\begin{array}{l}0,0109 \\
0,007 \\
0,0041 \\
0,0025 \\
0,0011 \\
0,0006\end{array}$ & $\begin{array}{l}0,5451 \\
0,4609 \\
0,1035 \\
0,3034 \\
0,3249 \\
03496\end{array}$ & $\begin{array}{l}0,1818 \\
0,0925 \\
0,0616 \\
0,0213 \\
0,0097 \\
0,0053\end{array}$ & $\begin{array}{l}0.1503 \\
0,0008 \\
0,0302 \\
0,0122 \\
0,0046 \\
0,0025 \\
\end{array}$ \\
\hline $\begin{array}{l}10 \\
20 \\
30 \\
50 \\
100 \\
200 \\
\end{array}$ & 0,8 & 0,6 & 0,2500 & $\begin{array}{l}0,0065 \\
0,0052 \\
0,0087 \\
0,0048 \\
0,0004 \\
0,0010 \\
\end{array}$ & $\begin{array}{l}0,0172 \\
0,0001 \\
0,0032 \\
0,0020 \\
0,0011 \\
0,0006\end{array}$ & $\begin{array}{l}0,4581 \\
0,3566 \\
0,2868 \\
0,2442 \\
0,2621 \\
0,2446\end{array}$ & $\begin{array}{l}0,1685 \\
0,0004 \\
0,0344 \\
0,0140 \\
0,0077 \\
0,0035\end{array}$ & $\begin{array}{l}0,1505 \\
0,0131 \\
0,0153 \\
0,0059 \\
0,0031 \\
0,0013\end{array}$ \\
\hline $\begin{array}{c}10 \\
20 \\
30 \\
50 \\
100 \\
200 \\
\end{array}$ & 0,8 & 0,7 & 0,1763 & $\begin{array}{l}0,7850 \\
0,7053 \\
0,8052 \\
0,8013 \\
0,7953 \\
0,8050 \\
\end{array}$ & $\begin{array}{l}0,0144 \\
0,0067 \\
0,0044 \\
0,0031 \\
0,0014 \\
0,0008\end{array}$ & $\begin{array}{l}0,2927 \\
0,2259 \\
0,2269 \\
0,1706 \\
0,1903 \\
0,1806\end{array}$ & $\begin{array}{l}0,1461 \\
0,0408 \\
0,0340 \\
0,0071 \\
0,0063 \\
0,0021\end{array}$ & $\begin{array}{l}0,0921 \\
0,0201 \\
0,0114 \\
0,0029 \\
0,0017 \\
0,0007 \\
\end{array}$ \\
\hline $\begin{array}{c}10 \\
20 \\
30 \\
50 \\
100 \\
200 \\
\end{array}$ & 0,8 & 0,8 & 0,1111 & $\begin{array}{l}0,8040 \\
0,7962 \\
0,7935 \\
0,8002 \\
0,7999 \\
0,7994\end{array}$ & $\begin{array}{l}0,0121 \\
0,0068 \\
0,0057 \\
0,0022 \\
0,0014 \\
0,0007\end{array}$ & $\begin{array}{l}0,2570 \\
0,1422 \\
0,1574 \\
0,1196 \\
0,1266 \\
0,1211\end{array}$ & $\begin{array}{l}0,1272 \\
0,328 \\
0,0222 \\
0,0050 \\
0,0025 \\
0,0012\end{array}$ & $\begin{array}{l}0,0768 \\
0,0106 \\
0,0062 \\
0,0015 \\
0,0007 \\
0,0003\end{array}$ \\
\hline $\begin{array}{c}10 \\
20 \\
30 \\
50 \\
100 \\
200 \\
\end{array}$ & 0,8 & 0,9 & 0,0326 & $\begin{array}{l}0,7900 \\
0,7998 \\
0,7928 \\
0,8020 \\
0,7989 \\
0,8056 \\
\end{array}$ & $\begin{array}{l}0,0114 \\
0,0074 \\
0,0064 \\
0,0026 \\
0,0015 \\
0,0007\end{array}$ & $\begin{array}{l}0,0838 \\
0,0711 \\
0,0539 \\
0,0637 \\
0,0549 \\
0,0556 \\
\end{array}$ & $\begin{array}{l}0,0333 \\
0,0285 \\
0,0028 \\
0,0020 \\
0,0011 \\
0,0005 \\
\end{array}$ & $\begin{array}{l}0,0160 \\
0,0067 \\
0,0008 \\
0,0005 \\
0,0002 \\
0,0001\end{array}$ \\
\hline $\begin{array}{c}10 \\
20 \\
30 \\
50 \\
100 \\
200 \\
\end{array}$ & 0,8 & 1,0 & 0,0 & $\begin{array}{l}0,8093 \\
0,7948 \\
0,7922 \\
0,8032 \\
0,8028 \\
0,7950\end{array}$ & $\begin{array}{l}0,0133 \\
0,0098 \\
0,0061 \\
0,0030 \\
0,0016 \\
0,0008 \\
\end{array}$ & $\begin{array}{l}0,1125 \\
0,0107 \\
0,0012 \\
0,0031 \\
0,0018 \\
0,0016 \\
\end{array}$ & $\begin{array}{l}0,0986 \\
0,0100 \\
0,0001 \\
0,0001 \\
0,0000 \\
0,0000\end{array}$ & $\begin{array}{l}0,0411 \\
0,0020 \\
0,0000 \\
0,0000 \\
0,0000 \\
0,0000\end{array}$ \\
\hline $\begin{array}{c}10 \\
20 \\
30 \\
50 \\
100 \\
200 \\
\end{array}$ & 0,9 & 0,0 & 1,0 & $\begin{array}{l}0,5040 \\
0,8808 \\
0,5007 \\
0,5032 \\
0,9024 \\
0,9030\end{array}$ & $\begin{array}{l}0,0044 \\
0,0026 \\
0,0014 \\
0,0010 \\
0,0003 \\
0,0002 \\
\end{array}$ & $\begin{array}{l}1,0867 \\
1,0890 \\
1,0762 \\
1,0403 \\
1,0248 \\
1,0390 \\
\end{array}$ & $\begin{array}{l}0,0350 \\
0,0707 \\
0,0679 \\
0,0604 \\
0,0104 \\
0,0178\end{array}$ & $\begin{array}{l}0,4941 \\
0,2512 \\
0,1634 \\
0,0914 \\
0,0436 \\
0,0219\end{array}$ \\
\hline
\end{tabular}


TABELA 8 - Média e variância da frequêncis génica e da taxa de fecundaço cruxads estimadas em $\mathrm{N}=100$ experimertos com amostras de trmenhos diferenter, extraides em populagies de dois alelos com diversas combinaç̄es de frequencias gênicas e coeficientes de endogemin

\begin{tabular}{|c|c|c|c|c|c|c|c|c|}
\hline $\mathbf{n}$ & $\mathbf{p}$ & $\bar{F}$ & $t$ & $\bar{p}$ & $\operatorname{Ver}(\hat{p})$ & t & $\operatorname{Var}(t)$ & $\sqrt{8}(t)$ \\
\hline $\begin{array}{c}10 \\
20 \\
30 \\
30 \\
100 \\
200 \\
\end{array}$ & 09 & 0,1 & 0,8182 & $\begin{array}{l}0,5035 \\
0,0045 \\
0,5057 \\
0,005 \\
00034 \\
08093\end{array}$ & $\begin{array}{l}0,0033 \\
0,0032 \\
0,0014 \\
0,0009 \\
0,0004 \\
0,0003\end{array}$ & 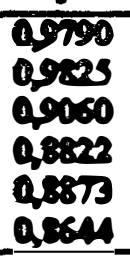 & $\begin{array}{l}0,1256 \\
0,0875 \\
0,1208 \\
0,0820 \\
0,0476 \\
0,0187\end{array}$ & $\begin{array}{l}0,1331 \\
0,2104 \\
6,1266 \\
0,0638 \\
0,0334 \\
0,0153\end{array}$ \\
\hline $\begin{array}{c}10 \\
20 \\
30 \\
50 \\
100 \\
200 \\
\end{array}$ & 0,9 & 0,2 & 0,6667 & $\begin{array}{l}0,5075 \\
0,5028 \\
0,0973 \\
0,0987 \\
0,5030 \\
0,8993 \\
\end{array}$ & $\begin{array}{l}0,0045 \\
0,0021 \\
0,0021 \\
0,0014 \\
0,0003 \\
0,0003 \\
\end{array}$ & $\begin{array}{l}0,9174 \\
0,8116 \\
0,7830 \\
0,7808 \\
0,7561 \\
0,6792 \\
\end{array}$ & $\begin{array}{l}0,1381 \\
0,1432 \\
0,1217 \\
0,0008 \\
0,0003 \\
0,0179\end{array}$ & $\begin{array}{l}0,3913 \\
0,1710 \\
0,0978 \\
0,0559 \\
0,0245 \\
0,0096\end{array}$ \\
\hline $\begin{array}{c}10 \\
20 \\
30 \\
50 \\
100 \\
200 \\
\end{array}$ & 0,9 & 0,3 & 0,5385 & $\begin{array}{l}0,0093 \\
0,0052 \\
0,8973 \\
0,8987 \\
0,5030 \\
0,8093 \\
\end{array}$ & $\begin{array}{l}0,0058 \\
0,0022 \\
0,0021 \\
0,0014 \\
0,0005 \\
0,0003\end{array}$ & $\begin{array}{l}0,8716 \\
0,7939 \\
0,7830 \\
0,7808 \\
0,7561 \\
0.6792\end{array}$ & $\begin{array}{l}0,1388 \\
0,1695 \\
0,1217 \\
0,0808 \\
0,0018 \\
0,0179 \\
\end{array}$ & $\begin{array}{l}0,3589 \\
0,1596 \\
0,0978 \\
0,0559 \\
0,0245 \\
0,0004\end{array}$ \\
\hline $\begin{array}{c}10 \\
20 \\
30 \\
50 \\
100 \\
200 \\
\end{array}$ & 0,9 & 0,4 & 0,4286 & $\begin{array}{l}0,0025 \\
0,9120 \\
0,0087 \\
0,0047 \\
0,9042 \\
0,0000\end{array}$ & $\begin{array}{l}0,0052 \\
0,0024 \\
0,0023 \\
0,0010 \\
0,0006 \\
0,0003\end{array}$ & $\begin{array}{l}0,7682 \\
0,5916 \\
0,5805 \\
0,4943 \\
0,4821 \\
0,430 \\
\end{array}$ & $\begin{array}{l}0,1856 \\
0,1859 \\
0,1366 \\
0,0646 \\
0,0413 \\
0,0164 \\
\end{array}$ & $\begin{array}{l}0,3220 \\
0,1068 \\
0,0630 \\
0,0247 \\
0,0109 \\
0,0041\end{array}$ \\
\hline $\begin{array}{c}10 \\
20 \\
30 \\
50 \\
100 \\
200 \\
\end{array}$ & 0,9 & 0,5 & 0,3333 & $\begin{array}{l}0,9143 \\
0,5018 \\
0,5012 \\
0,9035 \\
0,9000 \\
0,8982\end{array}$ & $\begin{array}{l}0,0035 \\
0,0032 \\
0,0026 \\
0,0014 \\
0,0008 \\
0,0003 \\
\end{array}$ & $\begin{array}{l}0,7433 \\
0,5057 \\
0,4491 \\
0,3874 \\
0,3720 \\
0,3327 \\
\end{array}$ & $\begin{array}{l}0,1964 \\
0,1737 \\
0,1098 \\
0,0361 \\
0,0257 \\
0,0076\end{array}$ & $\begin{array}{l}0,0888 \\
0,0856 \\
0,0414 \\
0,0164 \\
0,0066 \\
0,0024\end{array}$ \\
\hline $\begin{array}{c}10 \\
20 \\
30 \\
30 \\
100 \\
200 \\
\end{array}$ & 0,9 & 0,6 & 0,2500 & $\begin{array}{l}0,8880 \\
0,8985 \\
0,9030 \\
0,9027 \\
0,8972 \\
0,9014\end{array}$ & $\begin{array}{l}0,0083 \\
0,0010 \\
0,0023 \\
0,0012 \\
0,0003 \\
0,0004\end{array}$ & $\begin{array}{l}0,5739 \\
0,1642 \\
0,3500 \\
0,2850 \\
0,2639 \\
0,2625\end{array}$ & $\begin{array}{l}0,2272 \\
0,1707 \\
0,1183 \\
0,0312 \\
0,0159 \\
0,0077 \\
\end{array}$ & $\begin{array}{l}0,217 \\
0,0769 \\
0,0320 \\
0,0092 \\
0,0034 \\
0,0015 \\
\end{array}$ \\
\hline $\begin{array}{c}10 \\
0 \\
30 \\
50 \\
100 \\
200\end{array}$ & 0,9 & 0,7 & 0,1763 & $\begin{array}{l}0,8930 \\
0,8952 \\
09012 \\
0,8962 \\
0,9031 \\
0,8998\end{array}$ & $\begin{array}{l}0,0079 \\
0,0031 \\
0,0028 \\
0,0020 \\
0,0005 \\
0,0003\end{array}$ & $\begin{array}{l}0,4787 \\
0,3388 \\
0,2740 \\
0,2138 \\
0,1980 \\
01787 \\
\end{array}$ & $\begin{array}{l}0,2349 \\
0,1428 \\
0,0822 \\
0,0205 \\
0,0138 \\
0,0022\end{array}$ & $\begin{array}{l}0,1847 \\
0,0512 \\
0,0209 \\
0,0069 \\
0,0021 \\
0,0007\end{array}$ \\
\hline
\end{tabular}


TABELA 8 - Média e variéncia de frequencia genics e de tara de fecundagio cruzsda estinadas em N=100 experimentos com amostras de tamenhos diferentes, extraddas em populacio de dois alelos com diversas combinafoes de frequencias genicas e coeficientes de endogamia

\begin{tabular}{|c|c|c|c|c|c|c|c|c|}
\hline $\mathbf{n}$ & $p$ & $F$ & $t$ & $\overline{\mathbf{p}}$ & $\operatorname{Ver}(\hat{p})$ & $t$ & $\operatorname{Var}(t)$ & $\sqrt{8}(t)$ \\
\hline $\begin{array}{l}10 \\
20 \\
30 \\
50 \\
100 \\
200 \\
\end{array}$ & 0,9 & 0,8 & 0,1111 & $\begin{array}{l}0,5015 \\
0,5015 \\
0,0032 \\
0,5021 \\
0,9015 \\
0,5020\end{array}$ & $\begin{array}{l}0,0015 \\
0,0046 \\
0,0022 \\
0,0013 \\
0,0011 \\
0,0005\end{array}$ & $\begin{array}{l}0,268 \\
0,2006 \\
0,1909 \\
0,1125 \\
0,1219 \\
0,1182 \\
\end{array}$ & $\begin{array}{l}0,2210 \\
0,1332 \\
0,0664 \\
0,0231 \\
0,0050 \\
0,0017\end{array}$ & $\begin{array}{l}0,1740 \\
0,0400 \\
0,0139 \\
0,0029 \\
0,0008 \\
0,0003\end{array}$ \\
\hline $\begin{array}{c}10 \\
20 \\
30 \\
50 \\
100 \\
200 \\
\end{array}$ & 0.9 & 0,9 & 0,0526 & $\begin{array}{l}0,8995 \\
0,5030 \\
0,5055 \\
0,9010 \\
9,8997 \\
0,097\end{array}$ & $\begin{array}{l}0,0081 \\
0,0033 \\
0,0026 \\
0,0013 \\
0,0009 \\
0,0001 \\
\end{array}$ & $\begin{array}{l}0,3714 \\
0,1500 \\
0,1298 \\
0.0460 \\
0,0656 \\
0,0598 \\
\end{array}$ & $\begin{array}{l}0,2194 \\
0,0310 \\
0,0664 \\
0,0030 \\
0,0023 \\
0,0008\end{array}$ & $\begin{array}{r}91421 \\
9,0225 \\
0,0110 \\
0,0004 \\
9,0003 \\
00001 \\
\end{array}$ \\
\hline $\begin{array}{c}10 \\
20 \\
30 \\
50 \\
100 \\
200\end{array}$ & 0,9 & 1,0 & 0,0 & $\begin{array}{l}0,8985 \\
0,9112 \\
0,8947 \\
0,9002 \\
0,8980 \\
0,9032\end{array}$ & $\begin{array}{l}0,0079 \\
0,0050 \\
0,0034 \\
0,0019 \\
0,0009 \\
0,0004\end{array}$ & $\begin{array}{l}0,3114 \\
0,1407 \\
0,0217 \\
0,0009 \\
0,0014 \\
0,0032 \\
\end{array}$ & $\begin{array}{l}0,2154 \\
0,1215 \\
0,0199 \\
0,0000 \\
0,0000 \\
0,0000\end{array}$ & $\begin{array}{l}0,1241 \\
0,0280 \\
0,0027 \\
0,0000 \\
0,0000 \\
0,0000\end{array}$ \\
\hline
\end{tabular}


41.6. MEdin e varinacib do esthondor do conticiente de eredogamia an anólife de varîncia das frequências gênicas de amostres de individuos de uma populegâo no caso de alelos méltiplos

Quando uma populagåo apresenta $u$ alelos, com $u>2$, são realizadas u enálises de variência semelhantes \&̀ ańlise apresentada na Tabela 4. Em cada análise é feita uma estimativa do coeficiente de endogarnia Para se encontrar uma estimativa de F na populaģo considerando todos os alelos, existem duas maneiras sugeridas por REYNOLDS et al. (1983). A primeira consiste em obter a média aritmética das u estimativas $\hat{F}$. Assim, o estimador de $F$ em u alelos é dado por.

$$
\bar{F}=\frac{1}{u} \sum_{i=1}^{\bar{D}} \hat{F}_{i}=\frac{1}{u} \sum_{i=1}^{\bar{D}} \frac{\mathrm{QMI}_{\mathrm{i}}-\mathrm{QMG}_{\mathrm{i}}}{\mathrm{QM}_{\mathrm{i}}+\mathrm{QMG}_{\mathrm{i}}}
$$

Como as $u$ estimativas de $\hat{F}$ săo independentes, pois såo obtidas de $u$ and́lises de variância independentes, entåo a esperança matemática de $F$ foi obtida fazendo-se:

$$
\begin{aligned}
E[\bar{F}] & =E\left[\frac{1}{u} \sum_{i=1}^{n} \hat{F}_{i}\right] \\
& =\frac{1}{u} \sum_{i=1}^{n} E\left[\hat{F}_{i}\right] \\
& \approx F-\frac{F\left(1-F^{2}\right)}{n},
\end{aligned}
$$


correspondencio a mesma expressáo do valor esperado de f̂ no csoso de dois glelos.

A veriância de Fencontrada foi

$$
\operatorname{Var}[F] * \frac{\left(1-F^{2}\right)^{2}}{u n}
$$

A segunda maneira de extimar F na populaçäo consiste era

se tomar

$$
F^{*}=\frac{\sum_{i=1}^{\infty}\left(Q M_{i}-Q M G_{i}\right)}{\sum_{i=1}^{n}\left(Q M_{i}+Q M G_{i}\right)}
$$

que corresponde a estimar $F$ através de uma análise de variância conjunta envolvendo todos os alelos. Pelo mesmo processo utilizado no caso de dois alelos, encontrou-se:

$$
E\left[F^{*}\right] \approx F-\frac{F\left(1-F^{2}\right)}{u n}
$$

O resultado obtido mostrou que o estimador de $\mathrm{F}$ através da análise conjumta envolvendo todos os alelos foi menos tendencioso que - estimador que considerou a média aritmética dos extimadores de cada alelo.

A variância de $F^{*}$ encontrada foi

$$
\operatorname{Var}\left[F^{*}\right] * \frac{\left(1-F^{2}\right)^{2}}{u n}
$$

indicando que a análise conjunta estimou F com a mesma variância no caso de se usar a média dos estimadores de F de cada alelo. 
A Tabela 9 apresenta a média e a variéncia do coeficiente de endogamia estimado em N=100 experimentos com diferentes números de individuos, atrevés da média das estimativas em analises individuais e da análise conjunta em populagäes com três alelos com diferentes combinaçes de proporço gênice e coeficiente de endogarmia

Os valores obtidos comprovaram a validade das fórmulas propostas evidenciando que os resultados foram mais consistertes quando o alelo menos frequente da populaça nåo foi inferior a 0,20. Neste caso, percebeu-se que trabalhando-se com um minimo de 30 individuos, os dois métodos de cstimação apresentaram praticamente a mesma variância.

Quando a populacão apresentou algum alelo com frequência gênica inferior a $\mathbf{0 , 2 0}$ os dois métodos apresentaram variâncias bastantes discrepantes.

Os resultados mostraram ainda que a análise conjunta dos alelos produziu um estimador menos tendencioso que a média dos estimadores das análises individuais. Os valores observados nas diversas combinagões de frequências da Tabela 9 concordaram com os valores teóricos esperados da Tabela 10, havendo uma maior variabilidade nos resultados observados quando a populaçảo apresentou algum alelo raro.

Os resultados obtidos pare os dois extimadores de $F$ no caso de alelos múltiplos concordaram com WEIR \& COCKERHAM (1984) que sfirmam ser o método da análise conjunta mais eficiente. 
TABELA 9 - Média e variôncia do coeficiente de endogarnis estimadas através da média das estimativas em análises individusas (F) e através da anślise conjunta (F), em $N=100$ experimentos com amostras de tamanhos difercates extraidas em populapoes de trés alelos com diverses combinacöes de frequências génicas e coeficiente de endogamia.

\begin{tabular}{|c|c|c|c|c|c|c|}
\hline $\mathbf{n}$ & $\left(P_{1 ;}, P_{2} ; P_{3}\right)$ & $I$ & $F$ & $\operatorname{Var}(\bar{F})$ & $F$ & $\operatorname{Van}\left(F^{*}\right)$ \\
\hline $\begin{array}{c}10 \\
20 \\
30 \\
50 \\
100 \\
200 \\
\end{array}$ & $(0,40,0,30,0,30)$ & 0,0 & $\begin{array}{l}-0,0140 \\
-0,0286 \\
0,0273 \\
-0,0127 \\
-0,0216 \\
-0,0008 \\
\end{array}$ & $\begin{array}{l}0,0431 \\
0,0289 \\
0,0155 \\
0,0110 \\
0,0040 \\
0,0022 \\
\end{array}$ & $\begin{array}{l}-0,0150 \\
-0,0282 \\
0,0296 \\
-0,0119 \\
0,0220 \\
-0,0005\end{array}$ & $\begin{array}{l}0,0429 \\
0,0293 \\
0,0161 \\
0,0110 \\
0,0041 \\
0,0022 \\
\end{array}$ \\
\hline $\begin{array}{c}10 \\
20 \\
30 \\
50 \\
100 \\
200 \\
\end{array}$ & $i$ & 0,1 & $\begin{array}{l}0,0636 \\
0,0622 \\
0,0691 \\
0,0865 \\
0,0748 \\
0,0960 \\
\end{array}$ & $\begin{array}{l}0,0467 \\
0,0247 \\
0,0172 \\
0,0110 \\
0,0057 \\
0,0030 \\
\end{array}$ & $\begin{array}{l}0,0567 \\
0,0639 \\
0,0680 \\
0,0882 \\
0,0743 \\
0,0965 \\
\end{array}$ & $\begin{array}{l}0,0461 \\
0,0250 \\
0,0175 \\
0,0100 \\
0,0058 \\
0,0030\end{array}$ \\
\hline $\begin{array}{c}10 \\
20 \\
30 \\
50 \\
100 \\
200 \\
\end{array}$ & & 0,2 & $\begin{array}{l}0,1564 \\
0,1937 \\
0,1763 \\
0,1922 \\
0,1839 \\
0,1940 \\
\end{array}$ & $\begin{array}{l}0,0596 \\
0,0237 \\
0,0192 \\
0,0095 \\
0,0056 \\
0,0024 \\
\end{array}$ & $\begin{array}{l}0,1640 \\
0,1973 \\
0,1769 \\
0,1926 \\
0,1842 \\
0,1940 \\
\end{array}$ & $\begin{array}{l}0,0526 \\
0,0246 \\
0,0197 \\
0,0096 \\
0,0057 \\
0,0024 \\
\end{array}$ \\
\hline $\begin{array}{l}10 \\
20 \\
30 \\
50 \\
100 \\
200 \\
\end{array}$ & & 0,3 & $\begin{array}{l}0,2967 \\
0,3361 \\
0,2858 \\
0,2857 \\
0,2980 \\
0,2994 \\
\end{array}$ & $\begin{array}{l}0,0721 \\
0,0213 \\
0,0180 \\
0,0106 \\
0,0058 \\
0,0034 \\
\end{array}$ & $\begin{array}{l}0,3055 \\
0,3420 \\
0,2900 \\
0,2865 \\
0,2990 \\
0,2998 \\
\end{array}$ & $\begin{array}{l}0,0752 \\
0,0220 \\
0,0178 \\
0,0104 \\
0,0058 \\
0,0034\end{array}$ \\
\hline $\begin{array}{c}10 \\
20 \\
30 \\
50 \\
100 \\
200 \\
\end{array}$ & & 0,4 & $\begin{array}{l}0,3752 \\
0,3801 \\
0,3720 \\
0,3811 \\
0,3898 \\
0,3886 \\
\end{array}$ & $\begin{array}{l}0,0534 \\
0,0300 \\
0,0159 \\
0,0092 \\
0,0055 \\
0,0028\end{array}$ & $\begin{array}{l}0,3955 \\
0,3863 \\
0,3731 \\
0,3814 \\
0,3906 \\
0,3890\end{array}$ & $\begin{array}{l}0,0563 \\
0,0308 \\
0,0159 \\
0,0092 \\
0,0056 \\
0,0028\end{array}$ \\
\hline
\end{tabular}

$\bar{F} \quad$ : métia do estimador de $F$ utilizando a mtctia das estimativas em analises individuais em $\mathrm{N}=100$ experimentos;

Var(F): variancia do estimador de $F$ utilizando a mélia das cotimativas en analises individuais em $\mathrm{N}=100$ experimentos;

$F^{*} \quad$ :média do estimador de $F$ utilizando a análise conjunta em $N=100$ experimentos;

$\operatorname{Var}\left(F^{*}\right)$ : variância do estimador de $F$ utilizando a análise conjunta em $N=100$ experimentos. 
TABELA 9 - Média e variência do coeficiente de endogamis estimadas através da média das estimativas em análises individuais (F) e através da andilise conjunta (F), em $N=100$ experimentos com amostras de tamanhos diferentes extraidas em populaģes de três alelos com diverases combinasobes de frequências getnicas e coeficiente de endogamia.

\begin{tabular}{|c|c|c|c|c|c|c|}
\hline $\mathbf{n}$ & $\left(P_{1}, P_{2 ;} P_{3}\right)$ & $\bar{F}$ & $\overline{\mathbf{F}}$ & $\operatorname{Var}(\bar{F})$ & $F^{*}$ & $\sin \left(F^{*}\right)$ \\
\hline $\begin{array}{c}10 \\
20 \\
30 \\
50 \\
100 \\
200 \\
\end{array}$ & $(0,40 ; 0,30 ; 0,30)$ & 0,5 & $\begin{array}{l}0,4676 \\
0,4785 \\
0,4756 \\
0,4924 \\
0,4856 \\
0,4968\end{array}$ & $\begin{array}{l}0,0526 \\
0,0257 \\
0,0162 \\
0,0110 \\
0,0033 \\
0,0024 \\
\end{array}$ & $\begin{array}{l}0,4802 \\
0,4829 \\
0,4767 \\
0,4935 \\
0,4860 \\
0,4972 \\
\end{array}$ & $\begin{array}{l}0,0502 \\
0,0248 \\
0,0158 \\
0,0110 \\
0,0035 \\
0,0024\end{array}$ \\
\hline $\begin{array}{l}10 \\
20 \\
30 \\
50 \\
100 \\
200 \\
\end{array}$ & & 0,6 & $\begin{array}{l}0,5718 \\
0,6090 \\
0,5929 \\
0,5863 \\
0,5897 \\
0,6061 \\
\end{array}$ & $\begin{array}{l}0,0491 \\
0,0258 \\
0,0137 \\
0,0081 \\
0,0043 \\
0,0021\end{array}$ & $\begin{array}{l}0,5836 \\
0,6148 \\
0,5961 \\
0,5876 \\
0,5907 \\
0,6062\end{array}$ & $\begin{array}{l}0,0466 \\
0,0253 \\
0,0131 \\
0,0080 \\
0,0042 \\
0,0021\end{array}$ \\
\hline $\begin{array}{c}10 \\
20 \\
30 \\
50 \\
100 \\
200 \\
\end{array}$ & & 0.7 & $\begin{array}{l}0,6982 \\
0,7063 \\
0,6989 \\
0,6847 \\
0,6914 \\
0,7020 \\
\end{array}$ & $\begin{array}{l}0,0410 \\
0,0210 \\
0,0129 \\
0,0099 \\
0,0039 \\
0,001\end{array}$ & $\begin{array}{l}0,7119 \\
0,7130 \\
0,7011 \\
0,6852 \\
0,6919 \\
0,7022 \\
\end{array}$ & $\begin{array}{l}0,0386 \\
0,0198 \\
0,0126 \\
0,0098 \\
0,0038 \\
0,0018\end{array}$ \\
\hline $\begin{array}{c}10 \\
20 \\
30 \\
50 \\
100 \\
200 \\
\end{array}$ & & 0,8 & $\begin{array}{l}0,7811 \\
0,7885 \\
0,7900 \\
0,7816 \\
0,7860 \\
0,7950 \\
\end{array}$ & $\begin{array}{l}0,0378 \\
0,0132 \\
0,0094 \\
0,0057 \\
0,0031 \\
0,0015 \\
\end{array}$ & $\begin{array}{l}0,7903 \\
0,7933 \\
0,7906 \\
0,7818 \\
0,7872 \\
0,7952 \\
\end{array}$ & $\begin{array}{l}0,0324 \\
0,0134 \\
0,0093 \\
0,0057 \\
0,0031 \\
0,0015\end{array}$ \\
\hline $\begin{array}{c}10 \\
20 \\
30 \\
50 \\
100 \\
200 \\
\end{array}$ & & 0,9 & $\begin{array}{l}0,8889 \\
0,8904 \\
0,9132 \\
0,9006 \\
0,8905 \\
0,8960 \\
\end{array}$ & $\begin{array}{l}0,0192 \\
0,0091 \\
0,0027 \\
0,0025 \\
0,0013 \\
0,0007 \\
\end{array}$ & $\begin{array}{l}0,8919 \\
0,8922 \\
0,9130 \\
0,9006 \\
0,8910 \\
0,8962 \\
\end{array}$ & $\begin{array}{l}0,0150 \\
0,0084 \\
0,0026 \\
0,0026 \\
0,0013 \\
0,0007\end{array}$ \\
\hline $\begin{array}{c}10 \\
20 \\
30 \\
50 \\
100 \\
200 \\
\end{array}$ & & 1,0 & $\begin{array}{l}0,9951 \\
0,9962 \\
0,9930 \\
0,9940 \\
0,9961 \\
0,9953 \\
\end{array}$ & $\begin{array}{l}0,0008 \\
0,0004 \\
0,0005 \\
0,0002 \\
0,0001 \\
0,0000 \\
\end{array}$ & $\begin{array}{l}0,9957 \\
0,9968 \\
0,9933 \\
0,9943 \\
0,9961 \\
0,9953 \\
\end{array}$ & $\begin{array}{l}0,0006 \\
0,0002 \\
0,0005 \\
0,0002 \\
0,0001 \\
0,0000 \\
\end{array}$ \\
\hline
\end{tabular}


TABELA 9 - Média e variância do coeficiente de endogamia estimadas através da média das estimativas em análises individuais (F) e através da análise conjunta (F'), em N=100 experimentos com amostras de tamanhos diferentes extraídas em populacões de três alelos com diversas combinafões de frequências gênicas e coeficiente de endogamia.

\begin{tabular}{|c|c|c|c|c|c|c|}
\hline $\mathbf{n}$ & $\left(P_{1} ; P_{2} ; P_{3}\right)$ & $T$ & $\overline{\mathbf{F}}$ & $\operatorname{Var}(\bar{F})$ & $F$ & $\operatorname{Var}\left(F^{*}\right)$ \\
\hline $\begin{array}{c}10 \\
20 \\
30 \\
50 \\
100 \\
200 \\
\end{array}$ & $(0,50,0,30 ; 0,20)$ & 0,0 & $\begin{array}{l}0,0191 \\
0,0051 \\
-0,0129 \\
-0,0042 \\
-0,0053 \\
-0,0094\end{array}$ & $\begin{array}{l}0,0571 \\
0,0246 \\
0,0165 \\
0,0102 \\
0,0051 \\
0,0031 \\
\end{array}$ & $\begin{array}{c}-0,0138 \\
0,0085 \\
-0,00106 \\
-0,0028 \\
-0,0038 \\
-0,0076 \\
\end{array}$ & $\begin{array}{l}0,0666 \\
0,0274 \\
0,0180 \\
0,0106 \\
0,0054 \\
0,0034 \\
\end{array}$ \\
\hline $\begin{array}{c}10 \\
20 \\
30 \\
50 \\
100 \\
200 \\
\end{array}$ & & 0,1 & $\begin{array}{l}0,0876 \\
0,0918 \\
0,0626 \\
0,0956 \\
0,0857 \\
0,0977 \\
\end{array}$ & $\begin{array}{l}0,0558 \\
0,0256 \\
0,0184 \\
0,0116 \\
0,0045 \\
0,0026\end{array}$ & $\begin{array}{l}0,0869 \\
0,0951 \\
0,0646 \\
0,0971 \\
0,0864 \\
0,0989\end{array}$ & $\begin{array}{l}0,0598 \\
0,0273 \\
0,0183 \\
0,0115 \\
0,0045 \\
0,0026 \\
\end{array}$ \\
\hline $\begin{array}{c}10 \\
20 \\
30 \\
50 \\
100 \\
200 \\
\end{array}$ & & 0,2 & $\begin{array}{l}0,1780 \\
0,1723 \\
0,1670 \\
0,1931 \\
0,1956 \\
0,1894 \\
\end{array}$ & $\begin{array}{l}0,0535 \\
0,0326 \\
0,0237 \\
0,0105 \\
0,0074 \\
0,0028 \\
\end{array}$ & $\begin{array}{l}0,1829 \\
0,1804 \\
0,1698 \\
0,1938 \\
0,1958 \\
0,1912 \\
\end{array}$ & $\begin{array}{l}0,0627 \\
0,0340 \\
0,0238 \\
0,0108 \\
0,0073 \\
0,0030\end{array}$ \\
\hline $\begin{array}{c}10 \\
20 \\
30 \\
50 \\
100 \\
200 \\
\end{array}$ & & 0,3 & $\begin{array}{l}0,2509 \\
0,3097 \\
0,3053 \\
0,2808 \\
0,2935 \\
0,2883 \\
\end{array}$ & $\begin{array}{l}0,0620 \\
0,0313 \\
0,0216 \\
0,0107 \\
0,0057 \\
0,0041 \\
\end{array}$ & $\begin{array}{l}0,2674 \\
0,3159 \\
0,3093 \\
0,2835 \\
0,2951 \\
0,2902 \\
\end{array}$ & $\begin{array}{l}0,0652 \\
0,0312 \\
0,0213 \\
0,0104 \\
0,0057 \\
0,0041 \\
\end{array}$ \\
\hline $\begin{array}{c}10 \\
20 \\
30 \\
50 \\
100 \\
200 \\
\end{array}$ & & 0,4 & $\begin{array}{l}0,3933 \\
0,3843 \\
0,3738 \\
0,3756 \\
0,3849 \\
0,3897 \\
\end{array}$ & $\begin{array}{l}0,0695 \\
0,0305 \\
0,0192 \\
0,0129 \\
0,0066 \\
0,0034 \\
\end{array}$ & $\begin{array}{l}0,4015 \\
0,4042 \\
0,3787 \\
0,3757 \\
0,3885 \\
0,3909 \\
\end{array}$ & $\begin{array}{l}0,0721 \\
0,0301 \\
0,0188 \\
0,0128 \\
0,0064 \\
0,0032 \\
\end{array}$ \\
\hline $\begin{array}{c}10 \\
20 \\
30 \\
50 \\
100 \\
200\end{array}$ & & 0,5 & $\begin{array}{l}0,4475 \\
0,4954 \\
0,4772 \\
0,4919 \\
0,4981 \\
0,4907\end{array}$ & $\begin{array}{l}0,0687 \\
0,0270 \\
0,0167 \\
0,0097 \\
0,0044 \\
0,0028\end{array}$ & $\begin{array}{l}0,4678 \\
0,5036 \\
0,4846 \\
0,4927 \\
0,5002 \\
0,4922 \\
\end{array}$ & $\begin{array}{l}0,0664 \\
0,0246 \\
0,0165 \\
0,0105 \\
0,0043 \\
0,0029\end{array}$ \\
\hline
\end{tabular}


TABELA 9 - Média e variância do coeficiente de endogamia estimadas através da média das estimativas em enálises individuais (F) e através da análise conjunta (F), em $N=100$ experimentos com amostras de tamanhos diferentes extraídas em populacōes de três alelos com diversas combinacōes de frequências génicas e coeficiente de endogania.

\begin{tabular}{|c|c|c|c|c|c|c|}
\hline $\mathbf{n}$ & $\left(P_{1} ; P_{2} ; P_{3}\right)$ & $F$ & $\bar{F}$ & $\operatorname{Var}(\bar{F})$ & $F$ & $\operatorname{Var}\left(F^{*}\right)$ \\
\hline $\begin{array}{c}10 \\
20 \\
30 \\
50 \\
100 \\
200 \\
\end{array}$ & $(0,50,0,30 ; 0,20)$ & 0,6 & $\begin{array}{l}0,5654 \\
0,5949 \\
0,5887 \\
0,5980 \\
0,5845 \\
0,5907 \\
\end{array}$ & $\begin{array}{l}0,0688 \\
0,0254 \\
0,0162 \\
0,0100 \\
0,0056 \\
0,0026 \\
\end{array}$ & $\begin{array}{l}0,5943 \\
0,6035 \\
0,5958 \\
0,6003 \\
0,5857 \\
0,5906 \\
\end{array}$ & $\begin{array}{l}0,0623 \\
0,0228 \\
0,0138 \\
0,0106 \\
0,0056 \\
0,0026 \\
\end{array}$ \\
\hline $\begin{array}{c}10 \\
20 \\
30 \\
50 \\
100 \\
200 \\
\end{array}$ & & 0,7 & $\begin{array}{l}0,6806 \\
0,6945 \\
0,6903 \\
0,6809 \\
0,6933 \\
0,6944 \\
\end{array}$ & $\begin{array}{l}0,0494 \\
0,0251 \\
0,0174 \\
0,0110 \\
0,0035 \\
0,0018 \\
\end{array}$ & $\begin{array}{l}0,6959 \\
0,6955 \\
0,6942 \\
0,6840 \\
0,6950 \\
0,6952 \\
\end{array}$ & $\begin{array}{l}0,0447 \\
0,0240 \\
0,0162 \\
0,0107 \\
0,0033 \\
0,0018 \\
\end{array}$ \\
\hline $\begin{array}{c}10 \\
20 \\
30 \\
50 \\
100 \\
200 \\
\end{array}$ & & 0,8 & $\begin{array}{l}0,7891 \\
0,7713 \\
0,7926 \\
0,7836 \\
0,7866 \\
0,7995 \\
\end{array}$ & $\begin{array}{l}0,0391 \\
0,0155 \\
0,0130 \\
0,0054 \\
0,0028 \\
0,0018 \\
\end{array}$ & $\begin{array}{l}0,7967 \\
0,7812 \\
0,8016 \\
0,7870 \\
0,7881 \\
0,8001\end{array}$ & $\begin{array}{l}0,0333 \\
0,0130 \\
0,0114 \\
0,0051 \\
0,0027 \\
0,0018 \\
\end{array}$ \\
\hline $\begin{array}{c}10 \\
20 \\
30 \\
50 \\
100 \\
200 \\
\end{array}$ & & 0,9 & $\begin{array}{l}0,8792 \\
0,8962 \\
0,8654 \\
0,9020 \\
0,8977 \\
0,8950 \\
\end{array}$ & $\begin{array}{l}0,0192 \\
0,0092 \\
0,0086 \\
0,0031 \\
0,0016 \\
0,0009 \\
\end{array}$ & $\begin{array}{l}0,8867 \\
0,9002 \\
0,8711 \\
0,9049 \\
0,8982 \\
0,8949 \\
\end{array}$ & $\begin{array}{l}0,0160 \\
0,0079 \\
0,0070 \\
0,0028 \\
0,0015 \\
0,0009 \\
\end{array}$ \\
\hline $\begin{array}{c}10 \\
20 \\
30 \\
50 \\
100 \\
200 \\
\end{array}$ & & 1,0 & $\begin{array}{l}0,9909 \\
0,9959 \\
0,9957 \\
0,9952 \\
0,9956 \\
0,9941 \\
\end{array}$ & $\begin{array}{l}0,0022 \\
0,0003 \\
0,0003 \\
0,0002 \\
0,0001 \\
0,0000 \\
\end{array}$ & $\begin{array}{l}0,9918 \\
0,9959 \\
0,9959 \\
0,9954 \\
0,9958 \\
0,9942 \\
\end{array}$ & $\begin{array}{l}0,0013 \\
0,0003 \\
0,0002 \\
0,0002 \\
0,0001 \\
0,0000 \\
\end{array}$ \\
\hline $\begin{array}{c}10 \\
20 \\
30 \\
50 \\
100 \\
200 \\
\end{array}$ & $(0,50 ; 0,25 ; 0,25)$ & 0,0 & $\begin{array}{r}-0,0172 \\
-0,0254 \\
0,0002 \\
-0,0126 \\
-0,0012 \\
-0,0065 \\
\end{array}$ & $\begin{array}{l}0,0499 \\
0,0245 \\
0,0163 \\
0,0092 \\
0,0039 \\
0,0024 \\
\end{array}$ & $\begin{array}{l}-0,0195 \\
-0,0243 \\
0,0016 \\
-0,0127 \\
-0,0005 \\
-0,0066\end{array}$ & $\begin{array}{l}0,0532 \\
0,0259 \\
0,0168 \\
0,0094 \\
0,0039 \\
0,0025\end{array}$ \\
\hline
\end{tabular}


TABELA 9 - Média e variância do coeficiente de endogamia estimadas através da média das extimativas em análises individuais (F) e através da análise conjunta (F), em N=100 experimentos com amostras de tamanhos diferentes extraídas em populaçóes de três alelos com diversas combinagöes de frequencias géricas e coeficiente de endogamia.

\begin{tabular}{|c|c|c|c|c|c|c|}
\hline $\mathbf{n}$ & $\left(P_{1} ; P_{2} ; P_{3}\right)$ & $\mathbf{F}$ & $\overline{\mathbf{F}}$ & $\operatorname{Var}(\overline{\mathrm{F}})$ & $\vec{F}$ & $\operatorname{Var}\left(F^{*}\right)$ \\
\hline $\begin{array}{l}10 \\
20 \\
30 \\
50 \\
100 \\
200\end{array}$ & $(0,50 ; 0,25 ; 0,25)$ & 0,1 & $\begin{array}{l}0,0708 \\
0,1036 \\
0,0957 \\
0,0936 \\
0,0873 \\
0,0864\end{array}$ & $\begin{array}{l}0,0510 \\
0,0297 \\
0,0248 \\
0,0104 \\
0,0051 \\
0,0025\end{array}$ & $\begin{array}{l}0,0761 \\
0,1050 \\
0,0980 \\
0,0942 \\
0,0864 \\
0,0857\end{array}$ & $\begin{array}{l}0,0573 \\
0,0306 \\
0,0269 \\
0,0104 \\
0,0053 \\
0,0025\end{array}$ \\
\hline $\begin{array}{c}10 \\
20 \\
30 \\
50 \\
100 \\
200 \\
\end{array}$ & & 0,2 & $\begin{array}{l}0,1740 \\
0,1694 \\
0,2024 \\
0,1937 \\
0,1924 \\
0,1922 \\
\end{array}$ & $\begin{array}{l}0,0510 \\
0,0306 \\
0,0172 \\
0,0120 \\
0,0043 \\
0,0033\end{array}$ & $\begin{array}{l}0,1885 \\
0,1722 \\
0,2015 \\
0,1950 \\
0,1932 \\
0,1933\end{array}$ & $\begin{array}{l}0,0567 \\
0,0324 \\
0,0172 \\
0,0124 \\
0,0043 \\
0,0034\end{array}$ \\
\hline $\begin{array}{c}10 \\
20 \\
30 \\
50 \\
100 \\
200 \\
\end{array}$ & & 0,3 & $\begin{array}{l}0,2702 \\
0,2664 \\
0,3006 \\
0,2972 \\
0,3000 \\
0,2897\end{array}$ & $\begin{array}{l}0,0567 \\
0,0293 \\
0,0206 \\
0,0129 \\
0,0057 \\
0,0031 \\
\end{array}$ & $\begin{array}{l}0,2834 \\
0,2710 \\
0,3029 \\
0,2981 \\
0,3023 \\
0,2911 \\
\end{array}$ & $\begin{array}{l}0,0576 \\
0,0286 \\
0,0211 \\
0,0129 \\
0,0057 \\
0,0031\end{array}$ \\
\hline $\begin{array}{c}10 \\
20 \\
30 \\
50 \\
100 \\
200 \\
\end{array}$ & & 0,4 & $\begin{array}{l}0,3891 \\
0,3926 \\
0,3998 \\
0,3843 \\
0,3906 \\
0,3952 \\
\end{array}$ & $\begin{array}{l}0,0530 \\
0,0257 \\
0,0222 \\
0,0117 \\
0,0073 \\
0,0024 \\
\end{array}$ & $\begin{array}{l}0,4072 \\
0,3956 \\
0,4048 \\
0,3893 \\
0,3920 \\
0,3956 \\
\end{array}$ & $\begin{array}{l}0,0321 \\
0,0261 \\
0,0221 \\
0,0117 \\
0,0072 \\
0,0024 \\
\end{array}$ \\
\hline $\begin{array}{c}10 \\
20 \\
30 \\
50 \\
100 \\
200 \\
\end{array}$ & & 0,5 & $\begin{array}{l}0,4674 \\
0,4544 \\
0,5074 \\
0,4959 \\
0,4964 \\
0,4864 \\
\end{array}$ & $\begin{array}{l}0,0564 \\
0,0250 \\
0,0158 \\
0,0107 \\
0,0042 \\
0,0031 \\
\end{array}$ & $\begin{array}{l}0,4774 \\
0,4660 \\
0,5096 \\
0,4986 \\
0,4988 \\
0,4873 \\
\end{array}$ & $\begin{array}{l}0,0510 \\
0,0221 \\
0,0160 \\
0,0109 \\
0,0042 \\
0,001 \\
\end{array}$ \\
\hline $\begin{array}{l}10 \\
20 \\
30 \\
50 \\
100 \\
200\end{array}$ & & 0,6 & $\begin{array}{l}0,5626 \\
0,5770 \\
0,5705 \\
0,5868 \\
0,5834 \\
0,5927\end{array}$ & $\begin{array}{l}0,0410 \\
0,0243 \\
0,0167 \\
0,0081 \\
0,0052 \\
0,0020 \\
\end{array}$ & $\begin{array}{l}0,5898 \\
0,5808 \\
0,5749 \\
0,5909 \\
0,5851 \\
0,5936 \\
\end{array}$ & $\begin{array}{l}0,0358 \\
0,0221 \\
0,0160 \\
0,0077 \\
0,0050 \\
0,0020\end{array}$ \\
\hline
\end{tabular}


TABELA 9 - Média e variância do coeficiente de endogamia estimadas através da média das extimativas em análises individuais (F) e através da análise conjunta (F'), em $\mathrm{N}=100$ experimentos com amostras de tamanhos diferentes extraidas em populagōes de três alelos com diversas combinaçoes de frequências génicas e coeficiente de endogamia.

\begin{tabular}{|c|c|c|c|c|c|c|}
\hline $\mathbf{n}$ & $\left(P_{1} ; P_{2} ; P_{3}\right)$ & $\bar{T}$ & $\bar{F}$ & $\operatorname{Var}(\bar{F})$ & $\bar{F}$ & $\operatorname{Var}\left(F^{*}\right)$ \\
\hline $\begin{array}{c}10 \\
20 \\
30 \\
50 \\
100 \\
200\end{array}$ & $(0,50 ; 0,25 ; 0,25)$ & 0,7 & $\begin{array}{l}0,7076 \\
0,7043 \\
0,6945 \\
0,6945 \\
0,6960 \\
0,6912 \\
\end{array}$ & $\begin{array}{l}0,0467 \\
0,0205 \\
0,0149 \\
0,0095 \\
0,0033 \\
0,0017\end{array}$ & $\begin{array}{l}0,7189 \\
0,7106 \\
0,6964 \\
0,6956 \\
0,6964 \\
0,6917 \\
\end{array}$ & $\begin{array}{l}0,0415 \\
0,0192 \\
0,0146 \\
0,0094 \\
0,0033 \\
0,0017 \\
\end{array}$ \\
\hline $\begin{array}{c}10 \\
20 \\
30 \\
50 \\
100 \\
200\end{array}$ & & 0,8 & $\begin{array}{l}0,7422 \\
0,7935 \\
0,7773 \\
0,7955 \\
0,7971 \\
0,7963 \\
\end{array}$ & $\begin{array}{l}0,0409 \\
0,0119 \\
0,0081 \\
0,0051 \\
0,0029 \\
0,0016 \\
\end{array}$ & $\begin{array}{l}0,7564 \\
0,7974 \\
0,7807 \\
0,7973 \\
0,7971 \\
0,7964\end{array}$ & $\begin{array}{l}0,0412 \\
0,0110 \\
0,00882 \\
0,0048 \\
0,0029 \\
0,0016\end{array}$ \\
\hline $\begin{array}{c}10 \\
20 \\
30 \\
50 \\
100 \\
200\end{array}$ & & 0,9 & $\begin{array}{l}0,9105 \\
0,8810 \\
0,8775 \\
0,8978 \\
0,8904 \\
0,8930 \\
\end{array}$ & $\begin{array}{l}0,0124 \\
0,0093 \\
0,0072 \\
0,0028 \\
0,0017 \\
0,0007\end{array}$ & $\begin{array}{l}0,9103 \\
0,8811 \\
0,8804 \\
0,8990 \\
0,8907 \\
0,8935\end{array}$ & $\begin{array}{l}0,0115 \\
0,0095 \\
0,0069 \\
0,0027 \\
0,0017 \\
0,0007\end{array}$ \\
\hline $\begin{array}{c}10 \\
20 \\
30 \\
50 \\
100 \\
200\end{array}$ & - & 1,0 & $\begin{array}{l}0,9973 \\
0,9931 \\
0,9951 \\
0,9966 \\
0,9951 \\
0,9944 \\
\end{array}$ & $\begin{array}{l}0,0004 \\
0,0007 \\
0,0004 \\
0,0001 \\
0,0001 \\
0,0000\end{array}$ & $\begin{array}{l}0,9968 \\
0,9937 \\
0,9950 \\
0,9966 \\
0,9952 \\
0,9946\end{array}$ & $\begin{array}{l}0,0005 \\
0,0006 \\
0,0003 \\
0,0001 \\
0,0001 \\
0,0000\end{array}$ \\
\hline $\begin{array}{l}10 \\
20 \\
30 \\
50 \\
100 \\
200\end{array}$ & $(0,33 ; 0,33 ; 0,34)$ & 0,0 & $\begin{array}{l}-0,0232 \\
0,0151 \\
0,0054 \\
-0,0054 \\
-0,0044 \\
-0,0064 \\
\end{array}$ & $\begin{array}{l}0,0478 \\
0,0270 \\
0,0182 \\
0,0094 \\
0,0040 \\
0,0020 \\
\end{array}$ & $\begin{array}{l}-0,0213 \\
0,0148 \\
0,0045 \\
-0,0051 \\
0,0050 \\
-0,0064\end{array}$ & $\begin{array}{l}0,0531 \\
0,0280 \\
0,0185 \\
0,0094 \\
0,0041 \\
0,0020\end{array}$ \\
\hline $\begin{array}{l}10 \\
20 \\
30 \\
50 \\
100 \\
200 \\
\end{array}$ & & 0,1 & $\begin{array}{l}0,1136 \\
0,0975 \\
0,0978 \\
0,0860 \\
0,0880 \\
0,0914\end{array}$ & $\begin{array}{l}0,0486 \\
0,0221 \\
0,0151 \\
0,0122 \\
0,0048 \\
0,0022 \\
\end{array}$ & $\begin{array}{l}0,1168 \\
0,1001 \\
0,0973 \\
0,0857 \\
0,0878 \\
0,0915\end{array}$ & $\begin{array}{l}0,0515 \\
0,0228 \\
0,0148 \\
0,0121 \\
0,0048 \\
0,0022\end{array}$ \\
\hline
\end{tabular}


TABELA 9 - Média e variância do coeficiente de endogamia estimadas através da média das estimativas em análises individuais (F) e através da análise conjunta $\left(F^{*}\right)$, em $N=100$ experimentos com amostras de tamanhos diferentes extraidas em populacões de três alelos com diversas combinações de frequências gênicas e coeficiente de endogamia.

\begin{tabular}{|c|c|c|c|c|c|c|}
\hline $\mathbf{n}$ & $\left(P_{1} ; P_{2} ; P_{3}\right)$ & F & $\bar{F}$ & $\operatorname{Var}(\bar{F})$ & $F^{7}$ & Var(f*) \\
\hline $\begin{array}{c}10 \\
20 \\
30 \\
50 \\
100 \\
200 \\
\end{array}$ & $(0,33 ; 0,33 ; 0,34)$ & 0,2 & $\begin{array}{l}0,1404 \\
0,1986 \\
0,2044 \\
0,1795 \\
0,1978 \\
0,1948 \\
\end{array}$ & $\begin{array}{l}0,0652 \\
0,0258 \\
0,0168 \\
0,0087 \\
0,0054 \\
0,0027 \\
\end{array}$ & $\begin{array}{l}0,1532 \\
0,2015 \\
0,2078 \\
0,1811 \\
0,1981 \\
0,1949 \\
\end{array}$ & $\begin{array}{l}0,0709 \\
0,0259 \\
0,0168 \\
0,0087 \\
0,0054 \\
0,0027 \\
\end{array}$ \\
\hline $\begin{array}{c}10 \\
20 \\
30 \\
50 \\
100 \\
200 \\
\end{array}$ & & 0,3 & $\begin{array}{l}0,2999 \\
0,2954 \\
0,2663 \\
0,3183 \\
0,2995 \\
0,2903 \\
\end{array}$ & $\begin{array}{l}0,0543 \\
0,0325 \\
0,0173 \\
0,0124 \\
0,0055 \\
0,0020\end{array}$ & $\begin{array}{l}0,3112 \\
0,3008 \\
0,2686 \\
0,3188 \\
0,3000 \\
0,2906 \\
\end{array}$ & $\begin{array}{l}0,0559 \\
0,0320 \\
0,0170 \\
0,0124 \\
0,0055 \\
0,0020\end{array}$ \\
\hline $\begin{array}{c}10 \\
20 \\
30 \\
50 \\
100 \\
200 \\
\end{array}$ & & $\overline{0.4}$ & $\begin{array}{l}0,3794 \\
0,3840 \\
0,4171 \\
0,4040 \\
0,3943 \\
0,4010 \\
\end{array}$ & $\begin{array}{l}0,0547 \\
0,0238 \\
0,0194 \\
0,0120 \\
0,0049 \\
0,0027 \\
\end{array}$ & $\begin{array}{l}0,3898 \\
0,3922 \\
0,4196 \\
0,4055 \\
0,3952 \\
0,4014 \\
\end{array}$ & $\begin{array}{l}0,0544 \\
0,0236 \\
0,0190 \\
0,0120 \\
0,0049 \\
0,0027 \\
\end{array}$ \\
\hline $\begin{array}{c}10 \\
20 \\
30 \\
50 \\
100 \\
200 \\
\end{array}$ & & 0,5 & $\begin{array}{l}0,4894 \\
0,4888 \\
0,5171 \\
0,5072 \\
0,4963 \\
0,5052 \\
\end{array}$ & $\begin{array}{l}0,0482 \\
0,0253 \\
0,0186 \\
0,0119 \\
0,0036 \\
0,0026 \\
\end{array}$ & $\begin{array}{l}0,4958 \\
0,4977 \\
0,5197 \\
0,5088 \\
0,4972 \\
0,5055 \\
\end{array}$ & $\begin{array}{l}0,0463 \\
0,0241 \\
0,0181 \\
0,0119 \\
0,0036 \\
0,0026 \\
\end{array}$ \\
\hline $\begin{array}{c}10 \\
20 \\
30 \\
50 \\
100 \\
200 \\
\end{array}$ & & 0,6 & $\begin{array}{l}0,5256 \\
0,5983 \\
0,5849 \\
0,5834 \\
0,5875 \\
0,5967 \\
\end{array}$ & $\begin{array}{l}0,0483 \\
0,0239 \\
0,0108 \\
0,0096 \\
0,0033 \\
0,0022 \\
\end{array}$ & $\begin{array}{l}0,5407 \\
0,6047 \\
0,5874 \\
0,5858 \\
0,5880 \\
0,5971 \\
\end{array}$ & $\begin{array}{l}0,0458 \\
0,0226 \\
0,0107 \\
0,0095 \\
0,0033 \\
0,0022 \\
\end{array}$ \\
\hline $\begin{array}{c}10 \\
20 \\
30 \\
50 \\
100 \\
200 \\
\end{array}$ & & 0,7 & $\begin{array}{l}0,6494 \\
0,7060 \\
0,7002 \\
0,6775 \\
0,6956 \\
0,6988 \\
\end{array}$ & $\begin{array}{l}0,0468 \\
0,0167 \\
0,0111 \\
0,0064 \\
0,0040 \\
0,0015 \\
\end{array}$ & $\begin{array}{l}0,6577 \\
0,7068 \\
0,7032 \\
0,6793 \\
0,6959 \\
0,6992 \\
\end{array}$ & $\begin{array}{l}0,0432 \\
0,0169 \\
0,0105 \\
0,0064 \\
0,0040 \\
0,0015\end{array}$ \\
\hline
\end{tabular}


TABELA 9 - Média e variência do coeficiente de endogamia estimadas através da média das extimativas em análises individuais (F) e através da análise conjunta (F"), em $\mathrm{N}=100$ experimentos com amostras de tamanhos diferentes extraidas em populacôes de três alelos com diverses combinações de frequéncias génicas e coeficiente de endogamia

\begin{tabular}{|c|c|c|c|c|c|c|}
\hline $\mathbf{n}$ & $\left(P_{1 ;} P_{2 ;} P_{3}\right)$ & $\mathbf{F}$ & $\bar{F}$ & Vart & $F$ & $\operatorname{Var}\left(F^{*}\right)$ \\
\hline $\begin{array}{c}10 \\
20 \\
30 \\
50 \\
100 \\
200 \\
\end{array}$ & $(0,33 ; 0,33 ; 0,34)$ & 0,8 & $\begin{array}{l}0,7722 \\
0,7796 \\
0,7966 \\
0,7868 \\
0,7991 \\
0,7885 \\
\end{array}$ & $\begin{array}{l}0,0365 \\
0,0155 \\
0,0085 \\
0,0069 \\
0,0027 \\
0,0015 \\
\end{array}$ & $\begin{array}{l}0,7813 \\
0,7853 \\
0,7984 \\
0,7875 \\
0,7997 \\
0,7886 \\
\end{array}$ & $\begin{array}{l}0,0329 \\
0,0148 \\
0,0085 \\
0,0069 \\
0,0026 \\
0,0015\end{array}$ \\
\hline $\begin{array}{c}10 \\
20 \\
30 \\
50 \\
100 \\
200 \\
\end{array}$ & & 0,9 & $\begin{array}{l}0,8737 \\
0,9106 \\
0,8953 \\
0,8956 \\
0,8960 \\
0,8943 \\
\end{array}$ & $\begin{array}{l}0,0204 \\
0,0071 \\
0,0048 \\
0,0030 \\
0,0016 \\
0,0010 \\
\end{array}$ & $\begin{array}{l}0,8883 \\
0,9136 \\
0,8962 \\
0,8906 \\
0,8961 \\
0,8944 \\
\end{array}$ & $\begin{array}{l}0,0140 \\
0,0060 \\
0,0048 \\
0,0030 \\
0,0016 \\
0,0010 \\
\end{array}$ \\
\hline $\begin{array}{c}10 \\
20 \\
30 \\
50 \\
100 \\
200 \\
\end{array}$ & & 1,0 & $\begin{array}{l}0,9960 \\
0,9979 \\
0,9939 \\
0,9970 \\
0,9963 \\
0,9963 \\
\end{array}$ & $\begin{array}{l}0,0005 \\
0,0001 \\
0,0003 \\
0,0001 \\
0,0001 \\
0,0000 \\
\end{array}$ & $\begin{array}{l}0,9957 \\
0,9976 \\
0,9941 \\
0,9970 \\
0,9963 \\
0,9963\end{array}$ & $\begin{array}{l}0,0006 \\
0,0002 \\
0,0003 \\
0,0001 \\
0,0001 \\
0,0000 \\
\end{array}$ \\
\hline $\begin{array}{c}10 \\
20 \\
30 \\
50 \\
100 \\
200 \\
\end{array}$ & $(0,60 ; 0,30 ; 0,10)$ & 0,0 & $\begin{array}{l}0,0.430 \\
0,0128 \\
-0,0218 \\
-0,0246 \\
-0,0316 \\
-0,0229 \\
\end{array}$ & $\begin{array}{l}0,0611 \\
0,0266 \\
0,0221 \\
0,0082 \\
0,0042 \\
0,0021 \\
\end{array}$ & $\begin{array}{l}-0,0059 \\
0,0004 \\
0,0260 \\
-0,0190 \\
0,0256 \\
-0,0208\end{array}$ & $\begin{array}{l}0,0632 \\
0,0315 \\
0,0314 \\
0,0119 \\
0,0058 \\
0,0028 \\
\end{array}$ \\
\hline $\begin{array}{c}10 \\
20 \\
30 \\
50 \\
100 \\
200\end{array}$ & & 0,1 & $\begin{array}{l}0,1113 \\
0,1228 \\
0,0691 \\
0,0791 \\
0,0774 \\
0,0714 \\
\end{array}$ & $\begin{array}{l}0,0704 \\
0,0372 \\
0,0134 \\
0,0139 \\
0,0069 \\
0,0032 \\
\end{array}$ & $\begin{array}{l}0,0802 \\
0,1222 \\
0,0794 \\
0,0834 \\
0,0836 \\
0,0758 \\
\end{array}$ & $\begin{array}{l}0,0862 \\
0,0376 \\
0,0170 \\
0,0174 \\
0,0077 \\
0,0040\end{array}$ \\
\hline $\begin{array}{c}10 \\
20 \\
30 \\
50 \\
100 \\
200 \\
\end{array}$ & & 0,2 & $\begin{array}{l}0,2269 \\
0,1871 \\
0,1725 \\
0,1790 \\
0,1966 \\
0,1823 \\
\end{array}$ & $\begin{array}{l}0,0699 \\
0,0280 \\
0,0224 \\
0,0167 \\
0,0076 \\
0,0037 \\
\end{array}$ & $\begin{array}{l}0,2179 \\
0,1968 \\
0,1789 \\
0,1846 \\
0,1973 \\
0,1904 \\
\end{array}$ & $\begin{array}{l}0,0684 \\
0,0313 \\
0,0240 \\
0,0174 \\
0,0081 \\
0,0038\end{array}$ \\
\hline
\end{tabular}


TABELA 9 - Média e variancia do coeficiente de endogamia estimadas através da média das estimativas em análises individuais (F) e através da anólise conjunta (F"), em $\mathrm{N}=100$ experimentos com amostras de tamanhos diferentes extraidas em populaçoes de três alelos com diversas combinasões de frequências gênicas e coeficiente de endogamia.

\begin{tabular}{|c|c|c|c|c|c|c|}
\hline $\mathbf{n}$ & $\left(P_{1 ;} ; 2 ; P_{3}\right)$ & F & $\bar{F}$ & Ver $(\bar{F})$ & $F^{7}$ & $\operatorname{Var}\left(F^{*}\right)$ \\
\hline $\begin{array}{c}10 \\
20 \\
30 \\
50 \\
100 \\
200 \\
\end{array}$ & $(0,60 ; 0,30 ; 0,10)$ & $\overline{0,3}$ & $\begin{array}{l}0,2992 \\
0,2569 \\
0,2778 \\
0,2872 \\
0,2783 \\
0,2898 \\
\end{array}$ & $\begin{array}{l}0,0670 \\
0,0317 \\
0,0277 \\
0,0158 \\
0,0081 \\
0,0030 \\
\end{array}$ & $\begin{array}{l}0,2873 \\
0,2789 \\
0,2953 \\
0,2946 \\
0,2812 \\
0,2968 \\
\end{array}$ & $\begin{array}{l}0,0689 \\
0,0333 \\
0,0301 \\
0,0152 \\
0,0082 \\
0,0028 \\
\end{array}$ \\
\hline $\begin{array}{c}10 \\
20 \\
30 \\
50 \\
100 \\
200 \\
\end{array}$ & & 0,4 & $\begin{array}{l}0,3614 \\
0,4312 \\
0,3514 \\
0,3686 \\
0,3888 \\
0,3787 \\
\end{array}$ & $\begin{array}{l}0,0772 \\
0,0355 \\
0,0221 \\
0,0173 \\
0,0047 \\
0,0035 \\
\end{array}$ & $\begin{array}{l}0,3517 \\
0,4430 \\
0,3735 \\
0,3789 \\
0,3940 \\
0,3884 \\
\end{array}$ & $\begin{array}{l}0,0882 \\
0,0270 \\
0,0243 \\
0,0161 \\
0,0042 \\
0,0034\end{array}$ \\
\hline $\begin{array}{l}10 \\
20 \\
30 \\
50 \\
100 \\
200 \\
\end{array}$ & & 0,5 & $\begin{array}{l}0,5229 \\
0,4885 \\
0,4590 \\
0,4708 \\
0,4821 \\
0,4944 \\
\end{array}$ & $\begin{array}{l}0,0655 \\
0,0381 \\
0,0267 \\
0,0156 \\
0,0066 \\
0,0034\end{array}$ & $\begin{array}{l}0,5151 \\
0,4959 \\
0,4831 \\
0,4907 \\
0,4873 \\
0,4963 \\
\end{array}$ & $\begin{array}{l}0,0683 \\
0,0290 \\
0,0243 \\
0,0115 \\
0,0060 \\
0,0032 \\
\end{array}$ \\
\hline $\begin{array}{c}10 \\
30 \\
30 \\
50 \\
100 \\
200 \\
\end{array}$ & & 0,6 & $\begin{array}{l}0,6066 \\
0,5829 \\
0,5635 \\
0,5840 \\
0,5834 \\
0,6012 \\
\end{array}$ & $\begin{array}{l}0,0627 \\
0,0389 \\
0,0266 \\
0,0140 \\
0,0061 \\
0,0031 \\
\end{array}$ & $\begin{array}{l}0,5975 \\
0,5894 \\
0,5856 \\
0,5918 \\
0,5867 \\
0,6030 \\
\end{array}$ & $\begin{array}{l}0,0632 \\
0,0322 \\
0,0218 \\
0,0123 \\
0,0051 \\
0,0028 \\
\end{array}$ \\
\hline $\begin{array}{c}10 \\
20 \\
30 \\
50 \\
100 \\
200 \\
\end{array}$ & & 0,7 & $\begin{array}{l}0,6520 \\
0,6672 \\
0,7053 \\
0,6704 \\
0,6933 \\
0,6894 \\
\end{array}$ & $\begin{array}{l}0,0563 \\
0,0340 \\
0,0198 \\
0,0119 \\
0,0053 \\
0,0023 \\
\end{array}$ & $\begin{array}{l}0,6575 \\
06934 \\
0,7158 \\
0,6864 \\
0,6960 \\
0,6938 \\
\end{array}$ & $\begin{array}{l}0,0470 \\
0,0254 \\
0,0159 \\
0,0085 \\
0,0047 \\
0,0019 \\
\end{array}$ \\
\hline $\begin{array}{l}10 \\
20 \\
30 \\
50 \\
100 \\
200 \\
\end{array}$ & & 0,8 & $\begin{array}{l}0,7846 \\
0,7952 \\
0,7765 \\
0,7812 \\
0,7906 \\
0,7881 \\
\end{array}$ & $\begin{array}{l}0,0368 \\
0,0221 \\
0,0161 \\
0,0079 \\
0,0036 \\
0,0017 \\
\end{array}$ & $\begin{array}{l}0,7879 \\
0,8068 \\
0,7823 \\
0,7906 \\
0,7942 \\
0,7930\end{array}$ & $\begin{array}{l}0,0323 \\
0,0168 \\
0,0121 \\
0,0062 \\
0,0033 \\
0,0013\end{array}$ \\
\hline
\end{tabular}


TABELA 9 - Média e variância do coeficiente de endogamia estimadas através da média das estimativas em enálises individuais (F) e através da análise conjunta $\left(F^{*}\right)$, em $N=100$ experimentos com amostras de tamenhos diferentes extrádas em populaçoes de três alelos com diversas combinagõos de frequências gênicas e coeficiente de endogamia.

\begin{tabular}{|c|c|c|c|c|c|c|}
\hline $\mathbf{n}$ & $\left(P_{1 ;} P_{2} ; P_{3}\right)$ & $F$ & $\bar{F}$ & $\operatorname{Var}(\overline{\mathrm{F}})$ & $\vec{F}$ & $\operatorname{Var}\left(F^{*}\right)$ \\
\hline $\begin{array}{c}10 \\
20 \\
30 \\
50 \\
100 \\
200 \\
\end{array}$ & $(0,60 ; 0,30 ; 0,10)$ & 0,9 & $\begin{array}{l}0,8973 \\
0,8709 \\
0,8782 \\
0,8869 \\
0,8969 \\
0,8866 \\
\end{array}$ & $\begin{array}{l}0,0255 \\
0,0163 \\
0,0089 \\
0,0042 \\
0,0019 \\
0,0011\end{array}$ & $\begin{array}{l}0,9030 \\
0,8846 \\
0,8870 \\
0,8904 \\
0,8994 \\
0,8895\end{array}$ & $\begin{array}{l}0,0238 \\
0,0093 \\
0,0062 \\
0,0024 \\
0,0017 \\
0,0009\end{array}$ \\
\hline $\begin{array}{c}10 \\
20 \\
30 \\
50 \\
100 \\
200 \\
\end{array}$ & & 1,0 & $\begin{array}{l}0,9982 \\
0,9898 \\
0,9925 \\
0,9928 \\
0,9949 \\
0,9932\end{array}$ & $\begin{array}{l}0,0003 \\
0,0029 \\
0,0007 \\
0,0003 \\
0,0001 \\
0,0001\end{array}$ & $\begin{array}{l}0,9984 \\
0,9953 \\
0,9946 \\
0,9935 \\
0,9960 \\
0,9945\end{array}$ & $\begin{array}{l}0,0002 \\
0,0004 \\
0,0003 \\
0,0002 \\
0,0001 \\
0,0001\end{array}$ \\
\hline $\begin{array}{c}10 \\
20 \\
30 \\
50 \\
100 \\
200 \\
\end{array}$ & $(0,50 ; 0,40 ; 0,10)$ & 0,0 & $\begin{array}{l}0,0131 \\
0,0106 \\
-0,0034 \\
-0,0276 \\
-0,0032 \\
-0,0063 \\
\end{array}$ & $\begin{array}{l}0,0562 \\
0,0246 \\
0,0147 \\
0,0078 \\
0,0047 \\
0,0019 \\
\end{array}$ & $\begin{array}{r}-0,0243 \\
-0,0030 \\
0,0006 \\
-0,0224 \\
0,0049 \\
0,0010 \\
\end{array}$ & $\begin{array}{l}0,0623 \\
0,0277 \\
0,0202 \\
0,0118 \\
0,0063 \\
0,0025 \\
\end{array}$ \\
\hline $\begin{array}{c}10 \\
20 \\
30 \\
50 \\
100 \\
200 \\
\end{array}$ & & 0,1 & $\begin{array}{l}0,1323 \\
0,1086 \\
0,0868 \\
0,0915 \\
0,0783 \\
0,0912 \\
\end{array}$ & $\begin{array}{l}0,0567 \\
0,0365 \\
0,0202 \\
0,0129 \\
0,0057 \\
0,0026 \\
\end{array}$ & $\begin{array}{l}0,1093 \\
0,1042 \\
0,0935 \\
0,0971 \\
0,0840 \\
0,0968\end{array}$ & $\begin{array}{l}0,0720 \\
0,0381 \\
0,0240 \\
0,0146 \\
0,0069 \\
0,0031\end{array}$ \\
\hline $\begin{array}{c}10 \\
20 \\
30 \\
50 \\
100 \\
200 \\
\end{array}$ & & 0,2 & $\begin{array}{l}0,2201 \\
0,1408 \\
0,1854 \\
0,1741 \\
0,1851 \\
0,1880 \\
\end{array}$ & $\begin{array}{l}0,0668 \\
0,0309 \\
0,0206 \\
0,0128 \\
0,0070 \\
0,0035 \\
\end{array}$ & $\begin{array}{l}0,1976 \\
0,1540 \\
0,1928 \\
0,1834 \\
0,1901 \\
0,1884 \\
\end{array}$ & $\begin{array}{l}0,0694 \\
0,0329 \\
0,0221 \\
0,0137 \\
0,0074 \\
0,0034\end{array}$ \\
\hline $\begin{array}{c}10 \\
20 \\
30 \\
50 \\
100 \\
200 \\
\end{array}$ & & 0,3 & $\begin{array}{l}0,3415 \\
0,2818 \\
0,2803 \\
0,2745 \\
0,2754 \\
0,2946\end{array}$ & $\begin{array}{l}0,0637 \\
0,0353 \\
0,0251 \\
0,0123 \\
0,0085 \\
0,0028\end{array}$ & $\begin{array}{l}0,3306 \\
0,2989 \\
0,2942 \\
0,2816 \\
0,2810 \\
0,3020\end{array}$ & $\begin{array}{l}0,0565 \\
0,0359 \\
0,0258 \\
0,0116 \\
0,0082 \\
0,0033 \\
\end{array}$ \\
\hline
\end{tabular}


TABELA 9 - Média e variância do coeficiente de endogamia extimadas através da média das estimativas em análises individuais (F) e através da andilise conjunta (F), em $\mathrm{N}=100$ experimentos com amostras de tamanhos diferentes extrádas em populagôes de três alelos com diversas combinaçōes de frequências gênicas e coeficiente de endogamia.

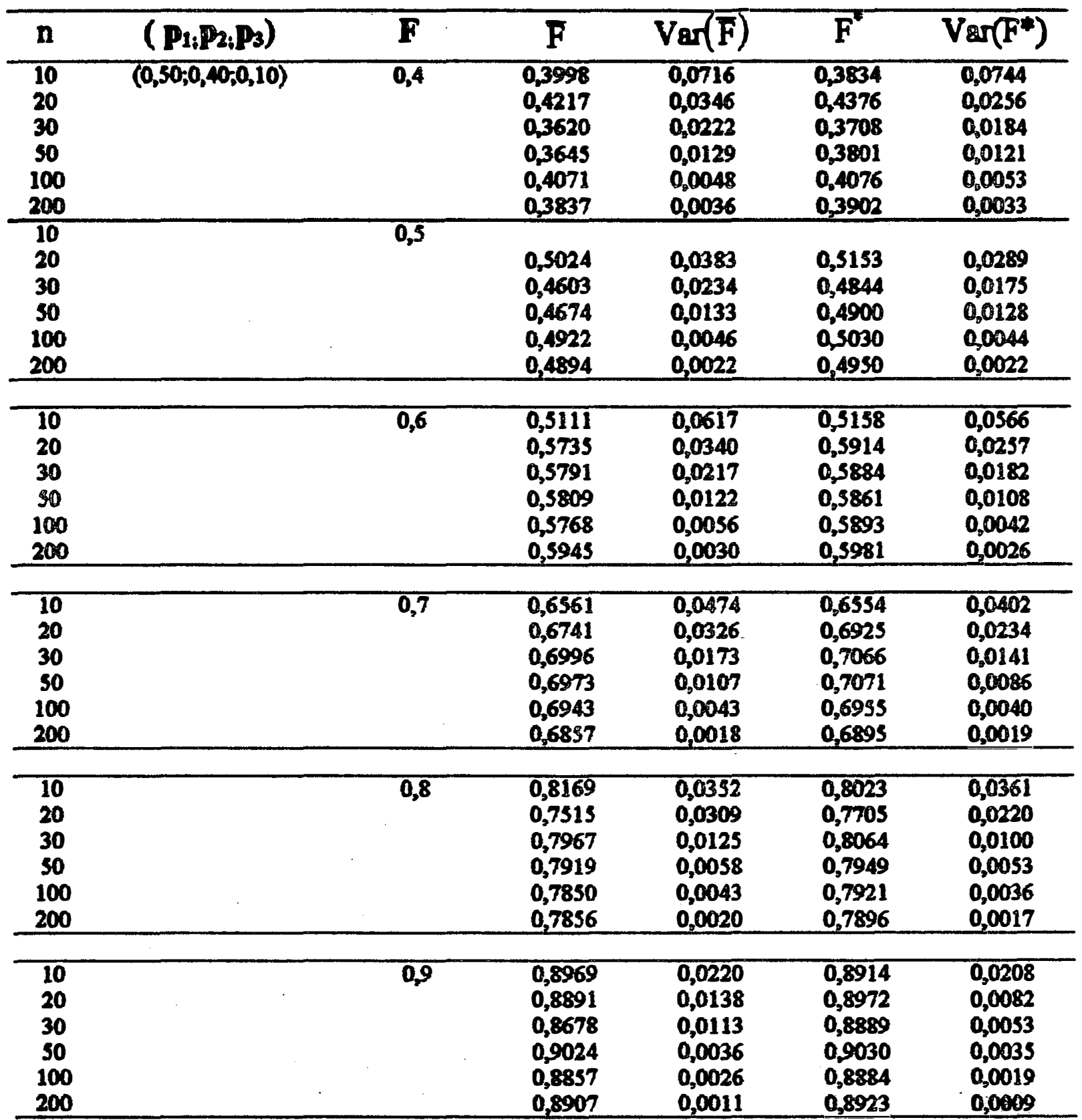


TABELA 9 - Média e variância do coeficiente de endogamia estimadas através da média das estimativas em análises individuais (F) e através da análise conjunta (F), em N-100 experimentos com amostras de tamnnhos diferentes extraídas em populacões de três alelos com diversas combinasōes de frequências génicas e coeficiente de endogania.

\begin{tabular}{|c|c|c|c|c|c|c|}
\hline $\mathbf{n}$ & $\left(P_{1} ; P_{2} ; P_{3}\right)$ & $F$ & $\mathbf{F}$ & $\operatorname{Var}(\bar{F})$ & $F^{2}$ & $\operatorname{Var}\left(F^{*}\right)$ \\
\hline $\begin{array}{c}10 \\
20 \\
30 \\
50 \\
100 \\
200 \\
\end{array}$ & $(0,50,0,40 ; 0,10)$ & 1,0 & $\begin{array}{l}0,9968 \\
0,9980 \\
0,9922 \\
0,9950 \\
0,9958 \\
0,9916\end{array}$ & $\begin{array}{l}0,0005 \\
0,0001 \\
0,0016 \\
0,0002 \\
0,0001 \\
0,0001 \\
\end{array}$ & $\begin{array}{l}0,9969 \\
0,9976 \\
0,9945 \\
0,9962 \\
0,9965 \\
0,9932 \\
\end{array}$ & $\begin{array}{l}0,0005 \\
0,0002 \\
0,0005 \\
0,0001 \\
0,0001 \\
0,0000\end{array}$ \\
\hline $\begin{array}{c}10 \\
20 \\
30 \\
50 \\
100 \\
200 \\
\end{array}$ & $(0,60 ; 0,39 ; 0,01)$ & 0,0 & $\begin{array}{l}0,2845 \\
0,2562 \\
0,1688 \\
0,1377 \\
0,0579 \\
-0,0047 \\
\end{array}$ & $\begin{array}{l}0,0714 \\
0,0376 \\
0,0406 \\
0,0373 \\
0,0212 \\
0,0044 \\
\end{array}$ & $\begin{array}{l}0,0030 \\
0,0235 \\
0,0060 \\
-0,0017 \\
0,0006 \\
-0,0141\end{array}$ & $\begin{array}{l}0,1153 \\
0,0472 \\
0,0280 \\
0,0189 \\
0,0069 \\
0,0045 \\
\end{array}$ \\
\hline $\begin{array}{c}10 \\
20 \\
30 \\
50 \\
100 \\
200 \\
\end{array}$ & & 0,1 & $\begin{array}{l}0,2978 \\
0,3101 \\
0,2451 \\
0,1773 \\
0,1083 \\
0,0694 \\
\end{array}$ & $\begin{array}{l}0,0656 \\
0,0376 \\
0,0494 \\
0,0350 \\
0,0166 \\
0,0047\end{array}$ & $\begin{array}{l}0,0762 \\
0,0696 \\
0,0772 \\
0,0857 \\
0,0978 \\
0,0953 \\
\end{array}$ & $\begin{array}{l}0,0930 \\
0,0439 \\
0,0320 \\
0,0161 \\
0,0071 \\
0,0050\end{array}$ \\
\hline $\begin{array}{c}10 \\
20 \\
30 \\
50 \\
100 \\
200 \\
\end{array}$ & & 0,2 & $\begin{array}{l}0,4306 \\
0,4016 \\
0,3417 \\
0,3096 \\
0,2011 \\
0,1470 \\
\end{array}$ & $\begin{array}{l}0,0662 \\
0,0528 \\
0,0465 \\
0,0329 \\
0,0246 \\
0,0088 \\
\end{array}$ & $\begin{array}{l}0,2321 \\
0,2211 \\
0,1911 \\
0,1977 \\
0,2003 \\
0,1901 \\
\end{array}$ & $\begin{array}{l}0,1063 \\
0,0480 \\
0,0326 \\
0,0175 \\
0,0094 \\
0,0047 \\
\end{array}$ \\
\hline $\begin{array}{c}10 \\
20 \\
30 \\
50 \\
100 \\
200 \\
\end{array}$ & & $\overline{0,3}$ & $\begin{array}{l}0,4407 \\
0,4648 \\
0,3892 \\
0,3470 \\
0,2779 \\
0,2232 \\
\end{array}$ & $\begin{array}{l}0,0648 \\
0,0352 \\
0,0452 \\
0,0407 \\
0,0255 \\
0,0108 \\
\end{array}$ & $\begin{array}{l}0,2113 \\
0,29644 \\
0,2804 \\
0,2776 \\
0,2943 \\
0,2929 \\
\end{array}$ & $\begin{array}{l}0,1002 \\
0,0364 \\
0,0307 \\
0,0262 \\
0,0092 \\
0,0043 \\
\end{array}$ \\
\hline $\begin{array}{c}10 \\
20 \\
30 \\
50 \\
100 \\
200 \\
\end{array}$ & & 0,4 & $\begin{array}{l}0,5238 \\
0,5124 \\
0,4450 \\
0,4396 \\
0,3462 \\
0,2682 \\
\end{array}$ & $\begin{array}{l}0,0675 \\
0,0430 \\
0,0412 \\
0,0351 \\
0,0237 \\
0,0046\end{array}$ & $\begin{array}{l}0,3665 \\
0,3843 \\
0,3721 \\
0,3999 \\
0,3951 \\
0,3840\end{array}$ & $\begin{array}{l}0,0942 \\
0,0476 \\
0,0296 \\
0,0160 \\
0,0091 \\
0,0028 \\
\end{array}$ \\
\hline
\end{tabular}


TABELA 9 - Média e variåncia do coeficiente de endogamia estimadas através de média das estimativas em enálises individusis (F) e através da análise conjunta (F"), em N=100 experimentos com amostras de tamanhos diferentes extraídas em populagões de três alelos com diversas combinaçỏes de frequências gênicas e coeficiente de endogamia.

\begin{tabular}{|c|c|c|c|c|c|c|}
\hline $\mathbf{n}$ & $\left(P_{1 ;}, P_{2 ;} p_{3}\right)$ & $\mathbf{F}$ & $\overline{\mathbf{F}}$ & $\operatorname{Var}(\bar{F})$ & $F^{*}$ & $\operatorname{Var}\left(F^{*}\right)$ \\
\hline $\begin{array}{c}10 \\
20 \\
30 \\
50 \\
100 \\
200 \\
\end{array}$ & $(0,60 ; 0,39 ; 0,01)$ & 0,5 & $\begin{array}{l}0,6183 \\
0,6045 \\
0,5857 \\
0,5131 \\
0,4786 \\
0,3960 \\
\end{array}$ & $\begin{array}{l}0,0510 \\
0,0373 \\
0,0339 \\
0,0310 \\
0,0265 \\
0,0149 \\
\end{array}$ & $\begin{array}{l}0,4617 \\
0,4803 \\
0,5150 \\
0,4929 \\
0,5009 \\
0,4926 \\
\end{array}$ & $\begin{array}{l}0,0863 \\
0,0500 \\
0,0275 \\
0,0143 \\
0,0056 \\
0,0037\end{array}$ \\
\hline $\begin{array}{c}10 \\
20 \\
30 \\
50 \\
100 \\
200 \\
\end{array}$ & & 0,6 & $\begin{array}{l}0,6957 \\
0,6596 \\
0,6509 \\
0,5981 \\
0,5408 \\
0,4963 \\
\end{array}$ & $\begin{array}{l}0,0414 \\
0,0348 \\
0,0256 \\
0,0286 \\
0,0290 \\
0,0176 \\
\end{array}$ & $\begin{array}{l}0,5969 \\
0,5856 \\
0,6024 \\
0,5798 \\
0,5912 \\
0,5898\end{array}$ & $\begin{array}{l}0,0585 \\
0,0363 \\
0,0142 \\
0,0118 \\
0,0067 \\
0,0040\end{array}$ \\
\hline $\begin{array}{c}10 \\
20 \\
30 \\
50 \\
100 \\
200 \\
\end{array}$ & & 0.7 & $\begin{array}{l}0,7743 \\
0,7758 \\
0,7077 \\
0,6974 \\
0,6332 \\
0,6073 \\
\end{array}$ & $\begin{array}{l}0,0270 \\
0,0243 \\
0,0305 \\
0,0268 \\
0,0281 \\
0,0181 \\
\end{array}$ & $\begin{array}{l}0,6874 \\
0,7170 \\
0,6861 \\
0,6906 \\
0,6924 \\
0,7027 \\
\end{array}$ & $\begin{array}{l}0,0510 \\
0,0286 \\
0,0172 \\
0,0118 \\
0,0040 \\
0,0024\end{array}$ \\
\hline $\begin{array}{c}10 \\
20 \\
30 \\
50 \\
100 \\
200 \\
\end{array}$ & & 0,8 & $\begin{array}{l}0,8404 \\
0,8182 \\
0,8078 \\
0,7664 \\
0,7365 \\
0,7150 \\
\end{array}$ & $\begin{array}{l}0,0377 \\
0,0285 \\
0,0236 \\
0,0274 \\
0,0238 \\
0,0207 \\
\end{array}$ & $\begin{array}{l}0,7965 \\
0,7970 \\
0,8013 \\
0,7944 \\
0,7839 \\
0,7903 \\
\end{array}$ & $\begin{array}{l}0,0546 \\
0,0207 \\
0,0111 \\
0,0074 \\
0,0031 \\
0,0024 \\
\end{array}$ \\
\hline $\begin{array}{c}10 \\
20 \\
30 \\
50 \\
100 \\
200 \\
\end{array}$ & & 0,9 & $\begin{array}{l}0,8996 \\
0,9134 \\
0,8944 \\
0,8991 \\
0,8518 \\
0,8147 \\
\end{array}$ & $\begin{array}{l}0,0234 \\
0,0112 \\
0,0133 \\
0,0153 \\
0,0189 \\
0,0175 \\
\end{array}$ & $\begin{array}{l}0,8747 \\
0,8983 \\
0,8866 \\
0,9058 \\
0,8978 \\
0,8903 \\
\end{array}$ & $\begin{array}{l}0,0274 \\
0,0085 \\
0,0063 \\
0,0048 \\
0,0020 \\
0,0009 \\
\end{array}$ \\
\hline $\begin{array}{c}10 \\
20 \\
30 \\
50 \\
100 \\
200 \\
\end{array}$ & & 1,0 & $\begin{array}{l}1,0000 \\
0,9803 \\
0,9858 \\
0,9754 \\
0,9526 \\
0,9494 \\
\end{array}$ & $\begin{array}{l}0,0000 \\
0,0065 \\
0,0041 \\
0,0066 \\
0,0110 \\
0,0093\end{array}$ & $\begin{array}{l}1,0000 \\
0,9931 \\
0,9942 \\
0,9932 \\
0,9937 \\
0,9941\end{array}$ & $\begin{array}{l}0,0000 \\
0,0006 \\
0,0005 \\
0,0003 \\
0,0001 \\
0,0001\end{array}$ \\
\hline
\end{tabular}


TABELA 9 - Módia e variância do coeficiente de endogamia estimadas através da média das estimativas em análises individuais (F) e através da análise conjunta (F'), em $\mathrm{N}=100$ experimentos com amostras de tamanhos diferentes extraídas em populacões de três alelos com diversas combinaşóes de frequências gênicas e coeficiente de endogamia.

\begin{tabular}{|c|c|c|c|c|c|c|}
\hline $\mathbf{n}$ & $\left(P_{1} ; P_{2}, P_{3}\right)$ & $\mathbf{F}$ & $\bar{F}$ & $\operatorname{Var}(\bar{F})$ & $\mathbf{F}$ & $\operatorname{Var}\left(F^{*}\right)$ \\
\hline $\begin{array}{c}10 \\
20 \\
30 \\
50 \\
100 \\
200 \\
\end{array}$ & $(0,60,0,20,0,20)$ & 0,0 & $\begin{array}{l}-0,0233 \\
0,0114 \\
-0,0265 \\
-0,0220 \\
-0,0166 \\
-0,0077 \\
\end{array}$ & $\begin{array}{l}0,0443 \\
0,0294 \\
0,0134 \\
0,0093 \\
0,0046 \\
0,0026 \\
\end{array}$ & $\begin{array}{l}-0,0290 \\
0,0018 \\
-0,0230 \\
-0,0198 \\
0,0163 \\
-0,0072\end{array}$ & $\begin{array}{l}0,0554 \\
0,0315 \\
0,0154 \\
0,0100 \\
0,0048 \\
0,0028 \\
\end{array}$ \\
\hline $\begin{array}{l}10 \\
20 \\
30 \\
50 \\
100 \\
200 \\
\end{array}$ & & 0,1 & $\begin{array}{l}0,0889 \\
0,0688 \\
0,0922 \\
0,1093 \\
0,0933 \\
0,0844\end{array}$ & $\begin{array}{l}0,0557 \\
0,0283 \\
0,0225 \\
0,0134 \\
0,0064 \\
0,0032 \\
\end{array}$ & $\begin{array}{l}0,0827 \\
0,0713 \\
0,0960 \\
0,1122 \\
0,0952 \\
0,0901 \\
\end{array}$ & $\begin{array}{l}0,0638 \\
0,0306 \\
0,0240 \\
0,0140 \\
0,0066 \\
0,0033 \\
\end{array}$ \\
\hline $\begin{array}{l}10 \\
20 \\
30 \\
50 \\
100 \\
200 \\
\end{array}$ & & 0,2 & $\begin{array}{l}0,1811 \\
0,2031 \\
0,1589 \\
0,1889 \\
0,1835 \\
0,1901 \\
\end{array}$ & $\begin{array}{l}0,0494 \\
0,0326 \\
0,0234 \\
0,0170 \\
0,0064 \\
0,0031 \\
\end{array}$ & $\begin{array}{l}0,1937 \\
0,2106 \\
0,1600 \\
0,1900 \\
0,1846 \\
0,1916 \\
\end{array}$ & $\begin{array}{l}0,0568 \\
0,0323 \\
0,0242 \\
0,0172 \\
0,0064 \\
0,0030 \\
\end{array}$ \\
\hline $\begin{array}{c}10 \\
20 \\
30 \\
50 \\
100 \\
200 \\
\end{array}$ & . & 0,3 & $\begin{array}{l}0,2385 \\
0,2815 \\
0,2961 \\
0,2894 \\
0,2972 \\
0,2976 \\
\end{array}$ & $\begin{array}{l}0,0707 \\
0,0406 \\
0,0201 \\
0,0101 \\
0,0066 \\
0,0036 \\
\end{array}$ & $\begin{array}{l}0,2505 \\
0,2930 \\
0,3035 \\
0,2924 \\
0,2982 \\
0,2985 \\
\end{array}$ & $\begin{array}{l}0,0760 \\
0,0421 \\
0,0196 \\
0,0099 \\
0,0065 \\
0,0035 \\
\end{array}$ \\
\hline $\begin{array}{c}10 \\
20 \\
30 \\
50 \\
100 \\
200 \\
\end{array}$ & & 0,4 & $\begin{array}{l}0,3554 \\
0,3871 \\
0,3849 \\
0,3786 \\
0,3804 \\
0,3837 \\
\end{array}$ & $\begin{array}{l}0,0544 \\
0,0353 \\
0,0191 \\
0,0140 \\
0,0073 \\
0,0040 \\
\end{array}$ & $\begin{array}{l}0,3764 \\
0,3920 \\
0,3910 \\
0,3819 \\
0,3824 \\
0,3851 \\
\end{array}$ & $\begin{array}{l}0,0551 \\
0,0323 \\
0,0187 \\
0,0140 \\
0,0072 \\
0,0041\end{array}$ \\
\hline $\begin{array}{c}10 \\
20 \\
30 \\
50 \\
100 \\
200 \\
\end{array}$ & . & 0,5 & $\begin{array}{l}0,4725 \\
0,4953 \\
0,4802 \\
0,5107 \\
0,4783 \\
0,4817 \\
\end{array}$ & $\begin{array}{l}0,0840 \\
0,0438 \\
0,0270 \\
0,0199 \\
0,0067 \\
0,0036 \\
\end{array}$ & $\begin{array}{l}0,4011 \\
0,5059 \\
0,5069 \\
0,4964 \\
0,4932 \\
0,4853 \\
\end{array}$ & $\begin{array}{l}0,1225 \\
0,0783 \\
0,0386 \\
0,0235 \\
0,0106 \\
0,0060 \\
\end{array}$ \\
\hline
\end{tabular}


TABELA 9 - Média e variância do coeficiente de endogamia estimadas através da média das estimativas em análises individuais (F) e através da análise conjunta (F), em $N=100$ experimentos com amostras de tamanhos diferentes extraídas em populagōes de três alelos com diversas combinacobes de frequências génicas e coeficiente de endogamia.

\begin{tabular}{|c|c|c|c|c|c|c|}
\hline $\mathbf{n}$ & $\left(P_{1 ;} P_{2} ; P_{3}\right)$ & $\bar{T}$ & $\mathbf{F}$ & $\operatorname{Var}(\vec{F})$ & $\vec{F}$ & $\operatorname{Var}\left(F^{*}\right)$ \\
\hline $\begin{array}{c}10 \\
20 \\
30 \\
50 \\
100 \\
200 \\
\end{array}$ & $(0,60,0,20,0,20)$ & 0,6 & $\begin{array}{l}0,5550 \\
0,5746 \\
0,5882 \\
0,5883 \\
0,6028 \\
0,5923 \\
\end{array}$ & $\begin{array}{l}0,0908 \\
0,0367 \\
0,0247 \\
0,0162 \\
0,0066 \\
0,0036 \\
\end{array}$ & $\begin{array}{l}0,5335 \\
0,5219 \\
0,5970 \\
0,5894 \\
0,5909 \\
0,5850 \\
\end{array}$ & $\begin{array}{l}0,1283 \\
0,0706 \\
0,0377 \\
0,0213 \\
0,0107 \\
0,0052 \\
\end{array}$ \\
\hline $\begin{array}{c}10 \\
20 \\
30 \\
50 \\
100 \\
200 \\
\end{array}$ & & 0.7 & $\begin{array}{l}0,7197 \\
0,6955 \\
0,6731 \\
0,6957 \\
0,6995 \\
0,7058 \\
\end{array}$ & $\begin{array}{l}0,0608 \\
0,0311 \\
0,0175 \\
0,0105 \\
0,0059 \\
0,0031\end{array}$ & $\begin{array}{l}0,7066 \\
0,6183 \\
0,7123 \\
0,6830 \\
0,6996 \\
0,7059 \\
\end{array}$ & $\begin{array}{l}0,0996 \\
0,0693 \\
0,0277 \\
0,0168 \\
0,0078 \\
0,0043 \\
\end{array}$ \\
\hline $\begin{array}{c}10 \\
20 \\
30 \\
50 \\
100 \\
200 \\
\end{array}$ & & 0,8 & $\begin{array}{l}0,7990 \\
0,7762 \\
0,7894 \\
0,7926 \\
0,7987 \\
0,7986 \\
\end{array}$ & $\begin{array}{l}0,0545 \\
0,0192 \\
0,0104 \\
0,0081 \\
0,0031 \\
0,0019 \\
\end{array}$ & $\begin{array}{l}0,7230 \\
0,7505 \\
0,7679 \\
0,7900 \\
0,8006 \\
0,7980 \\
\end{array}$ & $\begin{array}{l}0,1203 \\
0,0640 \\
0,0257 \\
0,0130 \\
0,0048 \\
0,0030 \\
\end{array}$ \\
\hline $\begin{array}{c}10 \\
20 \\
30 \\
50 \\
100 \\
200 \\
\end{array}$ & - & 0.9 & $\begin{array}{l}0,8958 \\
0,9088 \\
0,8937 \\
0,8973 \\
0,8936 \\
0,8954 \\
\end{array}$ & $\begin{array}{l}0,0224 \\
0,0084 \\
0,0067 \\
0,0041 \\
0,0021 \\
0,0012 \\
\end{array}$ & $\begin{array}{l}0,8729 \\
0,8832 \\
0,9001 \\
0,8933 \\
0,8905 \\
0,8962 \\
\end{array}$ & $\begin{array}{l}0,0619 \\
0,0348 \\
0,0092 \\
0,0073 \\
0,0026 \\
0,0016 \\
\end{array}$ \\
\hline $\begin{array}{c}10 \\
20 \\
30 \\
50 \\
100 \\
200 \\
\end{array}$ & & 1,0 & $\begin{array}{l}0,9944 \\
0,9991 \\
0,9911 \\
0,9921 \\
0,9946 \\
0,9937 \\
\end{array}$ & $\begin{array}{l}0,0010 \\
0,0001 \\
0,0005 \\
0,0003 \\
0,0001 \\
0,0001\end{array}$ & $\begin{array}{l}0,9951 \\
0,9992 \\
0,9915 \\
0,9928 \\
0,9946 \\
0,9940 \\
\end{array}$ & $\begin{array}{l}0,0008 \\
0,0001 \\
0,0005 \\
0,0003 \\
0,0001 \\
0,0000 \\
\end{array}$ \\
\hline $\begin{array}{c}10 \\
20 \\
30 \\
50 \\
100 \\
200\end{array}$ & $(0,50,0,45 ; 0,05)$ & 0,0 & $\begin{array}{l}0,0914 \\
0,0464 \\
-0,0039 \\
-0,0266 \\
-0,0155 \\
-0,0220\end{array}$ & $\begin{array}{l}0,0815 \\
0,0364 \\
0,0148 \\
0,0099 \\
0,0034 \\
0,0023\end{array}$ & $\begin{array}{c}-0,0714 \\
0,0102 \\
-0,0171 \\
-0,0219 \\
-0,0056 \\
-0,0131\end{array}$ & $\begin{array}{l}0,0928 \\
0,0413 \\
0,0224 \\
0,0186 \\
0,0066 \\
0,0044 \\
\end{array}$ \\
\hline
\end{tabular}


TABELA 9 - Média e variância do coeficiente de endogamia extimadas através da média das estimativas em análises individuais (F) e através da análise conjunta (F), em $\mathrm{N}=100$ experimentos com amostras de tamanhos diferentes extraidas em populagões de três alelos com diversas combinagöes de frequências gênicas e coeficiente de endogamia.

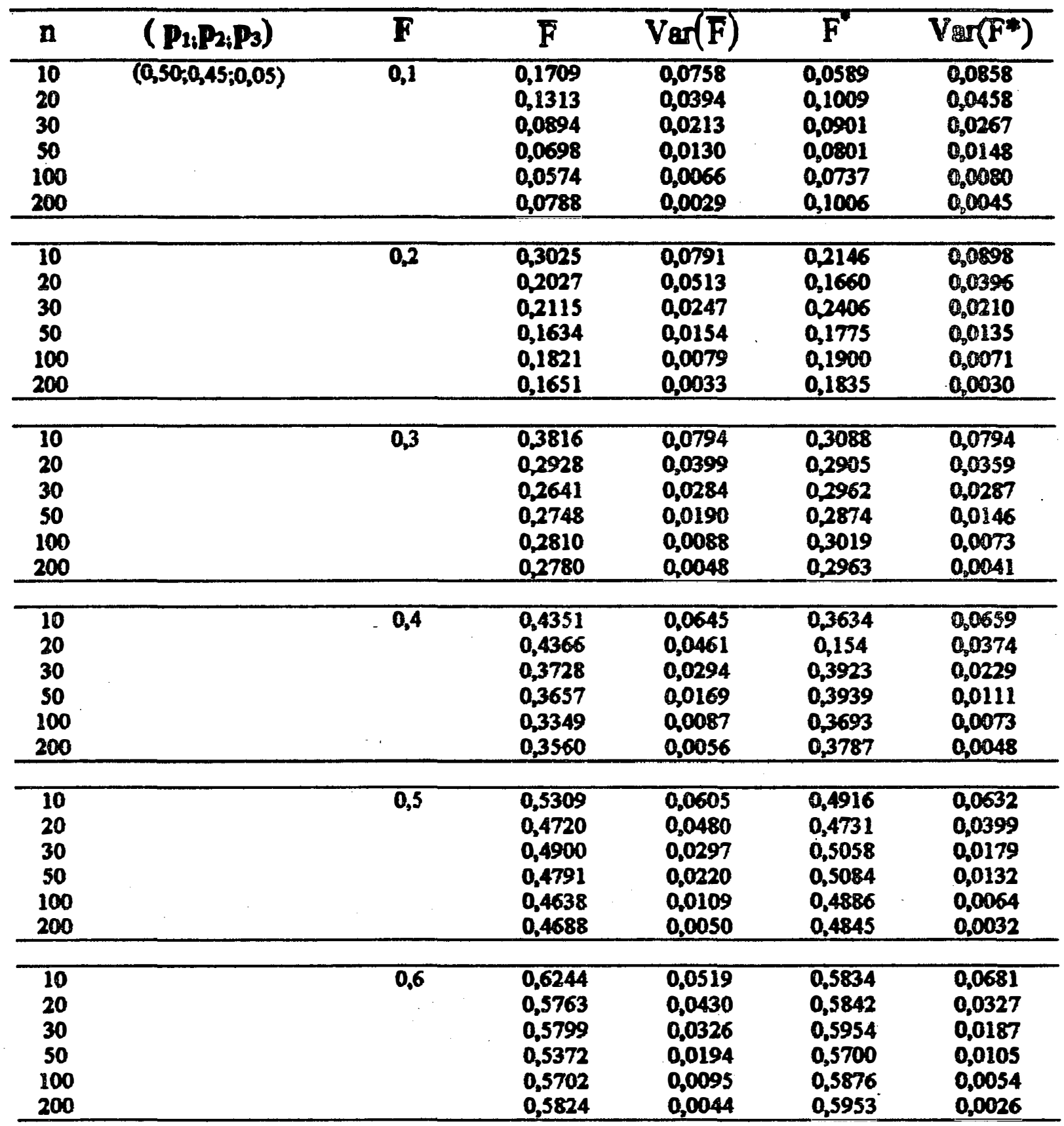


TABELA 9 - Media e variancia do coeficiente de endogamia cotimadas através da média das estimativas em análises individuais (F) e através da análise conjunta $\left(F^{*}\right)$, em $N=100$ experimentos com amostras de tamanhos diferentes extraidas em populacōes de três alelos com diversas combinações de frequências génicas e coeficiente de endogamia.

\begin{tabular}{|c|c|c|c|c|c|c|}
\hline $\mathbf{n}$ & $\left(P_{1} ; P_{2} ; P_{3}\right)$ & $E$ & $\bar{F}$ & $\operatorname{Var}(\bar{F})$ & $\vec{F}$ & $\operatorname{Var}\left(F^{*}\right)$ \\
\hline $\begin{array}{c}10 \\
20 \\
30 \\
50 \\
100 \\
200 \\
\end{array}$ & $(0,50 ; 0,45 ; 0,05)$ & 0,7 & $\begin{array}{l}0,6931 \\
0,6828 \\
0,6509 \\
0,6831 \\
0,6748 \\
0,6642 \\
\end{array}$ & $\begin{array}{l}0,0482 \\
0,0335 \\
0,0347 \\
0,0178 \\
0,0104 \\
0,0033 \\
\end{array}$ & $\begin{array}{l}0,6452 \\
0,6993 \\
0,6794 \\
0,7044 \\
0,6918 \\
0,6791 \\
\end{array}$ & $\begin{array}{l}0,0622 \\
0,0235 \\
0,0194 \\
0,0081 \\
0,0053 \\
0,0024\end{array}$ \\
\hline $\begin{array}{c}10 \\
20 \\
30 \\
50 \\
100 \\
200 \\
\end{array}$ & . & 0,8 & $\begin{array}{l}0,8243 \\
0,7914 \\
0,7691 \\
0,7545 \\
0,7816 \\
0,7815 \\
\end{array}$ & $\begin{array}{l}0,0356 \\
0,0236 \\
0,0236 \\
0,0194 \\
0,0055 \\
0,0025\end{array}$ & $\begin{array}{l}0,8090 \\
0,7949 \\
0,7824 \\
0,7878 \\
0,7958 \\
0,7870\end{array}$ & $\begin{array}{l}0,0350 \\
0,0173 \\
0,0116 \\
0,0087 \\
0,0033 \\
0,0015\end{array}$ \\
\hline $\begin{array}{c}10 \\
20 \\
30 \\
50 \\
100 \\
200\end{array}$ & & 0,9 & $\begin{array}{l}0,8989 \\
0,8892 \\
0,8504 \\
0,8762 \\
0,8803 \\
0,8886 \\
\end{array}$ & $\begin{array}{l}0,0226 \\
0,0167 \\
0,0158 \\
0,0095 \\
0,0050 \\
0,0016\end{array}$ & $\begin{array}{l}0,8867 \\
0,8946 \\
0,8703 \\
0,8925 \\
0,8912 \\
0,8969 \\
\end{array}$ & $\begin{array}{l}0,0292 \\
0,0106 \\
0,0072 \\
0,0034 \\
0,0022 \\
0,000\end{array}$ \\
\hline $\begin{array}{c}10 \\
20 \\
30 \\
50 \\
100 \\
200 \\
\end{array}$ & & 1,0 & $\begin{array}{l}0,9926 \\
0,9862 \\
0,9880 \\
0,9876 \\
0,9901 \\
0,9884 \\
\end{array}$ & $\begin{array}{l}0,0021 \\
0,0036 \\
0,0020 \\
0,0020 \\
0,0014 \\
0,0003 \\
\end{array}$ & $\begin{array}{l}0,9943 \\
0,9927 \\
0,9923 \\
0,9944 \\
0,9950 \\
0,9942 \\
\end{array}$ & $\begin{array}{l}0,0011 \\
0,0008 \\
0,0005 \\
0,0002 \\
0,0001 \\
0,0001\end{array}$ \\
\hline $\begin{array}{c}10 \\
20 \\
30 \\
50 \\
100 \\
200 \\
\end{array}$ & $(0,50 ; 0,49 ; 0,01)$ & 0,0 & $\begin{array}{l}0,2670 \\
0,2440 \\
0,1886 \\
0,1533 \\
0,0317 \\
-0,0026 \\
\end{array}$ & $\begin{array}{l}0,0534 \\
0,0336 \\
0,0444 \\
0,0312 \\
0,0161 \\
0,0028 \\
\end{array}$ & $\begin{array}{r}-0,0332 \\
-0,0089 \\
-0,0059 \\
0,0060 \\
-0,0145 \\
-0,0057 \\
\end{array}$ & $\begin{array}{l}0,0816 \\
0,0422 \\
0,0352 \\
0,0232 \\
0,0088 \\
0,0046 \\
\end{array}$ \\
\hline $\begin{array}{c}10 \\
20 \\
30 \\
50 \\
100 \\
200 \\
\end{array}$ & & $\overline{0,1}$ & $\begin{array}{l}0,3088 \\
0,3030 \\
0,2813 \\
0,2220 \\
0,1248 \\
0,0796 \\
\end{array}$ & $\begin{array}{l}0,0655 \\
0,0337 \\
0,0340 \\
0,0408 \\
0,0211 \\
0,0058 \\
\end{array}$ & $\begin{array}{l}0,0430 \\
0,1021 \\
0,0910 \\
0,0926 \\
0,1025 \\
0,1006 \\
\end{array}$ & $\begin{array}{l}0,1146 \\
0,0383 \\
0,0279 \\
0,0228 \\
0,0081 \\
0,0035 \\
\end{array}$ \\
\hline
\end{tabular}


TABELA 9 - Média e variância do coeficiente de endogamia cotimadas através da média das estimativas em enálises individuais (F) e através da análise conjunta (F'), em $N=100$ experimentos com amostras de tamanhos diferentes extraídas em populacōes de três alelos com diversas combinaçōes de frequências gênicas e coeficiente de endogamia.

\begin{tabular}{|c|c|c|c|c|c|c|}
\hline $\mathbf{n}$ & $\left(P_{1} ; P_{2} ; P_{3}\right)$ & $\bar{F}$ & $\overline{\mathbf{F}}$ & $\operatorname{Var}(\bar{F})$ & $\bar{F}$ & $\operatorname{Var}\left(f^{*}\right)$ \\
\hline $\begin{array}{c}10 \\
20 \\
30 \\
50 \\
100 \\
200 \\
\end{array}$ & $(0,50 ; 0,49 ; 0,01)$ & 0,2 & $\begin{array}{l}0,4266 \\
0,3912 \\
0,3307 \\
0,2600 \\
0,1994 \\
0,1483 \\
\end{array}$ & $\begin{array}{l}0,0653 \\
0,0467 \\
0,0391 \\
0,0352 \\
0,0231 \\
0,0043 \\
\end{array}$ & $\begin{array}{l}0,2179 \\
0,2140 \\
0,2034 \\
0,2076 \\
0,1929 \\
0,2068 \\
\end{array}$ & $\begin{array}{l}0,0969 \\
0,0569 \\
0,0244 \\
0,0185 \\
0,0087 \\
0,0044 \\
\end{array}$ \\
\hline $\begin{array}{c}10 \\
20 \\
30 \\
50 \\
100 \\
200 \\
\end{array}$ & & 0,3 & $\begin{array}{l}0,4267 \\
0,4115 \\
0,4235 \\
0,3768 \\
0,2657 \\
0,2216 \\
\end{array}$ & $\begin{array}{l}0,0633 \\
0,0460 \\
0,0448 \\
0,0406 \\
0,0252 \\
0,0062 \\
\end{array}$ & $\begin{array}{l}0,2223 \\
0,2487 \\
0,3120 \\
0,3024 \\
0,2813 \\
0,3103 \\
\end{array}$ & $\begin{array}{l}0,0979 \\
0,0565 \\
0,0271 \\
0,0175 \\
0,0067 \\
0,0032 \\
\end{array}$ \\
\hline $\begin{array}{c}10 \\
20 \\
30 \\
50 \\
100 \\
200 \\
\end{array}$ & & 0,4 & $\begin{array}{l}0,5610 \\
0,5111 \\
0,4797 \\
0,4276 \\
0,2979 \\
0,2868 \\
\end{array}$ & $\begin{array}{l}0,0543 \\
0,0345 \\
0,0461 \\
0,0337 \\
0,0201 \\
0,0101 \\
\end{array}$ & $\begin{array}{l}0,4074 \\
0,3917 \\
0,4050 \\
0,3675 \\
0,3778 \\
0,3872 \\
\end{array}$ & $\begin{array}{l}0,0808 \\
0,0313 \\
0,0267 \\
0,0153 \\
0,0112 \\
0,0040 \\
\end{array}$ \\
\hline $\begin{array}{c}10 \\
20 \\
30 \\
50 \\
100 \\
200 \\
\end{array}$ & . & 0,5 & $\begin{array}{l}0,5980 \\
0,6015 \\
0,5843 \\
0,5532 \\
0,4376 \\
0,3873 \\
\end{array}$ & $\begin{array}{l}0,0464 \\
0,0363 \\
0,0399 \\
0,0325 \\
0,0298 \\
0,0154 \\
\end{array}$ & $\begin{array}{l}0,4437 \\
0,5031 \\
0,5006 \\
0,5005 \\
0,4872 \\
0,4934 \\
\end{array}$ & $\begin{array}{l}0,0774 \\
0,0396 \\
0,0296 \\
0,0132 \\
0,0077 \\
0,0031 \\
\end{array}$ \\
\hline $\begin{array}{c}10 \\
20 \\
30 \\
50 \\
100 \\
200 \\
\end{array}$ & & 0,6 & $\begin{array}{l}0,6891 \\
0,6557 \\
0,6395 \\
0,5979 \\
0,5491 \\
0,5088 \\
\end{array}$ & $\begin{array}{l}0,0504 \\
0,0375 \\
0,0363 \\
0,0314 \\
0,0307 \\
0,0199 \\
\end{array}$ & $\begin{array}{l}0,5702 \\
0,5831 \\
0,6133 \\
0,6077 \\
0,5929 \\
0,5859 \\
\end{array}$ & $\begin{array}{l}0,0854 \\
0,0318 \\
0,0176 \\
0,0087 \\
0,0061 \\
0,0021 \\
\end{array}$ \\
\hline $\begin{array}{c}10 \\
20 \\
30 \\
50 \\
100 \\
200 \\
\end{array}$ & & 0,7 & $\begin{array}{l}0,7587 \\
0,7647 \\
0,7459 \\
0,6934 \\
0,6354 \\
0,5796 \\
\end{array}$ & $\begin{array}{l}0,0331 \\
0,0240 \\
0,0245 \\
0,0324 \\
0,0266 \\
0,0219 \\
\end{array}$ & $\begin{array}{l}0,6746 \\
0,7044 \\
0,7041 \\
0,6972 \\
0,6844 \\
0,6884 \\
\end{array}$ & $\begin{array}{l}0,0483 \\
0,0286 \\
0,0189 \\
0,0091 \\
0,0060 \\
0,0028 \\
\end{array}$ \\
\hline
\end{tabular}


TABELA 9. - Média e variância do coeficiente de endogamia cstimadas através da média das extimativas em análises individuais (F) e através da análise conjunta (F), em $N=100$ experimentos com amostras de tamanhos diferentes extrádas em populagỏes de três alelos com diversas combinaçoses de frequências gênicas e coeficiente de endogamia

\begin{tabular}{|c|c|c|c|c|c|c|}
\hline $\mathbf{n}$ & $\left(P_{1} ; P_{2} ; P_{3}\right)$ & $F$ & $\mathbf{F}$ & $\operatorname{Var}(\overline{\bar{F}})$ & $F$ & $\sqrt{\operatorname{ar}\left(F^{*}\right)}$ \\
\hline $\begin{array}{c}10 \\
20 \\
30 \\
50 \\
100 \\
200 \\
\end{array}$ & $(0,50 ; 0,49 ; 0,01)$ & 0,8 & $\begin{array}{l}0,8163 \\
0,8355 \\
0,7945 \\
0,8038 \\
0,7294 \\
0,7012 \\
\end{array}$ & $\begin{array}{l}0,0288 \\
0,0186 \\
0,0225 \\
0,0210 \\
0,0262 \\
0,0196 \\
\end{array}$ & $\begin{array}{l}0,7598 \\
0,8124 \\
0,7714 \\
0,8020 \\
0,7816 \\
0,7804 \\
\end{array}$ & $\begin{array}{l}0,0414 \\
0,0162 \\
0,0116 \\
0,0083 \\
0,0035 \\
0,0015\end{array}$ \\
\hline $\begin{array}{c}10 \\
20 \\
30 \\
50 \\
100 \\
200 \\
\end{array}$ & & 0,9 & $\begin{array}{l}0,0249 \\
0,9150 \\
0,8958 \\
0,8898 \\
0,8514 \\
0,8206 \\
\end{array}$ & $\begin{array}{l}0,0122 \\
0,0106 \\
0,0161 \\
0,0161 \\
0,0172 \\
0,0185\end{array}$ & $\begin{array}{l}0,8960 \\
0,8932 \\
0,9025 \\
0,9066 \\
0,8893 \\
0,8937 \\
\end{array}$ & $\begin{array}{l}0,0225 \\
0,0103 \\
0,0057 \\
0,0041 \\
0,0019 \\
0,0009\end{array}$ \\
\hline $\begin{array}{c}10 \\
20 \\
30 \\
50 \\
100 \\
200 \\
\end{array}$ & & 1,0 & $\begin{array}{l}0,9892 \\
0,9927 \\
0,9667 \\
0,9596 \\
0,9566 \\
0,9344 \\
\end{array}$ & $\begin{array}{l}0,0035 \\
0,0026 \\
0,0104 \\
0,0121 \\
0,0102 \\
0,0129 \\
\end{array}$ & $\begin{array}{l}0,9923 \\
0,9982 \\
0,9923 \\
0,9938 \\
0,9936 \\
0,9945 \\
\end{array}$ & $\begin{array}{l}0,0015 \\
0,0002 \\
0,0004 \\
0,0002 \\
0,0001 \\
0,0000\end{array}$ \\
\hline
\end{tabular}


TABELA 10 - Valor esperado e variância das estimativas do coeficiente de endogamia usendo a média das estimetivas em ańlises individusis (F) e a análise conjunta $\left(F^{*}\right) \mathrm{em}$ experimentos com amostra de tamanhos diferentes extraidas de populaģes com três alelos e diversos valores de coeficiente de endogamia.

\begin{tabular}{|c|c|c|c|c|c|}
\hline $\begin{array}{c}\mathbf{n} \\
10 \\
20 \\
30 \\
50 \\
100 \\
200 \\
\end{array}$ & $\frac{F}{0,0}$ & $\begin{array}{c}E(\bar{F}) \\
0,0 \\
0,0 \\
0,0 \\
0,0 \\
0,0 \\
0,0 \\
\end{array}$ & $\begin{array}{c}E\left(F^{*}\right) \\
0,0 \\
0,0 \\
0,0 \\
0,0 \\
0,0 \\
0,0 \\
\end{array}$ & $\begin{array}{c}\operatorname{Vgr}_{p}(\bar{F}) \\
0,0333 \\
0,0167 \\
0,0111 \\
0,0067 \\
0,0033 \\
0,0017 \\
\end{array}$ & $\begin{array}{c}\operatorname{cor}_{\mathrm{p}}\left(\mathrm{F}^{*}\right) \\
0,0333 \\
\mathbf{0 , 0 1 6 7} \\
0,0111 \\
0,0067 \\
0,0033 \\
\mathbf{0 , 0 0 1 7} \\
\end{array}$ \\
\hline $\begin{array}{c}10 \\
20 \\
30 \\
50 \\
100 \\
200 \\
\end{array}$ & 0,1 & $\begin{array}{l}0,0901 \\
0,0951 \\
0,0967 \\
0,0980 \\
0,0990 \\
0,0995 \\
\end{array}$ & $\begin{array}{l}0,0967 \\
0,0984 \\
0,0989 \\
0,0993 \\
0,0997 \\
0,0998 \\
\end{array}$ & $\begin{array}{l}0,0327 \\
0,0163 \\
0,0109 \\
0,0065 \\
0,0033 \\
0,0016 \\
\end{array}$ & $\begin{array}{l}0,0327 \\
0,0163 \\
0,0109 \\
0,0065 \\
0,0033 \\
0,0016\end{array}$ \\
\hline $\begin{array}{c}10 \\
20 \\
30 \\
50 \\
100 \\
200 \\
\end{array}$ & 0,2 & $\begin{array}{l}0,1808 \\
0,1904 \\
0,1936 \\
0,1962 \\
0,1981 \\
0,1990 \\
\end{array}$ & $\begin{array}{l}0,1936 \\
0,1968 \\
0,1979 \\
0,1987 \\
0,1994 \\
0,1997\end{array}$ & $\begin{array}{l}0,0307 \\
0,0154 \\
0,0102 \\
0,0061 \\
0,0031 \\
0,0013 \\
\end{array}$ & $\begin{array}{l}0,0307 \\
0,0154 \\
0,0102 \\
0,0061 \\
0,0031 \\
0,0015 \\
\end{array}$ \\
\hline $\begin{array}{c}10 \\
20 \\
30 \\
50 \\
100 \\
200 \\
\end{array}$ & 0,3 & $\begin{array}{l}0,2727 \\
0,2864 \\
0,2909 \\
0,2945 \\
0,2973 \\
0,2986\end{array}$ & $\begin{array}{l}0,2909 \\
0,2959 \\
0,2970 \\
0,2982 \\
0,2991 \\
0,2995 \\
\end{array}$ & $\begin{array}{l}0,0276 \\
0,0138 \\
0,0092 \\
0,0053 \\
0,0028 \\
0,0014 \\
\end{array}$ & $\begin{array}{l}0,0276 \\
0,0138 \\
0,0092 \\
0,0055 \\
0,0028 \\
0,0014 \\
\end{array}$ \\
\hline $\begin{array}{c}10 \\
20 \\
30 \\
50 \\
100 \\
200\end{array}$ & 0,4 & $\begin{array}{l}0,3664 \\
0,3832 \\
0,3888 \\
0,3983 \\
0,3966 \\
0,3983\end{array}$ & $\begin{array}{l}0,3888 \\
0,3944 \\
0,3963 \\
0,3978 \\
0,3989 \\
0,3994\end{array}$ & $\begin{array}{l}0,0235 \\
0,0118 \\
0,0078 \\
0,0047 \\
0,0024 \\
0,0012\end{array}$ & $\begin{array}{l}0,0235 \\
0,0118 \\
0,0078 \\
0,0047 \\
0,0024 \\
0,0012\end{array}$ \\
\hline
\end{tabular}

$\operatorname{Var}_{P}(F)$ : veriancia de $F$ umlizanda se o valor paramético de $F$;

$\operatorname{Var}_{P}\left(F^{*}\right)$ : variância de $F^{*}$ vuilizando-se o valor paramético de $F$. 
TABELA 10 - Valor esperado e variancia das extimativas do coeficiente de endogamia usando a média das estimativas em análises individuais (F) e a análise conjunta $\left(\mathrm{F}^{*}\right) \mathrm{em}$ experimentos com amostra de tamanhos diferentes extraídas de populagỏes com três alelos e diversos valores de coeficiente de endogamia.

\begin{tabular}{|c|c|c|c|c|c|}
\hline $\mathbf{n}$ & $F$ & $\bar{E}(\overline{\mathrm{F}})$ & $E\left(F^{*}\right)$ & $\sqrt{\operatorname{ar}}(\bar{F})$ & $\sqrt{8 r_{p}\left(F^{*}\right)}$ \\
\hline $\begin{array}{c}10 \\
20 \\
30 \\
50 \\
100 \\
200 \\
\end{array}$ & 0,5 & $\begin{array}{l}0,4625 \\
0,4813 \\
0,4875 \\
0,4925 \\
0,4963 \\
0,4981 \\
\end{array}$ & $\begin{array}{l}0,4875 \\
0,4938 \\
0,4958 \\
0,4975 \\
0,4988 \\
0,4994\end{array}$ & $\begin{array}{l}0,0188 \\
0,0094 \\
0,0063 \\
0,0038 \\
0,0019 \\
0,0009 \\
\end{array}$ & $\begin{array}{l}0,0188 \\
0,0094 \\
0,0063 \\
0,0038 \\
0,0019 \\
0,0009\end{array}$ \\
\hline $\begin{array}{c}10 \\
20 \\
30 \\
30 \\
100 \\
200 \\
\end{array}$ & 0,6 & $\begin{array}{l}0,5616 \\
0,5808 \\
0,5872 \\
0,5923 \\
0,5962 \\
0,5981 \\
\end{array}$ & $\begin{array}{l}0,5872 \\
0,5936 \\
0,5957 \\
0,5974 \\
0,5987 \\
0,5994\end{array}$ & $\begin{array}{l}0,0137 \\
0,0068 \\
0,0046 \\
0,0027 \\
0,0014 \\
0,0007 \\
\end{array}$ & $\begin{array}{l}0,0137 \\
0,0068 \\
0,0046 \\
0,0027 \\
0,0014 \\
0,0007 \\
\end{array}$ \\
\hline $\begin{array}{c}10 \\
20 \\
30 \\
50 \\
100 \\
200 \\
\end{array}$ & 0,7 & $\begin{array}{l}0,6643 \\
0,6822 \\
0,6881 \\
0,6929 \\
0,6964 \\
0,6962 \\
\end{array}$ & $\begin{array}{l}0,6881 \\
0,6941 \\
0,6960 \\
0,6976 \\
0,6988 \\
0,6994 \\
\end{array}$ & $\begin{array}{l}0,0087 \\
0,0043 \\
0,0029 \\
0,0017 \\
0,0009 \\
0,0004 \\
\end{array}$ & $\begin{array}{l}0,0087 \\
0,0043 \\
0,0029 \\
0,0017 \\
0,0009 \\
0,0004\end{array}$ \\
\hline $\begin{array}{c}10 \\
20 \\
30 \\
50 \\
100 \\
200 \\
\end{array}$ & 0,8 & $\begin{array}{l}0,7712 \\
0,7856 \\
0,7904 \\
0,7942 \\
0,7971 \\
0,7986 \\
\end{array}$ & $\begin{array}{l}0,7904 \\
0,7952 \\
0,7968 \\
0,7981 \\
0,7990 \\
0,7995 \\
\end{array}$ & $\begin{array}{l}0,0043 \\
0,0022 \\
0,0014 \\
0,0009 \\
0,0004 \\
0,0002\end{array}$ & $\begin{array}{l}0,0043 \\
0,0022 \\
0,0014 \\
0,0009 \\
0,0004 \\
0,0002 \\
\end{array}$ \\
\hline $\begin{array}{c}10 \\
20 \\
30 \\
50 \\
100 \\
200 \\
\end{array}$ & 0,9 & $\begin{array}{l}0,8829 \\
0,8915 \\
0,8943 \\
0,8966 \\
0,8983 \\
0,8991 \\
\end{array}$ & $\begin{array}{l}0,8943 \\
0,8972 \\
0,8981 \\
0,8989 \\
0,8994 \\
0,8997 \\
\end{array}$ & $\begin{array}{l}0,0012 \\
0,0006 \\
0,0004 \\
0,0002 \\
0,0001 \\
0,0001 \\
\end{array}$ & $\begin{array}{l}0,0012 \\
0,0006 \\
0,0004 \\
0,0002 \\
0,0001 \\
0,0001\end{array}$ \\
\hline $\begin{array}{c}10 \\
20 \\
30 \\
50 \\
100 \\
200 \\
\end{array}$ & 1,0 & $\begin{array}{l}1,0 \\
1,0 \\
1,0 \\
1,0 \\
1,0 \\
1,0\end{array}$ & $\begin{array}{l}1,0 \\
1,0 \\
1,0 \\
1,0 \\
1,0 \\
1,0\end{array}$ & $\begin{array}{l}0,0 \\
0,0 \\
0,0 \\
0,0 \\
0,0 \\
0,0\end{array}$ & $\begin{array}{l}0,0 \\
0,0 \\
0,0 \\
0,0 \\
0,0 \\
0,0\end{array}$ \\
\hline
\end{tabular}


4.1.7. O teste $F$ para o coeficiente de endogamia na análise de variância das frequências gênicas de amostras de Indivíduos de uma populạ̧ão

Na análise de variância apresentada na Tabela 4 um critério para testar

$$
\mathrm{H}_{0}: \mathrm{F}=0
$$

parece lógico ao assumir que o quociente

$$
\mathrm{C}=\frac{\mathrm{QMI}}{\mathrm{QMG}}
$$

tem distribuição de $\mathrm{F}$ com $\mathbf{v}_{1}=\mathrm{n}-1$ e $\mathbf{v}_{2}=\mathrm{n}$ graus de liberdade.

Para discutir a validade deste teste, foi necessário estudar a distribuição das somas de quadrados dividido pelas esperanças dos quadrados médios correspondentes.

A soma de quadrados de indivíduos foi definida por

$$
\mathrm{SQI}=\frac{1}{2} \sum_{\mathrm{i}=1}^{\mathrm{n}} \mathrm{y}_{\mathrm{i}}^{2}-\frac{1}{2 \mathrm{n}}\left(\sum_{\hat{i j}} \mathrm{y}_{\mathrm{ij}}\right)^{2}=2 \sum_{\mathrm{i}=1}^{\mathrm{D}}\left(\hat{p}_{\mathrm{i}}-\hat{\mathrm{p}}\right)^{2}
$$

sendo:

$\hat{\mathrm{p}}_{\mathrm{i}}$ a frequência gênica do alelo A no indivíduo $\mathrm{i}$, sendo $\hat{\mathrm{p}}_{\mathrm{i}}=0,0 ; 0,5$ e 1,0 se o indivíduo i tiver os genótipos as, $\mathrm{Aa}$ e $\mathrm{AA}$, respectivamente;

$\hat{\mathbf{p}}$ a frequência gênica do alelo $\mathrm{A}$ em $\mathbf{n}$ individuos.

A expressão da soma de quadrados de indivíduos pode ser escrita somando-se e subtraindo-se a frequência gênica teórica p, 


$$
\begin{aligned}
S Q I & =2 \sum_{i=1}^{n}\left(\hat{p}_{i}-\hat{p}\right)^{2}=2 \sum_{i=1}^{n}\left[\left(\hat{p}_{i}-p\right)-(\hat{p}-p)\right]^{2} \\
& =2 \sum_{i=1}^{n}\left[\left(\hat{p}_{i}-p\right)^{2}-2\left(\hat{p}_{i}-p\right)(\hat{p}-p)+(\hat{p}-p)^{2}\right] \\
& =2 \sum_{i=1}^{n}\left(\hat{p}_{i}-p\right)^{2}-2 n(\hat{p}-p)^{2}
\end{aligned}
$$

$\mathrm{Na}$ Tabela 4, sob $\mathrm{H}_{0}: \mathrm{F}=0$

$$
\begin{aligned}
& E[Q M I]=p(1-p), \text { entåo } \\
& \frac{(n-1) Q M I}{E[Q M I]}=\frac{S Q I}{E[Q M I]}=\frac{2 \sum_{i=1}^{n}\left(\hat{p}_{i}-p\right)^{2}-2 n(\hat{p}-p)^{2}}{p(1-p)} \\
&=\frac{\sum_{i=1}^{n}\left(\hat{p}_{i}-p\right)^{2}}{p(1-p)}-\frac{(\hat{p}-p)^{2}}{\frac{p(1-p)}{2 n}} \\
&=\sum_{i=1}^{n}\left(\frac{\hat{p}_{i}-p}{\sqrt{\frac{p(1-p)}{2}}}\right)^{2}-\left(\frac{\hat{p}-p}{\sqrt{\frac{p(1-p)}{2 n}}}\right)^{2} \\
&=\sum_{i=1}^{n} Z_{i j}^{2}-z_{2}^{2} .
\end{aligned}
$$

Mas na variável aleatória

$$
\mathrm{Z}_{1 \mathrm{i}}=\frac{\hat{\mathrm{p}}_{\mathbf{i}}-\mathrm{p}}{\sqrt{\frac{\mathrm{p}(1-\mathrm{p})}{2}}}
$$


a frequência gênica do alelo A no individuo $i, \hat{p}_{i}$ é tal que:

$$
\begin{gathered}
\text { घ[ } \left.\hat{p}_{i}\right]=p \text { e } \operatorname{Var}\left[\hat{p}_{i}\right]=\frac{1}{2} p(1-p)(1+F) . \\
\text { Sob } H_{0}: F=0, \operatorname{Var}\left[\hat{p}_{i}\right]=\frac{p(1-p)}{2}
\end{gathered}
$$

ou seja a frequência gênica do alelo A no individuo i

$$
\hat{p}_{i}=\bar{y}_{i}=\frac{1}{2} \sum_{j=1}^{2} y_{i j}
$$

tem distribuição binomial com densidade dada por:

$$
\begin{aligned}
& \mathrm{P}\left[\bar{Y}_{i}=\frac{k}{2}\right]=C_{2}^{k} p^{k}(1-p)^{2-k}, k=0,1,2 . \\
& \text { Como } \left.\quad Z_{Z_{i}}\right]=0 \quad \text { e } \quad \operatorname{Var}\left[Z_{i i}\right]=1, \text { entåo }
\end{aligned}
$$

a variável aleatória $\mathrm{Z}_{1 \mathrm{i}}$ tem distribuição aproximadamente normal com média zero e variância 1 e consequentemente,

$$
\sum_{i=1}^{n} Z_{l i}^{2}
$$

tem distribuiçăo aproximada de $\chi^{2}$ com $n$ graus de liberdade.

Na variável aleatória 


$$
Z_{2}=\frac{\hat{p}-p}{\sqrt{\frac{p(1-p)}{2 n}}}
$$

a frequência gênica da amostra, $\hat{\mathrm{p}}$, é tal que:

$$
E[\hat{p}]=p \quad \text { e } \quad \operatorname{Var}[\hat{p}]=\frac{1}{2 n} p(1-p)(1+F)
$$

Sob $H_{0}: F=0, \operatorname{Var}[\hat{p}]=\frac{p(1-p)}{2 n}$, ou seja, a frequéncia do gene A na amostra

$$
\hat{\mathbf{p}}=\frac{1}{2 \mathrm{n}} \sum_{\mathfrak{i j}} \mathbf{y}_{\ddot{i j}}
$$

tem distribuição binomial com densidade dada por:

$$
P\left[Y=\frac{k}{2 n}\right]=C_{2 \pi}^{k} p^{k}(1-p)^{2 n-k}, k=0,1, \ldots, 2 n
$$

Como $E\left[Z_{2}\right]=0$ e $\operatorname{Var}\left[Z_{2}\right]=1$, então a variével aleatória $Z_{2}$ tem distribuição aproximadamente normal com média zero e variância 1 , consequentemente $Z_{2}^{2}$ tem distribuição aproximada de $\chi^{2}$ com 1 grau de liberdade e portanto

$$
\frac{(\mathrm{n}-1) \mathrm{QMI}}{\mathrm{E}[\mathrm{QMI}]}
$$


tem distribuiçâo aproximada de $\chi^{2}$ com n-1 graus de liberdade.

A soma de quadrados de genes foi definida por:

$$
S Q G=\sum_{i=1}^{n} \sum_{j=1}^{2} y_{i j}^{2}-\frac{1}{2} \sum_{i} y_{i}^{2}=\sum_{i=1}^{n} \sum_{j=1}^{2}\left(y_{i j}-\hat{p}_{i}\right)^{2}
$$

sendo:

$y_{i j}$ a frequência do gene $j$ dentro do indivíduo $i$,

$\hat{\mathrm{p}}_{i}$ a frequência gênica do alelo $\mathrm{A}$ no indivíduo i.

De maneira análoga da SQI, somando-se e subtraindo-se

p,

$$
S Q G=\sum_{i=1}^{n} \sum_{j=1}^{2}\left(y_{i j}-p\right)^{2}-2 \sum_{j=1}^{n}\left(\hat{p}_{i}-p\right)^{2}
$$

Na Tabela 4, sob $\mathrm{H}_{0}: \mathrm{F}=0$

$$
E[Q M G]=p(1-p) .
$$

Assim,

$$
\begin{aligned}
\frac{n Q M G}{E[Q M G]} & =\frac{S Q G}{E[Q M G]}=\frac{\sum_{i=1}^{n} \sum_{j=1}^{2}\left(y_{i j}-p\right)^{2}-2 \sum_{i=1}^{n}\left(\hat{p}_{i}-p\right)^{2}}{p(1-p)} \\
& =\sum_{i=1}^{n} \sum_{j=1}^{2}\left(\frac{y_{i j}-p}{\sqrt{p(1-p)}}\right)^{2}-\sum_{i=1}^{n}\left(\frac{\hat{p}_{i}-p}{\sqrt{\frac{p(1-p)}{2}}}\right)^{2} \\
& =\sum_{j=1}^{n} \sum_{j=1}^{2} U_{i j}^{2}-\sum_{i=1}^{n} Z_{i}^{2} .
\end{aligned}
$$


Mas na variável aleatória

$$
\mathrm{U}_{i \mathrm{i}}=\frac{\mathrm{y}_{i j}-\mathrm{p}}{\sqrt{\mathrm{p}(1-\mathrm{p})}}
$$

a frequência $y_{i j}$ do gene $j$ dentro do individuo $i$ corresponde aos valores de uma variável binária, que apresenta distribuição de Bemoulli. Assim,

$$
E\left[y_{i j}\right]=p \quad \text { e } \quad \operatorname{Var}\left[y_{i j}\right]=p(1-p) .
$$

Como $E\left[U_{i j}\right]=0$ e $\operatorname{Var}\left[U_{i j}\right]=1$, entåo a variável $U_{i j}$ tem média e variância iguais à distribuição normal padronizada Assim,

$$
\sum_{i=1}^{n} \sum_{j=1}^{2} U_{i j}^{2}
$$

é a soma de 2 n valores ao quadrado de uma variável com características semelhantes a uma distribuição normal de média zero e variância 1 , podendo ser considerada como uma variável com características semelhantes a uma $\chi^{2}$ com $2 n$ graus de liberdade. Assim,

$$
\frac{\text { n } Q M G}{E[Q M G]}
$$


tem distribuição com caracteristicas semelhantes a uma $\chi^{2}$ com $n$ graus de liberdade.

Finalmente, conclui-se que

$$
\frac{\mathrm{QMI}}{\mathrm{p}(1-\mathrm{p})} \approx \frac{\chi_{(\mathrm{z}-1)}^{2}}{\mathrm{n}-1}
$$

e que

$$
\frac{\mathrm{QMG}}{\mathrm{p}(1-\mathrm{p})} \approx \frac{\chi_{(\mathrm{n})}^{2}}{\mathrm{n}}
$$

e em consequência, que

$$
\begin{aligned}
\frac{\mathrm{QMI}}{\mathrm{QMG}} & \approx \frac{\chi_{(\mathrm{z}-1)}^{2} /(\mathrm{n}-1)}{\chi_{(\mathrm{n})}^{2} / \mathrm{n}} \\
& \approx \mathrm{F}_{(\mathrm{n}-1, \mathrm{n})} .
\end{aligned}
$$

Portanto, o quociente QMU/QMG na análise de variância apresentada na Tabela 4 pode ser utilizado como uma aproximafão para testar a hipótese $\mathrm{H}_{0}: \mathrm{F}=0$.

A Tabela 11 apresenta a distribuição da estatística nível de significância, no teste da hipótese $\mathrm{H}_{0}: \mathrm{F}=0$, em $\mathrm{N}=1000$ experimentos considerando amostras de tamanhos diferentes extraidas em populaçōes com dois alelos e diversas frequências gênicas. Confrontandose os valores obtidos das estatísticas a saber: média, variância, percentis 0,95 e 0,99 com aqueles teóricos apresentados na Tabela 12, observou-se que utilizando-se 30 individuos o critério proposto foi válido se a frequência gênica da população esteve entre 0,30 e 0,70 . Para 50 
indivíduos o teste foi válido com a frequência entre 0,25 e 0,75 e com 100 indivíduos o teste foi válido com a frequência entre 0,20 e 0,80 .

Quando ums populacåo apresenta $u$ alelos, com $u>2$ pode-se pensar em fazer o teste para o coeficiente de endogamia utilizando a análise conjunte envolendo os $u$ alelos. Neste caso admite-se que na análise conjunta

$$
C=\frac{Q M I}{Q M G} \approx F_{[([-1), m]} .
$$

A Tabela 13 apresenta a distribuição da estatística nível de significância no teste da hipótese $\mathrm{H}_{0}: \mathrm{F}=0$, em $\mathrm{N}=1000$ experimentos considerando amostras de tamanhos diferentes extraídas em populaģões com três alelos e várias frequências gênicas,sendo mostrados os resultados das análises indivíduais e da análise conjunta.

Percebe-se que, quando a and́lise conjunta é realizada em populaģões em que a frequência de cada alelo não é menor que 0,20 e o número de indivíduos está entre 10 e 30, a média da distribuicão (Tabela 13) se aproximou da média tebrica (Tabela 12). A variância foi um pouco maior que a variância teórica, o percentil 0,95 ficou sempre acima enquanto que o percentil 0,99 apresentou valores considerados ideais. Estes resultados indicaram que o teste $F$ para o coeficiente de endogamia nestas condições só é válido com $\alpha=0,01$. Com $\alpha=0,05$ a distribuição do nivel de significância apresentou sempre $P_{95}$ maior que 0,95 ; portanto o teste $F$, se utilizado, ficará comprometido pelo aumento do erro tipo II. 
Nas populagóes onde algum alelo tinha frequência menor que 0,20 a distribuição do nível de significância apresentou forma diferente da distribuição teórice de F, impossibilitando a ưtilizagāo do teste, qualquer que seja o número de indivíduos utilizado. Quanto mais raro foi um alelo da populaç̧o, mais a distribuição do nível de significância da análise conjunta diferiu da distribuiçảo de F. 
TABELA 11- Distriburiço do nivel de significtncia no teste da hipotese $\mathrm{H}_{0}: \mathbf{F}=0$, em $N=1000$ experimeotos com enostres de tamanhos diferentes axtraldas em populapoes nto endoytmicas do dois alolos com diverses frequencias genicas.

\begin{tabular}{|c|c|c|c|c|c|c|c|c|c|c|c|}
\hline \multirow[b]{2}{*}{2} & \multirow[b]{2}{*}{ Estatistica } & \multicolumn{9}{|c|}{$\mathbf{P}$} & \multirow[b]{2}{*}{0,50} \\
\hline & & $\overline{0,05}$ & 0,10 & 0,15 & 0,20 & 0,25 & 0,30 & 0,35 & 0,40 & 0,45 & \\
\hline 5 & $\begin{array}{l}\overline{\mathbf{C}} \\
\mathbf{S}_{\mathbf{C}}^{2}\end{array}$ & $\begin{array}{l}6200 \\
\left({ }^{*}\right)\end{array}$ & $\begin{array}{l}3930 \\
\left(^{*}\right)\end{array}$ & $\begin{array}{l}2341 \\
\left({ }^{*}\right)\end{array}$ & $\begin{array}{l}1391 \\
\left({ }^{*}\right)\end{array}$ & $\begin{array}{l}851 \\
\left(^{*}\right)\end{array}$ & $\begin{array}{l}681 \\
\left({ }^{*}\right)\end{array}$ & $\begin{array}{l}561 \\
(*)\end{array}$ & $\begin{array}{l}361 \\
\left({ }^{*}\right)\end{array}$ & $\begin{array}{l}411 \\
\left({ }^{*}\right)\end{array}$ & $\begin{array}{l}231 \\
\left(^{*}\right)\end{array}$ \\
\hline & $P_{9 s}$ & 0,60 & 0,60 & 0,74 & 0,74 & 0,90 & 0,90 & 0,90 & 0,90 & 0,90 & 0,90 \\
\hline & $P_{90}$ & 0,60 & 0,74 & 0,90 & 0,90 & 1,00 & 1,00 & 1,00 & 1,00 & 1,00 & 1,00 \\
\hline 10 & $\begin{array}{l}\overline{\mathbf{C}} \\
\mathbf{S}_{\mathrm{C}}^{2}\end{array}$ & $\begin{array}{l}3670 \\
(*)\end{array}$ & $\begin{array}{l}1311 \\
\left({ }^{*}\right)\end{array}$ & $\begin{array}{l}431 \\
\left(^{*}\right)\end{array}$ & $\begin{array}{l}191 \\
\left(^{*}\right)\end{array}$ & $\begin{array}{l}101 \\
\left(^{*}\right)\end{array}$ & $\begin{array}{l}11 \\
(*)\end{array}$ & $\begin{array}{l}41 \\
(*)\end{array}$ & $\begin{array}{l}31 \\
(*)\end{array}$ & $\begin{array}{l}1,30 \\
1,19\end{array}$ & $\begin{array}{l}1,32 \\
1,60\end{array}$ \\
\hline & $P_{95}$ & 0,64 & 0,72 & 0,80 & 0,88 & 0,88 & 0,88 & 0,94 & 0,94 & 0,96 & 0,94 \\
\hline & $\mathbf{P}_{99}$ & 0,64 & 0,80 & 0,88 & 0,94 & 0,94 & 0,98 & 0,98 & 0,98 & 0,98 & 0,99 \\
\hline 15 & $\begin{array}{l}\bar{C} \\
S_{C}^{2}\end{array}$ & $\begin{array}{l}2480 \\
\left(^{*}\right)\end{array}$ & $\begin{array}{l}591 \\
(*)\end{array}$ & $\begin{array}{l}121 \\
(0)\end{array}$ & $\begin{array}{l}31 \\
(*)\end{array}$ & $\begin{array}{l}1,18 \\
0,63\end{array}$ & $\begin{array}{l}1,18 \\
0,83\end{array}$ & $\begin{array}{l}1,16 \\
0,57\end{array}$ & $\begin{array}{l}1,21 \\
0,76\end{array}$ & $\begin{array}{l}1,15 \\
0,61\end{array}$ & $\begin{array}{l}1,17 \\
0,56\end{array}$ \\
\hline & $\begin{array}{l}P_{95} \\
P_{90}\end{array}$ & $\begin{array}{c}0,61 \\
0,67\end{array}$ & $\begin{array}{c}0,73 \\
0,82 \\
\end{array}$ & $\begin{array}{l}0,85 \\
0,90\end{array}$ & $\begin{array}{l}0,90 \\
0,94\end{array}$ & $\begin{array}{c}0,90 \\
0,94\end{array}$ & $\begin{array}{c}0,92 \\
0,97\end{array}$ & $\begin{array}{l}0,95 \\
0,99\end{array}$ & $\begin{array}{c}0,95 \\
0,99\end{array}$ & $\begin{array}{c}0,97 \\
0,99\end{array}$ & $\begin{array}{l}0,97 \\
0,99\end{array}$ \\
\hline 20 & $\begin{array}{l}\overline{\mathbf{C}} \\
\mathbf{S}_{\mathrm{C}}^{2}\end{array}$ & $\begin{array}{l}1321 \\
(*)\end{array}$ & $\begin{array}{l}271 \\
\left({ }^{*}\right)\end{array}$ & $\begin{array}{l}1,14 \\
0,55\end{array}$ & $\begin{array}{l}1,15 \\
0,50\end{array}$ & $\begin{array}{l}1,13 \\
0,47\end{array}$ & $\begin{array}{l}1,10 \\
0,36\end{array}$ & $\begin{array}{l}1,09 \\
0,33\end{array}$ & $\begin{array}{l}1,12 \\
0,38\end{array}$ & $\begin{array}{l}1,11 \\
0,33\end{array}$ & $\begin{array}{l}1,10 \\
0,33\end{array}$ \\
\hline & $\begin{array}{l}P_{9 s} \\
P_{g s}\end{array}$ & $\begin{array}{l}0,64 \\
0,74 \\
\end{array}$ & $\begin{array}{l}0,74 \\
0,84 \\
\end{array}$ & $\begin{array}{l}0,84 \\
0,90\end{array}$ & $\begin{array}{l}0,88 \\
0,94 \\
\end{array}$ & $\begin{array}{l}0,92 \\
0,97\end{array}$ & $\begin{array}{l}0,95 \\
0,99 \\
\end{array}$ & $\begin{array}{l}0,95 \\
0,98\end{array}$ & $\begin{array}{l}0,95 \\
0,99\end{array}$ & $\begin{array}{l}0,96 \\
0,99\end{array}$ & $\begin{array}{l}0,96 \\
0,99\end{array}$ \\
\hline 25 & $\begin{array}{l}\overline{\bar{C}} \\
S_{C}^{2}\end{array}$ & $\begin{array}{l}751 \\
(*)\end{array}$ & $\begin{array}{l}81 \\
(*)\end{array}$ & $\begin{array}{l}31 \\
(*)\end{array}$ & $\begin{array}{l}1,11 \\
0,31\end{array}$ & $\begin{array}{l}1,12 \\
0,29\end{array}$ & $\begin{array}{l}1,09 \\
0,25\end{array}$ & $\begin{array}{l}1,08 \\
0,26\end{array}$ & $\begin{array}{l}1,07 \\
0,21\end{array}$ & $\begin{array}{l}1,11 \\
0,25\end{array}$ & $\begin{array}{l}1,07 \\
0,27\end{array}$ \\
\hline & $\begin{array}{l}\mathrm{P}_{95} \\
\mathrm{P}_{92}\end{array}$ & $\begin{array}{l}0,67 \\
0,71 \\
\end{array}$ & $\begin{array}{l}0,80 \\
0,84 \\
\end{array}$ & $\begin{array}{l}0,84 \\
0,90\end{array}$ & $\begin{array}{l}0,91 \\
0,95\end{array}$ & $\begin{array}{l}0,93 \\
0,98\end{array}$ & $\begin{array}{l}0,95 \\
0,98 \\
\end{array}$ & $\begin{array}{l}0,95 \\
0,99 \\
\end{array}$ & $\begin{array}{l}0,95 \\
0,99\end{array}$ & $\begin{array}{l}0,95 \\
0,99 \\
\end{array}$ & $\begin{array}{l}0,96 \\
0,99\end{array}$ \\
\hline 30 & $\begin{array}{l}\overline{\mathbf{C}} \\
\mathbf{S}_{\mathrm{C}}^{2}\end{array}$ & $\begin{array}{l}491 \\
\left(^{*}\right)\end{array}$ & $\begin{array}{l}11 \\
(*)\end{array}$ & $\begin{array}{l}1,09 \\
0,26\end{array}$ & $\begin{array}{l}1,07 \\
0,20\end{array}$ & $\begin{array}{l}1,09 \\
0,22\end{array}$ & $\begin{array}{l}1,09 \\
0,27\end{array}$ & $\begin{array}{l}1,08 \\
0,18\end{array}$ & $\begin{array}{l}1,08 \\
0,19\end{array}$ & $\begin{array}{l}1,07 \\
0,17\end{array}$ & $\begin{array}{l}1,08 \\
0,19\end{array}$ \\
\hline & $\begin{array}{l}\mathbf{P}_{95} \\
\mathbf{P}_{99}\end{array}$ & $\begin{array}{l}0,69 \\
0,75 \\
\end{array}$ & $\begin{array}{l}0,80 \\
0,87\end{array}$ & $\begin{array}{l}0,87 \\
0,92 \\
\end{array}$ & $\begin{array}{l}0,92 \\
0,96\end{array}$ & $\begin{array}{l}0,92 \\
0,97 \\
\end{array}$ & $\begin{array}{l}0,95 \\
0,99 \\
\end{array}$ & $\begin{array}{l}0,94 \\
0,98\end{array}$ & $\begin{array}{l}0,94 \\
0,99 \\
\end{array}$ & $\begin{array}{l}0,96 \\
0,98 \\
\end{array}$ & $\begin{array}{l}0,96 \\
0,99\end{array}$ \\
\hline
\end{tabular}

(*) : valores maiores que $10^{6}$;

(1) : valores mulupticados por $10^{-2}$;

C :valor obtido para a media da varifivel nivel de significhncia nos $\mathrm{N}=1000$ experimentos; $S_{C}^{2}$ : valor obtido para a variancia da variável nivel de significíncia nos $\mathrm{N}=1000$ experimentos,

$P_{95}$ : valor obtido para o percentil 0,95 da variável nivel de significância nos $\mathrm{N}=1000$ experimentos;

$P_{99}$ : valor obtido para pencentil 0,99 da variável nivel de significhncis nos $N=1000$ experimerros. 
TABELA 11- Distribuif̧a do ntvel de significhncis no teste de hipbtese $\mathrm{H}_{0}: \mathrm{F}=0$, em $N=1000$ experimentos com amostras de tamanhos diferentes extraldes em populacoes nito endogamicas de dois alelos com diveras frequencias getricas.

\begin{tabular}{|c|c|c|c|c|c|c|c|c|c|c|}
\hline & & & & & & $\overline{\mathbf{P}}$ & & & & \\
\hline $\bar{n}$ & Estatistica & 0,55 & 0,60 & 0,65 & 0,70 & 0,75 & 0,80 & 0,85 & 0,90 & 0,95 \\
\hline \multirow[t]{3}{*}{5} & & $\begin{array}{l}311 \\
\left(^{*}\right)\end{array}$ & $\begin{array}{l}431 \\
(*)\end{array}$ & $\begin{array}{l}491 \\
(*)\end{array}$ & $\begin{array}{l}541 \\
(*)\end{array}$ & $\begin{array}{l}961 \\
(*)\end{array}$ & $\begin{array}{l}1491 \\
(*)\end{array}$ & $\begin{array}{l}2520 \\
(*)\end{array}$ & $\begin{array}{l}3420 \\
(*)\end{array}$ & $\begin{array}{l}6380 \\
(*)\end{array}$ \\
\hline & $P_{95}$ & 0,90 & 0,90 & 0,90 & 0,90 & 0,90 & 0,74 & 0,74 & 0,60 & 0,60 \\
\hline & $P_{98}$ & 1,00 & 1,00 & 0,95 & 1,00 & 0,90 & 0,90 & 0,90 & 0,74 & 0,60 \\
\hline \multirow[t]{2}{*}{10} & $\begin{array}{l}\overline{\bar{C}} \\
\mathbf{S}_{\mathbf{C}}^{2}\end{array}$ & $\begin{array}{l}1,27 \\
1,21\end{array}$ & $\begin{array}{l}1,27 \\
1,27\end{array}$ & $\begin{array}{l}1,28 \\
1,36\end{array}$ & $\begin{array}{l}61 \\
(*)\end{array}$ & $\begin{array}{l}121 \\
(*)\end{array}$ & $\begin{array}{l}191 \\
(*)\end{array}$ & $\begin{array}{l}601 \\
\left.()^{*}\right)\end{array}$ & $\begin{array}{l}1511 \\
(*)\end{array}$ & $\begin{array}{l}3610 \\
\left(^{*}\right)\end{array}$ \\
\hline & $\begin{array}{l}\mathbf{P}_{95} \\
\mathbf{P}_{9 g}\end{array}$ & $\begin{array}{l}0,96 \\
0,99 \\
\end{array}$ & $\begin{array}{l}0,94 \\
0,98 \\
\end{array}$ & $\begin{array}{l}0,94 \\
0,98 \\
\end{array}$ & $\begin{array}{l}0,94 \\
0,98 \\
\end{array}$ & $\begin{array}{l}0,88 \\
0,94 \\
\end{array}$ & $\begin{array}{l}0,88 \\
0,94 \\
\end{array}$ & $\begin{array}{l}0,80 \\
0,88 \\
\end{array}$ & $\begin{array}{l}0,72 \\
0,80 \\
\end{array}$ & $\begin{array}{l}0,64 \\
0,72 \\
\end{array}$ \\
\hline \multirow[t]{2}{*}{15} & $\begin{array}{l}\bar{C} \\
S_{C}^{2}\end{array}$ & $\begin{array}{l}1,11 \\
0,47\end{array}$ & $\begin{array}{l}1,16 \\
0,49\end{array}$ & $\begin{array}{l}1,19 \\
(*)\end{array}$ & $\begin{array}{l}1,14 \\
0,56\end{array}$ & $\begin{array}{l}21 \\
(*)\end{array}$ & $\begin{array}{l}31 \\
(*)\end{array}$ & $\begin{array}{l}121 \\
(*)\end{array}$ & $\begin{array}{l}611 \\
(*)\end{array}$ & $\begin{array}{l}2061 \\
(\oplus)\end{array}$ \\
\hline & $\begin{array}{l}P_{9 s} \\
P_{90}\end{array}$ & $\begin{array}{l}0,97 \\
0,99\end{array}$ & $\begin{array}{l}0,97 \\
0,99\end{array}$ & $\begin{array}{l}0,94 \\
0,98\end{array}$ & $\begin{array}{l}0,94 \\
0,98\end{array}$ & $\begin{array}{l}0,90 \\
0,97\end{array}$ & $\begin{array}{l}0,85 \\
0,94\end{array}$ & $\begin{array}{l}0,79 \\
0,90\end{array}$ & $\begin{array}{l}0,73 \\
0,79\end{array}$ & $\begin{array}{l}0,67 \\
0,70\end{array}$ \\
\hline \multirow[t]{2}{*}{20} & $\begin{array}{l}\overline{\bar{C}} \\
\mathbf{S}_{C}^{2}\end{array}$ & $\begin{array}{l}, 10 \\
0,32\end{array}$ & $\begin{array}{l}1,14 \\
0,36\end{array}$ & $\begin{array}{l}1,11 \\
0,31\end{array}$ & $\begin{array}{l}1,14 \\
0,46\end{array}$ & $\begin{array}{l}1,11 \\
0,34\end{array}$ & $\begin{array}{l}1,14 \\
0,70\end{array}$ & $\begin{array}{l}11 \\
(*)\end{array}$ & $\begin{array}{l}191 \\
(*)\end{array}$ & $\begin{array}{l}1281 \\
\left({ }^{*}\right)\end{array}$ \\
\hline & $\begin{array}{l}\mathbf{P}_{95} \\
\mathbf{P}_{99}\end{array}$ & $\begin{array}{l}0,95 \\
0,99 \\
\end{array}$ & $\begin{array}{l}0,95 \\
0,99 \\
\end{array}$ & $\begin{array}{l}0,94 \\
0,99 \\
\end{array}$ & $\begin{array}{l}0,95 \\
0,99 \\
\end{array}$ & $\begin{array}{l}0,92 \\
0,97 \\
\end{array}$ & $\begin{array}{l}0,88 \\
0,94 \\
\end{array}$ & $\begin{array}{l}0,84 \\
0,92 \\
\end{array}$ & $\begin{array}{l}0,74 \\
0,84 \\
\end{array}$ & $\begin{array}{l}0,64 \\
0,69 \\
\end{array}$ \\
\hline \multirow[t]{2}{*}{$\overline{25}$} & $\begin{array}{l}\bar{C} \\
S_{C}^{2}\end{array}$ & $\begin{array}{l}801 \\
(*)\end{array}$ & $\begin{array}{l}1,07 \\
0,22\end{array}$ & $\begin{array}{l}1,09 \\
0,22\end{array}$ & $\begin{array}{l}1,08 \\
0,25\end{array}$ & $\begin{array}{l}1,10 \\
0,24\end{array}$ & $\begin{array}{l}1,06 \\
0,21\end{array}$ & $\begin{array}{l}11 \\
(*)\end{array}$ & $\begin{array}{l}11 \\
(*)\end{array}$ & $\begin{array}{l}61 \\
(*)\end{array}$ \\
\hline & $\begin{array}{l}P_{95} \\
P_{99}\end{array}$ & $\begin{array}{l}0,67 \\
0,71\end{array}$ & $\begin{array}{l}0,96 \\
0,99\end{array}$ & $\begin{array}{l}0,94 \\
0,99\end{array}$ & $\begin{array}{l}0,96 \\
0,99\end{array}$ & $\begin{array}{l}0,94 \\
0,98\end{array}$ & $\begin{array}{l}0,93 \\
0,97\end{array}$ & $\begin{array}{l}0,90 \\
0,95\end{array}$ & $\begin{array}{l}0,85 \\
0,90\end{array}$ & $\begin{array}{l}0,78 \\
0,84\end{array}$ \\
\hline \multirow[t]{2}{*}{30} & $\begin{array}{l}\bar{C} \\
S_{C}^{2}\end{array}$ & $\begin{array}{l}1,08 \\
0,21\end{array}$ & $\begin{array}{l}1,07 \\
0,18\end{array}$ & $\begin{array}{l}1,05 \\
0,18\end{array}$ & $\begin{array}{l}1,06 \\
0,20\end{array}$ & $\begin{array}{l}1,08 \\
0,19\end{array}$ & $\begin{array}{l}1,10 \\
0,22\end{array}$ & $\begin{array}{l}1,03 \\
0,24\end{array}$ & $\begin{array}{l}41 \\
(*)\end{array}$ & $\begin{array}{l}471 \\
(\%)\end{array}$ \\
\hline & $\begin{array}{l}P_{95} \\
P_{99}\end{array}$ & $\begin{array}{l}0,96 \\
0,99 \\
\end{array}$ & $\begin{array}{l}0,96 \\
0,99 \\
\end{array}$ & $\begin{array}{l}0,95 \\
0,99\end{array}$ & $\begin{array}{l}0,96 \\
0,99\end{array}$ & $\begin{array}{l}0,94 \\
0,97\end{array}$ & $\begin{array}{l}0,90 \\
0,96\end{array}$ & $\begin{array}{l}0,87 \\
0,92 \\
\end{array}$ & $\begin{array}{l}0,81 \\
0,84\end{array}$ & $\begin{array}{l}0,69 \\
0,73 \\
\end{array}$ \\
\hline
\end{tabular}


TABELA 11- Distribuiçăo do nfvel de aignifichncia no teste de hipotese $\mathrm{H}_{0}: \mathrm{F}=0$, em $N=1000$ experimentos com amostras de tamanbos difentes extradidas en populacoes nîn endogimicas de doir alelos com diversas froguencias genicas.

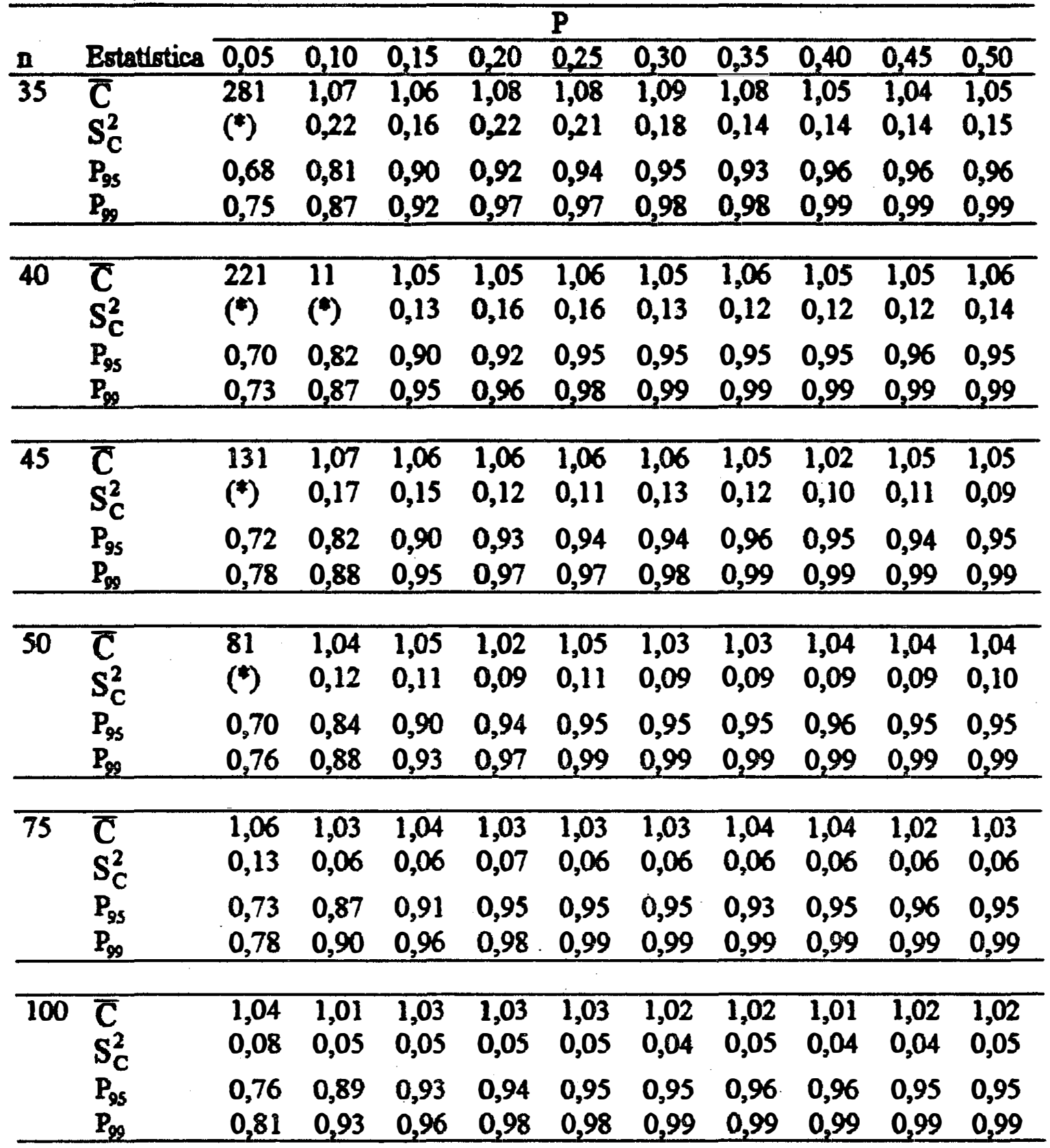


TABELA 11- Distribuifso do ntvel de significhncia no leste de hipbtese $\mathrm{H}_{0}: \mathrm{F}=0$, em $\mathbf{N}=1000$ experimentos com amootras de tamanhos diferentes extraddas em populaces ntio endoghmicas de dois alelos com diverses frequencias genicas.

\begin{tabular}{|c|c|c|c|c|c|c|c|c|c|c|}
\hline & & & & & & $\mathbf{P}$ & & & & \\
\hline I & Estatustica & 0,55 & 0,60 & 0,65 & 0,70 & 0,75 & 0,80 & 0,85 & 0,90 & 0,95 \\
\hline \multirow[t]{4}{*}{35} & $\overline{\mathrm{C}}$ & 1,06 & 1,06 & 1,06 & 1,06 & $1, \overline{06}$ & 1,06 & 1,04 & 11 & 330 \\
\hline & $\mathbf{S}_{\mathrm{C}}^{2}$ & 0,15 & 0,17 & 0,12 & 0,15 & 0,15 & 0,22 & 0,17 & $(*)$ & $\left({ }^{*}\right)$ \\
\hline & $P_{95}$ & 0,96 & 0,94 & 0,93 & 0,94 & 0,95 & 0,92 & 0,90 & 0,81 & 0,68 \\
\hline & $\mathbf{P}_{98}$ & 0,99 & 0,99 & 0,98 & 0,98 & 0,98 & 0,97 & 0,94 & 0,87 & 0,74 \\
\hline \multirow[t]{4}{*}{$\overline{40}$} & $\overline{\mathbf{C}}$ & 1,05 & 1,04 & 1,04 & 1,03 & 1,05 & 1,05 & 1,05 & 1,05 & 251 \\
\hline & $\mathbf{S}_{\mathrm{C}}^{2}$ & 0,11 & 0,12 & 0,13 & 0,13 & 0,13 & 0,15 & 0,27 & 0,20 & $(*)$ \\
\hline & $P_{9 s}$ & 0,94 & 0,95 & 0,94 & 0,96 & 0,95 & 0,93 & 0,90 & 0,82 & 0,70 \\
\hline & $P_{22}$ & 0,99 & 0,99 & 0,99 & 0,99 & 0,99 & 0,97 & 0,95 & 0,88 & 0,76 \\
\hline \multirow[t]{4}{*}{$\overline{45}$} & $\overline{\mathrm{C}}$ & 1,04 & 1,03 & 1.06 & 1.05 & 1.03 & 1.04 & 1.01 & 1,02 & 91 \\
\hline & $\mathbf{S}_{c}^{2}$ & 0,11 & 0,10 & 0,12 & 0,12 & 0,11 & 0,12 & 0,11 & 0,14 & $(*)$ \\
\hline & $\mathbf{P}_{95}$ & 0,95 & 0,94 & 0,95 & 0,93 & 0,95 & 0,93 & 0,90 & 0,83 & 0,72 \\
\hline & $\mathbf{P}_{98}$ & 0,99 & 0,99 & 0,99 & 0,99 & 0,98 & 0,97 & 0,95 & 0,88 & 0,78 \\
\hline \multirow[t]{4}{*}{50} & $\overline{\mathbf{C}}$ & 1,03 & 1,05 & 1,03 & 1,04 & 1,03 & 1,03 & 1,04 & 1,01 & 101 \\
\hline & $\mathbf{S}_{\mathrm{C}}^{2}$ & 0,10 & 0,10 & 0,09 & 0,11 & 0,09 & 0,10 & 0,11 & 0,10 & $\left(^{*}\right)$ \\
\hline & $P_{95}$ & 0,96 & 0,96 & 0,94 & 0,95 & 0,95 & 0,93 & 0,90 &, 084 & 0,70 \\
\hline & $\mathbf{P}_{p 8}$ & 0,99 & 0,99 & 0,99 & 0,98 & 0,98 & 0,98 & 0,94 & 0,88 & 0,76 \\
\hline \multirow[t]{4}{*}{75} & $\overline{\bar{c}}$ & 1,04 & 1,02 & 1,01 & 1,02 & 1,03 & 1,02 & 1,01 & 1,01 & 0,96 \\
\hline & $\mathbf{S}_{\mathrm{C}}^{2}$ & 0,06 & 0,06 & 0,06 & 0,06 & 0,06 & 0,06 & 0,06 & 0,06 & 0,04 \\
\hline & $P_{9 S}$ & 0,93 & 0,96 & 0,96 & 0,96 & 0,94 & 0,93 & 0,92 & 0,87 & 0,76 \\
\hline & $P_{99}$ & 0,99 & 0,99 & 0,99 & 0,99 & 0,99 & 0,98 & 0,96 & 0,91 & 0,79 \\
\hline \multirow[t]{3}{*}{100} & $\overline{\mathbf{C}}$ & 1,02 & 1,02 & 1,00 & 1,01 & 1,02 & 1,01 & 1,00 & 0,99 & 0,96 \\
\hline & $\mathbf{S}_{\mathrm{C}}^{2}$ & 0,04 & 0,04 & 0,04 & 0,04 & 0,04 & 0,04 & 0,04 & 0,04 & 0,03 \\
\hline & $\begin{array}{l}\mathbf{P}_{95} \\
\mathbf{P}_{98}\end{array}$ & $\begin{array}{l}0,95 \\
0,99 \\
\end{array}$ & $\begin{array}{l}0,95 \\
0,99 \\
\end{array}$ & $\begin{array}{l}0,96 \\
0,99\end{array}$ & $\begin{array}{l}0,94 \\
0,99\end{array}$ & $\begin{array}{l}0,95 \\
0,98\end{array}$ & $\begin{array}{l}0,93 \\
0,97\end{array}$ & $\begin{array}{l}0,94 \\
0,97\end{array}$ & $\begin{array}{l}0,89 \\
0,93\end{array}$ & $\begin{array}{l}0,76 \\
0,81\end{array}$ \\
\hline
\end{tabular}


TABELA 11-Dirtribrifia do ntvol de significhncia no teste da hipotese $\mathrm{H}_{0}: \mathrm{F}=0$, em $N=1000$ experimentos com arnotras de tamanhos diferentes extraidas en populagles nto endogenticas de dois alelos com diverses fregsencias gernicas.

\begin{tabular}{|c|c|c|c|c|c|c|c|c|c|c|c|}
\hline \multirow{6}{*}{$\frac{n}{150}$} & \multirow[b]{2}{*}{ Botatistica } & & \multicolumn{9}{|c|}{$\overline{\mathbf{P}}$} \\
\hline & & 0,05 & 0,10 & 0,15 & 0,20 & 0,25 & 0,30 & 0,35 & 0,40 & 0,45 & 0,50 \\
\hline & $\overline{\mathbf{C}}$ & 1,03 & 1,01 & 1,02 & $\overline{1,02}$ & 1,02 & 1,01 & 1,01 & 1,02 & 1,02 & 1,01 \\
\hline & \multirow{3}{*}{$\begin{array}{l}S_{C}^{2} \\
P_{95} \\
P_{99}\end{array}$} & 0,04 & 0,03 & 0,03 & 0,03 & 0,03 & 0,03 & 0,03 & 0,03 & $0 ; 03$ & 0,03 \\
\hline & & 0,80 & 0,91 & 0,93 & 0,94 & 0,93 & 0,94 & 0,94 & 0,95 & 0,94 & 0,96 \\
\hline & & 0,83 & 0,95 & 0,97 & 0,98 & 0,99 & 0,99 & 0,99 & 0,99 & 0,99 & 0,99 \\
\hline \multirow[t]{4}{*}{200} & \multirow{4}{*}{$\begin{array}{l}\bar{C} \\
S_{C}^{2} \\
P_{9 S} \\
P_{9 g}\end{array}$} & 1,03 & 1,01 & 1,00 & 1,01 & 1,00 & 1,00 & 1,00 & 1,00 & 1,00 & 1,01 \\
\hline & & 0,03 & 0,02 & 0,02 & 0,02 & 0,02 & 0,02 & 0,02 & 0,02 & 0,02 & 0,02 \\
\hline & & 0,82 & 0,93 & 0,95 & 0,94 & 0,96 & 0,95 & 0,96 & 0,94 & 0,95 & 0,96 \\
\hline & & 0,86 & 0,95 & 0,98 & 0,98 & 0,99 & 0,99 & 0,99 & 0,99 & 0,99 & 0,99 \\
\hline \multirow[t]{4}{*}{300} & \multirow{4}{*}{$\begin{array}{l}\bar{C} \\
S_{C}^{2} \\
P_{95} \\
P_{99}\end{array}$} & 1,02 & 1,00 & 1,00 & 1,00 & 1,00 & 1,00 & 1,00 & 1,00 & 1,00 & 1,00 \\
\hline & & 0,02 & 0,01 & 0,01 & 0,01 & 0,01 & 0,01 & 0,01 & 0,01 & 0,01 & 0,01 \\
\hline & & 0,85 & 0,94 & 0,93 & 0,94 & 0,94 & 0,96 & 0,95 & 0,95 & 0,95 & 0,95 \\
\hline & & 0,88 & 0,97 & 0,98 & 0,99 & 0,99 & 0,99 & 0,99 & 0,99 & 0,99 & 0,99 \\
\hline
\end{tabular}

\begin{tabular}{llllllllllll}
\hline 400 & $\mathbf{C}$ & 1,02 & 1,00 & 1,02 & 1,00 & 1,00 & 1,00 & 1,00 & 1,00 & 1,00 & 1,00 \\
& $\mathbf{S}_{\mathbf{C}}^{2}$ & 0,01 & 0,01 & 0,01 & 0,01 & 0,01 & 0,01 & 0,01 & 0,01 & 0,01 & 0,01 \\
& $\mathbf{P}_{9 s}$ & 0,87 & 0,94 & 0,93 & 0,95 & 0,95 & 0,96 & 0,95 & 0,95 & 0,96 & 0,95 \\
& $\mathbf{P}_{99}$ & 0,90 & 0,98 & 0,98 & 0,99 & 0,99 & 0,99 & 0,98 & 0,99 & 0,99 & 0,99 \\
\hline & & & & & & & & & & & \\
\hline 500 & $\overline{\mathbf{C}}$ & 1,02 & 1,00 & 1,00 & 1,00 & 1,00 & 1,00 & 1,00 & 1,00 & 1,00 & 1,00 \\
& $\mathbf{S}_{\mathbf{C}}^{2}(1)$ & 0,98 & 0,78 & 0,89 & 0,77 & 0,80 & 0,79 & 0,79 & 0,79 & 0,83 & 0,81 \\
& $\mathbf{P}_{95}$ & 0,89 & 0,94 & 0,94 & 0,94 & 0,95 & 0,94 & 0,94 & 0,95 & 0,96 & 0,95 \\
& $\mathbf{P}_{99}$ & 0,92 & 0,98 & 0,98 & 0,98 & 0,98 & 0,99 & 0,99 & 0,99 & 0,99 & 0,99 \\
\hline
\end{tabular}


TABELA 11- Distribuifso do ntvel de significancia no teste de finjblese $\mathrm{H}_{0}: \mathrm{F}=0$, em $N=1000$ experimentos com amostas de tamanhos difierentes extraldas em populacbes nio endogamicas de dois alelos com diversas frequetionas genicas.

\begin{tabular}{|c|c|c|c|c|c|c|c|c|c|c|}
\hline & & & & & & $\overline{\mathbf{P}}$ & & & & \\
\hline n & Estattstica & 0,55 & 0,60 & 0,65 & 0,70 & 0,75 & 0,80 & 0,85 & 0,90 & 0,95 \\
\hline 150 & $\overline{\mathbf{C}}$ & 1,02 & 1,02 & 1,00 & 1,01 & 1,00 & 1,00 & 0,99 & 0,99 & 0,95 \\
\hline & $\mathbf{S}_{\mathrm{C}}^{2}$ & 0,03 & 0,03 & 0,03 & 0,03 & 0,03 & 0,02 & 0,03 & 0,02 & 0,01 \\
\hline & $\begin{array}{l}\mathbf{P}_{9 g} \\
\mathbf{P}_{p g}\end{array}$ & $\begin{array}{l}0,94 \\
0,99\end{array}$ & $\begin{array}{l}0,95 \\
0,99\end{array}$ & $\begin{array}{l}0,95 \\
0,99\end{array}$ & $\begin{array}{l}0,95 \\
0,99\end{array}$ & $\begin{array}{l}0,95 \\
0,99\end{array}$ & $\begin{array}{l}0,95 \\
0,98\end{array}$ & $\begin{array}{l}0,95 \\
0,98\end{array}$ & $\begin{array}{l}0,91 \\
0,95\end{array}$ & $\begin{array}{l}0,80 \\
0,83\end{array}$ \\
\hline$\overline{200}$ & $\overline{\mathbf{C}}$ & 1,00 & 1,01 & 1,00 & 1,00 & 1,00 & 0,99 & 0,99 & 0,99 & 0,95 \\
\hline & $\mathbf{S}_{\mathrm{C}}^{2}$ & 0,02 & 0,02 & 0,02 & 0,02 & 0,02 & 0,02 & 0,02 & 0,02 & 0,01 \\
\hline & $\mathrm{P}_{95}$ & 0,95 & 0,96 & 0,94 & 0,96 & 0,96 & 0,96 & 0,95 & 0,93 & 0,83 \\
\hline & $P_{80}$ & 0,99 & 0,99 & 0,98 & 0,99 & 0,99 & 0,99 & 0,98 & 0,96 & 0,86 \\
\hline$\overline{300}$ & $\overline{\mathbf{C}}$ & 1,00 & 1,00 & 1,00 & 1,00 & 1,00 & 1,00 & 0,99 & 0,99 & 0,95 \\
\hline & $\mathbf{S}_{\mathrm{C}}^{2}$ & 0,01 & 0,01 & 0,01 & 0,01 & 0,01 & 0,01 & 0,01 & 0,01 & 0,01 \\
\hline & $P_{95}$ & 0,96 & 0,94 & 0,96 & 0,95 & 0,94 & 0,95 & 0,96 & 0,95 & 0,86 \\
\hline & $\mathbf{P}_{90}$ & 0,99 & 0,98 & 0,99 & 0,99 & 0,98 & 0,99 & 0,99 & 0,98 & 0,89 \\
\hline$\overline{400}$ & $\overline{\mathbf{C}}$ & 1,00 & 1,00 & 1,00 & 0,99 & 1,00 & 0,99 & 0,99 & 0,99 & 0,95 \\
\hline & $\mathrm{S}_{\mathrm{C}}^{2}$ & 0,01 & 0,01 & 0,01 & 0,01 & 0,01 & 0,01 & 0,01 & 0,01 & 0,01 \\
\hline & $P_{9 s}$ & 0,95 & 0,96 & 0,96 & 0,96 & 0,96 & 0,96 & 0,96 & 0,95 & 0,89 \\
\hline & $P_{99}$ & 0,99 & 0,99 & 0,99 & 0,99 & 0,99 & 0,99 & 0,99 & 0,98 & 0,91 \\
\hline 500 & $\overline{\mathbf{C}}$ & 1,00 & 0,99 & 1,00 & 1,00 & 0,99 & 1,00 & 0,98 & 0,98 & 0,94 \\
\hline & $S_{C}^{2}(1)$ & 0,85 & 0,75 & 0,76 & 0,82 & 0,79 & 0,77 & 0,77 & 0,69 & 0,35 \\
\hline & $P_{95}$ & 0,96 & 0,96 & 0,95 & 0,95 & 0,96 & 0,95 & 0,96 & 0,95 & 0,91 \\
\hline & $\mathbf{P}_{99}$ & 0,99 & 0,99 & 0,99 & 0,99 & 0,99 & 0,98 & 0,99 & 0,98 & 0,93 \\
\hline
\end{tabular}


Tabela 12 - Média e variância da distribuição $F$ de Snedecor na análise de variância com dois alelos e na análise de variância conjunta com três alelos, com amostras de tamanhos diterentes.

\begin{tabular}{|c|c|c|c|c|}
\hline $\mathbf{n}$ & $\mathbf{E}\left(\mathrm{F}_{\mathrm{g}}\right)$ & $\operatorname{Var}\left(F_{s}\right)$ & E(Frac) & Van(Fac) \\
\hline 5 & 1,667 & $9, \overline{722}$ & 1,154 & 0,504 \\
\hline 10 & 1,250 & 0,984 & 1,071 & 0,180 \\
\hline 15 & 1,154 & 0,467 & 1,046 & 0,108 \\
\hline 20 & 1,111 & 0,300 & 1,034 & 0,077 \\
\hline 25 & 1,087 & 0,220 & 1,027 & 0,060 \\
\hline 30 & 1,071 & 0,174 & 1,023 & 0,049 \\
\hline 35 & 1,061 & 0,143 & 1,019 & 0,041 \\
\hline 40 & 1,053 & 0,122 & 1,017 & 0,036 \\
\hline 45 & 1,046 & 0,106 & 1,015 & 0,031 \\
\hline 50 & 1,042 & 0,093 & 1,014 & 0,028 \\
\hline 75 & 1,027 & 0,059 & 1,009 & 0,018 \\
\hline 100 & 1,020 & 0,043 & 1,007 & 0,014 \\
\hline 150 & 1.014 & 0,028 & 1,004 & 0,009 \\
\hline 200 & 1,010 & 0,021 & 1,003 & 0,007 \\
\hline 300 & 1,007 & 0,014 & 1,002 & 0,004 \\
\hline 400 & 1,005 & 0,010 & 1,002 & 0,003 \\
\hline 500 & 1,004 & 0,008 & 1,001 & 0,003 \\
\hline
\end{tabular}

$\mathrm{F}_{\mathrm{S}}$ : F de Snedecor na andilise de variância com dois alelos;

$F_{s} a c$ : $F$ de Snedecor na análise de variância conjunta com três alelos. 
TABELA 13 - Distribuição do nível de significância no teste da hipótese $H_{0}: F=0$, em $N=1000$ experimentos com amostras de tamanhos diferentes extrádas em populagōes não endogâmicas de três alelos e diversas frequências gênicas, nas análises individuais e na análise conjunta.

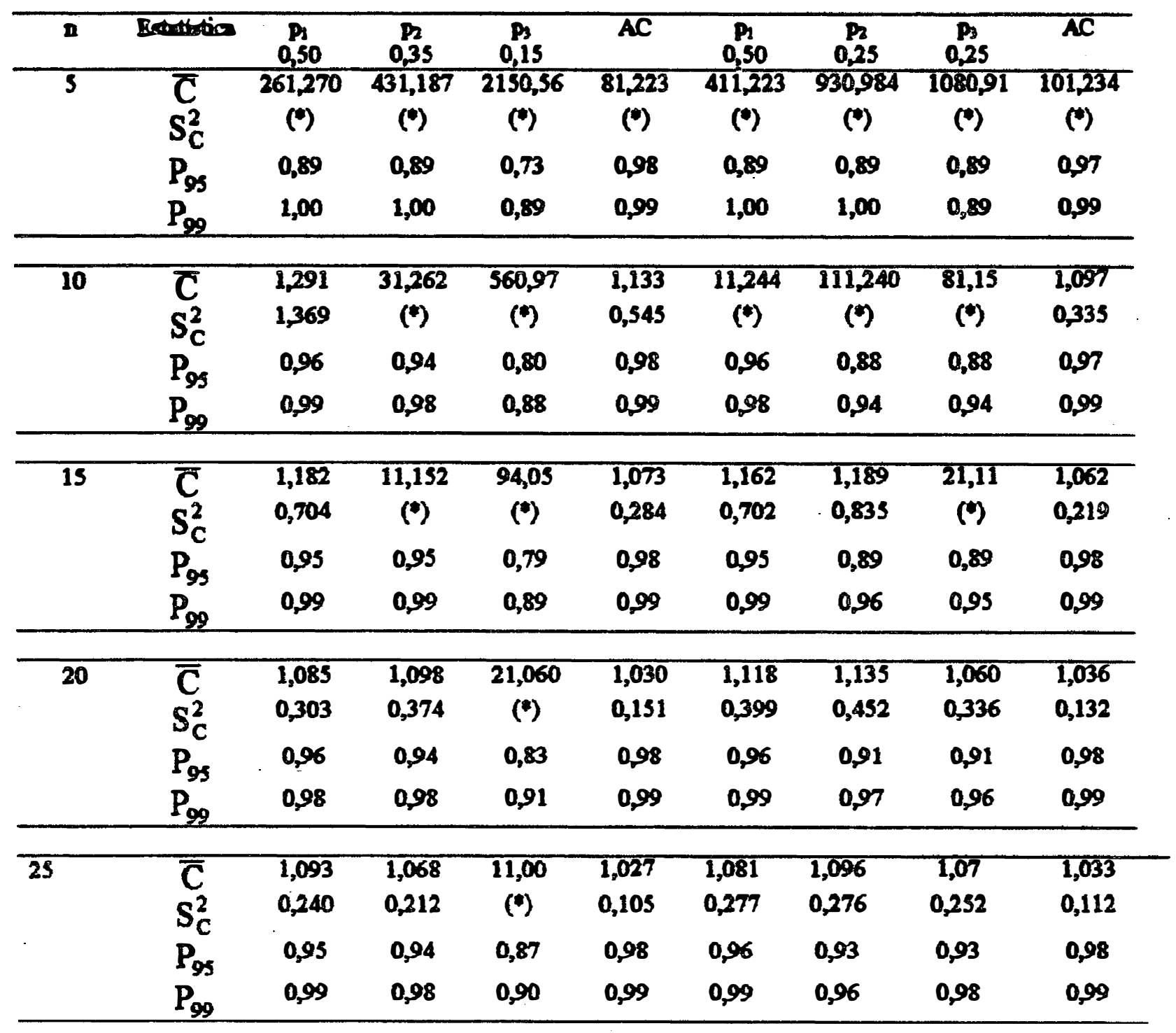

C : valor obtido para a média da variavel ntvel de significancia;

$\mathbf{S}_{\mathbf{C}}^{2}$ : valor obtido para a variância da varíavel ntvel de significancia;

$P_{95}$ : valor obtido para o percentil 0,95 da variável nivel de significhncia;

$P_{99}$ : valor obtido para o percentil 0,99 da varíivel ntvel de significtncia;

AC : anslise conjumta envovendo os tris alelos;

$(*)$ : valores maiores que $10^{4}$. 
TABELA 13 - Distribuição do nível de significåncia no teste da hipótese $\mathrm{H}_{0}: \mathrm{F}=0$, em $\mathrm{N}=1000$ experimentos com amostras de tamanhos diferentes extraídas em populaçoses não endogámicas de três alelos e diversas frequências gênicas, nas análises individuais e na análise conjunta.

\begin{tabular}{|c|c|c|c|c|c|c|c|c|c|}
\hline 30 & Estifistica & $\begin{array}{c}p_{1} \\
0,50 \\
1,073\end{array}$ & $\begin{array}{c}P_{2} \\
0,35 \\
1,074\end{array}$ & $\begin{array}{c}P_{3} \\
0,15 \\
1,000\end{array}$ & $\begin{array}{c}A C \\
1,027\end{array}$ & $\begin{array}{c}P_{1} \\
0,50 \\
1,055\end{array}$ & $\begin{array}{c}p_{2} \\
0,25 \\
1,084\end{array}$ & $\frac{P_{3}}{0,25}$ & $\begin{array}{c}A C \\
1,022\end{array}$ \\
\hline \multirow{3}{*}{30} & & 0,181 & 0,182 & 0,194 & 0,089 & 0,180 & 0,216 & 0,199 & 0,088 \\
\hline & & 0,95 & 0,96 & 0,88 & 0,98 & 0,96 & 0,94 & 0,94 & 0,98 \\
\hline & $P_{99}$ & 0,99 & 0,99 & 0,92 & 0,99 & 0,99 & 0,97 & 0,98 & 0,99 \\
\hline \multirow[t]{4}{*}{35} & & 1,055 & 1,055 & 1,020 & 1,019 & 1,058 & 1,081 & 1,030 & 1,022 \\
\hline & & 0,162 & 0,165 & 0,176 & 0,084 & 0,154 & 0,162 & 0,146 & 0,064 \\
\hline & & 0,96 & 0,96 & 0,89 & 0,99 & 0,95 & 0,93 & 0,93 & 0,97 \\
\hline & & 0,99 & 0,98 & 0,92 & 0,99 & 0,99 & 0,98 & 0,97 & 0,99 \\
\hline \multirow[t]{4}{*}{40} & & 1,041 & 1,055 & 1,010 & 1,014 & 1,030 & 1,053 & 1,010 & 1,014 \\
\hline & & 0,118 & 0,139 & 0,099 & 0,064 & 0,129 & 0,132 & 0,112 & 0,063 \\
\hline & & 0,94 & 0,95 & 0,89 & 0,98 & 0,96 & 0,94 & 0,95 & 0,98 \\
\hline & & 0,99 & 0,98 & 0,94 & 0,99 & 0,98 & 0,98 & 0,98 & 0,99 \\
\hline \multirow[t]{4}{*}{45} & & 1,042 & 1,053 & 1,010 & 1,018 & 1,036 & 1,053 & 1,010 & 1,010 \\
\hline & & 0,107 & 0,106 & 0,099 & 0,056 & 0,105 & 0,113 & 0,112 & 0,053 \\
\hline & $P_{95}$ & 0,94 & 0,93 & 0,89 & 0,98 & 0,95 & 0,94 & 0,95 & 0,98 \\
\hline & $P_{99}$ & 0,98 & 0,98 & 0,93 & 0,99 & 0,99 & 0,98 & 0,98 & 0,99 \\
\hline \multirow[t]{4}{*}{50} & & 1,022 & 1,029 & 0,980 & 0,998 & 1,043 & 1,033 & 1,030 & 1,013 \\
\hline & & 0,092 & 0,095 & 0,108 & 0,047 & 0,096 & 0,087 & 0,102 & 0,043 \\
\hline & & 0,95 & 0,95 & 0,91 & 0,98 & 0,95 & 0,94 & 0,94 & 0,97 \\
\hline & $P_{99}$ & 0,99 & 0,9 & 0,95 & 0,99 & 0,99 & 0,98 & 0,98 & 0,99 \\
\hline \multirow[t]{4}{*}{75} & $\overline{\bar{z}}$ & 1,022 & 0,030 & 0,970 & 1,002 & 1,017 & 1,032 & 0,99 & 1,001 \\
\hline & $\mathbf{S}_{C}^{2}$ & 0,064 & 0,063 & 0,050 & 0,033 & 0,056 & 0,062 & 0,062 & 0,029 \\
\hline & $P_{95}$ & 0,95 & 0,94 & 0,93 & 0,98 & 0,95 & 0,94 & 0,95 & 0,98 \\
\hline & $P_{99}$ & 0,99 & 0,99 & 0,96 & 0,99 & 0,99 & 0,99 & 0,99 & 0,99 \\
\hline
\end{tabular}


TABELA 13 - Distribuição do nivel de significåncia no teste da hipótese $\mathrm{H}_{0}: \mathrm{F}=0$, em $\mathrm{N}=1000$ experimentos com amostres de tamanhos diferentes extraidas em populaģ̋es não endogêmicas de três alelos e diversas frequências gênicas, nas andilises individuais e na análise conjunta.

\begin{tabular}{|c|c|c|c|c|c|c|c|c|c|}
\hline$n$ & Batrica & $\begin{array}{c}p_{1} \\
0,50\end{array}$ & $\begin{array}{c}p_{2} \\
0,35\end{array}$ & $\begin{array}{c}p_{3} \\
0,15\end{array}$ & $\overline{A C}$ & $\begin{array}{r}p \\
0,50\end{array}$ & $\begin{array}{c}p_{2} \\
0,25\end{array}$ & $\begin{array}{c}p_{3} \\
0,25 \\
\end{array}$ & $\overline{\mathrm{AC}}$ \\
\hline \multirow[t]{4}{*}{100} & $\bar{C}$ & 9,014 & 1,024 & 0,970 & 1,001 & 1,006 & 1,029 & 0,990 & 0,999 \\
\hline & $S^{2}$ & 0,040 & 0,040 & 0,038 & 0,021 & 0,041 & 0,046 & 0,038 & 0,022 \\
\hline & $P_{05}$ & 0,93 & 0,94 & 0,95 & 0.98 & 0,96 & 0,95 & 0,96 & 0,98 \\
\hline & $P_{99}$ & 0,99 & 0,98 & 0,98 & 0,99 & 0,99 & 0,98 & 0,99 & 0,99 \\
\hline \multirow[t]{4}{*}{150} & $\overline{\mathbf{C}}$ & 0,995 & 1,002 & 0,950 & 0,982 & 1,007 & 1,015 & 0,950 & 0,994 \\
\hline & $\mathbf{S}_{\mathrm{C}}^{2}$ & 0,027 & 0,026 & 0,030 & 0,014 & 0,030 & 0,028 & $.0,022$ & 0,015 \\
\hline & $P_{95}$ & 0,96 & 0,93 & 0,96 & 0,99 & 0,96 & 0,94 & 0,97 & 0,99 \\
\hline & $P_{99}$ & 0,99 & 0,99 & 0,98 & 1,00 & 0,99 & 0,98 & 0,99 & 1,00 \\
\hline \multirow[t]{4}{*}{200} & $C$ & 0,999 & 1,008 & 0,960 & 0,990 & 1,003 & 1,020 & 0,980 & 0,997 \\
\hline & $\mathrm{S}_{\mathrm{c}}^{2}$ & 0,020 & 0,021 & 0,016 & 0,011 & 0,020 & 0,022 & 0,020 & 0,010 \\
\hline & $P_{95}$ & 0,95 & 0,95 & 0,96 & 0,99 & 0,95 & 0,94 & 0,97 & 0,98 \\
\hline & $\mathrm{P}_{99}$ & 0,99 & 0,99 & 0,99 & 1,00 & 0,99 & 0,99 & 0.99 & 1,00 \\
\hline \multirow[t]{4}{*}{300} & $\overline{\mathbf{C}}$ & 0,996 & 1,000 & 0,950 & 0,985 & 0,996 & 1,009 & 0,980 & 0,991 \\
\hline & $\mathbf{S}_{\mathrm{C}}^{2}$ & 0,013 & 0,014 & 0,011 & 0,008 & 0,014 & 0,014 & 0,013 & 0,007 \\
\hline & $P_{95}$ & 0,96 & 0,96 & 0,97 & 0,99 & 0,96 & 0,95 & 0,97 & 0,989 \\
\hline & $P_{99}$ & 0,99 & 0,99 & 0,99 & 1,00 & 0,99 & 0,99 & 0,99 & 1,00 \\
\hline \multirow[t]{4}{*}{400} & $\overline{\overline{\mathbf{C}}}$ & 0,993 & 0,994 & 0,950 & 0,983 & 0,998 & 1,006 & 0,97 & 0,991 \\
\hline & $\mathbf{S}_{\mathrm{C}}^{2}$ & 0,010 & 0,010 & 0,008 & 0,005 & 0,010 & 0,011 & 0,009 & 0,005 \\
\hline & $P_{95}$ & 0,95 & 0,95 & 0,98 & 0,99 & 0,95 & 0,95 & 0,97 & 0,99 \\
\hline & $P_{99}$ & 0,99 & 0,99 & 0,99 & 1,00 & 0,99 & 0,99 & 0,99 & 1,00 \\
\hline \multirow[t]{4}{*}{500} & $\overline{\overline{\mathbf{C}}}$ & 0,994 & 1,003 & 0,950 & 0,986 & 0,998 & 1,00 & 0,080 & 0,994 \\
\hline & $\mathbf{S}_{\mathrm{C}}^{2}$ & 0,008 & 0,008 & 0,006 & 0,004 & 0,008 & 0,008 & 0,007 & 0,004 \\
\hline & $P_{95}$ & 0,95 & 0,94 & 0,98 & 0,99 & 0,94 & 0,94 & 0,96 & 0,98 \\
\hline & $P_{99}$ & 0,99 & 0,99 & 0,99 & $1, \infty 0$ & 0,98 & 0,98 & 0,99 & $1, \infty 0$ \\
\hline
\end{tabular}


TABELA 13 - Distribuiçåo do nivel de significância no teste da hipótese $\mathrm{H}_{0}: \mathrm{F}=0$, em $\mathrm{N}=1000$ experimentos com amostras de tamanhos diferentes extrádas em populaç⿸es não endogâmicas de três alelos e diversas frequências gênicas, nas análises individuais e na análise conjunta

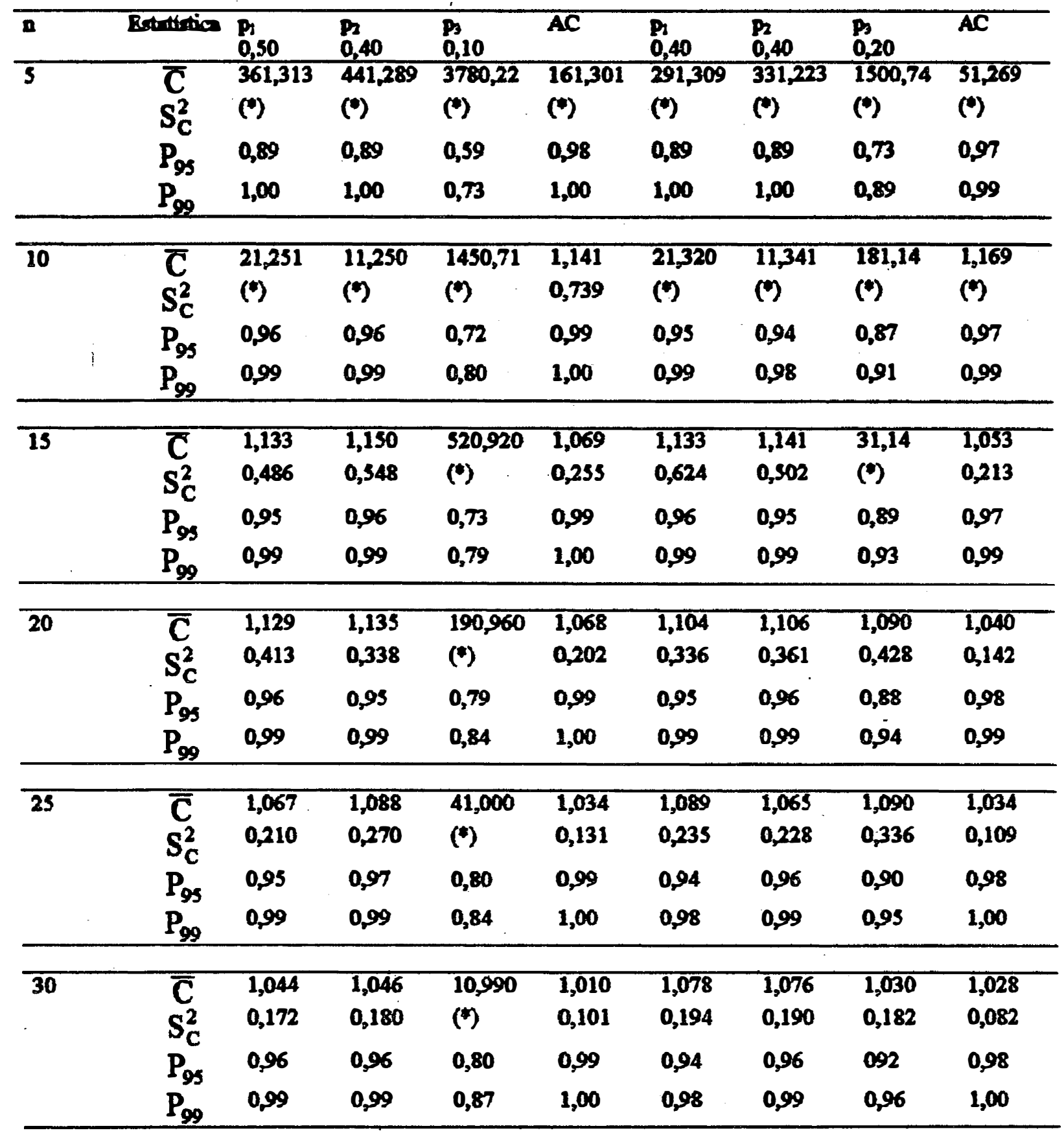


TABELA 13 - Distribuição do nivel de significância no teste da hipótese $\mathrm{H}_{0}$ : $\mathrm{F}=0$, em $\mathrm{N}=1000$ experimentos com amostras de tamanhos diferentes extraidas em populagỏes não endogâmicas de três alelos e diversas frequências gênicas, nas análises individuais e na análise conjunta

\begin{tabular}{|c|c|c|c|c|c|c|c|c|c|}
\hline $\bar{n}$ & Estation & $p_{1} p_{0,50}$ & $\begin{array}{l}p_{2} \\
0,40\end{array}$ & $\begin{array}{l}p_{3} \\
0,10\end{array}$ & $\overline{\mathbf{A C}}$ & $\begin{array}{l}p_{1} \\
0,40\end{array}$ & $\begin{array}{l}p_{2} \\
0,40\end{array}$ & $p_{9}$ & $\overline{\mathrm{AC}}$ \\
\hline \multirow[t]{4}{*}{$\overline{35}$} & $\overline{\mathbf{C}}$ & 1,034 & 1,049 & 10,970 & 1,009 & 1,061 & 1,057 & 1,020 & 1,018 \\
\hline & $\mathbf{S}_{C}^{2}$ & 0,142 & 0,148 & (*) & 0,085 & 0,142 & 0,140 & 0,151 & 0,060 \\
\hline & $P_{9 s}$ & 0,96 & 0,96 & 0,81 & 0,99 & 0,96 & 0,93 & 0,92 & 0,98 \\
\hline & $\mathrm{P}_{99}$ & 0,99 & 0,99 & 0,87 & 1,00 & 0,99 & 0,99 & 0,96 & 1,00 \\
\hline \multirow[t]{4}{*}{40} & $\overline{\overline{\mathbf{C}}}$ & 1,039 & 1,055 & 10,970 & 1,017 & 1,029 & 1,036 & 1,020 & 1,002 \\
\hline & $\mathbf{S}_{\mathrm{C}}^{2}$ & 0,117 & 0,124 & (*) & 0,070 & 0,123 & 0,120 & 0,120 & 0,055 \\
\hline & $\mathrm{P}_{95}$ & 0,95 & 0,94 & 0,82 & 0,99 & 0,96 & 0,93 & 0,53 & 0,98 \\
\hline & $\mathrm{P}_{99}$ & 0,99 & 0,99 & 0,86 & 1,00 & 0,99 & 0,99 & 0,96 & 1,00 \\
\hline \multirow[t]{4}{*}{$\overline{45}$} & $\overline{\mathbf{C}}$ & 1,024 & 1,037 & 0,960 & 1,002 & 1,050 & 1,035 & 1,020 & 1,019 \\
\hline & $S_{C}^{2}$ & 0,095 & 0,111 & 0,108 & 0,057 & 0,112 & 0,110 & 0,108 & 0,051 \\
\hline & $P_{9 s}$ & 0,95 & 0,95 & 0,83 & 0,99 & 0,95 & 0,93 & 0,93 & 0,98 \\
\hline & $P_{99}$ & 0,99 & 0,99 & 0,87 & 1,00 & 0,99 & 0,99 & 0,97 & 1,00 \\
\hline \multirow[t]{4}{*}{50} & $\overline{\mathbf{C}}$ & 1,050 & 1,053 & 0,960 & 1,023 & 1,022 & 1,043 & 1,000 & 1,004 \\
\hline & $\mathrm{S}_{\mathrm{C}}^{2}$ & 0,091 & 0,093 & 0,074 & 0,054 & 0,091 & 0,105 & 0,088 & 0,046 \\
\hline & $P_{9 s}$ & 0,95 & 0,94 & 0,84 & 0,98 & 0,95 & 0,95 & 0,94 & 0,99 \\
\hline & $P_{99}$ & 0,99 & 0,99 & 0,88 & 1,00 & 0,99 & 0,99 & 0,98 & 1,00 \\
\hline \multirow[t]{4}{*}{75} & $\bar{C}$ & 1,021 & 1,029 & 0,940 & 1,002 & 1,036 & 1,040 & 1,000 & 1,016 \\
\hline & $\mathbf{S}_{r}^{2}$ & 0,054 & 0,058 & 0,039 & 0,033 & 0,059 & 0,039 & 0,057 & 0,030 \\
\hline & $P_{95}$ & 0,95 & 0,93 & 0,88 & 0,98 & 0,94 & 0,94 & 0,94 & 0,98 \\
\hline & $\mathrm{P}_{99}$ & 0,99 & 0,99 & 0,91 & 1,00 & 0,99 & 0,99 & 0,98 & 1,00 \\
\hline \multirow[t]{4}{*}{100} & $\mathrm{C}$ & 1,001 & 1,011 & 0,930 & 0,989 & 1,021 & 1,013 & 0,990 & 1,002 \\
\hline & $\mathbf{S}_{\mathrm{C}}^{2}$ & 0,043 & 0,047 & 0,030 & 0,027 & 0,043 & 0,043 & 0,041 & 0,022 \\
\hline & $P_{95}$ & 0,96 & 0,96 & 0,90 & 0,99 & 0,95 & 0,96 & 0,95 & 0,98 \\
\hline & $P_{99}$ & 0,99 & 0,99 & 0,93 & 1,00 & 0,99 & 0,99 & 0,98 & 1,00 \\
\hline
\end{tabular}


TABELA 13 - Distribuiçåo do nf́vel de significância no teste da hipótese $\mathrm{H}_{0}: \mathrm{F}=0$, em $\mathrm{N}=1000$ experimentos com amostras de tamanhos diferentes extraidas em populaçóes nåo endogâmicas de três alelos e diversas frequências gênicas, nas análises individuais e na análise conjunta

\begin{tabular}{|c|c|c|c|c|c|c|c|c|c|}
\hline $\mathbf{n}$ & Bration & $\begin{array}{l}P_{1} \\
0,50\end{array}$ & $\begin{array}{l}p_{2} \\
0,40\end{array}$ & $\begin{array}{l}P_{3} \\
0,10\end{array}$ & $\overline{A C}$ & $\begin{array}{l}p_{1} \\
0,40\end{array}$ & $\begin{array}{l}p_{2} \\
0,40\end{array}$ & $\begin{array}{l}P_{3} \\
0,20\end{array}$ & AC \\
\hline \multirow[t]{4}{*}{150} & & $\overline{1,014}$ & $\overline{1,012}$ & 0,930 & 0,996 & 1,011 & 1,007 & 0,970 & 0,994 \\
\hline & & 0,030 & 0,031 & 0,019 & 0,018 & 0,029 & 0,028 & 0,024 & 0,014 \\
\hline & & 0,95 & 0,96 & 0,93 & 0,99 & 0,95 & 0,96 & 0,96 & 0,98 \\
\hline & $P_{99}$ & 0,99 & 0,99 & 0,95 & 1,00 & 0,99 & 0,99 & 0,99 & 1,00 \\
\hline \multirow[t]{4}{*}{200} & & 0,997 & 1,001 & 0,930 & 0,985 & 1,007 & 1,009 & 0,970 & 0,995 \\
\hline & & 0,021 & 0,021 & 0,012 & 0,013 & 0,021 & 0,020 & 0,018 & 0,010 \\
\hline & & 0,96 & 0,96 & 0,94 & 0,99 & 0,95 & 0,94 & 0,96 & 0,98 \\
\hline & $P_{99}$ & 0,99 & 0,99 & 0,97 & 1,00 & 0,99 & 0,99 & 0,99 & 1,00 \\
\hline \multirow[t]{4}{*}{300} & & 0,997 & 0,996 & 0,930 & 0,983 & 1,000 & 0,997 & 0,970 & 0,987 \\
\hline & & 0,013 & 0,013 & 0,008 & 0,008 & 0,014 & 0,014 & 0,012 & 0,007 \\
\hline & $P_{95}$ & 0,96 & 0,96 & 0,97 & 0,99 & 0,96 & 0,96 & 0,97 & 0,99 \\
\hline & $P_{99}$ & 0,99 & 0,99 & 0,98 & 1,00 & 0,99 & 0,99 & 0,99 & 1,00 \\
\hline \multirow[t]{4}{*}{400} & $\overline{\mathbf{C}}$ & 0,999 & 1,003 & 0,930 & 0,988 & 0,995 & 0,998 & 0,930 & 0,987 \\
\hline & $S_{C}^{2}$ & 0,010 & 0,010 & 0,006 & 0,006 & 0,010 & 0,010 & 0,009 & 0,005 \\
\hline & $P_{95}$ & 0,96 & 0,95 & 0,98 & 0,99 & 0,95 & 0,96 & 0,97 & 0,99 \\
\hline & $\mathrm{P}_{99}$ & 0,99 & 0,59 & 0,99 & 1,00 & 0,99 & 0,99 & 0,99 & 1,00 \\
\hline \multirow[t]{4}{*}{500} & $\overline{\mathbf{C}}$ & 1,001 & 1,001 & 0,93 & 0,989 & 1,003 & 1,001 & 0,97 & 0,992 \\
\hline & $\mathrm{S}_{\mathrm{C}}^{2}$ & 0,008 & 0,009 & 0,005 & 0,005 & 0,008 & 0,008 & 0,007 & 0,004 \\
\hline & $P_{95}$ & 0,95 & 0,96 & 0,98 & 0,99 & 0,95 & 0,95 & 0,97 & 0,99 \\
\hline & $P_{99}$ & 0,99 & 0,99 & 0,99 & 1,00 & 0,99 & 0,99 & 0,99 & 1,00 \\
\hline
\end{tabular}


TABELA 13 - Distribuiçåo do nível de significância no teste da hipótese $\mathrm{H}_{0}: \mathrm{F}=0$, em $\mathrm{N}=1000$ experimentos com amostras de tamanhos diferentes extraidas em populasరెes nă endogâmicas de três alelos e diversas frequências gênicas, nas análises individuais e na análise conjunta.

\begin{tabular}{|c|c|c|c|c|c|c|c|c|c|}
\hline n & Estatiotica & $\begin{array}{l}p_{1} \\
0,50\end{array}$ & & $p_{3}, 05$ & $A C$ & $\begin{array}{l}p_{1} \\
0,50\end{array}$ & $\begin{array}{l}P_{2} \\
0,49\end{array}$ & $\stackrel{p}{0}, 01_{1}$ & $A C$ \\
\hline \multirow[t]{4}{*}{3} & $\bar{c}$ & 271,279 & 381,264 & 5949,79 & 171,272 & 231,404 & 251,401 & 9169,17 & 221,398 \\
\hline & $\mathbf{S}_{\mathrm{C}}^{2}$ & & $(")$ & & & & $(*)$ & & \\
\hline & $P_{g s}$ & 0,89 & 0,89 & 0,60 & 0,99 & 0,89 & 0,89 & 0,48 & 0,99 \\
\hline & $\mathrm{P}_{99}$ & 1,00 & 1,00 & 0,60 & 1,00 & 1,00 & 1,00 & 0,48 & 1.00 \\
\hline \multirow[t]{4}{*}{10} & $\overline{\mathbf{C}}$ & 11,258 & 11,294 & 3850,19 & 1,219 & 1,342 & 1,371 & 8519,29 & 1,334 \\
\hline & $\mathbf{S}_{\mathrm{C}}^{2}$ & $(*)$ & $(*)$ & $(*)$ & 1,139 & 1,524 & 1,624 & $(\theta)$ & 1,394 \\
\hline & $\mathrm{P}_{95}$ & 0,96 & 0,96 & 0,64 & 0,99 & 0,94 & 0,94 & 0,49 & 0,99 \\
\hline & $P_{99}$ & 0,98 & 0,99 & 0,68 & 1,00 & 0,98 & 0,98 & 0,53 & 1,00 \\
\hline \multirow[t]{4}{*}{15} & $\overline{\mathbf{C}}$ & 1,197 & 1,198 & 2440,47 & 1,138 & 1,143 & 1,158 & 7839,43 & 1,143 \\
\hline & $\mathbf{S}_{\mathrm{c}}^{2}$ & 0,729 & 0,803 & (*) & 0,490 & 0,436 & 0,448 & (') & 0,424 \\
\hline & $P_{95}$ & 0,96 & 0,96 & 0,61 & 0,99 & 0,95 & 0,95 & 0,50 & 0,99 \\
\hline & $\mathrm{P}_{99}$ & 0,99 & 0,99 & 0,67 & 1,00 & 0,99 & 0,99 & 0,53 & 1,00 \\
\hline \multirow[t]{4}{*}{20} & $\overline{\mathbf{C}}$ & 1,110 & 1,108 & 1350,68 & 1,074 & 1,108 & 1,123 & 6789,64 & 1,107 \\
\hline & $\mathbf{S}_{\mathrm{C}}^{2}$ & 0,305 & 0,355 & (*) & 0,224 & 0,299 & 0,303 & (*) & 0,273 \\
\hline & $P_{95}$ & 0,95 & 0,96 & 0,64 & 0,99 & 0,95 & 0,95 & 0,54 & 0,99 \\
\hline & $P_{99}$ & 0,99 & 0,99 & 0,74 & 1,00 & 0,99 & 0,99 & 0,54 & 1,00 \\
\hline \multirow[t]{4}{*}{25} & $\overline{\mathbf{C}}$ & 1,062 & 1,092 & 830,77 & 1,046 & 1,091 & 1,107 & 6479,70 & 1,093 \\
\hline & $\mathbf{S}_{\mathrm{C}}^{2}$ & 0,223 & 0,246 & (*) & 0,161 & 0,299 & 0,303 & $(*)$ & 0,284 \\
\hline & $P_{95}$ & 0,95 & 0,94 & 0,67 & 0,99 & 0,96 & 0,45 & 0,54 & 0,99 \\
\hline & $P_{99}$ & 0,99 & 0,99 & 0,71 & 1,00 & 0,99 & 0,99 & 0,58 & 1,00 \\
\hline \multirow[t]{4}{*}{30} & $\overline{\mathbf{C}}$ & 1,065 & 1,070 & 500,83 & 1,043 & 1,061 & 1,079 & 3599,88 & 1,065 \\
\hline & $\mathbf{S}_{\mathrm{C}}^{2}$ & 0,170 & 0,171 & (*) & 0,124 & 0,173 & 0,188 & (*) & 0,165 \\
\hline & $P_{95}$ & 0,94 & 0,96 & 0,69 & 0,99 & 0,96 & 0,96 & 0,54 & 0,99 \\
\hline & $P_{99}$ & 0,99 & 0,99 & 0,73 & 1,00 & 0,99 & 0,99 & 0,57 & 1,00 \\
\hline
\end{tabular}


TABELA 13 - Distribuiģão do nivel de significância no teste da hipótese $\mathrm{H}_{0}$ : $\mathrm{F}=0$, em $\mathrm{N}=1000$ experimentos com amostras de tamanhos diferentes extraídas em populaçes não endogâmicas de três alelos e diversas frequências gênicas, nas análises individuais e ns análise conjunta.

\begin{tabular}{|c|c|c|c|c|c|c|c|c|c|}
\hline $\mathrm{n}$ & Exitistice & & & $p_{3}$ & $A C$ & 0,50 & $\begin{array}{l}P_{2} \\
0,49\end{array}$ & $\begin{array}{l}p_{3} \\
0,01\end{array}$ & $\overline{A C}$ \\
\hline \multirow[t]{4}{*}{35} & $\overline{\mathbf{C}}$ & 1,050 & 1,060 & 310,87 & 1,032 & 1,068 & 0,090 & 3449,91 & 1,074 \\
\hline & $\mathbf{S}_{C}^{2}$ & 0,134 & 0,142 & $(")$ & 0,098 & 0,157 & 0,169 & $(*)$ & 0,133 \\
\hline & $P_{95}$ & 0,94 & 0,94 & 0,68 & 0,99 & 0,96 & 0,94 & 0,53 & 0,99 \\
\hline & $P_{99}$ & 0,99 & 0,99 & 0,75 & 1,00 & 0,99 & 0,99 & 0,57 & 1,00 \\
\hline \multirow[t]{4}{*}{40} & $\overline{\mathbf{C}}$ & 1,063 & 1,073 & 200,89 & 1,045 & 1,018 & 1,038 & 4770,04 & 1,025 \\
\hline & $\mathbf{S}_{\mathrm{C}}^{2}$ & 0,150 & 0,141 & $(*)$ & 0,106 & 0,112 & 0,119 & (") & 0,108 \\
\hline & $\mathbf{P}_{95}$ & 0,95 & 0,95 & 0,70 & 0,99 & 0,96 & 0,96 & 0,53 & 0,999 \\
\hline & $\mathrm{P}_{99}$ & 0,99 & 0,99 & 0,76 & 1,00 & 0,99 & 0,99 & 0,56 & 1,00 \\
\hline \multirow[t]{4}{*}{45} & $\overline{\mathbf{C}}$ & 1,041 & 1,046 & 110,90 & 1,024 & 1,058 & 1,073 & 4280,14 & 1,062 \\
\hline & $S_{C}^{2}$ & 0,112 & 0,119 & (*) & 0,084 & 0,115 & 0113 & (") & 0,108 \\
\hline & $P_{95}$ & 0,95 & 0,95 & 0,72 & 0,99 & 0,95 & 0,94 & 0,56 & 0,99 \\
\hline & $P_{99}$ & 0,99 & 0,99 & 0,77 & 1,00 & 0,99 & 0,99 & 0,59 & 1,00 \\
\hline \multirow[t]{4}{*}{30} & $\overline{\mathbf{C}}$ & 1,019 & 10,32 & 70,91 & 1,010 & 1,048 & 1,063 & 3960,2 & 1,053 \\
\hline & $S_{C}^{2}$ & 0,081 & 0,081 & $(*)$ & 0,060 & 0,097 & 0,101 & $(*)$ & 0,094 \\
\hline & $P_{95}$ & 0,95 & 0,93 & 0,70 & 0,99 & 0,95 & 0,95 & 0,53 & 0,99 \\
\hline & $P_{99}$ & 0,99 & 0,99 & 0,76 & 1,00 & 0,99 & 0,99 & 0,56 & 1,00 \\
\hline \multirow[t]{4}{*}{75} & $\overline{\mathbf{C}}$ & 1,023 & 1,024 & 0,92 & 1,009 & 1,019 & 1,033 & 2630,47 & 1,024 \\
\hline & $\mathbf{S}_{\mathrm{C}}^{2}$ & 0,057 & 0,057 & 0,001 & 0,042 & 0,060 & 0,061 & (*) & 0,057 \\
\hline & $P_{95}$ & 0,94 & 0,94 & 0,73 & 0,99 & 0,95 & 0,95 & 0,57 & 0,99 \\
\hline & $P_{99}$ & 0,98 & 0,99 & 0,80 & 1,00 & 0,99 & 0,99 & 0,59 & 1,00 \\
\hline \multirow[t]{4}{*}{100} & $\overline{\mathbf{C}}$ & 1,009 & 1,019 & 0,91 & 1,002 & 1,008 & 1,022 & 1510,69 & 1,014 \\
\hline & $\mathbf{S}_{\mathrm{C}}^{2}$ & 0,043 & 0,044 & 0,00084 & 0,032 & 0,045 & 0,046 & (") & 0,043 \\
\hline & $P_{95}$ & 0,95 & 0,95 & 0,77 & 0,99 & 0,96 & 0,93 & 0,56 & 0,99 \\
\hline & $P_{99}$ & 0,99 & 0,99 & 0,81 & 1,00 & 0,99 & 0,99 & 0,60 & 1,00 \\
\hline
\end{tabular}


TABELA 13 - Distribuiģão do nível de significância no teste da hipótese $\mathrm{H}_{0}: \mathrm{F}=0$, em $\mathrm{N}=1000$ experimentos com amostras de tamanhos diferentes extraídas em populagöes não endogâmicas de três alelos e diversas frequências gênicas, nas andalises individuais e na andilise conjunta.

\begin{tabular}{|c|c|c|c|c|c|c|c|c|c|}
\hline $\bar{D}$ & Enticen & $\begin{array}{l}p_{1} \\
0,50\end{array}$ & $\begin{array}{l}p_{2} \\
0.45\end{array}$ & $\begin{array}{l}p_{3} \\
0,05\end{array}$ & $A C$ & $\begin{array}{l}p_{1} \\
0_{2}, 50\end{array}$ & $\begin{array}{l}p_{2} \\
0,49\end{array}$ & $\begin{array}{l}P_{3} \\
0,01\end{array}$ & AC \\
\hline \multirow[t]{4}{*}{150} & $\overline{\mathbf{C}}$ & 0,996 & 1,010 & 0,910 & 0,992 & 1,003 & 1,020 & 550,88 & 1,011 \\
\hline & $\mathbf{S}_{\mathrm{C}}^{2}$ & 0,024 & 0,026 & 0,00058 & 0,018 & 0,027 & 0,027 & $(*)$ & 0,026 \\
\hline & $P_{95}$ & 0,95 & 0,95 & 0,80 & 0,99 & 0,95 & 0,94 & 0,58 & 0,99 \\
\hline & $P_{99}$ & 0,99 & 0,99 & 0,83 & 1,00 & 0,99 & 0,99 & 0,60 & 1,00 \\
\hline \multirow[t]{4}{*}{200} & $\overline{\mathbf{C}}$ & 1,006 & 1,014 & 0,910 & 0,999 & 0,995 & 1,012 & 310,93 & 1,003 \\
\hline & $\mathbf{S}_{\mathrm{C}}^{2}$ & 0,020 & 0,020 & 0,00041 & 0,015 & 0,020 & 0,021 & (*) & 0,019 \\
\hline & $P_{95}$ & 0,95 & 0,95 & 0,83 & 0,99 & 0,96 & 0,95 & 0,58 & 0,99 \\
\hline & $\mathrm{P}_{99}$ & 0,99 & 0,99 & 0,86 & 1,00 & 0,99 & 0,99 & 0,61 & 1,00 \\
\hline \multirow[t]{4}{*}{300} & $\overline{\mathbf{C}}$ & 1,002 & 1,008 & 0,910 & 0,995 & 0,994 & 1,009 & 30,98 & 1,001 \\
\hline & $\mathbf{S}_{\mathrm{C}}^{2}$ & 0,014 & 0,013 & 0,00029 & 0,010 & 0,013 & 0,013 & (") & 0,013 \\
\hline & $P_{95}$ & 0,95 & 0,95 & 0,87 & 0,99 & 0,96 & 0,95 & 0,60 & 0,99 \\
\hline & $P_{99}$ & 0,99 & 0,99 & 0,89 & 1,00 & 0,99 & 0,99 & 0,63 & 1,00 \\
\hline \multirow[t]{4}{*}{400} & $\overline{\mathbf{C}}$ & 0,999 & 1,007 & 0,91 & 0,99 & 1,001 & 1,017 & 0,98 & 1,008 \\
\hline & $\mathbf{S}_{\mathrm{C}}^{2}$ & 0,010 & 0,010 & 0,0002 & 0,0074 & 0,010 & 0,010 & 0,0004 & 0,010 \\
\hline & $P_{95}$ & 0,95 & 0,95 & 0,89 & 0,99 & 0,96 & 0,94 & 0,61 & 0,99 \\
\hline & $P_{99}$ & 0,99 & 0,99 & 0,91 & 1,00 & 0,99 & 0,99 & 0,63 & 1,00 \\
\hline \multirow[t]{4}{*}{500} & $\overline{\mathbf{C}}$ & 0,995 & 1,004 & 0,910 & 0,991 & 0,992 & 1,008 & 0,98 & 1,000 \\
\hline & $\mathrm{S}_{\mathrm{C}}^{2}$ & 0,008 & 0,008 & 0,00016 & 0,006 & 0,008 & 0,008 & 0,00004 & 0,008 \\
\hline & $P_{95}$ & 0,96 & 0,96 & 0,91 & 0,99 & 0,96 & 0,94 & 0,62 & 0,99 \\
\hline & $\mathrm{P}_{99}$ & 0,99 & 0,99 & 0,93 & 1,00 & 0,99 & 0,99 & 0,64 & 1,00 \\
\hline
\end{tabular}


TABELA 13 - Distribuição do nivel de significância no teste da hipb́tese $\mathrm{H}_{0}: \mathrm{F}=0$, em $\mathrm{N}=1000$ experimentos com amostras de manhos diferentes extraidas em populagỏes não endogâmicas de três alelos e diversas frequências gênicas, nas análises individuais e na análise conjunta.

\begin{tabular}{|c|c|c|c|c|c|c|c|c|c|}
\hline D. & Extitica & $\begin{array}{l}P_{1} \\
0,40\end{array}$ & $\begin{array}{l}p_{2} \\
0,45\end{array}$ & $\begin{array}{l}p_{3} \\
0,15\end{array}$ & $\mathbf{A C}$ & $\begin{array}{l}p_{1} \\
0,40\end{array}$ & $\begin{array}{l}p_{2} \\
0,35\end{array}$ & $\begin{array}{l}P_{3} \\
0,25\end{array}$ & $A C$ \\
\hline \multirow[t]{4}{*}{5} & & 421,71 & 321,321 & 2140,58 & 61,289 & 361,196 & 271,238 & 970,950 & 21,231 \\
\hline & & $(*)$ & $(*)$ & (1) & (*) & $(\omega)$ & (*) & $(\varphi)$ & $(\theta)$ \\
\hline & & 0,89 & 0,89 & 0,73 & 0,98 & 0,89 & 0,89 & 0,89 & 0,07 \\
\hline & & 1,00 & 1,00 & 0,89 & 0,99 & 1,00 & 1,00 & 1,00 & 0,99 \\
\hline \multirow[t]{4}{*}{10} & & 41,290 & 11,255 & 610,950 & 1,135 & 31,208 & 21,263 & 131,170 & 1,109 \\
\hline & & $(v)$ & $(*)$ & (1) & 0,894 & $(*)$ & $(\omega)$ & $(*)$ & 0,455 \\
\hline & & 0,96 & 0,97 & 0,80 & 0,98 & 0,94 & 0,94 & 0,88 & 0,97 \\
\hline & $\mathbf{P}$ & 0,99 & 0,99 & 0,88 & 0,99 & 0,98 & 0,98 & 0,94 & 0,99 \\
\hline \multirow[t]{4}{*}{15} & & 1,165 & 1,137 & 51,070 & 1,059 & 1,203 & 1,232 & 1,110 & 1,090 \\
\hline & & 0,746 & 0,451 & $(*)$ & 0,219 & 0,763 & 0,892 & 0,505 & 0,240 \\
\hline & & 0,96 & 0,97 & 0,85 & 0,98 & 0,95 & 0,94 & 0,94 & 0,97 \\
\hline & $\mathrm{P}$ & 0,99 & 0,99 & 0,89 & 0,99 & 0,99 & 0,99 & 0,97 & 0,99 \\
\hline \multirow[t]{4}{*}{20} & & 1,113 & 1,127 & 11,07 & 1,055 & 1,119 & 1,092 & 1,11 & 1,042 \\
\hline & & 0,326 & 0,366 & $\left({ }^{+}\right)$ & 0,158 & 0,379 & 0,324 & 0,386 & 0,134 \\
\hline & $P_{g}$ & 0,95 & 0,96 & 0,83 & 0,98 & 0,95 & 0,93 & 0,91 & 0,98 \\
\hline & & 0,99 & 0,99 & 0,91 & 0,99 & 0,99 & 0,99 & 0,97 & 0,99 \\
\hline \multirow[t]{4}{*}{25} & & 1,082 & 1,087 & 1,040 & 1,032 & 1,068 & 1,109 & 1,070 & 1,036 \\
\hline & & 0,244 & 0,252 & 0,335 & 0,124 & 0,210 & 0,280 & 0,308 & 0,108 \\
\hline & & 0,94 & 0,95 & 0,87 & 0,98 & 0,95 & 0,95 & 0,93 & 0,98 \\
\hline & $P_{99}$ & 0,99 & 0,99 & 0,90 & 0,99 & 0,99 & 0,99 & 0,97 & 0,99 \\
\hline \multirow[t]{4}{*}{30} & $\Gamma$ & 1,055 & 1,057 & 1,010 & 1,015 & 1,079 & 1,082 & 1,040 & 1,030 \\
\hline & & 0,166 & 0,167 & 0,195 & 0,085 & 0,186 & 0,202 & 0,184 & 0,082 \\
\hline & $\mathbf{P}_{9}$ & 0,94 & 0,96 & 0,87 & 0,98 & 0,94 & 0,95 & 0,94 & 0,98 \\
\hline & $P_{99}$ & 0,99 & 0,99 & 0,92 & 0,99 & 0,99 & 0,99 & 0,93 & 0,99 \\
\hline
\end{tabular}


TABELA 13 - Distribuiģão do nivel de significância no teste da hipótese $\mathrm{H}_{0}: \mathrm{F}=0$, em $\mathrm{N}=1000$ experimentos com amostras de tamanhos diferentes extraidas em populacoóes não endogâmicas de três alelos e diverses frequências gênicas, nas andilises individuais e na análise conjunta.

\begin{tabular}{|c|c|c|c|c|c|c|c|c|c|}
\hline n & Extition & $\begin{array}{l}p_{1} \\
0_{2} 40\end{array}$ & $\begin{array}{l}p_{2} \\
0,45\end{array}$ & $\begin{array}{l}P_{3} \\
0,15\end{array}$ & $\overline{A C}$ & $\begin{array}{l}P_{1} \\
0,40\end{array}$ & $\begin{array}{l}p_{2} \\
0.35\end{array}$ & $\begin{array}{l}P_{3} \\
0.25\end{array}$ & $A C$ \\
\hline \multirow[t]{4}{*}{-35} & & 1,054 & 1,046 & 1,010 & 1,014 & 1,048 & 1,055 & 1,020 & 1,012 \\
\hline & & 0,133 & 0,139 & 0,140 & 0,066 & 0,142 & 0,156 & 0,141 & 0,069 \\
\hline & & 0,93 & 0,96 & 0,89 & 0,98 & 0,96 & 0,96 & 0,95 & 0,98 \\
\hline & F & 0,99 & 0,99 & 0,94 & 0,99 & 0,99 & 0,99 & 0,98 & 0,99 \\
\hline \multirow[t]{4}{*}{40} & & 1,049 & 1,043 & 1,000 & 1,014 & 1,043 & 1,048 & 1,040 & 1,017 \\
\hline & & 0,120 & 0,114 & 0,120 & 0,062 & 0,120 & 0,132 & $0,124$. & 0,059 \\
\hline & & 0,96 & 0,95 & 0,89 & 0,98 & 0,96 & 0,96 & 0,95 & 0,98 \\
\hline & $P_{99}$ & 0,99 & 0,99 & 0,93 & 0,99 & 0,99 & 0,99 & 0,98 & 0,99 \\
\hline \multirow[t]{4}{*}{45} & & 1,044 & 1,043 & 0,990 & 1,011 & 1,020 & 1,016 & 1,010 & 0,093 \\
\hline & & 0,111 & 0,118 & 0,104 & 0,057 & 0,100 & 0,098 & 0,106 & 0,047 \\
\hline & & 0,96 & 0,96 & 0,90 & 0,98 & 0,95 & 0,95 & 0,94 & 0,98 \\
\hline & $\mathbf{P}$ & 0,99 & 0,99 & 0,93 & 0,99 & 0,99 & 0,99 & 0,98 & 0,99 \\
\hline \multirow[t]{4}{*}{50} & & 1,033 & 1,031 & 0,980 & 1,004 & 1,033 & 1,038 & 0,990 & 1,001 \\
\hline & & 0,092 & 0,090 & 0,091 & 0,047 & 0,092 & 0,095 & 0,083 & 0,042 \\
\hline & $P_{95}$ & 0,96 & 0,95 & 0,91 & 0,98 & 0,96 & 0,94 & 0,93 & 0,98 \\
\hline & $P_{99}$ & 0,99 & 0,99 & 0,95 & 0,99 & 0,99 & 0,99 & 0,99 & 0,99 \\
\hline \multirow[t]{4}{*}{75} & & 1,033 & 1,036 & 0,980 & 1,009 & 1,035 & 1,044 & 1,000 & 1,014 \\
\hline & $S_{C}$ & 0,061 & 0,064 & 0,053 & 0,031 & 0,064 & 0,062 & 0,063 & 0,031 \\
\hline & $P_{95}$ & 0,93 & 0,94 & 0,93 & 0,98 & 0,95 & 0,94 & 0,95 & 0,98 \\
\hline & $P_{99}$ & 0,99 & 0,99 & 0,97 & 0,99 & 0,99 & 0,99 & 0,99 & 0,99 \\
\hline \multirow[t]{4}{*}{100} & $C$ & 1,018 & 1,024 & 0,960 & 1,001 & 1,006 & 1,016 & 0,990 & 0,993 \\
\hline & 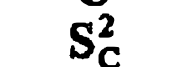 & 0,044 & 0,044 & 0,036 & 0,024 & 0,043 & 0,042 & 0,042 & 0,020 \\
\hline & & 0,95 & 0,95 & 0,95 & 0,98 & 0,96 & 0,95 & 0,96 & 0,98 \\
\hline & $P_{99}$ & 0,99 & 0,99 & 0,98 & 0,99 & 0,99 & 0,99 & 0,99 & 0,99 \\
\hline
\end{tabular}


TABELA 13 - Distribuigão do nivel de significância no teste da hipótese $\mathrm{H}_{0}: \mathrm{F}=0$, em $\mathrm{N}=1000$ experimentos com amostras de tamanhos diferentes extrádas em populagß̉es năo endogâmicas de três alelos e diversas frequências gênicas, nas análises individusis e ns análise conjunta

\begin{tabular}{|c|c|c|c|c|c|c|c|c|c|}
\hline $\mathrm{n}$ & Entition & $\begin{array}{l}P_{1} \\
0,40\end{array}$ & $\begin{array}{l}P_{2} \\
0,45\end{array}$ & $\begin{array}{l}p_{3} \\
0,15\end{array}$ & $\mathbf{A C}$ & $\begin{array}{l}P_{1} \\
0,40\end{array}$ & $\begin{array}{l}p_{2} \\
0,35\end{array}$ & $\begin{array}{l}P_{3} \\
0,25\end{array}$ & $A C$ \\
\hline \multirow[t]{4}{*}{150} & & 1,012 & 1,003 & 0,960 & 0,993 & 1,013 & 1,011 & 0,980 & 0,997 \\
\hline & & 0,028 & 0,028 & 0,022 & 0,015 & 0,028 & 0,026 & 0,027 & 0,013 \\
\hline & & 0,94 & 0,94 & 0,96 & 0,98 & 0,95 & 0,94 & 0,96 & 0,98 \\
\hline & & 0,99 & 0,99 & 0,98 & 0,99 & 0,99 & 0,99 & 0,99 & 0,99 \\
\hline \multirow[t]{4}{*}{200} & & 1,004 & 1,003 & 0,960 & 0,990 & 1,005 & 1,014 & 0,980 & 0995 \\
\hline & & 0,023 & 0,022 & 0,018 & 0,012 & 0,019 & 0,020 & 0,020 & 0,010 \\
\hline & 1 & 0,95 & 0,96 & 0,97 & 0,99 & 0,95 & 0,93 & 0,96 & 0,98 \\
\hline & $P_{99}$ & 0,99 & 0,99 & 0,99 & 1,00 & 0,99 & 0,98 & 0,99 & 0,99 \\
\hline \multirow[t]{4}{*}{300} & & 1,000 & 0,999 & 0,960 & 0,988 & 0,996 & 1,005 & 0,980 & 0,991 \\
\hline & & 0,013 & 0,013 & 0,011 & 0,007 & 0,012 & 0,013 & 0,013 & 0,006 \\
\hline & P & 0,95 & 0,96 & 0,97 & 0,99 & 0,96 & 0,95 & 0,96 & 0,98 \\
\hline & $P_{99}$ & 0,99 & 0,99 & 0,99 & 1,00 & 0,99 & 0,99 & 0,99 & 0,99 \\
\hline \multirow[t]{4}{*}{400} & & 1,002 & 1,000 & 0,950 & 0,988 & 1,002 & 1,009 & 0,980 & $\cos 95$ \\
\hline & $S_{C}$ & 0,010 & 0,010 & 0,008 & 0,006 & 0,010 & 0,011 & 0,009 & 0,003 \\
\hline & $P_{95}$ & 0,95 & 0,95 & 0,97 & 0,99 & 0,93 & 0,96 & 0,97 & 0,98 \\
\hline & $P_{99}$ & 0,98 & 0,99 & 0,99 & 1,00 & 0,99 & 0,99 & 0,99 & 0,99 \\
\hline \multirow[t]{4}{*}{300} & $\overline{\bar{C}}$ & 1,002 & 0,998 & 0,950 & 0,987 & 1,000 & 1,004 & 0,98 & 0,993 \\
\hline & $\mathbf{S}_{\mathbf{C}}$ & 0,008 & 0,008 & 0,006 & 0,004 & 0,008 & 0,008 & 0,007 & 0,004 \\
\hline & $P_{9 s}$ & 0,96 & 0,96 & 0,97 & 0,99 & 0,96 & 0,94 & 0,97 & 0,98 \\
\hline & $P_{99}$ & 0,99 & 0,99 & 0,99 & 1,00 & 0,99 & 0,99 & 0,99 & 0,99 \\
\hline
\end{tabular}


TABELA 13 - Distribuição do nivel de significância no teste da hipótese $\mathrm{H}_{0}: \mathrm{F}=0$, em $\mathrm{N}=1000$ experimentos com amostras de tamanhos diferentes extraídas em populagöes não endogâmicas de três alelos e diversas frequências gênicas, nas análises individuais e na análise conjunta

\begin{tabular}{|c|c|c|c|c|c|c|c|c|c|}
\hline $\mathbf{n}$ & Brtition & $\begin{array}{l}P_{1} \\
0,40\end{array}$ & $\begin{array}{l}p_{2} \\
0,30\end{array}$ & Ps & $\overline{A C}$ & $\begin{array}{l}p_{1} \\
0,40\end{array}$ & 0,59 & $\begin{array}{l}P_{3} \\
0,01\end{array}$ & $\overline{A C}$ \\
\hline \multirow[t]{4}{*}{5} & & 401,23 & $601, \overline{132}$ & $591, \overline{04}$ & 11,23 & 401,21 & 371,26 & 9099,18 & 361,23 \\
\hline & & $(*)$ & $(1)$ & $(*)$ & ()$\left.^{*}\right)$ & (*) & $(9)$ & & $(*)$ \\
\hline & & 0,89 & 0,89 & 0,89 & 0,97 & 0,89 & 0,89 & 0,48 & 0,98 \\
\hline & & 1,00 & 1,00 & 0,89 & 0,99 & 1,00 & 1,00 & 0,48 & 1,00 \\
\hline \multirow[t]{4}{*}{10} & & 11,289 & 41,214 & 31,21 & 1,109 & 1,33 & 1,36 & 8169,36 & 1,32 \\
\hline & & $(*)$ & $(*)$ & $(*)$ & 0,505 & 1,41 & 1,36 & $(*)$ & 1,24 \\
\hline & & 0,94 & 0,88 & 0,94 & 0,97 & 0,94 & 0,94 & 0,49 & 0,99 \\
\hline & & 0,98 & 0,98 & 0,98 & 0,99 & 0,98 & 0,98 & 0,56 & 1,00 \\
\hline \multirow[t]{4}{*}{15} & & 11,161 & 1,183 & 11,12 & 1,068 & 1,16 & 1,18 & 7669,46 & 1,16 \\
\hline & & $(n)$ & 0,734 & $(\omega)$ & 0,196 & 0,96 & 0,98 & $(\theta)$ & 0,94 \\
\hline & & 0,96 & 0,94 & 0,94 & 0,98 & 0,94 & 0,94 & 0,50 & 0,99 \\
\hline & $P_{99}$ & 0,99 & 0,98 & 0,98 & 0,99 & 0,98 & 0,98 & 0,55 & 1,00 \\
\hline \multirow[t]{4}{*}{20} & & 1,126 & 1,164 & 1,090 & 1,055 & 1,09 & 1,10 & 7029,59 & 1,09 \\
\hline & ${ }^{3} \mathrm{C}$ & 0,335 & 0,733 & 0,355 & 0,146 & 0,34 & 0,34 & $(*)$ & 0,32 \\
\hline & & 0,95 & 0,94 & 0,94 & 0,97 & 0,96 & 0,96 & 0,50 & 0,99 \\
\hline & $P_{99}$ & 0,99 & 0,98 & 0,98 & 0,99 & 0,99 & 0,99 & 0,54 & 1,00 \\
\hline \multirow[t]{4}{*}{25} & & 1,112 & 1,081 & 1,100 & 1,045 & 1,09 & 1,10 & 6239,75 & 1,09 \\
\hline & $D_{C}$ & 0,263 & 0,254 & 0,263 & 0,105 & 0,27 & 0,29 & $(*)$ & 0,26 \\
\hline & & 0,95 & 0,94 & 0,94 & 0,97 & 0,94 & 0,94 & 0,54 & 0,99 \\
\hline & $P_{99}$ & 0,99 & 0,98 & 0,98 & 0,99 & 0,99 & 0,99 & 0,54 & 1,00 \\
\hline \multirow[t]{4}{*}{30} & $\overline{\bar{\gamma}}$ & 1,069 & 1,101 & 1,070 & 1,039 & 1,06 & 1,08 & 5749,85 & 1,07 \\
\hline & ${ }^{3} \mathrm{C}$ & 0,169 & 0,252 & 0,226 & 0,086 & 0,18 & 0,18 & $(*)$ & 0,17 \\
\hline & & 0,94 & 0,95 & 0,94 & 0,97 & 0,95 & 0,95 & 0,54 & 0,99 \\
\hline & $r_{90}$ & 0,99 & 0,98 & 0,98 & 0,99 & 0,99 & 0,99 & 0,57 & 1,00 \\
\hline
\end{tabular}


TABELA 13 - Distribuiçåo do nivel de significåncia no teste da hipótese $\mathrm{H}_{0}: \mathrm{F}=0$, em $\mathrm{N}=1000$ experimentos com amostras de tamanhos diferentes extrádas em populagỏes nåo endogâmicas de três alelos e diversas frequências gênicas, nas and́lises individuais e na análise conjunta.

\begin{tabular}{|c|c|c|c|c|c|c|c|c|c|}
\hline $\bar{n}$ & Estitio & $\begin{array}{l}P_{1} \\
0,40\end{array}$ & $\begin{array}{l}p_{2} \\
0,30\end{array}$ & $\begin{array}{l}P_{3} \\
Q_{3}, 30\end{array}$ & $\overline{A C}$ & $\begin{array}{l}p_{1} \\
0,40\end{array}$ & $\begin{array}{l}p_{2} \\
0,59\end{array}$ & $\begin{array}{l}p_{3} \\
0,01\end{array}$ & $\overline{A C}$ \\
\hline \multirow[t]{4}{*}{35} & $\overline{\mathbf{C}}$ & 1,034 & 1,050 & 1,030 & 1,012 & 1,06 & 1,08 & 5209,95 & 1,06 \\
\hline & $\mathbf{S}_{\mathbf{C}}^{2}$ & 0,146 & 0,151 & 0,154 & 0,067 & 0,15 & 0,16 & $(*)$ & 0,14 \\
\hline & $P_{o g}$ & 0,95 & 0,93 & 0,95 & 0,98 & 0,95 & 0,94 & 0,33 & 0,99 \\
\hline & $P_{99}$ & 0,99 & 0,99 & 0,99 & 0,99 & 0,99 & 0,99 & 0,57 & 1,00 \\
\hline \multirow[t]{4}{*}{40} & $\overline{\mathbf{C}}$ & 1,041 & 1,031 & 1,020 & 1,005 & 1,05 & 1,06 & 4910,01 & 1,05 \\
\hline & $\mathbf{S}_{\mathrm{C}}^{2}$ & 0,120 & 0,109 & 0,117 & 0,053 & 0,11 & 0,11 & & 0,11 \\
\hline & $\mathrm{P}_{95}$ & 0,97 & 0,95 & 0,95 & 0,98 & 0,96 & 0,96 & 0,53 & 0,99 \\
\hline & $P_{9}$ & 0,99 & 0,99 & 0,98 & 0,99 & 0,99 & 0,99 & 0,56 & 1,00 \\
\hline \multirow[t]{4}{*}{45} & $\overline{\mathbf{C}}$ & 1,050 & 1,055 & 1,050 & 1,027 & 1,05 & 1,07 & 400,11 & 1,06 \\
\hline & $\mathbf{S}_{\mathrm{C}}^{2}$ & 0,107 & 0,108 & 0,108 & 0,050 & 0,11 & 0,11 & $\left({ }^{*}\right)$ & 0,11 \\
\hline & $\mathrm{P}_{95}$ & 0,94 & 0,94 & 0,94 & 0,97 & 0,95 & 0,94 & 0,56 & 0,99 \\
\hline & $P_{99}$ & 0,98 & 0,97 & 0,98 & 0,99 & 0,99 & 0,98 & 0,59 & 1,00 \\
\hline \multirow[t]{4}{*}{30} & $\overline{\mathbf{C}}$ & 1,031 & 1,047 & 1,010 & 1,009 & 1,04 & 1,05 & 3850,22 & 1,04 \\
\hline & $\mathbf{S}_{\mathrm{C}}^{2}$ & 0,089 & 0,102 & 0,096 & 0,045 & 0,10 & 0,10 & $(*)$ & 0,09 \\
\hline & $\mathrm{P}_{95}$ & 0,95 & 0,94 & 0,96 & 0,98 & 0,95 & 0,96 & 0,56 & 0,99 \\
\hline & $\mathrm{P}_{99}$ & 0,99 & 0,98 & 0,99 & 0,99 & 0,99 & 0,99 & 0,59 & 1,00 \\
\hline \multirow[t]{4}{*}{75} & $\overline{\mathbf{C}}$ & 1,020 & 1,025 & 1,000 & 1,001 & 1,03 & 1,05 & 2580,48 & 1,04 \\
\hline & $S_{C}^{2}$ & 0,058 & 0,056 & 0,057 & 0,026 & 0,06 & 0,07 & (") & 0,06 \\
\hline & $P_{95}$ & 0,95 & 0,94 & 0,95 & 0,97 & 0,95 & 0,95 & 0,55 & 0,99 \\
\hline & $P_{99}$ & 0,99 & 0,98 & 0,99 & 0,99 & 0,99 & 0,99 & 0,59 & 1,00 \\
\hline \multirow[t]{4}{*}{100} & $\overline{\mathbf{C}}$ & 1,019 & 1,026 & 1,000 & 1,006 & 1,02 & 1,03 & 1640,66 & 1,02 \\
\hline & $S_{C}^{2}$ & 0,043 & 0,047 & 0,042 & 0,021 & 0,04 & 0,04 & (*) & 0,04 \\
\hline & $P_{95}$ & 0,95 & 0,95 & 0,96 & 0,98 & 0,95 & 0,94 & 0,56 & 0,99 \\
\hline & $P_{99}$ & 0,99 & 0,99 & 0,99 & 0,99 & 0,99 & 0,99 & 0,59 & 1,00 \\
\hline
\end{tabular}


TABELA 13 - Distribuiçåo do nivel de significância no teste da hipótese $\mathrm{H}_{0}: \mathrm{F}=0$, em $\mathrm{N}=1000$ experimentos com amostras de tamanhos diferentes extraidas em populagboes não endogâmicas de três alelos e diversas frequências gênicas, nas análises individuais e na análise conjunta.

\begin{tabular}{|c|c|c|c|c|c|c|c|c|c|}
\hline$\overline{\mathbf{n}}$ & Estristac & $\begin{array}{l}p_{1} \\
0,40\end{array}$ & $\begin{array}{l}P_{2} \\
0,30\end{array}$ & $\begin{array}{l}P_{3} \\
0,30\end{array}$ & $\overline{A C}$ & $\begin{array}{l}p_{1} \\
0,40\end{array}$ & $\begin{array}{l}p_{2} \\
0,59\end{array}$ & $\begin{array}{l}P_{3} \\
0,01\end{array}$ & $A C$ \\
\hline \multirow[t]{4}{*}{150} & $\bar{C}$ & 1,011 & 1,009 & 0,990 & 0,998 & 1,01 & 1,02 & $-630,86$ & 1,02 \\
\hline & $\mathbf{S}_{\mathrm{C}}^{2}$ & 0,028 & 0,026 & 0,027 & 0,013 & 0,03 & 0,03 & (*) & 0,03 \\
\hline & $P_{0 s}$ & 0,95 & 0,93 & 0,96 & 0,98 & 0,95 & 0,93 & 0,58 & 0,99 \\
\hline & $P_{99}$ & 0,99 & 0,98 & 0,99 & 0,99 & 0,99 & 0,99 & 0,60 & 1,00 \\
\hline \multirow[t]{4}{*}{200} & $\overline{\mathbf{C}}$ & 1,004 & 1,013 & 0,990 & 0,999 & 1,00 & 1,02 & 200,95 & 1,01 \\
\hline & $\mathbf{S}_{\mathrm{C}}^{2}$ & 0,019 & 0,021 & 0,020 & 0,010 & 0,02 & 0,02 & (*) & 0,02 \\
\hline & $P_{95}$ & 0,95 & 0,95 & 0,95 & 0,98 & 0,95 & 0,94 & 0,58 & 0,99 \\
\hline & $\mathrm{P}_{99}$ & 0,99 & 0,99 & $0,99 !$ & 0,99 & 0,99 & 0,99 & 0,60 & 1,00 \\
\hline \multirow[t]{4}{*}{300} & $\overline{\mathbf{C}}$ & 1,000 & 1,007 & 0,990 & 0,994 & 1,00 & 1,01 & 30,98 & 1,01 \\
\hline & $\mathbf{S}_{\mathrm{C}}^{2}$ & 0,014 & 0,014 & 0,014 & 0,007 & 0,02 & 0,01 & (") & 0,01 \\
\hline & $\mathrm{P}_{95}$ & 0,96 & 0,95 & 0,97 & 0,98 & 0,96 & 0,95 & 0,60 & 1,00 \\
\hline & $P_{99}$ & 0,99 & 0,99 & 0,99 & 0,99 & 0,99 & 0,99 & 0,63 & 1,00 \\
\hline \multirow[t]{4}{*}{400} & $\overline{\mathbf{C}}$ & 0,998 & 1,000 & 0,980 & 0,991 & 1,00 & 1,02 & 0,98 & 1,01 \\
\hline & $\mathrm{S}_{\mathrm{C}}^{2}$ & 0,010 & 0,010 & 0,009 & 0,005 & 0,01 & 0,01 & $\left(^{*}\right)$ & 0,01 \\
\hline & $P_{95}$ & 0.96 & 0,95 & 0,96 & 0,98 & 0,95 & 0,94 & 0,60 & 1,00 \\
\hline & $P_{99}$ & 0,99 & 0,99 & 0,99 & 0,99 & 0,99 & 0,99 & 0,63 & 1,00 \\
\hline \multirow[t]{4}{*}{500} & $\overline{\mathbf{C}}$ & 0,994 & 1,003 & 0,980 & 0,991 & 1,00 & 1,01 & 0,98 & 1,01 \\
\hline & $S_{C}^{2}$ & 0,008 & 0,009 & 0,007 & 0,004 & $0,01$. & 0,01 & $(*)$ & 0,01 \\
\hline & $P_{95}$ & 0,95 & 0,95 & 0,96 & 0,98 & 0,95 & 0,93 & 0,62 & 1,00 \\
\hline & $P_{99}$ & 0,99 & 0,99 & 0,99 & 0,99 & 0,99 & 0,98 & 0,63 & 1,00 \\
\hline
\end{tabular}


TABELA 13 - Distribuiçåo do nivel de significaincia no teste da hipbtese $\mathrm{H}_{0}: \mathrm{F}=0$, em $\mathrm{N}=1000$ experimentos com emostras de tamanhos diferentes extrádas em populasỏes nåo endogâmicas de três alelos e diversas frequências gênicas, nas andalises individuais e na análise conjunta.

\begin{tabular}{|c|c|c|c|c|c|c|c|c|c|}
\hline D & Expitica & $\begin{array}{l}p_{1} \\
0.70\end{array}$ & & $\begin{array}{l}p_{p} \\
0,10\end{array}$ & $\overline{A C}$ & $\begin{array}{l}p_{1} \\
0,80\end{array}$ & $\begin{array}{l}p_{2} \\
0,10\end{array}$ & $\begin{array}{l}p_{3} \\
0,10\end{array}$ & $\overline{\mathrm{AC}}$ \\
\hline \multirow[t]{3}{*}{5} & $\begin{array}{l}\overline{\bar{C}} \\
\mathbf{S}_{C}^{2}\end{array}$ & $\begin{array}{l}761,03 \\
(*)\end{array}$ & $\begin{array}{l}1740,74 \\
\text { (*) }\end{array}$ & $\begin{array}{l}3370,26 \\
(*)\end{array}$ & $\begin{array}{l}551,03 \\
\text { (") }\end{array}$ & $\begin{array}{l}1370,76 \\
(*)\end{array}$ & $\begin{array}{l}372025 \\
\text { (") }\end{array}$ & $\begin{array}{l}3760,22 \\
\text { (*) }\end{array}$ & $\begin{array}{l}1190,81 \\
\text { (") }\end{array}$ \\
\hline & $P_{9 g}$ & 0,89 & 0,74 & 0,60 & 0,92 & 0,74 & 0,60 & 0,60 & 0,88 \\
\hline & $P_{99}$ & 1,00 & 0,89 & 0,74 & 0,99 & 0,89 & 0.74 & 0,74 & 0,92 \\
\hline \multirow[t]{3}{*}{10} & $\begin{array}{l}\overline{\bar{C}} \\
S_{C}^{2}\end{array}$ & $\begin{array}{l}31,22 \\
(*)\end{array}$ & $\begin{array}{l}111,23 \\
(*)\end{array}$ & $\begin{array}{l}1380,72 \\
(*)\end{array}$ & $\begin{array}{l}21,13 \\
\left(^{*}\right)\end{array}$ & $\begin{array}{l}211,22 \\
\left({ }^{*}\right)\end{array}$ & $\begin{array}{l}1570,80 \\
\left(^{*}\right)\end{array}$ & $\begin{array}{l}1260,75 \\
\text { (") }\end{array}$ & $\begin{array}{l}181,09 \\
(*)\end{array}$ \\
\hline & $P_{95}$ & 0,94 & 0,88 & 0,72 & 0,96 & 0,80 & 0,72 & 0,72 & 0,90 \\
\hline & $P_{99}$ & 0,98 & 0,91 & 0,80 & 0,99 & 0,94 & 0,80 & 0,80 & 0,96 \\
\hline \multirow[t]{3}{*}{15} & $\begin{array}{l}\bar{C} \\
S_{C}^{2}\end{array}$ & $\begin{array}{l}1,15 \\
0,71\end{array}$ & $\begin{array}{l}51,19 \\
\text { (*) }\end{array}$ & $\begin{array}{l}40,92 \\
\text { (") }\end{array}$ & $\begin{array}{l}1,06 \\
0,26\end{array}$ & $\begin{array}{l}11,13 \\
(*)\end{array}$ & $\begin{array}{l}431,04 \\
(*)\end{array}$ & $\begin{array}{l}350,91 \\
(*)\end{array}$ & $\begin{array}{l}11,03 \\
(")\end{array}$ \\
\hline & $P_{95}$ & 0,94 & 0,90 & 0,73 & 0,96 & 0,89 & 0,73 & 0,73 & 0,93 \\
\hline & $P_{99}$ & 0,97 & 0,95 & 0,79 & 0,99 & 0,94 & 0,79 & 0,85 & 0,96 \\
\hline \multirow[t]{3}{*}{20} & $\begin{array}{l}\overline{\bar{C}} \\
\mathbf{S}_{\mathrm{C}}^{2}\end{array}$ & $\begin{array}{l}1,10 \\
0,39\end{array}$ & $\begin{array}{l}11,19 \\
(*)\end{array}$ & $\begin{array}{l}210,98 \\
(*)\end{array}$ & $\begin{array}{l}1,06 \\
0,22\end{array}$ & $\begin{array}{l}1,12 \\
0,69\end{array}$ & $\begin{array}{l}231,10 \\
(*)\end{array}$ & $\begin{array}{l}170,97 \\
\text { (*) }\end{array}$ & $\begin{array}{l}1,5 \\
0,37\end{array}$ \\
\hline & $P_{95}$ & 0,94 & 0,88 & 0,79 & 0,98 & 0,88 & 0,79 & 0,79 & 0,94 \\
\hline & $P_{99}$ & 0,98 & 0,94 & 0,84 & 0,99 & 0,94 & 0,84 & 0,84 & 0,97 \\
\hline \multirow[t]{4}{*}{25} & $\overline{\mathbf{C}}$ & 1,07 & 1,09 & 30,98 & 1,03 & 1,08 & 61,17 & 40,97 & 1,03 \\
\hline & $\mathbf{S}_{\mathrm{C}}^{2}$ & 0,24 & 0,28 & $(*)$ & 0,12 & 0,29 & $(*)$ & (*) & 0,15 \\
\hline & $P_{95}$ & 0,95 & 0,90 & 0,80 & 0,97 & 0,90 & 0,76 & 0,80 & 0,94 \\
\hline & $\mathrm{P}_{99}$ & 0,98 & 0,95 & 0,84 & 0,99 & 0,95 & 0,84 & 0,84 & 0,98 \\
\hline \multirow[t]{4}{*}{30} & $\overline{\mathbf{C}}$ & 1,04 & 1,06 & 60,99 & 1,01 & 1,06 & 31,13 & 20,97 & 1,02 \\
\hline & $S_{C}^{2}$ & 0,19 & 0,20 & $(*)$ & 0,10 & 0,20 & $(*)$ & $(*)$ & 0,10 \\
\hline & $P_{95}$ & 0,96 & 0,92 & 0,81 & 0,98 & 0,92 & 0,81 & 0,81 & 0,96 \\
\hline & $\mathrm{P}_{99}$ & 0,99 & 0,96 & 0,87 & 0,99 & 0,97 & 0,87 & 0,87 & 0,99 \\
\hline
\end{tabular}


TABELA 13 - Distribuição do nivel de significância no teste da hipótese $\mathrm{H}_{0}: \mathrm{F}=0$, em $\mathrm{N}=1000$ experimentos com amostras de tamanhos diferentes extraidas em populações næ̃o endogâmicas de três alelos e diversas frequências gênicas, nas análises individuais e na análise conjunta.

\begin{tabular}{|c|c|c|c|c|c|c|c|c|c|}
\hline n & Estatica & $\begin{array}{l}p_{1} \\
0,70 \\
0\end{array}$ & $\begin{array}{l}p_{2} \\
0,20\end{array}$ & $\begin{array}{l}p_{3} \\
0,10\end{array}$ & AC & $\begin{array}{l}P_{1} \\
0,80\end{array}$ & $\begin{array}{l}p_{2} \\
0,10 \\
0,10\end{array}$ & $\begin{array}{l}p_{3} \\
0,10\end{array}$ & $\mathbf{A C}$ \\
\hline \multirow[t]{4}{*}{35} & $\overline{\mathbf{C}}$ & 1,04 & 1,08 & 10,98 & 1,01 & 1,06 & 1,09 & 0,97 & 1,01 \\
\hline & $\mathbf{S}_{\mathrm{C}}^{2}$ & 0,14 & 0,21 & (*) & 0,08 & 0,18 & 0,26 & 0,11 & 0,08 \\
\hline & $P_{95}$ & 0,95 & 0,93 & 0,81 & 0,98 & 0,92 & 0,81 & 0,81 & 0,96 \\
\hline & $P_{99}$ & 0,99 & 0,97 & 0,87 & 0,99 & 0,95 & 0,87 & 0,84 & 0,98 \\
\hline \multirow[t]{4}{*}{40} & $\overline{\mathbf{C}}$ & 1,03 & 1,06 & 0,97 & 1,01 & 1,04 & 1,08 & 0,97 & 1,01 \\
\hline & $\mathbf{S}_{\mathrm{C}}^{2}$ & 0,11 & 0,13 & 0,12 & 0,06 & 0,12 & 0,25 & 0,10 & 0,06 \\
\hline & $P_{95}$ & 0,95 & 0,93 & 0,82 & 0,99 & 0,93 & 0,82 & 0,82 & 0,97 \\
\hline & $P_{99}$ & 0,98 & 0,97 & 0,87 & 0,99 & 0,96 & 0,87 & 0,87 & 0,99 \\
\hline \multirow[t]{4}{*}{45} & $\overline{\mathbf{C}}$ & 1,03 & 1,05 & 0,98 & 1,01 & 1,02 & 1,08 & 0,99 & 1,00 \\
\hline & $\mathbf{S}_{\mathrm{C}}^{2}$ & 0,11 & 0,11 & 0,11 & 0,06 & 0,11 & 0,25 & 0,15 & 0,06 \\
\hline & $P_{95}$ & 0,95 & 0,93 & 0,83 & 0,98 & 0,93 & 0,83 & 0,83 & 0,97 \\
\hline & $P_{99}$ & 0,98 & 0,97 & 0,87 & 0,99 & 0,97 & 0,87 & 0,88 & 0,99 \\
\hline \multirow[t]{4}{*}{ so } & $\overline{\mathbf{C}}$ & 1,05 & 1,05 & 0,97 & 1,02 & 1,02 & 1,08 & 0,95 & 1,00 \\
\hline & $\mathbf{S}_{\mathrm{C}}^{2}$ & 0,11 & 0,12 & 0,08 & 0,06 & 0,10 & 0,13 & 0,07 & 0,05 \\
\hline & $P_{95}$ & 0,95 & 0,93 & 0,84 & 0,98 & 0,93 & 0,84 & 0,84 & 0,97 \\
\hline & $P_{99}$ & 0,99 & 0,97 & 0,90 & 0,99 & 0,97 & 0,88 & 0,89 & 0,99 \\
\hline \multirow[t]{4}{*}{75} & $\overline{\mathbf{C}}$ & 1,00 & 1,02 & 0,94 & 0,99 & 1,01 & 1,05 & 0,95 & 0,99 \\
\hline & $\mathbf{S}_{\mathbf{C}}^{2}$ & 0,06 & 0,06 & 0,05 & 0,03 & 0,05 . & 0,07 & 0,04 & 0,03 \\
\hline & $P_{95}$ & 0,96 & 0,96 & 0,88 & 0,99 & 0,95 & 0,87 & 0,87 & 0,98 \\
\hline & $P_{99}$ & 0,99 & 0,98 & 0,92 & 1,00 & 0,98 & 0,91 & 0,91 & 0,99 \\
\hline \multirow[t]{4}{*}{100} & $\overline{\mathbf{C}}$ & 1,01 & 1,02 & 0,94 & 0,99 & 1,00 & 1,01 & 0,95 & 0,98 \\
\hline & $\mathbf{S}_{\mathrm{C}}^{2}$ & 0,04 & 0,04 & 0,03 & 0,02 & 0,04 & 0,04 & 0,03 & 0,02 \\
\hline & $P_{95}$ & 0,95 & 0,94 & 0,90 & 0,99 & 0,95 & 0,89 & 0,90 & 0,98 \\
\hline & $P_{99}$ & 0,99 & 0,97 & 0,93 & 1,00 & 0,99 & 0,92 & 0,93 & 0,99 \\
\hline
\end{tabular}


TABELA 13 - Distribuição do nivel de significância no teste da hipótese $\mathrm{H}_{0}: \mathrm{F}=0$, em $\mathrm{N}=1000$ experimentos com amostras de tamanhos diferentes extraídas em populações não endogâmicas de três alelos e diversas frequências gênicas, nas análises individusis e na análise conjunta.

\begin{tabular}{|c|c|c|c|c|c|c|c|c|c|}
\hline $\mathrm{n}$ & Estutisticen & $\begin{array}{l}p_{1} \\
0,70\end{array}$ & $\begin{array}{l}p_{2} \\
0,20\end{array}$ & $\begin{array}{l}p_{9} \\
0,10\end{array}$ & $A C$ & $\begin{array}{l}p_{1} \\
0,80\end{array}$ & $\begin{array}{l}p_{2} \\
0,10\end{array}$ & $\begin{array}{l}p_{9} \\
0,10\end{array}$ & $\overline{A C}$ \\
\hline \multirow[t]{4}{*}{150} & $\overline{\mathbf{C}}$ & 1,00 & 1,03 & 0,93 & 0,99 & 0,99 & 1,02 & 0,93 & 0,98 \\
\hline & $\mathbf{S}_{\mathrm{C}}^{2}$ & 0,03 & 0,03 & 0,02 & 0,02 & 0,03 & 0,03 & 0,02 & 0,02 \\
\hline & $P_{95}$ & 0,96 & 0,95 & 0,93 & 0,99 & 0,95 & 0,91 & 0,92 & 0,98 \\
\hline & $P_{99}$ & 0,99 & 0,99 & 0,95 & 1,00 & 0,99 & 0,94 & 0,95 & 0,99 \\
\hline \multirow[t]{4}{*}{200} & $\overline{\overline{\mathbf{C}}}$ & 1,00 & 1,01 & 0,94 & 0,99 & 0,99 & 1,02 & 0,94 & 0,98 \\
\hline & $\mathrm{S}_{\mathrm{C}}^{2}$ & 0,02 & 0,02 & 0,01 & 0,01 & 0,02 & 0,02 & 0,01 & 0,01 \\
\hline & $P_{95}$ & 0,96 & 0,93 & 0,95 & 0,99 & 0,95 & 0,93 & 0,95 & 0,99 \\
\hline & $P_{99}$ & 0,99 & 0,99 & 0,97 & 1,00 & 0,99 & 0,96 & 0,97 & 1,00 \\
\hline \multirow[t]{4}{*}{300} & $\overline{\bar{C}}$ & 1,00 & 1,02 & 0,94 & 0,99 & 0,99 & 1,02 & 0,93 & 0,98 \\
\hline & $\mathrm{S}_{\mathrm{C}}^{2}$ & 0,02 & 0,02 & 0,01 & 0,01 & 0,01 & 0,02 & 0,01 & 0,01 \\
\hline & $\mathrm{P}_{95}$ & 0,96 & 0,94 & 0,96 & 0,99 & 0,95 & 0,94 & 0,96 & 0,99 \\
\hline & $P_{99}$ & 0,99 & 0,98 & 0,98 & 1,00 & 0,99 & 0,97 & 0,98 & 1,00 \\
\hline \multirow[t]{4}{*}{400} & $\overline{\mathbf{C}}$ & 0,99 & 1,01 & 0,93 & 0,99 & 0,98 & 1,02 & 0,93 & 0,98 \\
\hline & $\mathrm{S}_{\mathrm{C}}^{2}$ & 0,01 & 0,01 & 0,01 & 0,01 & 0,01 & 0,01 & 0,01 & 0,01 \\
\hline & $P_{95}$ & 0,95 & 0,94 & 0,97 & 0,99 & 0,95 & 0,93 & 0,98 & 0,99 \\
\hline & $P_{99}$ & 0,99 & 0,99 & 0,99 & 1,00 & 0,99 & 0,98 & 0,99 & 1,00 \\
\hline \multirow[t]{4}{*}{500} & $\overline{\mathbf{C}}$ & 0,99 & 1,01 & 0,93 & 0,98 & 0,98 & 1,02 & 0,93 & 0,98 \\
\hline & $\mathbf{S}_{\mathrm{C}}^{2}$ & 0,01 & 0,01 & 0,01 & 0,01 & 0,01 & 0,01 & 0,01 & 0,01 \\
\hline & $P_{95}$ & 0,96 & 0,95 & 0,98 & 0,99 & 0,96 & 0,92 & 0,98 & 0,99 \\
\hline & $P_{g y}$ & 0,99 & 0,99 & 0,99 & 1,00 & 0,99 & 096 & 0,99 & 1,00 \\
\hline
\end{tabular}


TABELA 13 - Distribuição do nivel de significância no teste da hipótese $\mathrm{H}_{0}: \mathrm{F}=0$, em $\mathrm{N}=1000$ experimentos com amostras de tamanhos diferentes extraidas em populaçōes não endogâmicas de três alelos e diversas frequências génicas, nas análises individuais e na análise conjunta.

\begin{tabular}{|c|c|c|c|c|c|c|c|c|c|}
\hline a & Bration & $\begin{array}{l}P_{1} \\
0,70\end{array}$ & $\begin{array}{l}p_{3} \\
0,25\end{array}$ & $p_{3}, 05$ & $\overline{A C}$ & $\begin{array}{l}p_{1} \\
0,70\end{array}$ & $p_{2}{ }_{0,15}$ & $\begin{array}{l}p_{3} \\
0,15\end{array}$ & $\overline{\mathbf{A C}}$ \\
\hline \multirow[t]{4}{*}{5} & $\overline{\mathbf{C}}$ & 611,08 & 861,01 & 6179,74 & 471,10 & 661,08 & 2520,51 & 2170,60 & 421,08 \\
\hline & $\mathbf{S}_{C}^{2}$ & $(*)$ & $(*)$ & & $(*)$ & $(")$ & $(*)$ & & (*) \\
\hline & $P_{0 s}$ & 0,89 & 0,89 & 0,59 & 0,97 & 0,89 & 0,74 & 0,73 & 0,92 \\
\hline & $P_{90}$ & 1,00 & 0,89 & 0,59 & 0,99 & 1,00 & 0,89 & 0,89 & 0,99 \\
\hline \multirow[t]{3}{*}{10} & $\begin{array}{c}\bar{C} \\
\mathbf{S}_{\mathrm{C}}^{2}\end{array}$ & $\begin{array}{l}31,24 \\
\left(^{*}\right)\end{array}$ & $\begin{array}{l}81,21 \\
(*)\end{array}$ & $\begin{array}{l}3780,21 \\
\left({ }^{*}\right)\end{array}$ & $\begin{array}{l}11,18 \\
\text { (") }\end{array}$ & $\begin{array}{l}81,24 \\
\left({ }^{*}\right)\end{array}$ & $\begin{array}{l}491,09 \\
\text { (*) }\end{array}$ & $\begin{array}{l}480,97 \\
\text { (*) }\end{array}$ & $\begin{array}{l}41,12 \\
(*)\end{array}$ \\
\hline & $\mathrm{P}_{95}$ & 0,88 & 0,88 & 0,60 & 0,98 & 0,94 & 0,80 & 0,80 & 0,95 \\
\hline & $\mathrm{P}_{99}$ & 0,98 & 0,94 & 0,68 & 0,99 & 0,98 & 0,88 & 0,88 & 0,99 \\
\hline \multirow[t]{4}{*}{15} & $\overline{\mathbf{C}}$ & 1,20 & 1,24 & 2470,46 & $\overline{1,14}$ & 11,20 & 101,20 & 71,05 & 1,10 \\
\hline & $\mathbf{S}_{\mathrm{C}}^{2}$ & 0,85 & 1.00 & $(*)$ & 0,59 & $(n)$ & $(*)$ & $(*)$ & 0,37 \\
\hline & $P_{95}$ & 0,94 & 0,89 & 0,64 & 0,98 & 0,94 & 0,84 & 0,79 & 0,95 \\
\hline & $P_{99}$ & 0,98 & 0,96 & 0,73 & 0,99 & 0,97 & 0,89 & 0,89 & 0,99 \\
\hline \multirow[t]{4}{*}{20} & $\overline{\mathbf{C}}$ & 1,10 & 1,11 & 1330,68 & 1.06 & 1,08 & 31,13 & 21,02 & 1,02 \\
\hline & $\mathrm{S}_{\mathrm{C}}^{2}$ & 0,36 & 0,33 & $(*)$ & 0.22 & 0,36 & $(*)$ & $(*)$ & 0,14 \\
\hline & $P_{9 s}$ & 0,94 & 0,91 & 0,64 & 0,98 & 0,94 & 0,83 & 0,84 & 0,96 \\
\hline & $\mathrm{P}_{99}$ & 0,98 & 0,96 & 0,69 & 0,99 & 0,97 & 0,89 & 0,91 & 0,99 \\
\hline \multirow[t]{4}{*}{25} & $\overline{\mathbf{C}}$ & 1.07 & 1.11 & 980.75 & 1.05 & 1.09 & 11.14 & 11.04 & 1.04 \\
\hline & $\mathbf{S}_{\mathrm{C}}^{2}$ & 0.26 & 0.33 & $(*)$ & 0.19 & 0.25 & $(*)$ & (*) & 0.13 \\
\hline & $P_{95}$ & 0.94 & 0.93 & 0.67 & 0.99 & 0.94 & 0.87 & 0.86 & 0.97 \\
\hline & $\mathrm{P}_{99}$ & 0.98 & 0.97 & 0.71 & 1.00 & 0.98 & 0.93 & 0.91 & 0.99 \\
\hline \multirow[t]{4}{*}{30} & $\overline{\mathbf{C}}$ & 1,05 & 1,07 & 400,85 & 1,03 & 1,06 & 1,09 & 1,02 & 1,02 \\
\hline & $\mathbf{S}_{\mathrm{C}}^{2}$ & 0,17 & 0,18 & $\left.{ }^{*}\right)$ & 0.12 & 0,19 & 0,37 & 0,19 & 0,10 \\
\hline & $P_{95}$ & 0,94 & 0,92 & 0,69 & 0,99 & 0,95 & 0,87 & 0,87 & 0,97 \\
\hline & $P_{99}$ & 0,99 & 0,98 & 0,73 & 1.00 & 0.99 & 0,92 & 0,92 & 0,99 \\
\hline
\end{tabular}


TABELA 13 - Distribuiçåo do nivel de significância no teste da hipótese $\mathrm{H}_{0}: \mathrm{F}=0$, em $\mathrm{N}=1000$ experimentos com amostres de tamanhos diferentes extraidss em populaç̃es não endogâmicas de três alelos e diversas frequências gênicas, nas análises individuais e na andlise conjunta

\begin{tabular}{|c|c|c|c|c|c|c|c|c|c|}
\hline n & Rotutition & $\begin{array}{l}P_{1} \\
0.70\end{array}$ & $\begin{array}{l}p_{2} \\
0,25\end{array}$ & $\begin{array}{l}p_{3} \\
0,05\end{array}$ & $A C$ & $\begin{array}{l}P_{1} \\
0,70\end{array}$ & $\begin{array}{l}p_{2} \\
0,15\end{array}$ & $\begin{array}{l}p_{3} \\
0,15\end{array}$ & $\overline{A C}$ \\
\hline \multirow[t]{4}{*}{$\overline{35}$} & & 1,06 & 1,08 & 380,86 & 1,04 & 1,08 & 1,10 & 1,01 & 1,03 \\
\hline & & 0,15 & 0,19 & $(*)$ & 0,11 & 0,19 & 0,22 & 0,18 & 0,08 \\
\hline & & 0,95 & 0,95 & 0,68 & 0,99 & 0,94 & 0,87 & 0,89 & 0,97 \\
\hline & $P_{99}$ & 0,99 & 0,98 & 0,75 & 1,00 & 0.99 & 0,92 & 0,94 & 0,99 \\
\hline \multirow[t]{4}{*}{40} & & 1,03 & 1,06 & 180,89 & 1,02 & 1,02 & 1,06 & 0,99 & 1,00 \\
\hline & & 0,13 & 0,14 & $(*)$ & 0,09 & 0,12 & 0,18 & 0,14 & 0,06 \\
\hline & $P_{95}$ & 0,95 & 0,94 & 0,69 & 0,99 & 0,94 & 0,90 & 0,90 & 0,98 \\
\hline & & 0,99 & 0,98 & 0,73 & 1,00 & 0,99 & 0,95 & 0,95 & 0,99 \\
\hline \multirow[t]{4}{*}{45} & & 1,03 & 1,05 & 100,90 & 1,02 & 1,04 & 1,09 & 0,98 & 1,01 \\
\hline & & 0,12 & 0,12 & $(v)$ & 0,08 & 0,12 & 0,17 & 0,09 & 0,06 \\
\hline & $r_{95}$ & 0,95 & 0,95 & 0,72 & 0,99 & 0,94 & 0,90 & 0,90 & 0,98 \\
\hline & $P_{99}$ & 0,99 & 0,99 & 0,75 & 1,00 & 0,99 & 0,93 & 0,96 & 0,99 \\
\hline \multirow[t]{4}{*}{50} & & 1,03 & 1,06 & 60,91 & 1,02 & 1,03 & 1,07 & 0,99 & 1,01 \\
\hline & & 0,10 & 0,10 & $(\bullet)$ & 0,07 & 0,10 & 0,13 & 0,10 & 0,05 \\
\hline & $P_{95}$ & 0,95 & 0,94 & 0,70 & 0,99 & 0,95 & 0,90 & 0,92 & 0,98 \\
\hline & & 0,98 & 0,98 & 0,76 & 1,00 & 0,99 & 0,94 & 0,95 & 0,99 \\
\hline \multirow[t]{4}{*}{75} & $\overline{\mathbf{C}}$ & 1,02 & 1,05 & 0,92 & 1,02 & 1,02 & 1,04 & 0,97 & 1,00 \\
\hline & $\mathbf{s}$ & 0,06 & 0,07 & 0,14 & 0,04 & 0,06 & 0,07 & 0,05 & 0,03 \\
\hline & & 0,95 & 0,93 & 0,76 & 0,99 & 0,95 & 0,92 & 0,93 & 0,98 \\
\hline & $P_{99}$ & 0,99 & 0,98 & 0,80 & 1,00 & 0,99 & 0,95 & 0,96 & 0,59 \\
\hline \multirow[t]{4}{*}{100} & $\overline{\bar{z}}$ & 1,00 & 1,02 & 0,91 & 0,99 & 1,01 & 1,04 & 0,98 & 1,00 \\
\hline & $\mathbf{S}_{\mathrm{c}}^{2}$ & 0,04 & 0,04 & 0,09 & 0,03 & 0,05 & 0,05 & 0,04 & 0,02 \\
\hline & $P_{95}$ & 0,95 & 0,94 & 0,76 & 0,99 & 0,95 & 0,94 & 0,95 & 0,99 \\
\hline & $\mathbf{P}_{99}$ & 0,99 & 0,98 & 0,81 & 1,00 & 0,99 & 0,97 & 0,98 & 1,00 \\
\hline
\end{tabular}


TABELA 13 - Distribuiçåo do nível de significância no teste da hipótese $\mathrm{H}_{0}: \mathrm{F}=0$, em $\mathrm{N}=1000$ experimentos com amostras de tamanhos diferentes extrádas em populacōes não endogâmicas de três alelos e diversas frequências gênicas, nas andlises individusis $\mathrm{e} n \mathrm{a}$ andlise conjunta.

\begin{tabular}{|c|c|c|c|c|c|c|c|c|c|}
\hline $\bar{n}$ & Rotitio & $\begin{array}{l}P 3 \\
0,70\end{array}$ & $\begin{array}{l}p_{2} \\
0,25\end{array}$ & $\begin{array}{l}P_{3} \\
0,05\end{array}$ & AC & $\begin{array}{l}P_{1} \\
0,70\end{array}$ & p.15 & $\begin{array}{l}p_{3} \\
0,15\end{array}$ & $A C$ \\
\hline \multirow[t]{4}{*}{150} & & 0,99 & 1,01 & 0,91 & 0,99 & 1,00 & 1,02 & 0,96 & 0,99 \\
\hline & & 0,02 & 0,03 & 0,06 & 0,02 & 0,03 & 0,03 & 0,02 & 0,02 \\
\hline & $P_{s}$ & 0,96 & 0,95 & 0,80 & 0,99 & 0,95 & 0,94 & 0,96 & 0,99 \\
\hline & $P_{99}$ & 0,99 & 0,99 & 0,83 & 1,00 & 0,99 & 0,97 & 0,99 & 1,00 \\
\hline \multirow[t]{4}{*}{200} & & 1,00 & 1,02 & 0,91 & 1,00 & 0,99 & 1,02 & 0,95 & 0,98 \\
\hline & ${ }^{N} \mathrm{C}$ & 0,02 & 0,02 & 0,05 & 0,02 & 0,02 & 0,02 & 0,02 & 0,01 \\
\hline & $\mathbf{P}_{\mathbf{g}}$ & 0,96 & 0,94 & 0,83 & 0,99 & 0,96 & 0,93 & 0,97 & 0,99 \\
\hline & $P_{99}$ & 0,99 & 0,99 & 086 & 1,00 & 0,99 & 0,98 & 0,99 & 1,00 \\
\hline \multirow[t]{4}{*}{300} & & 1,00 & 1,02 & 0,91 & 0,99 & 0,99 & 1,02 & 0,96 & 0,99 \\
\hline & $S_{\mathbf{C}}^{2}$ & 0,01 & 0,02 & 0,03 & 0,01 & 0,01 & 0,02 & 0,01 & 0,01 \\
\hline & $P_{9}$ & 0,96 & 0,93 & 0,87 & 0,99 & 0,95 & 0,93 & 0,97 & 0,99 \\
\hline & $P_{99}$ & 0,99 & 0,98 & 0,90 & 1,00 & 0,99 & 0,98 & 0,99 & 1,00 \\
\hline \multirow[t]{4}{*}{400} & $\overline{\mathbf{C}}$ & 1,00 & 1,02 & 0,91 & 1,00 & 0,99 & 1,01 & 0,95 & 0,98 \\
\hline & & 0,01 & 0,01 & 0,02 & 0,01 & 0,01 & 0,01 & 0,01 & 0,01 \\
\hline & $P_{95}$ & 0,95 & 0,93 & 0,89 & 0,99 & 0,96 & 0,93 & 0,97 & 0,99 \\
\hline & $P_{99}$ & 0,99 & 0,98 & 0,92 & 1,00 & 0,99 & 0,98 & 0,99 & 1,00 \\
\hline \multirow[t]{4}{*}{500} & & 0,99 & 1,01 & 0,91 & 0,99 & 0,99 & 1,01 & 0,93 & 0,99 \\
\hline & $\mathbf{S}_{\mathrm{C}}^{2}$ & 0,01 & 0,01 & 0,02 & 0,01 & 0,01 & 0,01 & 0,01 & 0,01 \\
\hline & $P_{95}$ & 0,96 & 0,95 & 0,91 & 0,99 & 0,95 & 0,94 & 0,97 & 0,99 \\
\hline & $P_{99}$ & 0,99 & 0,99 & 0,93 & 1,00 & 0,99 & 0,99 & 0,99 & 1,00 \\
\hline
\end{tabular}


TABELA 13 - Distribuição do nível de significância no teste da hipótese $\mathrm{H}_{0}: \mathrm{F}=0$, em $\mathrm{N}=1000$ experimentos com amostras de tamanhos diferentes extraidas em populaçőes não endogâmicas de três alelos e diversas frequências gênicas, nas análises individuais e na análise conjunta.

\begin{tabular}{|c|c|c|c|c|c|c|c|c|c|}
\hline$\overline{\mathbf{D}}$ & Rotatifice & $\begin{array}{l}P_{1} \\
0,70\end{array}$ & $\begin{array}{l}p_{2} \\
0,29\end{array}$ & $\begin{array}{l}P_{3} \\
0,01\end{array}$ & $\overline{A C}$ & $\begin{array}{l}P_{1} \\
0,60\end{array}$ & $\begin{array}{l}p_{2} \\
0,30\end{array}$ & $\begin{array}{l}p_{3} \\
0,10\end{array}$ & $\overline{A C}$ \\
\hline \multirow[t]{4}{*}{5} & & 741,07 & $871, \overline{06}$ & 9059,19 & 731,08 & 331,29 & $481, \overline{13}$ & 3860,20 & 151,22 \\
\hline & & (*) & (*) & $(*)$ & $(*)$ & $(*)$ & $(*)$ & (*) & $(\omega)$ \\
\hline & & 0,89 & 0,89 & 0,48 & 0,98 & 0,89 & 0,89 & 0,59 & 0,98 \\
\hline & $P_{99}$ & 1,00 & 0,89 & 0,48 & 0,99 & 1,00 & 0,89 & 0,74 & 0,99 \\
\hline \multirow[t]{4}{*}{10} & & 31,26 & 41,29 & 8189,36 & 31,26 & 11,22 & 51,23 & 1520,70 & 11,11 \\
\hline & & $(*)$ & $(*)$ & (*) & $(\boldsymbol{*})$ & $(*)$ & $(t)$ & (*) & $(*)$ \\
\hline & & 0,94 & 0,88 & 0,49 & 0,98 & 0,94 & 0,94 & 0,72 & 0,98 \\
\hline & & 0,98 & 0,98 & 0,56 & 1,00 & 0,98 & 0,98 & 0,80 & 0,99 \\
\hline \multirow[t]{4}{*}{15} & & 1,14 & 1,16 & 7499,50 & 1,14 & 1,16 & 1,17 & 440,93 & 1,08 \\
\hline & & 0,48 & 0,51 & $(*)$ & 0,46 & 0,55 & 0,63 & (*) & 0,25 \\
\hline & $P_{95}$ & 0,94 & 0,94 & 0,50 & 0,99 & 0,96 & 0,94 & 0,73 & 0,98 \\
\hline & $P_{99}$ & 0,97 & 0,97 & 0,35 & 1,00 & 0,99 & 0,98 & 0.79 & 1,00 \\
\hline \multirow[t]{4}{*}{20} & & 1,08 & 1,11 & 7139,57 & 1,09 & 1,12 & 1,14 & 230,96 & 1,07 \\
\hline & & 0,36 & 0,34 & (*) & 0,30 & 0,34 & 0,36 & $\left(^{*}\right)$ & 0,20 \\
\hline & $P_{95}$ & 0,94 & 0,94 & 0,50 & 0,99 & 0,95 & 0,94 & 0,79 & 0,98 \\
\hline & $P_{99}$ & 0,98 & 0,98 & 0,54 & 1,00 & 0,99 & 0,98 & 0,84 & 1,00 \\
\hline \multirow[t]{4}{*}{25} & $\bar{\tau}$ & 1,08 & 1,11 & 6129,77 & 1,09 & 1,11 & 1,12 & 60,98 & 1,06 \\
\hline & & 0,26 & 0,30 & $(*)$ & 0,25 & 0,32 & 0,35 & $(*)$ & 0,20 \\
\hline & & 0,94 & 0,93 & 0,54 & 0,99 & 0,96 & 0,94 & 0,80 & 0,99 \\
\hline & $P_{99}$ & 0,99 & 0,98 & 0,56 & 1,00 & 0,99 & 0,99 & 0,87 & 1,00 \\
\hline \multirow[t]{4}{*}{30} & $\mathrm{C}$ & 1,06 & 1,09 & 5559,88 & 1,07 & 1,08 & 1,09 & 1,00 & 1,04 \\
\hline & $\mathbf{S}_{\mathbf{C}}^{2}$ & 0,18 & 0,20 & $(*)$ & 0,18 & 0,24 & 0,23 & 0,20 & 0,14 \\
\hline & $P_{05}$ & 0,94 & 0,94 & 0,54 & 0,99 & 0,96 & 0,95 & 0,81 & 0,99 \\
\hline & $P_{99}$ & 0,98 & 0,97 & 0,58 & 1,00 & 0,99 & 0,98 & 0,87 & 1,00 \\
\hline
\end{tabular}


TABELA 13 - Distribuição do nivel de significância no teste da hipótese $\mathrm{H}_{0}: \mathrm{F}=0$, em $\mathrm{N}=1000$ experimentos com amostras de tamanhos diferentes extraidas em populacóes não endogâmicas de três alelos e diversas frequências gênicas, nas and́lises individuais e na análise conjunta

\begin{tabular}{|c|c|c|c|c|c|c|c|c|c|}
\hline n & Eotititica & $\begin{array}{l}P_{1} \\
0,70\end{array}$ & $\begin{array}{l}p_{2} \\
0,29\end{array}$ & $\begin{array}{l}p_{3} \\
0,01\end{array}$ & $A C$ & $\begin{array}{l}P_{1} \\
0,60\end{array}$ & $\begin{array}{l}p_{2} \\
0,30\end{array}$ & $\begin{array}{l}p_{3} \\
0,10\end{array}$ & $\overline{A C}$ \\
\hline \multirow[t]{4}{*}{35} & & 1,04 & 1,07 & 3239,95 & 1,05 & 1,05 & 1,08 & 0,99 & 1,02 \\
\hline & & 0,14 & 0,14 & (*) & 0,13 & 0,16 & 0,17 & 0,17 & 0,09 \\
\hline & 10 & 0,94 & 0,94 & 0,53 & 0,99 & 0,96 & 0,94 & 0,81 & 0,99 \\
\hline & $P_{99}$ & 0,99 & 0,99 & 0,57 & 1,00 & 0,99 & 0,98 & 0,87 & 1,00 \\
\hline \multirow[t]{4}{*}{40} & & 1,02 & 1,05 & 4830,03 & 1,03 & 1,05 & 1,05 & 0,99 & 1,02 \\
\hline & & 0,11 & 0,12 & $(\theta)$ & 0,11 & 0,13 & 0,13 & 0,16 & 0,08 \\
\hline & $P_{95}$ & 0,95 & 0,94 & 0,53 & 0,99 & 0,95 & 0,95 & 0,82 & 0,99 \\
\hline & $P_{99}$ & 0,99 & 0,99 & 0,56 & 1,00 & 0,99 & 0,99 & 0,87 & 1,00 \\
\hline \multirow[t]{4}{*}{45} & & 1,03 & 1,06 & 4660,06 & 1,04 & 1,04 & 1,04 & 0,97 & 1,01 \\
\hline & $S_{C}$ & 0,11 & 0,11 & $(*)$ & 0,10 & 0,11 & 0,11 & 0,10 & 0,06 \\
\hline & $P_{95}$ & 0,95 & 0,95 & 0,53 & 0,99 & 0,94 & 0,95 & 0,83 & 0,99 \\
\hline & $P_{99}$ & 0,99 & 0,98 & 0,36 & 1,00 & 0,98 & 0,99 & 0,88 & 1,00 \\
\hline \multirow[t]{4}{*}{50} & & 1,03 & 1,05 & 3770,24 & 1,04 & 1,02 & 1,03 & 20,95 & 1,00 \\
\hline & $S_{C}^{2}$ & 0,09 & 0,09 & $(*)$ & 0,08 & 0,09 & 0,10 & $(*)$ & 0,05 \\
\hline & $P_{95}$ & 0,95 & 0,95 & 0,56 & 0,99 & 0,96 & 0,95 & 0,86 & 0,99 \\
\hline & $P_{99}$ & 0,99 & 0,99 & 0,58 & 1,00 & 0,99 & 0,99 & 0,90 & 1,00 \\
\hline \multirow[t]{4}{*}{75} & 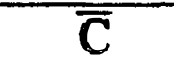 & 1,01 & 1,04 & 2510,49 & 1,02 & 1,02 & 1,03 & 0,95 & 1,00 \\
\hline & $S_{C}^{2}$ & 0,06 & 0,06 & $(*)$ & 0,06 & 0,06 & 0,06 & 0,05 & 0,03 \\
\hline & $P_{95}$ & 0,96 & 0,95 & 0,57 & 0,99 & 0,95 & 0,95 & 0,88 & 0,98 \\
\hline & $P_{99}$ & 0,99 & 0,99 & 0,59 & 1,00 & 0,99 & 0,99 & 0,92 & 1,00 \\
\hline \multirow[t]{4}{*}{100} & $\overline{\overline{\mathbf{C}}}$ & 1,01 & 1,03 & 1500,69 & 1,02 & 1,01 & 1,01 & 094 & 1,00 \\
\hline & $S_{C}^{2}$ & 0,05 & 0,05 & $(*)$ & 0,05 & 0,04 & 0,04 & 0,03 & 0,03 \\
\hline & $P_{95}$ & 0,95 & 0,95 & 0,96 & 0,99 & 0,95 & 0,95 & 0,89 & 0,99 \\
\hline & $P_{99}$ & 0,99 & 0,99 & 0,58 & 1,00 & 0,99 & 0,99 & 0,93 & 1,00 \\
\hline
\end{tabular}


TABELA 13 - Distribuição do nível de significância no teste da hipótese $\mathrm{H}_{0}: \mathrm{F}=0$, em $\mathrm{N}=1000$ experimentos com amostras de tamanhos diferentes extraidas em populacões não endogâmicas de três alelos e diversas frequências génicas, nas andlises individuais e na análise conjunta.

\begin{tabular}{|c|c|c|c|c|c|c|c|c|c|}
\hline n & Rotition & $\begin{array}{l}P_{1} \\
0,70\end{array}$ & $\begin{array}{l}P_{2} \\
0,29\end{array}$ & $\begin{array}{l}P_{3} \\
0,01\end{array}$ & $A C$ & $\begin{array}{l}P_{1} \\
0,60\end{array}$ & $\begin{array}{l}P_{2} \\
0,30\end{array}$ & $\begin{array}{l}P_{3} \\
0,10\end{array}$ & $\overline{A C}$ \\
\hline \multirow[t]{4}{*}{150} & $\overline{\mathbf{C}}$ & 1,00 & 1,03 & 670,85 & 1,01 & 1,00 & 1,02 & 0,93 & 1,00 \\
\hline & $S_{C}^{2}$ & 0,03 & 0,03 & $(\omega)$ & 0,03 & 0,03 & 0,03 & 0,02 & 0,02 \\
\hline & $P_{95}$ & 0,96 & 0,95 & 0,57 & 0,99 & 0,96 & 0,95 & 0,93 & 0,99 \\
\hline & $P_{99}$ & 0,99 & 0,99 & 0,60 & 1,00 & 0,99 & 0,99 & 0,96 & 1,00 \\
\hline \multirow[t]{4}{*}{200} & & 0,99 & 1,02 & 310,92 & 1,01 & 1,00 & 1,01 & 0,93 & 0,99 \\
\hline & $\mathbf{S}$ & 0,02 & 0,02 & $(*)$ & 0,02 & 0,02 & 0,02 & 0,01 & 0,01 \\
\hline & $P_{95}$ & 0,96 & 0,95 & 0,58 & 0,99 & 0,95 & 0,96 & 0,95 & 0,99 \\
\hline & $P_{99}$ & 0,99 & 0,99 & 0,61 & 1,00 & 0,99 & 0,99 & 0,97 & 1,00 \\
\hline \multirow[t]{4}{*}{300} & & 1,00 & 1,02 & 60,97 & 1,01 & 1,00 & 1,01 & 0,93 & 0,99 \\
\hline & ${ }^{D_{C}}$ & 0,01 & 0,01 & $(*)$ & 0,01 & 0,01 & 0,02 & 0,01 & 0,01 \\
\hline & $P_{9}$ & 0,95 & 0,92 & 0,59 & 0,99 & 0,96 & 0,95 & 0,96 & 0,99 \\
\hline & $P_{99}$ & 0,99 & 0,98 & 0,62 & 1,00 & 0,99 & 0,99 & 0,98 & 1,00 \\
\hline \multirow[t]{4}{*}{400} & $\bar{c}$ & 0,99 & 1,01 & 0,99 & 1,00 & 0,99 & 1,00 & 0,93 & 0,98 \\
\hline & $S_{C}^{2}$ & 0,01 & 0,01 & $(*)$ & 0,01 & 0,01 & 0,01 & 0,01 & 0,01 \\
\hline & $P_{9}$ & 0,95 & 0,93 & 0,61 & 0,99 & 0,96 & 0,93 & 0,97 & 0,99 \\
\hline & $P_{99}$ & 0,99 & 0,98 & 0,63 & 1,00 & 0,99 & 0,99 & 0,99 & 1,00 \\
\hline \multirow[t]{4}{*}{500} & $\overline{\overline{\mathbf{C}}}$ & 1,00 & 1,01 & 10,98 & 1,00 & 1,00 & 1,00 & 0,93 & 0,99 \\
\hline & $S_{C}^{2}$ & 0,01 & 0,01 & $(*)$ & 0,01 & 0,01 & 0,01 & 0,01 & 0,01 \\
\hline & $P_{95}$ & 0,96 & 0,94 & 0,62 & 0,99 & 0,96 & 0,95 & 0,98 & 0,09 \\
\hline & $P_{99}$ & 0,99 & 0,98 & 0,64 & 1,00 & 0,99 & 0,99 & 0,99 & 1,00 \\
\hline
\end{tabular}


TABELA 13 - Distribuiçåo do nivel de significância no teste da hipótese $\mathrm{H}_{0}: \mathrm{F}=0$, em $\mathrm{N}=1000$ experimentos com amostras de tamanhos diferentes extraídas em populagões não endogâmicas de três alelos e diversas frequências gênicas, nas análises individuais e na análise conjunta.

\begin{tabular}{|c|c|c|c|c|c|c|c|c|c|}
\hline n & Entitition & $\begin{array}{l}p_{1} \\
0,60\end{array}$ & $\begin{array}{l}\mathrm{P}_{2} \\
0,35\end{array}$ & $\begin{array}{l}p_{3} \\
0,05\end{array}$ & $\overline{A C}$ & $\begin{array}{l}P_{1} \\
0,60\end{array}$ & $\begin{array}{l}p_{2} \\
0,25\end{array}$ & $\begin{array}{l}P_{3} \\
0,15\end{array}$ & AC \\
\hline \multirow[t]{4}{*}{5} & & 361,19 & 401,20 & 6089,76 & 261,20 & 401,19 & 1080,94 & 2220,59 & 191,16 \\
\hline & & $(1)$ & $(*)$ & $(*)$ & $(*)$ & $(\omega)$ & $(*)$ & $(*)$ & $(\varphi)$ \\
\hline & 10 & 0,89 & 0,89 & 0,59 & 0,98 & 0,89 & 0,89 & 0,74 & 0,96 \\
\hline & $P_{99}$ & 1,00 & 1,00 & 0,59 & 1,00 & 1,00 & 0,89 & 0,89 & 0,99 \\
\hline \multirow[t]{4}{*}{10} & & 11,33 & 21,36 & 3900,18 & 1,27 & 11,30 & 81,23 & 600,95 & 1,13 \\
\hline & & $(*)$ & $(*)$ & $(*)$ & 1,46 & $(1)$ & $(*)$ & $(*)$ & 0,58 \\
\hline & $P_{g}$ & 0,94 & 0,94 & 0,64 & 0,99 & 0,94 & 0,88 & 0,80 & 0,96 \\
\hline & $P_{g}$ & 0,99 & 0,98 & 0,64 & 1,00 & 0,98 & 0,94 & 0,91 & 0,99 \\
\hline \multirow[t]{4}{*}{15} & & 1,14 & 1,15 & 2210,51 & 1,10 & 1,16 & 11,17 & 151,07 & 1,07 \\
\hline & & 0,46 & 0,54 & $(*)$ & 0,34 & 0,80 & $(*)$ & $(*)$ & 0,28 \\
\hline & & 0,95 & 0,94 & 0,61 & 0,99 & 0,95 & 0,90 & 0,79 & 0,97 \\
\hline & $P_{99}$ & 0,98 & 0,98 & 0,67 & 1,00 & 0,99 & 0,95 & 0,89 & 0,99 \\
\hline \multirow[t]{4}{*}{20} & & 1,08 & 1,09 & 1390,67 & 1,05 & 1,15 & 1,16 & 61,06 & 1,07 \\
\hline & & 0,36 & 0,32 & $(*)$ & 0,22 & 0,39 & 0,43 & $(*)$ & 0,17 \\
\hline & $P_{95}$ & 0,95 & 0,93 & 0,64 & 0,99 & 0,96 & 0,92 & 0,84 & 0,98 \\
\hline & $P_{99}$ & 0,99 & 0,99 & 0,69 & 1,00 & 0,99 & 0,98 & 0,91 & 0,99 \\
\hline \multirow[t]{4}{*}{25} & & 1,07 & 1,08 & 880,76 & 1,05 & 1,07 & 1,08 & $11,0 S$ & 1,03 \\
\hline & $S_{\mathrm{C}}$ & 0,24 & 0,24 & (") & 0,17 & 0,24 & 0,23 & $(*)$ & 0,12 \\
\hline & $P_{95}$ & 0,94 & 0,95 & 0,67 & 0,99 & 0,96 & 0,93 & 0,87 & 0,98 \\
\hline & $P_{99}$ & 0,99 & 0,99 & 0,71 & 1,00 & 0,99 & 0,97 & 0,93 & 1,00 \\
\hline \multirow[t]{4}{*}{30} & $\overline{\mathbf{C}}$ & 1,08 & 1,10 & 450,84 & 1,06 & 1,06 & 1,09 & 1,02 & 1,03 \\
\hline & $S_{C}^{2}$ & 0,18 & 0,20 & $(*)$ & 0,13 & 0,18 & 0,21 & 0,24 & 0,10 \\
\hline & $P_{95}$ & 0,94 & 0,95 & 0,69 & 0,99 & 0,96 & 0,92 & 0,87 & 0,98 \\
\hline & $\mathbf{P}_{99}$ & 0,99 & 0,99 & 0,73 & 1,00 & 0,99 & 0,96 & 0,92 & 1,00 \\
\hline
\end{tabular}


TABELA 13 - Distribuição do nivel de significância no teste da hipótese $\mathrm{H}_{0}: \mathrm{F}=0$, em $\mathrm{N}=1000$ experimentos com amostras de tamanhos diferentes extraídas em populaç̃es não endogâmicas de três alelos e diversas frequências gênicas, nas análises individuais e na análise conjunta.

\begin{tabular}{|c|c|c|c|c|c|c|c|c|c|}
\hline $\bar{n}$ & Estatistica & $\begin{array}{l}P_{1} \\
0,60\end{array}$ & $\begin{array}{l}P_{2} \\
0,35\end{array}$ & $\begin{array}{l}P_{3} \\
0,05\end{array}$ & $\overline{A C}$ & $\begin{array}{l}P_{1} \\
0,60\end{array}$ & $\begin{array}{l}P_{2} \\
0,25\end{array}$ & $\begin{array}{l}P_{3} \\
0,15\end{array}$ & $\overline{A C}$ \\
\hline \multirow[t]{4}{*}{35} & $\overline{\overline{\mathbf{C}}}$ & 1,06 & 1,07 & 290,87 & 1,04 & 1,06 & 1,07 & 0,99 & 1,02 \\
\hline & $S^{2}$ & 0,17 & 0,17 & $(*)$ & 0,11 & 0,13 & 0,19 & 0,13 & 0,07 \\
\hline & Pos & 0,96 & 0,95 & 0,71 & 0,99 & 0,96 & 0,94 & 0,87 & 0,98 \\
\hline & $P_{99}$ & 0,99 & 0,99 & 0,75 & 1,00 & 0,99 & 0,98 & 0,94 & 1,00 \\
\hline \multirow[t]{4}{*}{40} & 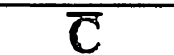 & 1,05 & 1,06 & 250,88 & 1,04 & 1,04 & 1,05 & 0,99 & 1,01 \\
\hline & $S^{2}$ & 0,12 & 0,13 & $(*)$ & 0,09 & 0,12 & 0,14 & 0,13 & 0,06 \\
\hline & $P_{0 s}$ & 0,95 & 0,94 & 0,69 & 0,99 & 0,95 & 0,94 & 0,89 & 0,98 \\
\hline & $P_{99}$ & 0,99 & 0,99 & 0,76 & 1,00 & 0,99 & 0,98 & 0,93 & 1,00 \\
\hline \multirow[t]{4}{*}{45} & $\overline{\mathbf{C}}$ & 1,04 & 1,05 & 120,90 & 1,02 & 1,04 & 1,04 & 1,00 & 1,01 \\
\hline & $S_{C}^{2}$ & 0,11 & 0,11 & $(*)$ & 0,08 & 0,12 & 0,12 & 0,11 & 0,06 \\
\hline & $P_{95}$ & 0,95 & 0,94 & 0,71 & 0,99 & 0,95 & 0,95 & 0,90 & 0,98 \\
\hline & $\mathrm{P}_{99}$ & 0,99 & 0,98 & 0,74 & 1,00 & 0,99 & 0,98 & 0,95 & 1,00 \\
\hline \multirow[t]{4}{*}{50} & $\overline{\mathbf{C}}$ & 1,04 & 1,05 & 50,91 & 1,02 & 1,03 & 1,06 & 0,98 & 1,01 \\
\hline & $S_{C}^{2}$ & 0,10 & 0,11 & $(*)$ & 0,08 & 0,10 & 0,11 & 0,10 & 0,06 \\
\hline & $P_{95}$ & 0,95 & 0,95 & 0,70 & 0,99 & 0,96 & 0,99 & 0,92 & 0,98 \\
\hline & $P_{99}$ & 0,99 & 0,99 & 0,76 & 1,00 & 0,99 & 0,98 & 0,96 & 1,00 \\
\hline \multirow[t]{4}{*}{75} & $\overline{\bar{C}}$ & 1,02 & 1,03 & 10,92 & 1,01 & 1,01 & 1,03 & 0,97 & 1,00 \\
\hline & $S_{C}^{2}$ & 0,06 & 0,06 & 0,12 & 0,04 & 0,06 & 0,06 & 0,05 & 0,03 \\
\hline & $P_{95}$ & 0,95 & 0,94 & 0,75 & 0,99 & 0,96 & 0,95 & 0,93 & 0,99 \\
\hline & $P_{99}$ & 0,99 & 0,98 & 0,77 & 1,00 & 0,99 & 0,98 & 0,96 & 1,00 \\
\hline \multirow[t]{4}{*}{100} & $\overline{\mathbf{C}}$ & 1,02 & 1,03 & 0,91 & 1,01 & 1,01 & 1,03 & 0,97 & 1,00 \\
\hline & $\mathbf{S}_{\mathrm{C}}^{2}$ & 0,05 & 0,05 & 0,08 & 0,04 & 0,05 & 0,05 & 0,04 & 0,02 \\
\hline & $P_{95}$ & 0,96 & 0,95 & 0,77 & 0,99 & 0,96 & 0,93 & 0,94 & 0,99 \\
\hline & $P_{99}$ & 0,99 & 0,99 & 0,81 & 1,00 & 0,99 & 0,99 & 0,97 & 1,00 \\
\hline
\end{tabular}


TABELA 13 - Distribuição do nivel de significância no reste ds hipótese $\mathrm{H}_{0}: \mathrm{F}=0$, em $\mathrm{N}=1000$ experimentos com amostras de tamanhos diferentes extraidas em populacōes não endogâmicas de três alelos e diversas frequências gênicas, nas andilises individuais e no análise conjunta.

\begin{tabular}{|c|c|c|c|c|c|c|c|c|c|}
\hline D & Extian & $\begin{array}{l}p_{1} \\
0,60\end{array}$ & $\begin{array}{c}p 2 \\
0,35 \\
\end{array}$ & $\begin{array}{r}p_{3} \\
0,05 \\
\end{array}$ & $\overline{A C}$ & $\begin{array}{c}p_{1} \\
0,60 \\
\end{array}$ & $\begin{array}{c}p_{3} \\
0,25 \\
\end{array}$ & $\begin{array}{c}p_{3} \\
0,15\end{array}$ & $A C$ \\
\hline \multirow[t]{4}{*}{150} & $\overline{\mathbf{C}}$ & 1,01 & 1,02 & 0,91 & 1,00 & 1,00 & 1,03 & 0,95 & 0,99 \\
\hline & $\mathbf{S}_{\mathrm{C}}^{2}$ & 0,03 & 0,03 & 0,06 & 0,02 & 0,03 & 0,03 & 0,02 & 0,02 \\
\hline & $P_{95}$ & 0,95 & 0,94 & 0,81 & 0,99 & 0,96 & 0,94 & 0,96 & 0,99 \\
\hline & $\mathrm{P}_{99}$ & 0,99 & 0,99 & 0,83 & 1,00 & 0,99 & 0,98 & 0,98 & 1,00 \\
\hline \multirow[t]{4}{*}{200} & $\overline{\mathbf{C}}$ & 1,00 & 1,01 & 0,91 & 1,00 & 0,99 & 1,01 & 0,95 & 0,99 \\
\hline & $\mathbf{S}_{\mathrm{C}}^{2}$ & 0,02 & 0,02 & 0,04 & 0,02 & 0,02 & 0,02 & 0,02 & 0,01 \\
\hline & $P_{95}$ & 0,96 & 0,96 & 0,83 & 0,99 & 0,95 & 0,94 & 0,96 & 0,99 \\
\hline & $P_{99}$ & 0,99 & 0,99 & 0,86 & 1,00 & 0,99 & 0,98 & 0,99 & 1,00 \\
\hline \multirow[t]{4}{*}{300} & $\overline{\mathbf{C}}$ & 1,00 & 1,01 & 0,91 & 1,00 & 0,99 & 1,00 & 0,95 & 0,99 \\
\hline & $\mathbf{S}_{\mathrm{C}}^{2}$ & 0,01 & 0,01 & 0,02 & 0,01 & 0,01 & 0,01 & 0,01 & 0,01 \\
\hline & $P_{95}$ & 0,95 & 0,94 & 0,86 & 0,99 & 0,95 & 0,95 & 0,97 & 0,99 \\
\hline & $P_{99}$ & 0,99 & 0,98 & 0,89 & 1,00 & 0,99 & 0,99 & 0,99 & 1,00 \\
\hline \multirow[t]{4}{*}{400} & $\overline{\mathbf{C}}$ & 1,00 & 1,02 & 0,91 & 1,00 & 1,00 & 1,00 & 0,95 & 0,98 \\
\hline & $\mathbf{S}_{\mathrm{C}}^{2}$ & 0,01 & 0,01 & 0,01 & 0,01 & 0,01 & 0,01 & 0,01 & 0,01 \\
\hline & $\mathrm{P}_{95}$ & 0,95 & 0,94 & 0,89 & 0,99 & 0,93 & 0,95 & 0,97 & 0,99 \\
\hline & $P_{99}$ & 0,99 & 0,99 & 0,91 & 1,00 & 0,99 & 0,98 & 0,99 & 1,00 \\
\hline \multirow[t]{4}{*}{500} & $\overline{\overline{\mathbf{C}}}$ & 1,00 & 1,01 & 0,91 & 1,00 & 1,00 & 1,01 & 0,93 & 0,99 \\
\hline & $S_{C}^{2}$ & 0,01 & 0,01 & 0,01 & 0,01 & 0,01 & 0,01 & 0,01 & 0,01 \\
\hline & $P_{95}$ & 0,96 & 0,96 & 0,91 & 0,99 & 0,96 & 0,95 & 0,98 & 0,99 \\
\hline & $P_{99}$ & 0,99 & 0,99 & 0,92 & 1,00 & 0,99 & 0,99 & 0,99 & 1,00 \\
\hline
\end{tabular}


TABELA 13 - Distribuição do nivel de significância no teste da hipótese $\mathrm{H}_{0}: \mathrm{F}=0$, em $\mathrm{N}=1000$ experimentos com amostras de tamanhos diferentes extrádas em populações não endogâmicas de três alelos e diversas frequências gênicas, nas análises individuais e na análise conjunta.

\begin{tabular}{|c|c|c|c|c|c|c|c|c|c|}
\hline $\mathbf{n}$ & Rotution & $\begin{array}{c}p_{1} \\
0,60 \\
251,2\end{array}$ & $\begin{array}{c}P_{2} \\
0,20 \\
50\end{array}$ & $\begin{array}{c}p_{3} \\
0,20 \\
3681\end{array}$ & AC & $\begin{array}{c}p_{1} \\
0,60 \\
20120\end{array}$ & $\begin{array}{c}P_{2} \\
0,39 \\
22126\end{array}$ & $\begin{array}{c}P_{3} \\
0,01 \\
015017\end{array}$ & काक \\
\hline \multirow{3}{*}{5} & $\mathrm{~S}^{2}$ & $\begin{array}{c}351,23 \\
(1)\end{array}$ & $\begin{array}{c}1500,80 \\
(*)\end{array}$ & $\begin{array}{c}1360,81 \\
(*)\end{array}$ & $\begin{array}{c}181,17 \\
(*)\end{array}$ & $\begin{array}{c}341,20 \\
(*)\end{array}$ & $\begin{array}{c}331,25 \\
(*)\end{array}$ & $\begin{array}{c}9129,17 \\
(4)\end{array}$ & $\begin{array}{c}321,22 \\
(1)\end{array}$ \\
\hline & $P_{0}$ & 0,89 & 0,74 & 0,74 & 0,97 & 0,89 & 0,89 & 0,49 & 0,99 \\
\hline & $P_{99}$ & 1,00 & 0,89 & 0,89 & 0,99 & 1,00 & 1,00 & 0,49 & 1,00 \\
\hline \multirow[t]{4}{*}{10} & & 1,29 & 171,21 & 211,11 & 1,12 & 11,31 & 11,33 & 843931 & 11,30 \\
\hline & & 1,32 & $(\omega)$ & $(*)$ & 0,46 & $(\bullet)$ & (H) & $(*)$ & $(*)$ \\
\hline & $P_{0 s}$ & 0,94 & 0,80 & 0,88 & 0,96 & 0,94 & 0,94 & 0,49 & 0,99 \\
\hline & $P_{99}$ & 0,98 & 0,94 & 0,88 & 0,99 & 0,98 & 0,98 & 0,49 & 1,00 \\
\hline \multirow[t]{4}{*}{15} & & 1,13 & 51,18 & 31,12 & 1,06 & 1,17 & 1,20 & 7809,44 & 1,18 \\
\hline & & 0,60 & (") & $(*)$ & 0,22 & 0,73 & 0,73 & $(*)$ & 0,70 \\
\hline & $P_{9 s}$ & 0,96 & 0,90 & 0,90 & 0,97 & 0,95 & 0,95 & 0,50 & 0,99 \\
\hline & $P_{99}$ & 0,99 & 0,94 & 0,94 & 0,99 & 0,98 & 0,99 & 0,55 & 1,00 \\
\hline \multirow[t]{4}{*}{20} & & 1,12 & 1,18 & 21,10 & 1,06 & 1,10 & 1,12 & 7209,56 & 1,10 \\
\hline & & 0,37 & 0,71 & (*) & 0,17 & 0,35 & 0,35 & $(*)$ & 0,34 \\
\hline & $P_{95}$ & 0,95 & 0,88 & 0,92 & 0,98 & 0,96 & 0,96 & 0,50 & 0,99 \\
\hline & $P_{99}$ & 0,99 & 0,94 & 0,96 & 0,99 & 0,99 & 0,99 & 0,54 & 1,00 \\
\hline \multirow[t]{4}{*}{25} & & 1,10 & 1,11 & 1,03 & 1,05 & 1,05 & 1,07 & 6339,69 & 1,6 \\
\hline & $S_{C}$ & 0,24 & 0,28 & 0,21 & 0,11 & 0,26 & 0,29 & $(*)$ & 0,26 \\
\hline & $P_{95}$ & 0,95 & 0,90 & 090 & 0,98 & 0,96 & 0,96 & 0,54 & 0,99 \\
\hline & $P_{99}$ & 0,99 & 0,95 & 0,95 & 0,99 & 0,99 & 0,99 & 0,56 & 1,00 \\
\hline \multirow[t]{4}{*}{30} & $\overline{\overline{\mathbf{C}}}$ & 1,06 & 1,08 & 1,03 & 1,02 & 1,06 & 1,08 & 5959,80 & 1,06 \\
\hline & $S_{C}^{2}$ & 0,18 & 0,21 & 0,17 & 0,08 & 0,18 & 0,20 & $(*)$ & 0,18 \\
\hline & $P_{95}$ & 0,96 & 0,90 & 0,92 & 0,98 & 0,96 & 0,94 & 0,54 & 0,99 \\
\hline & $P_{99}$ & 0,99 & 0,94 & 0,96 & 0,99 & 0,99 & 0,99 & 0,58 & 1,00 \\
\hline
\end{tabular}


TABELA 13 - Distribuiçảo do nivel de significância no teste da hipótese $\mathrm{H}_{0}: \mathrm{F}=0$, em $\mathrm{N}=1000$ experimentos com amostras de tamanhos diferentes extrádas em populaçes não endogâmicas de três alelos e diversas frequências gênicas, nas análises individuais e ns análise conjunta.

\begin{tabular}{|c|c|c|c|c|c|c|c|c|c|}
\hline n & Rstintic & $\begin{array}{c}p_{1} \\
0.60\end{array}$ & $\begin{array}{c}p_{2} \\
0,20\end{array}$ & $\begin{array}{c}P_{3} \\
0,20\end{array}$ & $\overline{A C}$ & $\begin{array}{c}p_{1} \\
0,60\end{array}$ & $\begin{array}{c}p_{2} \\
0,39\end{array}$ & $\begin{array}{c}P_{3} \\
0,01\end{array}$ & $\overline{A C}$ \\
\hline 35 & $\overline{\overline{\mathbf{C}}}$ & 1,06 & 1,05 & 1,03 & 1,02 & $\overline{1}, \overline{04}$ & 1,06 & 3539,89 & 1,05 \\
\hline \multirow[t]{3}{*}{. } & & 0,13 & 0,16 & 0,16 & 0,08 & 0,15 & 0,16 & () & 0,15 \\
\hline & $P_{95}$ & 0,96 & 0,92 & 0,92 & 0,98 & 0,96 & 0,95 & 0,53 & 0,99 \\
\hline & $P_{99}$ & 0,99 & 0,97 & 0,96 & 0,99 & 0,99 & 0,99 & 0,57 & 1,00 \\
\hline \multirow[t]{4}{*}{40} & $\bar{\pi}$ & 1,05 & 1,06 & 1,01 & 1,02 & 1,04 & 1,07 & 4770,04 & 1,05 \\
\hline & & 0,12 & 0,14 & 0,11 & 0,06 & 0,12 & 0,13 & $(*)$ & 0,11 \\
\hline & $P_{95}$ & 0,95 & 0,92 & 0,93 & 0,98 & 0,94 & 0,94 & 0,53 & 0,99 \\
\hline & $P_{99}$ & 0,99 & 0,96 & 0,97 & 0,99 & 0,99 & 0,99 & 0,56 & 1,00 \\
\hline \multirow[t]{4}{*}{45} & & 1,05 & 1,04 & 1,00 & 1,01 & 1,05 & 1,07 & 4550,08 & 1,06 \\
\hline & ${ }^{\Delta_{C}}$ & 0,11 & 0,11 & 0,10 & 0,03 & 0,10 & 0,11 & $(*)$ & 0,10 \\
\hline & & 0,95 & 0,93 & 0,95 & 0,98 & 0,95 & 0,94 & 0,53 & 0,99 \\
\hline & $P_{99}$ & 0,99 & 0,98 & 0,97 & 0,99 & 0,99 & 0,99 & 0,56 & 1,00 \\
\hline \multirow[t]{4}{*}{50} & & 1,02 & 1,05 & 1,01 & 1,00 & 1,01 & 1,03 & 4130,17 & 1,02 \\
\hline & $S_{c}$ & 0,09 & 0,11 & 0,09 & 0,05 & 0,09 & 0,10 & (*) & 0,09 \\
\hline & $P_{95}$ & 0,95 & 0,94 & 0,94 & 0,98 & 0,99 & 0,95 & 0,56 & 0,99 \\
\hline & $P_{99}$ & 0,99 & 0,97 & 0,97 & 1,00 & 0,99 & 0,99 & 0,59 & 1,00 \\
\hline \multirow[t]{4}{*}{75} & $\overline{\overline{\mathbf{C}}}$ & 1,02 & 1,03 & 0,97 & 1,00 & 1,02 & 1,04 & 2800,43 & 1,03 \\
\hline & & 0,06 & 0,06 & 0,05 & 0,03 & 0,06 & 0,06 & $(*)$ & 0,06 \\
\hline & $P_{95}$ & 0,95 & 0,94 & 0,95 & 0,99 & 0,95 & 0,94 & 0,54 & 0,99 \\
\hline & $P_{99}$ & 0,99 & 0,99 & 0,98 & 1,00 & 0,99 & 0,98 & 0,59 & 1,00 \\
\hline \multirow[t]{4}{*}{100} & $\overline{\overline{\mathrm{C}}}$ & 1,02 & 1,03 & 0,98 & 1,00 & 1,01 & 1,03 & 1580,67 & 1,02 \\
\hline & $\mathbf{S}_{\mathrm{C}}^{2}$ & 0,04 & 0,05 & 0,04 & 0,02 & 0,05 & 0,05 & $(*)$ & 0,04 \\
\hline & $P_{95}$ & 0,95 & 0,94 & 0,95 & 0,98 & 0,95 & 0,95 & 0,55 & 0,99 \\
\hline & $P_{99}$ & 0,99 & 0,98 & 0,98 & 1,00 & 0,99 & 0,99 & 0,59 & 1,00 \\
\hline
\end{tabular}


TABELA 13 - Distribuiģão do nivel de significância no teste da hipótese $\mathrm{H}_{0}: \mathrm{F}=0$, em $\mathrm{N}=1000$ experimentos com amostras de tamanhos diferentes extraídas em populaçoes não endogâmicas de três alelos e diversas frequências gênicas, nas andilises individuais e na análise conjunta.

\begin{tabular}{|c|c|c|c|c|c|c|c|c|c|}
\hline $\mathrm{n}$ & Extion & $\begin{array}{c}p_{1} \\
0,60\end{array}$ & $\begin{array}{c}p_{2} \\
0,20\end{array}$ & $\begin{array}{c}p_{3} \\
0,20\end{array}$ & $\overline{A C}$ & $\begin{array}{c}p_{1} \\
0,60\end{array}$ & $\begin{array}{c}p_{2} \\
0,39\end{array}$ & $\begin{array}{c}p_{3} \\
0,01\end{array}$ & $\overline{A C}$ \\
\hline \multirow[t]{4}{*}{150} & $\overline{\overline{\mathbf{C}}}$ & 1,01 & 1,01 & 0,97 & 0,99 & 1,00 & 1,02 & 630,86 & 1,01 \\
\hline & $\mathbf{S}_{\mathrm{C}}^{2}$ & 0,03 & 0,03 & 0,02 & 0,01 & 0,03 & 0,03 & $\left({ }^{(2)}\right.$ & 0,03 \\
\hline & $P_{95}$ & 0,95 & 0,93 & 0,96 & 0,98 & 0,95 & 0,93 & 0,58 & 0,99 \\
\hline & $P_{99}$ & 0,99 & 0,98 & 0,99 & 1,00 & 0,99 & 0,99 & 0,60 & 1,00 \\
\hline \multirow[t]{2}{*}{200} & $\overline{\mathbf{C}}$ & 1,00 & 1,01 & 0,97 & 0,99 & 1,00 & 1,02 & 180,95 & 1,01 \\
\hline & $\mathbf{S}_{\mathrm{C}}^{2}$ & 0,02 & 0,02 & 0,02 & 0,01 & 0,02 & 0,02 & $(*)$ & 0,02 \\
\hline \multirow[t]{2}{*}{$i$} & $P_{95}$ & 0,95 & 0,95 & 0,96 & 0,99 & 0,95 & 0,95 & 0,58 & 1,00 \\
\hline & $P_{99}$ & 0,99 & 0,98 & 0,99 & 1,00 & 0,99 & 0,99 & 0,60 & 1,00 \\
\hline \multirow[t]{4}{*}{300} & $\overline{\mathrm{C}}$ & 1,00 & 1,01 & 0,97 & 0,99 & 1,00 & 0,02 & 40,98 & 1,01 \\
\hline & $\mathbf{S}_{\mathrm{C}}^{2}$ & 0,01 & 0,01 & 0,01 & 0,01 & 0,01 & 0,01 & $(*)$ & 0,01 \\
\hline & $P_{95}$ & 0,96 & 0,94 & 0,97 & 0,99 & 0,95 & 0,93 & 0,59 & 0,99 \\
\hline & $P_{99}$ & 0,99 & 0,98 & 0,99 & 1,00 & 0,99 & 0,98 & 0,62 & 1,00 \\
\hline \multirow[t]{4}{*}{400} & $\overline{\mathbf{C}}$ & 0,99 & 1,01 & 0,97 & 0,99 & 0,99 & 1,01 & 50,97 & 1,00 \\
\hline & $\mathbf{S}_{\mathrm{C}}^{2}$ & 0,01 & 0,01 & 0,01 & 0,01 & 0,01 & 0,01 & $(")$ & 0,01 \\
\hline & $P_{95}$ & 0,96 & 0,94 & 0,96 & 0,99 & 0,96 & 0,95 & 0,61 & 1,00 \\
\hline & $P_{99}$ & 0,99 & 0,98 & 0,99 & 1,00 & 0,99 & 0,99 & 0,63 & 1,00 \\
\hline \multirow[t]{4}{*}{500} & $\overline{\mathbf{C}}$ & 0,99 & 1,00 & 0,97 & 0,99 & 0,99 & 1,01 & 0,98 & 1,00 \\
\hline & $\mathrm{S}_{\mathrm{C}}^{2}$ & 0,01 & 0,01 & 0,01 & 0,01 & 0,01 & 0,01 & 0,01 & 0,01 \\
\hline & $P_{95}$ & 0,96 & 0,95 & 0,97 & 0,99 & 0,97 & 0,95 & 0,61 & 1,00 \\
\hline & $P_{99}$ & 0,99 & 0,99 & 0,99 & 1,00 & 0,99 & 0,99 & 0,64 & 1,00 \\
\hline
\end{tabular}


TABELA 13 - Distribuição do nivel de significância no reste da hipótese $H_{0}: F=0$, em $N=1000$ experimentos com amostras de tamanhos diferentes extraídas em populasőes não endogâmicas de três alelos e diversas frequências gếnicas, nas and́lises individuais e na análise conjunta.

\begin{tabular}{|c|c|c|c|c|c|}
\hline D & Extion & $\begin{array}{c}p_{1} \\
0,50\end{array}$ & $\begin{array}{c}p_{2} \\
0,30\end{array}$ & $\begin{array}{c}p_{3} \\
0,20\end{array}$ & $\overline{A C}$ \\
\hline \multirow[t]{3}{*}{5} & $\begin{array}{c}\bar{C} \\
S_{c}^{2}\end{array}$ & $\begin{array}{c}211,30 \\
(*)\end{array}$ & $\begin{array}{c}711,03 \\
(")\end{array}$ & $\begin{array}{c}1340,77 \\
(7)\end{array}$ & $\begin{array}{c}41,20 \\
\left({ }^{*}\right)\end{array}$ \\
\hline & $P_{9 s}$ & 0,89 & 0,89 & 0,74 & 0,98 \\
\hline & $P_{99}$ & 1,00 & 1,00 & 0,89 & 0,99 \\
\hline \multirow[t]{4}{*}{10} & $\overline{\mathbf{C}}$ & 1,25 & 51,25 & 211,13 & 1,10 \\
\hline & $\mathbf{S}_{\mathrm{C}}^{2}$ & 1,27 & $(*)$ & $(*)$ & $(*)$ \\
\hline & $P_{95}$ & 0,96 & 0,94 & 0,80 & 0,98 \\
\hline & $P_{99}$ & 0.99 & 0.98 & 0,94 & 0,99 \\
\hline \multirow[t]{4}{*}{15} & $\overline{\mathbf{C}}$ & 1,12 & 1,17 & 21,09 & 1,05 \\
\hline & $\mathbf{S}_{\mathrm{C}}^{2}$ & 0,49 & 0,53 & $(*)$ & 0,20 \\
\hline & $P_{95}$ & 0,96 & 0,92 & 0,90 & 0,98 \\
\hline & $P_{99}$ & 0,99 & 0,97 & 0,94 & 0,99 \\
\hline \multirow[t]{4}{*}{20} & $\overline{\mathbf{C}}$ & 1,09 & 1,12 & 1,10 & 1,03 \\
\hline & $S_{C}^{2}$ & 0,34 & 0,44 & 0,46 & 0,14 \\
\hline & $P_{95}$ & 0,96 & 0,94 & 0,92 & 0,98 \\
\hline & $P_{99}$ & 0,99 & 0,98 & 0,96 & 0,99 \\
\hline \multirow[t]{4}{*}{25} & $\overline{\mathbf{C}}$ & 1,06 & 1,06 & 1,02 & 1,01 \\
\hline & $S_{C}^{2}$ & 0,20 & 0,19 & 0,20 & 0,09 \\
\hline & $\mathrm{P}_{95}$ & 0,96 & 0,94 & 0,90 & 0,98 \\
\hline & $P_{99}$ & 0,99 & 0,98 & 0,95 & 0,99 \\
\hline \multirow[t]{4}{*}{30} & $\overline{\mathbf{C}}$ & 1,09 & 1,07 & 1,07 & 1,04 \\
\hline & $S_{C}^{2}$ & 0,22 & 0,21 & 0,30 & 0,10 \\
\hline & $P_{95}$ & 0,96 & 0,95 & 0,92 & 0,98 \\
\hline & $P_{99}$ & 0,99 & 0,99 & 0,96 & 0,99 \\
\hline
\end{tabular}


TABELA 13 - Distribuição do nivel de significância no teste da hipótese $\mathrm{H}_{0}: \mathrm{F}=0$, em $\mathrm{N}=1000$ experimentos com amostras de tamanhos diferentes extraídas em populacỏes não endogâmicas de três alelos e diversas frequências gênicas, nas análises individuais e na análise conjunta

\begin{tabular}{|c|c|c|c|c|c|}
\hline $\bar{D}$ & Roturitic & $\begin{array}{c}p_{1} \\
0,50\end{array}$ & $\begin{array}{c}p_{3} \\
0,30\end{array}$ & $\begin{array}{c}p_{3} \\
0,20\end{array}$ & $\overline{A C}$ \\
\hline \multirow[t]{4}{*}{35} & $\overline{\mathbf{C}}$ & 1,06 & 1,06 & 1,04 & 1,02 \\
\hline & $\mathbf{S}_{\mathrm{C}}^{2}$ & 0,15 & 0,16 & 0,16 & 0,07 \\
\hline & $P_{g s}$ & 0,95 & 0,94 & 0,93 & 0,98 \\
\hline & $P_{99}$ & 0,99 & 0,98 & 0,97 & 0,99 \\
\hline \multirow[t]{4}{*}{40} & $\overline{\mathbf{C}}$ & 1,04 & 1,06 & 1,03 & 1,02 \\
\hline & $S_{C}^{2}$ & 0,12 & 0,16 & 0,16 & 0,07 \\
\hline & $P_{95}$ & 0,95 & 0,94 & 0,93 & 0,98 \\
\hline & $P_{99}$ & 0,99 & 0,99 & 0,96 & 0,99 \\
\hline \multirow[t]{4}{*}{45} & $\overline{\overline{\mathbf{C}}}$ & 1,05 & 1,05 & 1,01 & 1,02 \\
\hline & $\mathbf{S}_{\mathrm{C}}^{2}$ & 0,10 & 0,11 & 0,10 & 0,05 \\
\hline & $P_{9 s}$ & 0,95 & 0,94 & 0,93 & 0,98 \\
\hline & $P_{99}$ & 0,99 & 0,99 & 0,97 & 1,00 \\
\hline \multirow[t]{4}{*}{50} & $\overline{\mathbf{C}}$ & 1,03 & 1,03 & 1,00 & 1,00 \\
\hline & $\mathbf{S}_{\mathrm{C}}^{2}$ & 0,09 & 0,10 & 0,09 & 0,05 \\
\hline & $\mathrm{P}_{93}$ & 0,96 & 0,95 & 0,93 & 0,98 \\
\hline & $\mathrm{P}_{99}$ & 0,99 & 0,98 & 0,97 & 1,00 \\
\hline \multirow[t]{4}{*}{75} & $\overline{\overline{\mathbf{C}}}$ & 1,03 & 1,03 & 1,00 & 1,01 \\
\hline & $\mathbf{S}_{\mathrm{C}}^{2}$ & 0,05 & 0,06 & 0,06 & 0,03 \\
\hline & $P_{95}$ & 0,93 & 0,94 & 0,95 & 0,97 \\
\hline & $P_{99}$ & 0,98 & 0,98 & 0,98 & 0,99 \\
\hline \multirow[t]{4}{*}{100} & $\overline{\mathbf{C}}$ & 1,02 & 1,02 & 0,99 & 1,00 \\
\hline & $\mathbf{S}_{\mathrm{C}}^{2}$ & 0,04 & 0,05 & 0,04 & 0,02 \\
\hline & $P_{95}$ & 0,94 & 0,95 & 0,96 & 0,98 \\
\hline & $\mathrm{P}_{99}$ & 0,99 & 0,99 & 0,98 & 1,00 \\
\hline
\end{tabular}


TABELA 13 - Distribuição do nível de significância no teste da hipótese $\mathrm{H}_{0}: \mathrm{F}=0$, em $\mathrm{N}=1000$ experimentos com amostres de tamanhos diferentes extraldas em populaçōes não endogâmicas de três alelos e diversas frequências gênicas, nas and́lises individuais e na análise conjunta.

\begin{tabular}{|c|c|c|c|c|c|}
\hline n & Edtion & $\begin{array}{c}p_{1} \\
0,50\end{array}$ & $\begin{array}{c}p 2 \\
0,30\end{array}$ & $\begin{array}{c}p_{3} \\
0,20\end{array}$ & AC \\
\hline \multirow[t]{4}{*}{150} & $\overline{\mathbf{C}}$ & 1,02 & 1,02 & 0,98 & 1,00 \\
\hline & $\mathbf{S}_{\mathrm{C}}^{2}$ & 0,03 & 0,03 & 0,03 & 0,02 \\
\hline & $P_{9 s}$ & 0,94 & 0,94 & 0,96 & 0,98 \\
\hline & $\mathrm{P}_{99}$ & 0,99 & 0,99 & 0,99 & 1,00 \\
\hline \multirow[t]{4}{*}{200} & $\overline{\mathbf{C}}$ & 1,00 & 1,01 & 0,98 & 1,00 \\
\hline & $S_{C}^{2}$ & 0,02 & 0,02 & 0,02 & 0,01 \\
\hline & $P_{95}$ & 0,93 & 0,95 & 0,96 & 0,98 \\
\hline & $\mathrm{P}_{99}$ & 0,99 & 0,99 & 0,99 & 1,00 \\
\hline \multirow[t]{4}{*}{300} & $\overline{\mathbf{C}}$ & 1,00 & 1,00 & 0,97 & 1,00 \\
\hline & $\mathrm{S}_{\mathrm{C}}^{2}$ & 0,01 & 0,01 & 0,01 & 0,01 \\
\hline & $P_{95}$ & 0,96 & 0,95 & 0,96 & 0,99 \\
\hline & $P_{99}$ & 0,99 & 0,99 & 0,99 & 1,00 \\
\hline \multirow[t]{4}{*}{400} & $\overline{\mathbf{C}}$ & 1,00 & 1,01 & 0,97 & 1,00 \\
\hline & $S_{C}^{2}$ & 0,01 & 0,01 & 0,01 & 0,01 \\
\hline & $P_{95}$ & 0,95 & 0,93 & 0,97 & 0,98 \\
\hline & $P_{99}$ & 0,99 & 0,99 & 0,99 & 1,00 \\
\hline \multirow[t]{4}{*}{300} & $\overline{\mathbf{C}}$ & 1,00 & 1,00 & 0,97 & 0,99 \\
\hline & $\mathbf{S}_{\mathbf{C}}^{2}$ & 0,01 & 0,01 & 0,01 & 0,01 \\
\hline & $P_{95}$ & 0,96 & 0,95 & 0,97 & 0,99 \\
\hline & $\mathrm{P}_{99}$ & 0,99 & 0,99 & 0,99 & 1,00 \\
\hline
\end{tabular}




\subsection{Amostras de individuos de populações diferentes}

\subsubsection{Obtenção das esperanças dos quadrados médios na anf́lise de variâncla das frequêtncias gênicas de amostras de indfúduos de populaçōes diferentes}

A and́lise de variância apresentada na Tabela 5 corresponde à análise de um experimento hierárquico com o primeiro fator hierárquico tendo n níveis e o segundo 2 níveis. Para esta análise, de acordo com os procedimentos da Estatística Experimental e as expressões de WEIR (1990), as somas de quadrados são definidas por:

SQPopulacões $\quad=\frac{1}{2 n} \sum_{i=1}^{r} y_{i}^{2}-\frac{1}{2 r n}\left(\sum_{i j k} y_{i j k}\right)^{2}=2 n \sum_{i=1}^{r}\left(\hat{p}_{A_{i}}-\hat{p}_{A}\right)^{2}$

SQIndividuos d. Pop. $=\frac{1}{2} \sum_{\mathrm{ij}} \mathrm{y}_{\mathrm{ij} .}^{2}-\frac{1}{2 n} \sum_{\mathrm{i}=1}^{\mathrm{r}} \mathrm{y}_{\mathrm{i} .}^{2} \quad=\mathrm{n} \sum_{\mathrm{i}=1}^{\mathrm{r}}\left[\hat{\mathrm{p}}_{\mathrm{A}_{\mathrm{i}}}+\hat{\mathrm{p}}_{\mathrm{AA}_{\mathrm{i}}}-2 \hat{\mathrm{p}}_{\mathrm{A}_{\mathrm{i}}}^{2}\right]$

SQGenes d. Ind. $\quad=\sum_{\mathrm{ijk}} \mathrm{y}_{\mathrm{ijk}}^{2}-\frac{1}{2} \sum_{\mathrm{ij}} \mathrm{y}_{\mathrm{ij} .}^{2} \quad=\mathrm{n} \sum_{\mathrm{i}=1}^{\mathrm{r}}\left[\hat{\mathrm{p}}_{\mathrm{A}_{\mathrm{i}}}-\hat{\mathrm{p}}_{\mathrm{AA}}\right]$

sendo:

$\hat{p}_{A}$ a frequência gênica estimada do alelo $A$ em todas as populações;

$\hat{p}_{A_{i}}$ a frequência gênica estimada do alelo $A$ na população $i$;

$\hat{\mathrm{p}}_{\mathrm{AA}_{1}}$ a frequência estimada de indivíduos homozigóticos em relação 80 alelo $A$, na população i .

A expressão da soma de quadrados de populaçōes pode ainda ser escrita como: 


$$
\text { SQPopulafoes }=2 n \sum_{i=1}^{8} \hat{p}_{\Lambda_{1}}^{2}-\frac{2 n}{r}\left(\sum_{j=1}^{r} \hat{p}_{\Lambda_{1}}\right)^{2}=(a)-(b) .
$$

A esperança matemática de SQPopulaçōes é feita obtendo as esperanças de (a) e de (b).

$$
E[a]=E\left[2 n \sum_{i=1}^{x} \hat{p}_{A_{1}}^{2}\right]=2 n \sum_{i=1}^{x} E\left[\hat{p}_{A_{1}}^{2}\right]
$$

De acordo com WEIR (1990), o valor esperado da frequéncia gênica amostral ao quadrado deve refletir os dois níveis de relacionamento dos diferentes genes dentro das populafỏes, ambos consequência da amostragem genética. Assim,

$$
E\left[\hat{p}_{A_{1}}^{2}\right]=p_{A}^{2}+p_{A}\left(1-p_{A}\right) \theta+\frac{1}{2 n} p_{A}\left(1-p_{A}\right)(1+F-2 \theta)
$$

e portanto,

$$
\begin{aligned}
E[a] & =2 n p_{A}^{2}+2 n r p_{A}\left(1-p_{A}\right) \theta+\operatorname{rp}_{A}\left(1-p_{A}\right)(1+F-2 \theta) \\
E[b] & =E\left[\frac{2 n}{r}\left(\sum_{i=1}^{x} \hat{p}_{A_{1}}\right)^{2}\right]=\frac{2 n}{r} E\left[\left(\sum_{i=1}^{x} \hat{p}_{A_{1}}\right)^{2}\right] \\
& =2 n r p_{A}^{2}+2 n p_{A}\left(1-p_{A}\right) \theta+p_{A}\left(1-p_{A}\right)(1+F-2 \theta)
\end{aligned}
$$


Reunindo-se os resultados de $\mathrm{E}(\mathrm{a})$ e $\mathrm{E}(\mathrm{b})$, obtem-se:

$E[S Q P o p u l a g ̊ ̋ e s]=E[a]-E[b]$

$$
=(r-1) p_{A}\left(1-p_{A}\right)[(1-F)+2(F-\theta)+2 n \theta] .
$$

A esperança matemática de SQIndivíduos d. Pop. é obtida fazendo:

E[SQInd. d. Pop. $]=E\left\{n \sum_{i=1}^{x}\left[\hat{p}_{A_{1}}+\hat{p}_{A_{A_{1}}}-2 \hat{p}_{A_{1}}^{2}\right]\right\}$

$$
\begin{aligned}
& =n \sum_{i=1}^{r} E\left[\hat{p}_{A_{i}}\right]+n \sum_{i=1}^{r} E\left[\hat{p}_{A_{A_{i}}}\right]-2 n \sum_{i=1}^{r} E\left[\hat{p}_{A_{i}}^{2}\right] \\
& =r(n-1) p_{A}\left(1-p_{A}\right)[(1-F)+2(F-\theta)] .
\end{aligned}
$$

No caso da SQGenes d. Ind., tem-se:

$$
\begin{aligned}
E[\text { SQGenes d. Ind. }] & =E\left\{n \sum_{i=1}^{r}\left[\hat{p}_{A_{i}}-\hat{p}_{A A_{i}}\right]\right\} \\
& =n r p_{A}\left(1-p_{A}\right)[1-F]
\end{aligned}
$$

Portanto, desconsiderando o índice $A$, os valores esperados dos quadrados médios na análise de variôncia para as frequências gênicas de uma amostra de indivíduos de populafões diferentes, são os seguintes: 
$\mathrm{E}\left[\mathrm{QM}\right.$ Populaø̃oes] $\quad=\frac{1}{\mathrm{r}-1} \mathrm{E}[\mathrm{SQ}$ Populą̧סes $]$

$$
=p(1-p)[(1-F)+2(F-\theta)+2 n \theta] .
$$

$\mathrm{E}[\mathrm{QM}$ Indivíduos d. Pop. $]=\frac{1}{\mathrm{r}(\mathrm{n}-1)} \mathrm{E}[\mathrm{SQ}$ Individuos d. Pop. $]$

$$
=p(1-p)[(1-F)+2(F-\theta)] e
$$

$\mathrm{E}[\mathrm{QMGenes} \mathrm{d}$. Ind. $] \quad=\frac{1}{\mathrm{r} \mathbf{n}} \mathrm{E}[$ SQGenes d. Ind. $]$

$$
=p(1-p)[1-F] \text {. }
$$

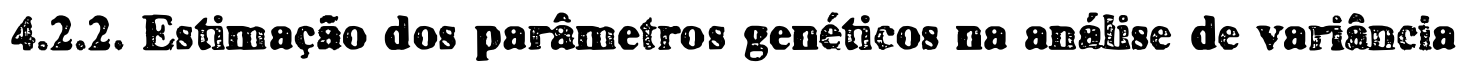
das frequências gênicas de amostras de indivíduos de populaçōes diferentes

$\mathrm{Na}$ análise de variância apresentada na Tabela 5 pode ser identificado o componente de variância devido a genes

$$
\sigma_{\mathrm{G}}^{2}=\mathrm{p}(1-\mathrm{p})[1-\mathrm{F}] \text {, }
$$

que é estimado pelo método dos momentos por: 


$$
\hat{\sigma}_{\mathrm{G}}^{2}=\text { QMG. }
$$

O componente de variância devido a individuos

$$
\sigma_{1}^{2}=p(1-p)(F-\theta) \text {, }
$$

é estimado através do método dos momentos por:

$$
\hat{\sigma}_{\mathrm{I}}^{2}=\frac{\mathrm{QMI}-\mathrm{QMG}}{2} .
$$

O componente de variância devido a populações

$$
\sigma_{\mathrm{P}}^{2}=\mathrm{p}(1-\mathrm{p}) \theta
$$

tem estimativa pelo método dos momentos dada por

$$
\hat{\sigma}_{\mathbf{P}}^{2}=\frac{\mathrm{QMP}-\mathrm{QMI}}{2 \mathrm{n}} .
$$

A soma dos componentes de variância devido a genes, a indivíduos e a população, fornece a variância total dada por

$$
\sigma^{2}=\sigma_{\mathrm{G}}^{2}+\sigma_{\mathrm{I}}^{2}+\sigma_{\mathrm{p}}^{2}=\mathrm{p}(1-\mathrm{p})(1-\mathrm{F})+\mathrm{p}(1-\mathrm{p})(\mathrm{F}-\theta)+\mathrm{p}(1-\mathrm{p}) \theta=\mathrm{p}(1-\mathrm{p}) .
$$


que é estimada por

$\hat{\sigma}^{2}=\mathrm{QMG}+\frac{\mathrm{QMI}-\mathrm{QMO}}{2}+\frac{\mathrm{QMP}-\mathrm{QMI}}{2 \mathrm{n}}=\frac{\mathrm{QMP}+(\mathrm{n}-1) \mathrm{QMI}+\mathrm{n} \mathbf{Q} \mathbf{M G}}{2 \mathrm{n}}$.

O quociente entre o componente de variância devido a populafões e a variância total fornece o valor paramétrico do coeficiente de coancestria $\theta$, isto é,

$$
\frac{\sigma_{\mathrm{p}}^{2}}{\sigma^{2}}=\frac{p(1-p) \theta}{p(1-p)}=\theta
$$

Assim, utilizando-se a aproximação que considera a estimativa de um quociente como sendo o quociente das estimativas, encontra-se a estimativa de $\theta$ dada pela seguinte expressão:

$$
\hat{\theta}=\frac{\hat{\sigma}_{\mathrm{p}}}{\hat{\sigma}^{2}}=\frac{\mathrm{QMP}-\mathrm{QMI}}{\mathrm{QMP}+(\mathrm{n}-1) \mathrm{QMI}+\mathrm{nQMG}}
$$

O componente de variância devido a genes pode ser escrito

como

$$
\sigma_{\mathrm{G}}^{2}=\mathrm{p}(1-\mathrm{p})(1-\mathrm{F})=\sigma^{2}-\mathrm{F} \sigma^{2} \text {. }
$$

que fornece 


$$
F=1-\frac{\sigma_{\sigma}^{2}}{\sigma^{2}}
$$

e portanto a estimativa do coeficiente de endogamia de todos os indivíduos das populagões, $F$, é a seguinte:

$$
\hat{\mathrm{F}}=1-\frac{\hat{\sigma_{\mathrm{G}}}}{\hat{\sigma}^{2}}=1-\frac{2 \mathrm{QMG}}{\mathrm{QMP}+(\mathrm{n}-1) \mathrm{QMI}+\mathrm{nQMG}} .
$$

O quociente entre o componente de variância devido a indivíduos e a soma dos componentes de variância devido a genes e devido a individuos

$$
\frac{\sigma_{I}^{2}}{\sigma_{\mathrm{I}}^{2}+\sigma_{\mathrm{I}}^{2}}=\frac{\mathrm{p}(1-\mathrm{p})(\mathrm{F}-\theta)}{\mathrm{p}(1-\mathrm{p})(1-\mathrm{F})+\mathrm{p}(1-\mathrm{p})(\mathrm{F}-\theta)}=\frac{\mathrm{F}-\theta}{1-\theta}=f
$$

fornece o coeficiente de endogmia dos indivíduos dentro das populações, que é estimado por:

$$
\hat{\mathbf{f}}=\frac{\hat{\sigma}_{\mathrm{I}}^{2}}{\hat{\sigma}_{\mathrm{G}}^{2}+\hat{\sigma}_{\mathrm{I}}^{2}}=\frac{1 / 2(\mathrm{QMI}-\mathrm{QMG})}{\mathrm{QMG}+1 / 2(\mathrm{QMI}-\mathrm{QMG})}=\frac{\mathrm{QMI}-\mathrm{QMG}}{\mathrm{QMI}+\mathrm{QMG}} .
$$


4.2.3. Estimação da tara de fecundação crumado ma antilise de varlância com das frequências gênicas de amoutras de Individuos de populaçóes diferentes

No modelo em questân, adnitindo-se equilibrio de Wright, isto $\dot{E}$, equilfbrio com endogamia, a taxa de fecundação cruzada $t$, se relaciona com f através da seguinte expressåo:

$$
f=\frac{1-t}{1+t},
$$

a qual pode ser resolvida em termos de $t$ fornecendo

$$
t=\frac{1-f}{1+f} .
$$

Portanto, uma vez obtida uma estimativa de $f$, ela pode ser urilizada para fornecer uma estimativa de $t$ como segue:

$$
\hat{\mathbf{t}}=\frac{1-\hat{\mathrm{f}}}{1+\hat{\mathrm{f}}} .
$$


4.2.4. Média e vartîncla dos estimadores dos paraimetros genéticos obtidos na análise de varîncla das frequênclas gênicas de amostras de individuos de populaçães diferentes

Utilizando-se a expressão aproximada através do desenvolvimento em série de Taylor da função $X / Y$ no ponto $X=\mu_{x}$ e $Y=\mu_{Y}$, conforme MOOD et al. (1974), encontrou-se:

$$
\begin{aligned}
E[\hat{F}] & =E\left[1-\frac{2 n Q M G}{Q M P+(n-1) Q M I+n Q M G}\right] \\
& \approx F+\frac{(1+P) n^{2} \operatorname{Var}(Q M G)-(1-F)(n-1)^{2} \operatorname{Var}(Q M I)-(1-P) \operatorname{Var}(Q M P)}{[2 m(1-P)]^{2}} .
\end{aligned}
$$

Admitindo que o número de individuos e a frequência gênica sejam tais que:

$$
\operatorname{Var}(\mathrm{QM}) \approx \frac{2[\mathrm{E}(\mathrm{QM})]^{2}}{\mathbf{v}}
$$

e que o número de populą̧̃es $r$ seja tal que $r-1 \approx r$, então:

$$
E[\hat{F}] \approx F-\frac{F\left(1-F^{2}\right)}{r n}-\frac{2}{r} \theta^{2}
$$

A expressão mostrou que o estimador obtido pelo método dos momentos é tendencioso, considerando-se a aproximação de primeira 
ordem pela série de Taylor. O viés do estimador é negativo, ou seja as estimativas de $\mathrm{F}$ obtidas pelo método dos momentos serão, em média, inferiores ao verdadeiro valor de $F$.

A variância de $\hat{\mathrm{F}}$ foi desenvolvida pelo mesmo raciocinio, fornecendo:

$$
\operatorname{Var}[\hat{F}] \approx \frac{\left(1-F^{2}\right)^{2}}{\mathrm{rn}}+\frac{2}{\mathrm{r}}[\theta(1-F)]^{2}
$$

Para o coeficiente de coancestria $\theta$, analogamente obtiram-

se:

$$
E[\hat{\theta}] \approx \theta+\frac{\theta}{\mathrm{rn}}\left[(1-F)^{2}-2(1-\theta)^{2}-2 \mathrm{n} \theta(1-\theta)\right] \quad e
$$

$\operatorname{Var}[\hat{\theta}] \approx \frac{1}{\mathrm{In}}\left[\theta^{2}(1-F)^{2}+2 \theta(1-\theta)(1+F)+2(n-3) \theta^{2}(1-\theta)-2(n-1) \theta^{3}(1-\theta)\right]$.

Para o coeficiente de endogamia dos individuos dentro das populaşães, pelo mesmo processo encontraram-se:

$$
\begin{gathered}
E[\hat{f}] \approx f-\frac{f\left(1-f^{2}\right)}{r n} \\
\operatorname{Var}[\hat{f}] \approx \frac{\left(1-f^{2}\right)^{2}}{r n}
\end{gathered}
$$

que foram expressões semelhantes àquelas obtidas no caso do coeficiente de endogamia de uma amostra de indivíduos de uma população. 
4.2.5. Media e varîncla do estimador da taxa de fecundação cruzada na análise de varifincla das frequênclas gênicas de amostras de individuos de populaçães diferentes

A esperangse matemátice do estimador

$$
\hat{\mathbf{t}}=\frac{1-\hat{\mathrm{f}}}{1+\hat{\mathrm{f}}}
$$

foi desenvolvida através da expansão em série de Taylor da função $X / Y$ no ponto $\mathrm{X}=\mu_{\mathrm{X}}$ e $\mathrm{Y}=\mu_{\mathrm{Y}}$, fornecendo:

$E[\hat{t}] \approx \frac{1-f+(f / r n)\left(1-f^{2}\right)}{1+f-(f / r n)\left(1-f^{2}\right)}+\frac{2}{r n} \frac{\left(1-f^{2}\right)^{2}}{\left[1+f-(f / r n)\left(1-f^{2}\right)\right]^{3}}$.

O resultado mostrou que o estimador foi tendencioso, ou seja, $E[\hat{\mathbf{t}}]=\mathbf{t}$ apenas quando $\mathbf{n} \rightarrow \infty$.

A variância de $\hat{\mathfrak{t}}$ foi obtida pelo mesmo racioctrio levando d seguinte expressão:

$$
\operatorname{Var}[\hat{t}] \circledast \frac{(2 t)^{2}}{r n}
$$




\section{CONCLUSÕES}

Os resultados obtidos e discutidos neste trabalho permitiram as seguintes conclusões:

\subsection{Ańlilise das frequências gênicas de amostras de indivíduos de uma população}

a. Os estimadores do coeficiente de endogamia e da taxa de fecundação cruzada obtidos pelo método dos momentos foram tendenciosos. $\mathrm{O}$ viés do estimador do coeficiente de endogamia foi negativo, enquanto que o da taxa de fecundação cruzada foi positivo. As expressões das tendências dos estimadores apresentaram-se em função de $1 / n$ tomando-se despreziveis com $o$ aumento de $n$. Quando a frequência gênica da populą̧æå estava entre 0,2 e 0,8 e se trabalhou no mínimo com 50 indivíduos, es estimativas praticamente coincidiram com os valores dos parâmetros.

b. A fórmula da variância do estimador do coeficiente de endogamia foi semelhante àquela proposta por FISHER (1970) para a variância do coeficiente de correląão intraclasse. A fórmula apresentou bons resultados quando a frequência gênica da população estava entre 0,3 e 0,7 , o coeficiente de endogamia foi inferior a 0,5 e se trabalhou com pelo menos 30 indivíduos. 
c. Os três estimadores da variância do estimador do coeficiente de endogamia fomeceram resultados semelhantes nas faizas de valores citados no item anterior. Deve-se preferir, por simplicidade, o terceiro deles, que assemelha-se à expressão de FISHER (1970), substituindo-se os parâmetros por suas estimativas, dado por

$$
\operatorname{Vâr}(\hat{\mathrm{F}})=\frac{\left(1-\hat{\mathrm{F}}^{2}\right)^{2}}{\mathbf{n}}
$$

d. O estimador da variância do estimador da taxa de fecundação cruzada fomeceu resultados satisfatórios quando a frequência gênica da populaçâo estava entre 0,3 e 0,7 , o coeficiente de endogamia era inferior a 0,4 e o número de indivíduos era no mínimo 30.

e. No caso de alelos múltiplos, a estimação do coeficiente de endogamia através da análise conjunta se mostrou menos tendenciosa que a média das estimativas das análises individuais de cads alelo, apesar de apresentarem mesma variância.

f. No caso de dois alelos, o critério proposto por COCKERHAM (1969) para testar a nulidade do coeficiente de endogamia foi válido utilizando-se: 30 indivíduos se a frequência gênica da população estava entre 0,30 e 0,70; 50 individuos se a frequência gênica estava entre 0,25 e 0,75 e 100 individuos se a frequência gênica estava entre 0,20 e 0,80 . 
g. No caso de três alelos, o teste F através da análise conjunta envolvendo os três alelos, só foi válido se a frequência de cada alelo não foi inferior a 0,20 , o número de indivíduos estava entre 10 e 30 e o nivel de significância adotado foi de 0,01 .

\subsection{Análise das frequências gênicas de uma amostra de individuos de populaçôes diferentes}

a. Os estimadores do coeficiente de endogamia de todos indivíduos das populações, do coeficiente de endogamia dos indivíduos dentro das populações, do coeficiente de coancestria e da taxa de fecundaçåo cruzada obtidos pelo método dos momentos foram tendenciosos. No caso dos coeficientes de endogamia, as tendências dos estimadores foram negativas.

b. As fórmulas das variâncias dos estimadores dos coeficientes de endogamia e da taxa de fecundação cruzada apresentaram expressões semelhantes às fómulas no caso de uma amostra de indivíduos de uma populaçảo. 


\section{REFERÊNCIAS BIBLIOGRÁFICAS}

BARBIN, D. Componentes de variancia. Piracicaba, ESALQ, Departamento de Matemática e Estatística, 1993. 112p.

BARBIN, D. \& PIMENTEL GOMES, F. Variância do coeficiente de herdabilidade obtido a partir da análise de variância segundo o modelo de blocos incompletos. Ciência e Cultura, São Paulo, 23 (1): 80 - 83, 1970.

BARNDORFF - NIELSEN, O. E. \& J J RGENSEN, B. Proper dispersion models. Informes de Matemática, MMPA CNPq, Rio de Janeiro, Série B - 068, 98 p. 1991.

BIELER, G. S. \& WILLIAMS, R L. Ratio estimates, the delta method, and quantal response tests for increased carcinogenicity. Biometrics, Alexandria, 49 (3): 793 - 801, 1993.

BURNHAM, K. P. \& REXSTAD, E. A. Modeling heterogeneity in survival rates of banded waterfowl. Biometrics, Alexandria, 49 (4): 1194 1208, 1993. 
COCKERHAM, C. C. Variance of gene frequency. Evolution, Lencaster, 23: 72 - 84, 1969.

COCKERHAM, C. C. Analysis of gene frequencies. Genetics, Baltimore, $74: 679-800,1973$.

COCKERHAM, C.C. \& WEIR, B. S. Variance of actual inbroeding. Theoritical Population Biology, New York, 23: 85 - 109, 1983.

COX, C. Fieller's theorem, the likelihood and the delts method. Biometrics, Alexgndris 46 (3): 709 - 718, 1990.

CROW, J. F. Fundamentos de genética. Tradugåo de Henrique Krieger, Rio de Janeiro, Livros Técnicos e Científicos, 1978. 277 p.

CRUMP, S. L. The estimation of variance components in analysis of variance. Biometrics, Washington, 2(1): 7 - 11, 1946.

DANIELS, H. E. The estimation of components of variance. Jounal of the Royal Statistical Society Supplementt, Londres, V7 : 186 - 197, 1939.

DEMETRIO, C. G. B. Modelos lineares generalizados na perinentaçao agronómica. In: SIMPÓSIO DE ESTATÍSTICA APLICADA NA EXPERMMENTAÇÃo AGRONÓMICA, 5, Porto Alegre, 1993. Quinto... Porto Alegre, UFRS, 1993. 126 p. 
EFRON, B. The jackknife, the bootstrap and other resampling plans. CBMSNSF Regional Conference Series in Applied Mathematics, Monograph 38, STAM , Philadelphia, 1982.

FALCONER, D. S. Introduction to quantitative genetics. New York, The Ronald Press Co. 1964. 365 p.

FISHER, R A. Statistical methods for research workers. New York, $14^{\text {th }}$ edition, Hafner Press, 1970. 362 p.

GORDON, I. L. ; BITH, D. E. \& BALAAM, L. N. Variance of heritability ratios estimated from phenotypic variance components. Biometrics, Alexandria, 28 (2): 401 - 405. 1972.

HALLAUER, A. R \& MIRANDA FILHO, J. B. Quantitative genetics in maize breeding. Ames, lowa State University Press, 1981. 468 p.

HARTL, D. L. \& CLARK, A. G. Principles of population genetics. Sunderland, Sinauer Associates' Inc. Publishers, 1989. 681 p.

IWAISAKI, H. \& WILTON, J. M. Regression of genotypic on phenotypic value of a ratio - defined character. Biometrics, Alexandria, 49 (4): 1154 - 1163, 1993. 
JOHNSON, N. L. \& KOTZ, S. Distributions in statistics: continuous wrivariate distributions - 2, New York, John Wiley \& Sons, 1970. $360 \mathrm{p}$.

JфRGENSEN, B. Marimum likelihood estimation and large - sample inference for generalized linear and non linear regression models. Biometrika, Cambrigde, 70: $19-28,1983$.

JфRGENSEN, B. Exponential dispersion models. Joumal of the Royal Statistical Society B, Londres, 49 (2): 127 - 162, 1987a

JфRGENSEN, B. Small dispersion asymptotics. Revista Brasileira de Probabilidade e Estatistica, SẼo Peulo, IME / USP, 1: 59 - 90, $1987 \mathrm{~b}$.

KENDAL, G. M. \& STUART, A. The advanced theory of statistics. Vol. 1, $2^{\text {ed }}$ edition, Londres, Charles Griffin \& Company Limited, 1963. 433 p.

KSHIRSAGAR, A. M. A course in linear models. New York, Mancel Dekker, Inc. $1983.421 \mathrm{p}$.

LEITE, J. G. \& SINGER, J. M. Métodos assintóticos em estatistica. In: SLMPÓSIO NACIONAL DE PROBABIIDADR E ESTATÍSTICA, 9, São Paulo, 1990. Nono... Sæ̃o Paulo, MEUUSP. 1990. 130 p. 
LONG, J. C. The allelic correlation struture of gainj and kalam - speaking people. I. The estimation and interpretation of Wright's F-statistics. Genetics, Baltimore, 112: 629 - 647, 1986.

MOOD, A. M. ; GLAYBIL, F. A. \& BOES, D. C. Introduction to the theory of statistics, $3^{\text {rd }}$ edition, Tokyo, McGraw - Hill Kogakusha, Ltd., 1974. $564 \mathrm{p}$.

MORAES, M. L. T. Variabilidade genética por isoenzimas e caracteres quantitativos em duas populaçסes naturais de aroeira Myracrodruon urundeuva F.F. \& M.F. Allemão - Anarcadiaceae (Syn: Astronium urundeuva (Fr. Allemão) Engler). Piracicaba, 1992. 139 p. (Doutorado - Escola Superior de Agricultura “Luiz de Queiroz" / USP).

MORAES, M. L. T. A técnica de eletroforese e a caracterização das isoenzimas. In: KAGEYAMA, P. Y.; REIS, M. S. dos GANDARA, F.

A. (Coords.) Estimadores de variaçào genética e taxa de cruzamento em populaçz̃es de espécies arbóreas. Piracicaba: ESALQ/USP, 1993. p. 9-31.

MORI, E. S. Variabilidade genética isoenzimática em uma população de Eucalyptus grandis Hill ex Maiden submetida a diferentes intensidades de seleção. Piracicaba, 1993. 119 p. (Doutorado - Escola Superior de Agricultura "Luiz de Queiroz" / USP ). 
NEI, M. Analysis of gene diversity in subdivided populations. Proceedings of the National Academy of Sciences, Weshington, 70 (12) : 3321 - 3323, 1973.

NEI, M. F - statistics and analysis of gene diversity in subdivided populations. Ann. Hum. Genet., Londres, 41: 225 - 233, 1977.

NEI, M. \& CHAKRAVARTh, A. Drift variances of $F_{S T}$ and $G_{S T}$ statistics obtained from a finite number of isolated populations. Theoritical Population Biology, New York, 11: 307 - 325, 1977.

NELDER, J. A \& WEDDERBURN, R W. M. Generalized linear models. Jownal of the Royal Statistical Society A, Londres, 135 (3): 378 - 384, 1972.

OSBORNE, R \& PATERSON, W. S. B. On the sampling variance of heritability estimates derived from variance analysis. Proceedings of the Royal Society of Edinburgh, Edinburgh, 64: 456, 1952.

PAIVA, J. R Variabilidade enzimática em populaçסes naturais de seringueira (Hevea brasiliensis (WLLD. EX. ADR. E JUSS.) MÜELL. ARG.). Piracicaba, 1992. 145 p. (Doutorado - Escola Superior de Agricultura "Luiz de Queiroz" (USP). 
PAIVA, J. R; KAGEYAMA, P. Y. \& VENCOVSKY, R Outcrossing rates and inbreeding coefficients in rubber trees (Hevea brasiliensis WWLLD. EX. ADR E JUSS.) MÜELL. ARG.) Revista Brasileira de Genética, Ribeirão Preto, 16 (4): 1003 - 1011, 1993.

REYNOLDS, J.; WEIR, B. S. \& COCKERHAM, C. C. Estimation of the coancestry coefficient: basis for a short - term genetic distance. Genetics, Baltimore, 105: 767 - 779, 1983.

ROBERTSON, A. \& HILL, W. G. Deviations from Hardy - Weinberg proportions: sampling variances and use in estimation of inbreeding coefficients. Genetics, Baltimore, 107: 703 - 718, 1984.

SANTOS, E. M. \& ALBIERI, S. Correlação intraclasse - uma aplicação. In: SIMPÓSIO NACIONAL DE PROBABILIDADE E ESTATISTICA, 5, São Paulo, 1982. Atas... São Paulo, IME NSP, 1982. 113 - 118.

SAS Language guide for personal computers, Version 6 Edition, Cary, NC, SAS Institute Inc., 1985.429 p.

SATERTHWAITE, F. E. An aproximate distribution of estimates of variance components. Biometrics, Washington, 2(3): 110 - 114, 1946.

SEARLE, S. R Sampling variances of estimates of components of variance. Annals Mathematical Statistics, Ann Arbor, 29: 167 - 178, 1958. 
SEARLE, S. R Linear models. New York, John Wiley \& Sons, 1971. 532 p.

SOUZA JUNIOR, C. L. Componentes de variancia genética e suas implicaçzes no melhoramento vegetal. Piracicaba, FEALQ, 1989. $134 \mathrm{p}$.

SUTHERLAND, T. M. The correlation between feed efficiency and rate of gain, a ratio and its denominator. Biometrics, Alexandria, 21(3): 739 $749,1965$.

SWIGER, L. A.; HARVEY, W. R; EVERSON, D. O. \& GREGORY, K. E. The variance of intraclass correlation involving groups with one observation. Biometrics, Alexandria, 20(4): 413 - 417, 1964.

VALÉRIO FILHO, W. V. Comparação de métodos para estimação de componentes de variancia através da simulação de dados. Piracicaba, 1991, 160 p. (Doutorado - Escola Superior de Agricultura "Luiz de Queiroz" (USP).

VELLO, N. A. \& VENCOVSKY, R Variâncias associadas às estimativas de variâncias genéticas e coeficientes de herdabilidade. Relatório Cientifico do Departamento de Genética e Instituto de Genética, Piracicaba, 8: $238-248,1974$. 
VENCOVSKY, R Análise de variância de frequências alélicas.In: Congresso Latino Americano de Genética, 10, Rio de Janeiro, 1992. Proceedings, Revista Brasileira de Genética. Suplemento 1, Ribeiråo Preto, $15(1): 53$ - 60, 1992.

VENCOVSKY, R Estimadores de diversidade. In: KAGEYAMA, P. Y; REIS, M. S. dos \& GANDARA, F. B. (Coords.) Estimadores de Variaçao Genética e Taxa de Cruzamento em Populações de Espécies Arbóreas. Piracicaba ESALQ NUSP,1993. p. 32 - 45.

VENCOVSKY, $R$ Variance of an estimate of the outcrossing rate. Revista Brasileira de Genética, Ribeirão Preto, 17(3) : 349-351, 1994.

WEIR B. S. Genetic data analysis: methods for discrete population genetic data. Sunderland, Sinauer Associates Inc. Publishers, 1990. 377 p.

WEIR, B. S. \& COCKERHAM, C. C. Estimating F-statistics for the analysis of population struture. Evolution, Lancaster, 38(6): 1358 - 1370, 1984.

WRIGHT, S. The interpretation of population struture by F-statistes with special regard to systems of mating. Evolution, Lancaster, 19: $395-420$, 1965. 


\section{APÉNDICE}

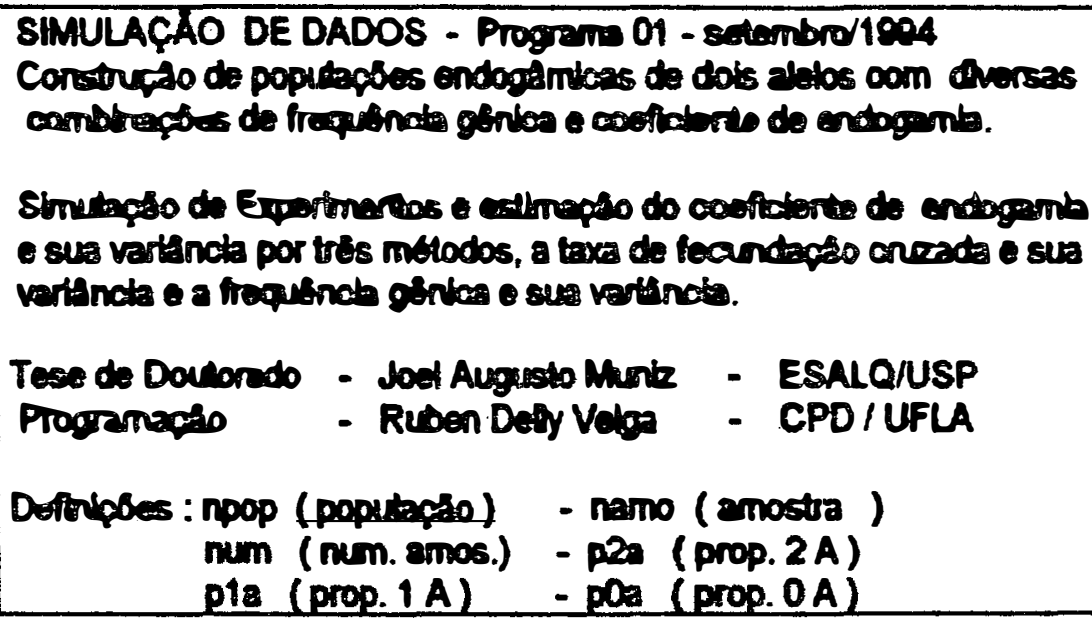


$\cos 2+1$

end;

H couse ge hice and court be fint then do;

$x 1=1$;

$\operatorname{los} 1+1$

and;

$H$ court ge hico and court it fino then do;

$x 1=0$;

coso +1

end;

come + $x 1$

somea + $x 1^{1} \times 1$

ond; $P$ end $\Rightarrow=$ mamo (amotses) "I

squat = som - soms"some/(2 namo);

sqhd = .5" (sorreq) - some"some/(2 namo);

eqpenes = eqlotel - sqind;

qund = sqind/(namo-1);

qungere.s = engancoshemp;

pchap = soma / (2 $\mathrm{namo})$;

$H$ onindones = 0 then do;

Fchap =0;

VI_Fctap $=0$;

R_Fchap $=0$;

B FChap = 0;

end;

else do;

Fchap = ( qmind - quoones ) $/($ amind + qugenes ) ;

If Fchap = 1 then do;

V1_Fchap $=0$;

R_Fchap = 0 ;

B_Fctap = 0;

end;

clse do;

V1_Fchap $=(2 \text { rame } 1)^{*}(1 \text { fchap })^{* * 2} 2(1+$ fotap $\left.)\right)^{* t} 2 /$

(2namo*(namo-1));

R_Fctap $=(2 \text { namo }+3)^{*}(1$ fotrap $) *+2(1+$ fotap $) *+2 /$

(2 (namo+1)* (namo+2));

B_Fchap $=\left(\left(1-\right.\right.$ Fchap $\left.^{* * 2} 2(1+\text { Fohep })^{* *} 2\right) /$ nemo;

end;

ond;

tFchap $=(1-F c h a p)(1+F$ chap $) ;$

V_tFchap = (4tifchap"tFchap)/namo;

output amo;

ond; $\mu$ and $\Rightarrow 1=1$ to $\mathrm{mum}$ ( expertit. )

end; $\mu$ end $\Rightarrow$ namo $=.$.

end; $\mu$ end $\Rightarrow p=$...

and; $\mu$ end $\Rightarrow p=\ldots$

$\because$

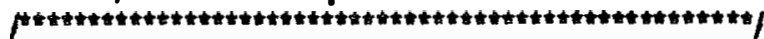

Proc Univariate $=\Rightarrow$ gera arquito: Unl

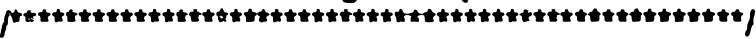

proc sort data = amo; by namo p f;

proo untwertate dato = amo noprint ; 
ver Fchap;

by ramo p f;

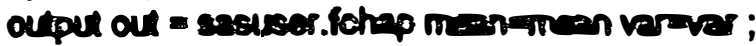

proc univatedata = amo nopers ;

ver potrap;

by ramo p f;

ovpu oul = sasuser.pchop mosirman varac?;

proc unvata data = amo nopred ;

ver tfoctap;

by rano p f;

outple ou = sesuser. If chap man=men varwe;

proc untertate data = ano noprts:

ver v_ffohn:;

by namo p f;

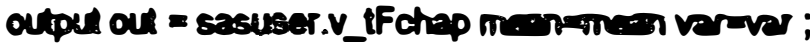

proc univate data = amo noprit :

var vi_Fohrp;

by ramo p f;

ouput ou = sasuser.vt_Fchap man mean versar ;

proc untratate data = amo nopint;

vor V2_Fchap;

by namo p f;

oupul out = sasuser.V2_Fchap manmean verwe ;

proc untartete data = amo noprts ;

ver B_Fchap;

by namo pl:

oupur out = sasuser. B_Fchap men mean verwe ;

proc print data = easuret. Fohap;

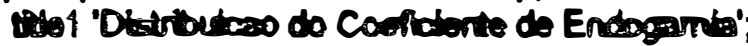

tive2 'Strabceo de Dados * Joel ESALQUSP';

the ;

tHed 'FCHAP 100 experimertos";

lootnot ";

proc prtint data = sasuser.Pchap;

tils "PCHAP 100 exporimentos:;

proc print data = easuset.lFctap;

MVA TFCHAP 100 expotimenos";

proc print data = easuset.v tFchap;

tha V TFCHAP 100 opertiontos";

proc print data = sasuser.vt_Fchap;

thod V1_FCHAP 100 experivientas:;

proc pith data = sasuser.V__Fchap;

tho 'V2_FCHAP 100 expertmentos";

proc print data = sasuser. B_Fchap;

tlo4 V3_FCHAP 100 expertmentos:;

In: 
8DMUACKO DE DADO8 - Properm 02 - temtio 1994

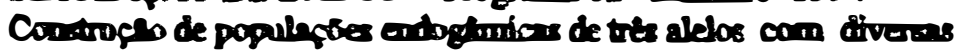

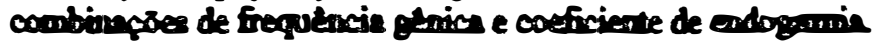

Simalaclo de Experimer to e estimalo do coticiot a de endog-

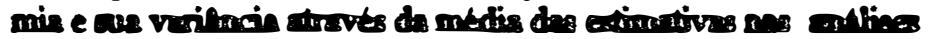

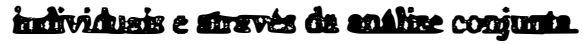

Teae de Durtundo - Joel Anganto Muniz - RSALQ/USP

Progamenos - Ruben Delly Veige - CPDUFLA

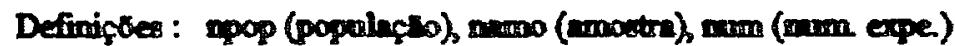
pa1 1 (prop A1A1) ... pa323 (prop. A3A3)

* Britedis de dado:

* Dador p1, p2, p3 ef $\rightarrow$

* Definioso de Populacao

$\bullet$

$*$

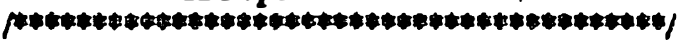

dite dudos (keep $=$ pl p2 p3 f),

window stut color = mager.s.

rows $=23$

cothimis $=78$

\#05 @28

'BEM VINDO AO IISTRMA 8AS'

108@18

'SMULACAO DE DADOS \# COEFICLENTE DE ENDOGAMIA'

\#14@16

Tese Dootusdo : Joed A M. \#EALQ - UBP

\#16 16

Proginger :CPD - URLA \# Delly"

\#21 225

Digite < ENTER > pare contimut

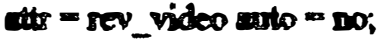

window dados color = blue

गणne $=12$

$\cos 2 \sin =50$

irow $=10$ icohum -10

\$02@12

Entre com os velores sbaixo :"

\#05@20

T1 : '@30 pl 3.1

tor = rev_video I

Q20 P2:'@30p23.1

attr = rev videol

Q20 P3:'@30 p3 3.1

itt = rev_video II

Q20 T:'@30f 3.1

thr = rev_video ;

window confi color - btue

rows $=12$

contume $=50$

ivow $=10$ icohmm $=10$

\#02@12

DADO\& PARA CONFERENCLA :"

\#05@20

P1 : '\$30 p1 3.1

ther_video $p=y e d$

Q20 P2:"@30 p2 3.1

ttr $=$ rev_video $p=$ yeal 


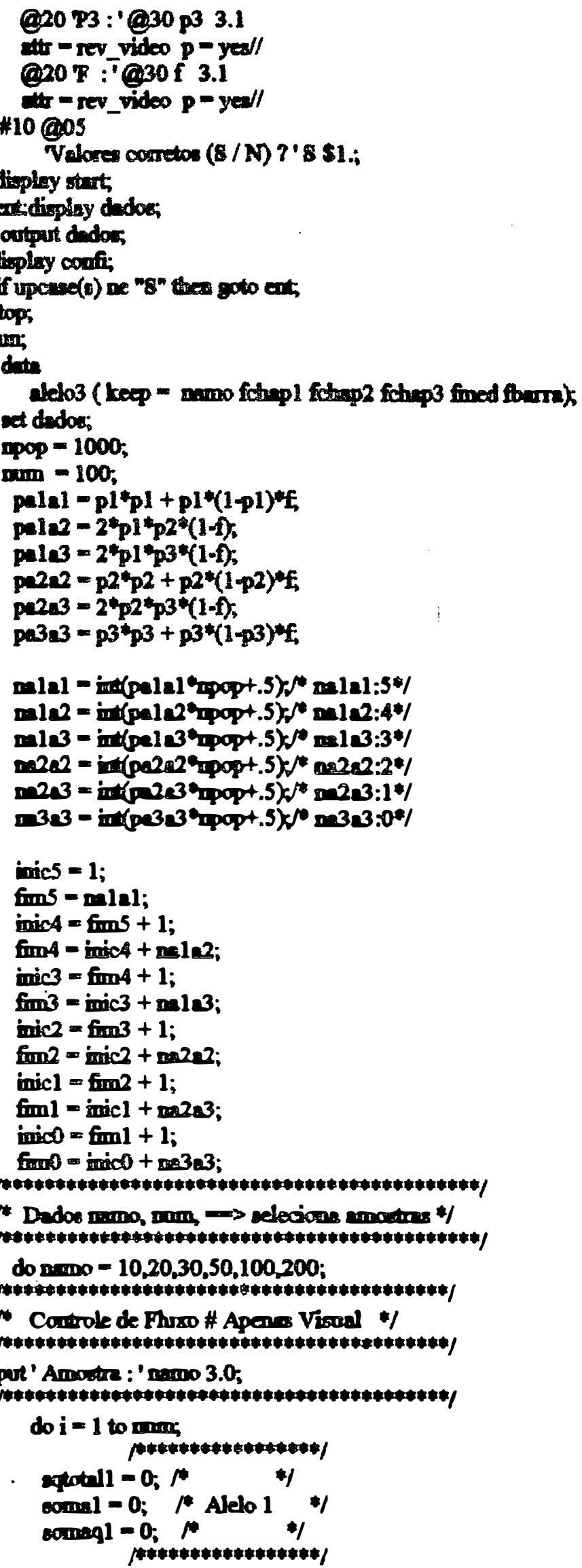




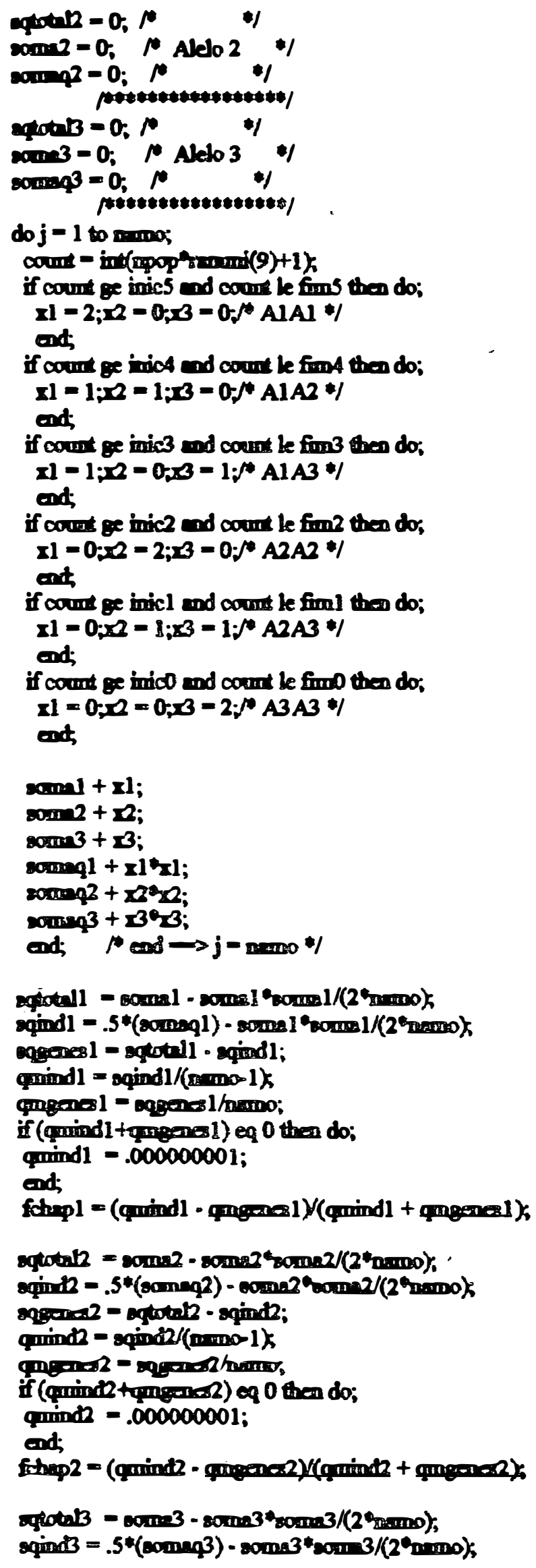




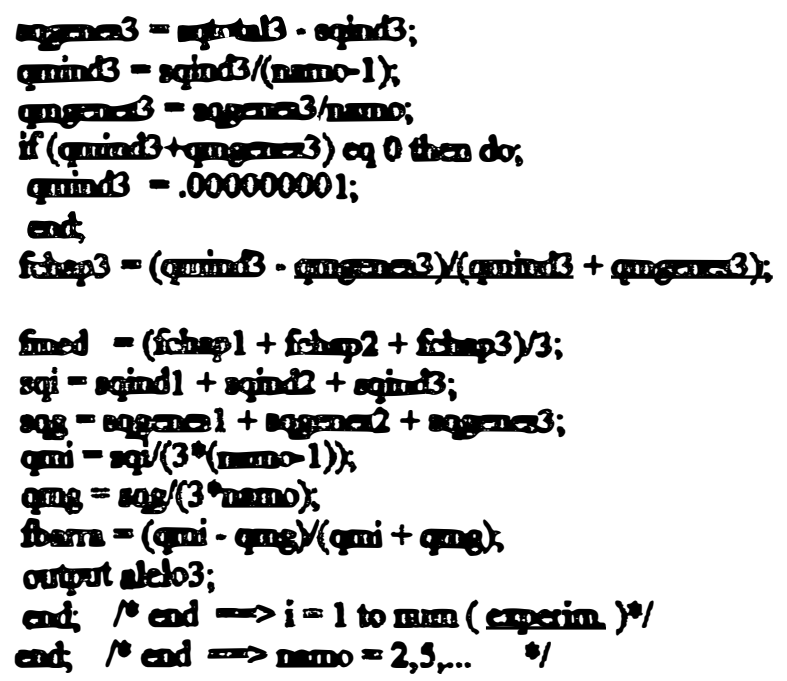

proc cort data = alelo3; by nemo ;

proc univeriute dates = delo3 opprims;

ver fehpl ;

by nemo:

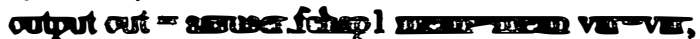

proc exivarite data - clelas mopriet;

ver fich 2 ;

by nemo:

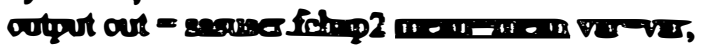

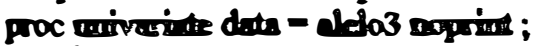

ver fichep 3 :

by nemo:

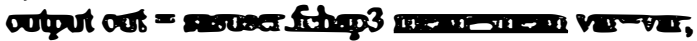

proc univerite dus = clelo3 soprim;

ver funed;

by nemo:

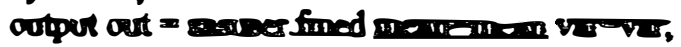

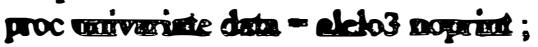

ver forre:

by nexp;

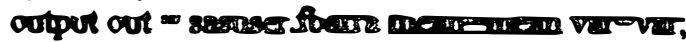

proc prims dain = maver.Fchipl;

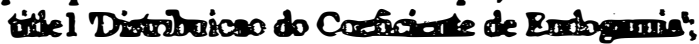

title2 simulscao de Deibo" Joet\# ESALQ USP:

title3;

titeA FCRAP1 \# 100 experimentos";

footuote";

proc print data = ansaner. Fch 2;

tille4 TCHAP2 \# 100 exparimertos ";

proc print dat = earoser.Fchup3;

title4 TCRAP3 \# 100 experimantos:

proc prine dats - ensuser fineds

title4 TMRD \# 100 experimen tos';

proc prims data = asoser fours;

title4 TBARRA \# 100 exparimen to9:"

rin; 


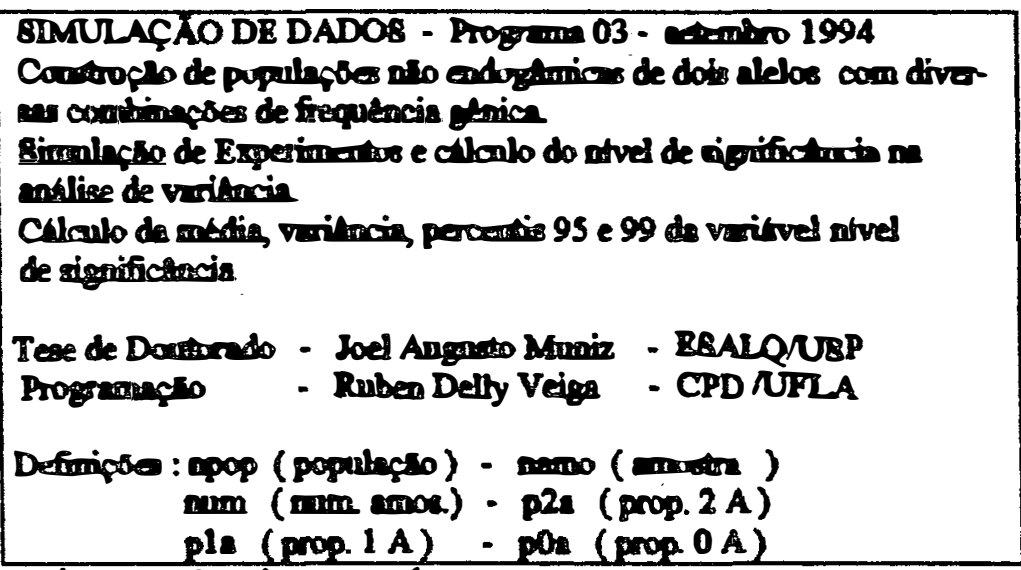

options po-60 sodite noinmior.

dite ano ( keep = nemo p ficalc o inim):

$f=0 ;$ тpop-1000; mim-1000;

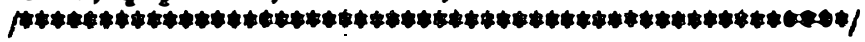

* Dados P, f $\Rightarrow$ Gere Populaca

$*$

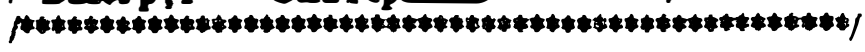

$d o p=.05$ to .95 by .05 ;

$p^{2}=p^{2} p+p *(1-p) *$

pla $=2 p^{*}(1-p) *(1-i)$

pon $-(1-p)(1-p)+p^{*}(1-p) * 4$

ma $=$ int (p2artpopt.5);

nle = in (platipopt.5k

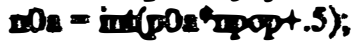

inic2 = 1;

$\operatorname{fin} 2=12$

imicl $=02 a+1$

find $=n 2 s+1+n 1 s$

inico $=-22 s+1+$ nls +1

fimo = Ipop;

M

* Do anos, nim $\rightarrow$ relecions

*

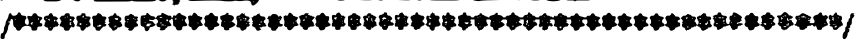

do namo $=5,10,15,20,25,30,35,40,45,50,75,100,150,200,300,400,500$,

do $\mathrm{i}=1$ to $\mathrm{imm} ;$

actor -0

$800 \pi=0$

$\operatorname{sem}=0$.

$d o j=1$ to nema;

count = in (1poptramini(g)+1)

if coun ge inic2 and coum le find then do;

$x 1=2$;

end

if count ge inicl and courr le fiml then do;

$x 1=1$;

erd

if couns ge inico ad ocum le fino then do;

$\mathrm{xl}=0$;

ent

$80 \mathrm{ma}+\mathrm{xl}$

coman + x1 thel;

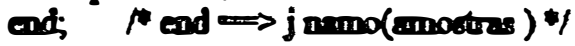




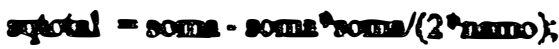

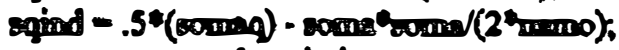

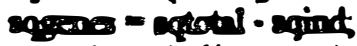

quind = aqued (n ano-1)

Tripere - an -1=hamp;

if cirngens = 0 the do,

fonle $=9999$,

end:

elae do:

foulc $=$ quind/Aragenes,

end:

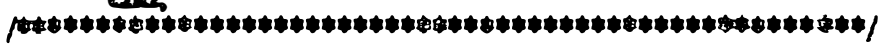

Teste I

$\because$

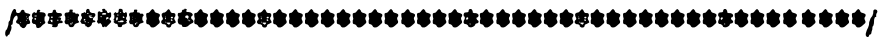

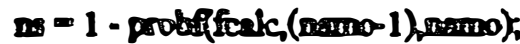

output amo;

eads

ent $p$ and $\rightarrow i=1$ to man ( Experim $) * 1$

end; $P$ end $\Rightarrow$ nomo...

$\%$

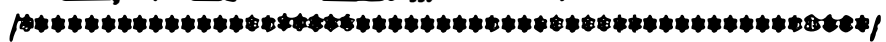

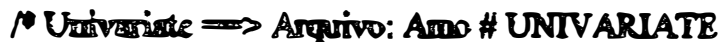

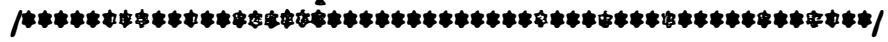

Proc sont dets - cono; by namo P;

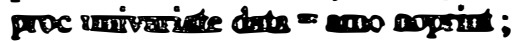

titlel Distribuicas do Coeficlate de Rostramin:

title2 'sirgerlaceso de Dadost,

title3 Toelc?

ver fealic;

by nomo p :

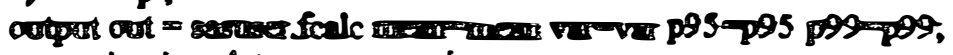

proc varivariate dets = emo noprind:

title3 Na;

vex 10.5.

by maseo p;

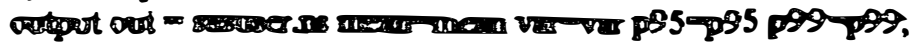

rin; 
8DMULCCXO DE DADO8 - PUgum 04 - ctento 1994

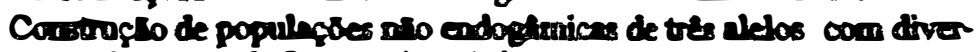

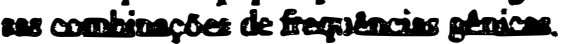

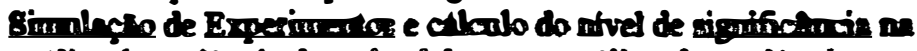
antlise de verimcir de conds alelo e an entlige de verimeis conjumin

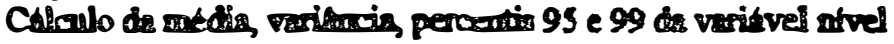

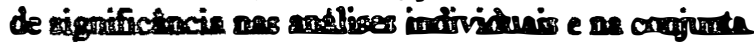

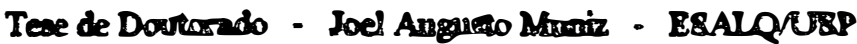

Programpero - Rober Delly Veiga - CPD NFLA

Defimipoes : ppop (popalacio) - ramo (amoun )

Inm (arm

ple $(\operatorname{prop} 1 \mathrm{~A}) \cdot \operatorname{pos}(\operatorname{prop} 0 \mathrm{~A})$

Options po-66 nodate anominber,

- Extredu de Dados:

Hatrade de p1, p2, p3 ef

* Definiceo de Populaceo

$*$

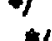

dets dados $($ keep $=$ p1 p2 p3 f)

window color $=$ os

$$
\operatorname{ros}=23
$$

cohnimis $=78$

\#05@28

'BEM VINDO AO SISTEMA 8A5'

\#08@18

SMULACAO DE DADOS \# COEFICIENTE DE ENDOGAMIA'

\#14 @16

Tese Dourarado : Joel A. M. \# ESALQ - UEP'

\#16@16

Prugrumana : CPD - URLA\# Delly"

\#21@25

Digite < ENTER > pare cortingers

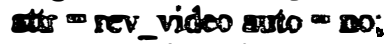

Findow dedos color $=$ bre

TONTS $=12$

cothming $=50$

H02@12

irow $=10$ icotanis $=10$

Trite com os valores ebaiso :"

\#05 @20

P1 : '@30 pl 3.2

tte = rev_video I

Q20 T2:'@30 p2 3.2

ther $=\mathrm{rev}$ video!

@20 P3:'@30p3 3.2

att = rev video II

Q20 T:'@30f 3.2

Hir = rev_video ;

window coafi color = blue

TOW' $=12$

cotuming $=50$

ivow $=10$ icohmen $=10$

\#02 @12

DADO8 PARA CONFRRENCIA :'

\#05@20 
P1 : '@30 p1 3.2

ther_video $p=y e d$

Q20 T2:' @30p2 3.2

itt $=$ rEv_video $p=$ yed

(2.20 P3:'@30p3 3.2

Ittrer_video $p=y e d l$

@20 T: :@30f 3.2

ther_vidoo $p=$ yeal

*10 g0s

Valore costos $(8 / N)$ T' 8 \$1.;

dieplay tout

entedioplay dadow

outpot dindos.

disply coati;

if upcouds) ne "gn" then goto eit

rop;

תim;

dite

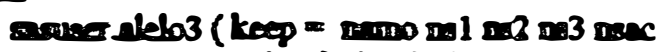
fealcl folle2 falc3 fac).

dados;

apop = 1000;

$\operatorname{Inm}=1000$

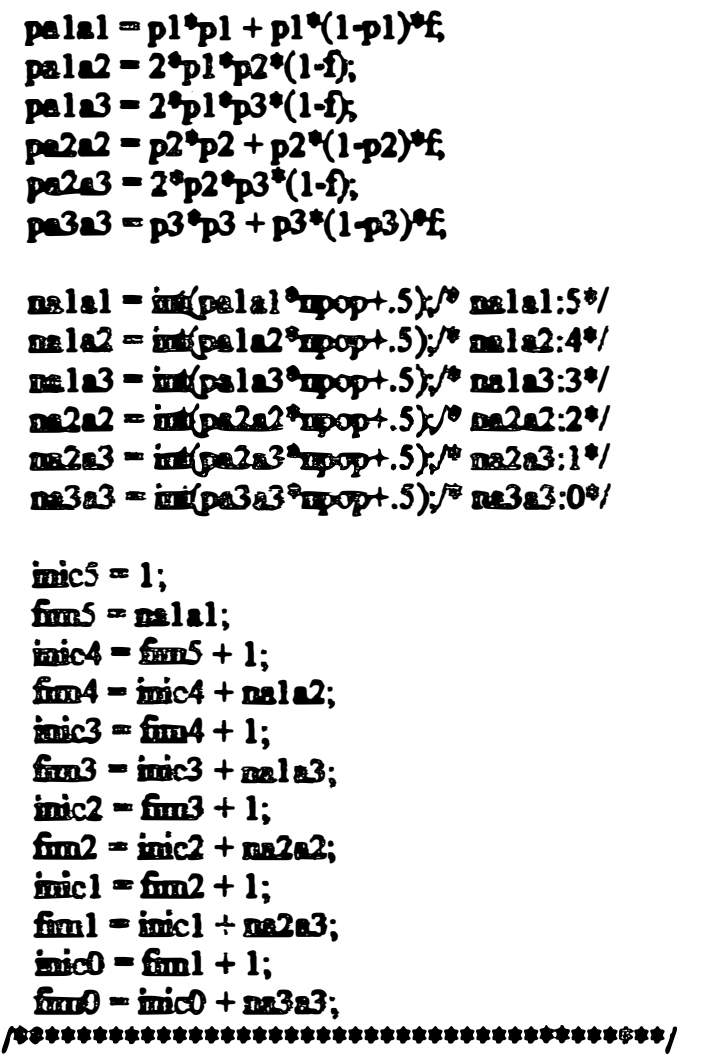

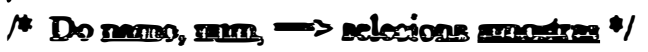

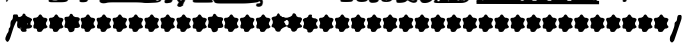

do n.mo $=5,10,15,20,25,30,35,40,45,50,75$, $100,150,200,300,400,500$;

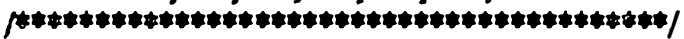

- Colitole de Flaro \# Aperies Viron *

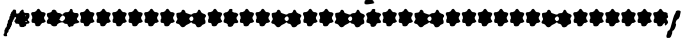

put' ' Amoder : ' nemo 3.0; 


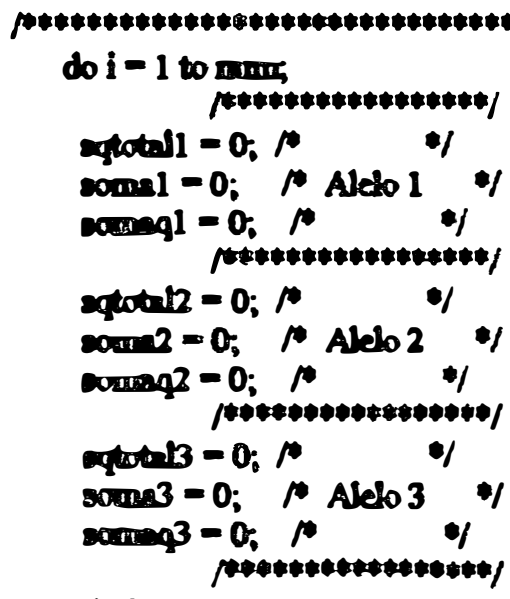

$d o j=1$ to $\mathrm{s}$ ind come = int(cpophamin $(9)+1)$;

if coure ge inics and count le fims then do, $x 1=2 ;-02=0 ;-3=0 ; / * A l A 1 * /$ ench

if counc ge imict and coum le fimt then do; $x 1=1 ; x_{2}=1 ;-3=0 ; * A 1 A 2 *$ end

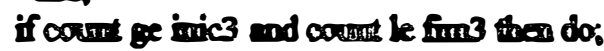
$x 1=1 ;-2=0 ;-3=1 ; / * A 1 A 3 \%$ end

if count inic2 and coum le finm theo dos $x 1=0,-2=2 ; \times 3=0,-1 * 2.22 \%$ ents

If cound ge iniel ad cour ie finl thes dor $x 1=0,20=1 ;-3=1 ; * A 2 A 3 *$ end

if count ge inico and count le find then do; $x 1=0,203=0,23=2 ; * A 3 A 3 * 1$ and somel + xl;

$\operatorname{cosen} 2+x$

$\sin 3+23$

soxanl + xl kxl;

armeg +2020

somen 3 + 23923

enct $p 1000 \Rightarrow j=$ remo

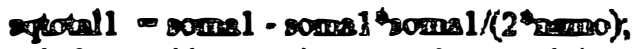

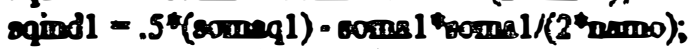

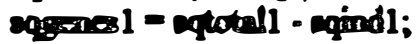

quind $=$ sqind $1 /($ namo-1);

cinger al = caperesl/n imo;

if oingeros! eq 0 then do;

fealcl $=9999$.

end;

che do;

fcalcl = quind $/ q_{\text {moresesl; }}$

end

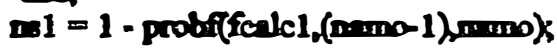

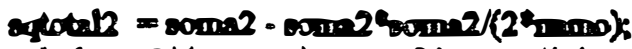

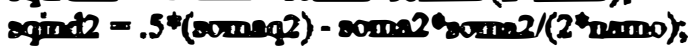

sogene. $2=\operatorname{sqdath} 2$ - sqind2; 


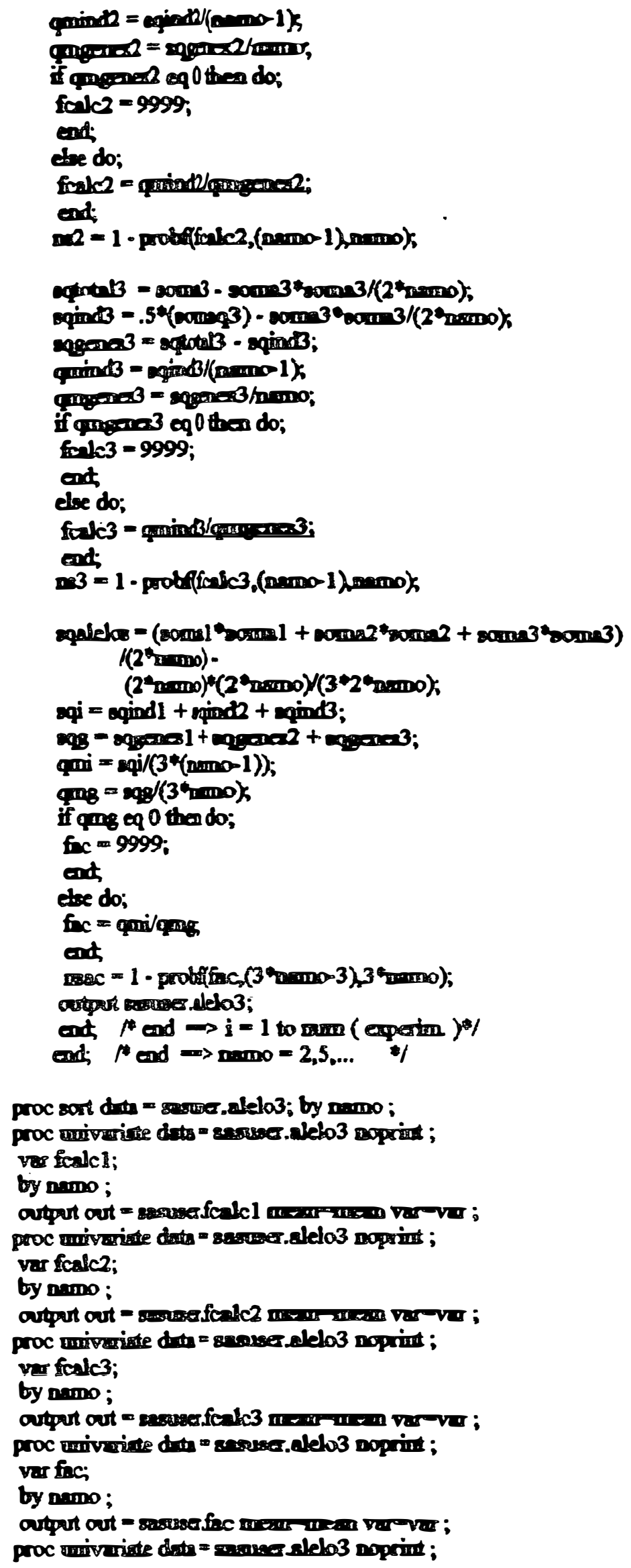


virnol;

by momo;

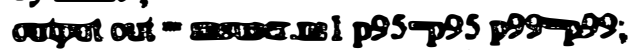

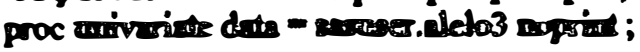

ver 20:

by mano:

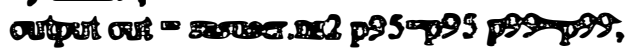

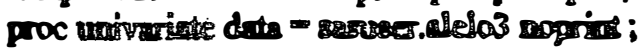

var De3;

by mono:

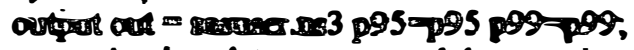

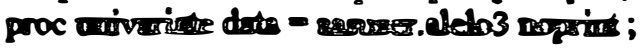

ver insec;

by $\operatorname{san} 0$;

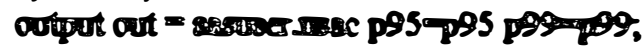

rini;

proc prine dits = amperficalcl;

titlel Dietribuiceo do Coefiosenter de Endognimi:;

title? simalacso de Dadoo I Adelos \# FCALC1;

proc priat d = forices;

titlel Distriburicao do Coeficier te de Endognums;

title2 sianolnoso de Dadoo \# 3 Aleto \# PCALC2",

proc pind dat -

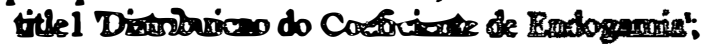

tither siunulaces de Dados \# 3 Aletoe \# PCALC3;

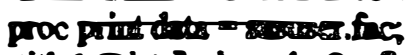

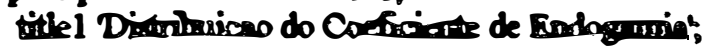

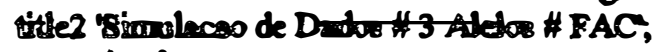

proc prist dits - seavern 1;

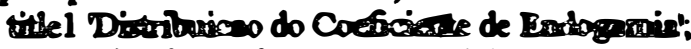

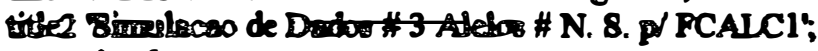

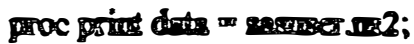

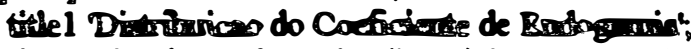

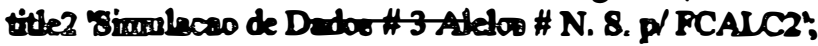

proc prim dut - anseress:

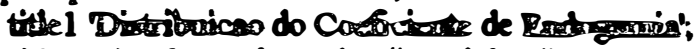

tinles airsulscao de Dedos \# 3 Alelo \# N. 8. p/ FCALC3;

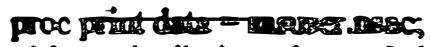

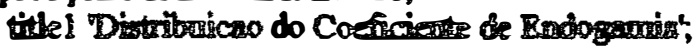

titlez simasleceo de Dedos \# 3 Alebo \# N. 8. p/ EAC;,

तnis; 